Florida International University

FIU Digital Commons

FIU Electronic Theses and Dissertations

University Graduate School

$10-28-2016$

\title{
A Carbon and Oxygen Stable Isotope- Dendrochronology Study of Trees from South Florida: Implications for the Development of a High-Resolution Subtropical Paleoclimate Record
}

Carrie E. Rebenack

Florida International University, crebe001@fiu.edu

DOI: $10.25148 /$ etd.FIDC001213

Follow this and additional works at: https://digitalcommons.fiu.edu/etd

Part of the Biogeochemistry Commons

\section{Recommended Citation}

Rebenack, Carrie E., "A Carbon and Oxygen Stable Isotope-Dendrochronology Study of Trees from South Florida: Implications for the Development of a High-Resolution Subtropical Paleoclimate Record" (2016). FIU Electronic Theses and Dissertations. 3009.

https://digitalcommons.fiu.edu/etd/3009

This work is brought to you for free and open access by the University Graduate School at FIU Digital Commons. It has been accepted for inclusion in FIU Electronic Theses and Dissertations by an authorized administrator of FIU Digital Commons. For more information, please contact dcc@fiu.edu. 
FLORIDA INTERNATIONAL UNIVERSITY

Miami, Florida

\title{
A CARBON AND OXYGEN STABLE ISOTOPE-DENDROCHRONOLOGY STUDY OF TREES FROM SOUTH FLORIDA: IMPLICATIONS FOR THE DEVELOPMENT OF A HIGH-RESOLUTION SUBTROPICAL PALEOCLIMATE RECORD
}

\author{
A dissertation submitted in partial fulfillment of \\ the requirements for the degree of \\ DOCTOR OF PHILOSOPHY \\ in \\ GEOSCIENCES
}

by

Carrie E. Rebenack

2016 
To: Dean Michael R. Heithaus

College of Arts, Sciences and Education

This dissertation, written by Carrie E. Rebenack, and entitled A Carbon and Oxygen Stable IsotopeDendrochronology Study of Trees from South Florida: Implications for the Development of a High-

Resolution Subtropical Paleoclimate Record, having been approved in respect to style and intellectual content, is referred to you for judgment.

We have read this dissertation and recommend that it be approved.

René M. Price

Michael Ross

Evelyn Gaiser

William Anderson, Major Professor

Date of Defense: October 28, 2016

The dissertation of Carrie E. Rebenack is approved.

Dean Michael R. Heithaus

College of Arts, Sciences and Education

Andrés G. Gil

Vice President for Research and Economic Development and Dean of the University Graduate School

Florida International University, 2016 


\section{DEDICATION}

To Mom and in memory of Dad. Thank you for being amazing role models, for encouraging independent thinking, and for teaching me to always take the high road no matter how much harder it may seem. Dad, your silly, contagious and often unexplained bursts of hissing laughter, willingness to model barrettes and makeup (but, disappointingly, not nail polish), and unwavering determination to throw my hula hoop over the barn has given me a fun sense of humor and many wonderful memories. Mom, you have always had patience for my creative side, nurtured my love of reading, and have supported me through every turn I have taken in life. You have an incredible strength, Mom, and I am lucky enough to just now find some of that in myself. I love both of you. 


\section{ACKNOWLEDGMENTS}

My journey to this point has been much more serpentine and unpredictable than I ever could have imagined at the start. There were many times, particularly in the last few years, when the path almost disappeared and I wondered if I could find it again. I really would like to thank Drs. Evelyn Gaiser and René Price for directing me to the trail markers at the time when I had deviated the farthest from my path. This past spring, you both said exactly the right things at exactly the right time, even though neither of you knew how truly lost I was. I sincerely want to thank my entire committee, Dr. Michael Ross, Dr. René Price, and Dr. Evelyn Gaiser, and my major advisor, Dr. William Anderson, for being supportive and for having patience with my personal process of getting to this point.

I would also like to thank Dr. Paolo Cherubini of the Swiss Federal Research Institute WSL for helping me tremendously with editing, for offering encouragement and mentorship, and for the best gnocchi I have ever had. I also owe Drs. Hugh Willoughby and Danielle Ogurcak a huge debt of gratitude for their assistance with data analysis; I could never have written code for MATLAB or R on my own. Dr. Samantha Evans was a big influence on me at the beginning of my graduate career; she not only provided mentorship, but also friendship and support. Even from the other side of the country, she has always been available to offer knowledge, encouragement, and advice. I credit Mark Kershaw for teaching me everything I know about stable isotope analysis and laboratory professionalism. He had patience for my countless questions and he was always cheerfully willing to troubleshoot any problem with lab equipment or isotope data analysis. I cannot properly express the level of respect and gratitude, both inside and outside the lab, I have for Mark and his wonderful wife, Susie Escorcia.

I could not have finished my data collection without the help of the Stable Isotope Laboratory Lab Manager, John Harris. His dedication and knack for making big things happen using very limited resources has allowed me to complete my oxygen isotope analysis. He was able 
to resurrect a finicky TC/EA after multiple meltdowns and I am eternally grateful for his tenacity. I would also like to thank my fellow Stable Isotope Lab graduate students, Heather Black, Annie Palya, Sarah Strand, and Amber Kiger, for making my time in the lab a little less lonely. In addition, I owe a special thanks to lab tech, Valentin Nechita, for being a really good friend; I thoroughly enjoyed my time working with him and his dancing was always on point!

The slash pine tree disks were collected by the National Key Deer Refuge and I would like to thank the refuge staff, especially Anne Morkill and Phillip Hughes, for supplying the samples for my dissertation research, for granting me access to the pine rocklands for additional data collection, and for providing overnight accommodations. Field work is never a one woman job and I would like to acknowledge Dr. Pamela Sullivan, Dr. Danielle Ogurcak, Greg Losada, and Adam Hines for helping me core trees. I owe Adam an extra debt of gratitude for taking me to the tree islands near the $\mathrm{C}$-111 canal, helping me core trees in knee-deep water, and for being so kind when I had a fainting spell from the heat. Unfortunately, the samples that we collected that day did not make it into this dissertation, but, with the exception of the minor fainting episode (and the billions of spiders), I truly had a wonderful experience that day.

There were many people who indirectly helped my complete this dissertation. I appreciate the friendship, advice, and friendly ears of my fellow graduate students, Javiera Hernandez, Dr. Julie Johnson, Dr. David Lagomasino, Dr. Tatiana Gaona-Navaez, Shiva Pokharel, and Dr. Emily Nodine. Thank you to the staff at the writing center for hosting the Dissertation Writing Retreats. I would like to specifically acknowledge Drs. Paula Gillespie and Glenn Hutchinson for being so supportive and very kind with their words. I was lucky enough to be placed with Rodolfo 'Rudy' Rego as a teaching assistant during my most difficult semester. Rudy is an incredible educator and I sincerely appreciate his willingness to act as a resource to help me improve my own teaching strategies and techniques. I truly respect him and I cannot express how instrumental he was in helping me focus on a direction after graduate school. 
There were two people who kept me from straying too far into the deep, dark woods during my worst times. Armeen Irani always supplied the breadcrumbs to bring me back to the path. I am forever indebted to her kindness, honesty, and encouragement of self-empowerment. I am also in debt to my best friend, Kevin Chau. He has always been there, unquestioningly, to provide emotional support, bring me food when my cabinets were empty, to push me through the toughest days, and to celebrate the best days with pizza, ice cream, and 80's movies. In addition, his knowledge of Adobe Photoshop helped me many times in the development of many of the figures throughout this dissertation.

There are many friends outside of FIU who helped me with various things. Won Lichter, Troy Shaver, Carol and Chase Garza, and my dearest Syed Noor helped to remind me who I am and gave me some of the best memories of my life. Thanks to Natalie and Jerry Deschant for helping me cut transects out of my tree disk samples. Jim Zade and Lucy Alas are wonderful and supportive landlords who gave me a beautiful garden to view as I sat writing. Thank you to my roommate, Jacob Bell, for putting up with piles of papers all over the living room and for being silly when I needed a laugh.

Lastly, I offer my sincerest gratitude to my family. Mom, Dad, Sarah, Emily, Grandma, Uncle Chick, Ridley, Natalie, Fourth-Sister-Nathan, Aunt Chris and Uncle Clair, thank you for believing in me and for listening to me talk about my research. And, finally, thank you to my baby girls, Emma (Beembee) and Penny (Teetee) for your unconditional love; every day, good or bad, was for you. 


\section{ABSTRACT OF THE DISSERTATION \\ A CARBON AND OXYGEN STABLE ISOTOPE-DENDROCHRONOLOGY STUDY OF \\ TREES FROM SOUTH FLORIDA: IMPLICATIONS FOR THE DEVELOPMENT OF A \\ HIGH-RESOLUTION SUBTROPICAL PALEOCLIMATE RECORD}

by

Carrie E. Rebenack

Florida International University, 2016

Miami, Florida

Professor William Anderson, Major Professor

The global paleoclimate archive is lacking in tropical dendrochronology studies as a result of limitations from inconsistent tree-ring production imposed by precipitation-driven seasonality. The slash pine, Pinus elliottii Engelm. var. densa, is the dominant canopy species of Big Pine Key (BPK) rocklands and has been shown to produce complicated, but distinct, ring structures; however, traditional dendrochronology studies have not established correlations between ring width measurements and major climate drivers controlling South Florida precipitation. My study utilized the carbon $\left(\delta^{13} \mathrm{C}\right)$ and oxygen $\left(\delta^{18} \mathrm{O}\right)$ isotope records in the $\alpha$-cellulose component of treerings to extract information about the physiological responses of trees to climate and tropical cyclone activity. The $\delta^{13} \mathrm{C}$ measurements in the earlywood and latewood of four P. elliottii var. densa trees were used to build a chronology (1922-2005) and to distinguish annual growth from intra-annual density fluctuations (IADFs). Empirical orthogonal functions were used to determine individual response to precipitation, El Niño-Southern Oscillation (ENSO), and the Atlantic Multidecadal Oscillation (AMO). There is a distinct relationship between the $\delta^{13} \mathrm{C}$ values of cellulose and ENSO; however the nature (direct vs. inversely correlated) is temporally controlled by the prevailing phase of the AMO. The appearance of some IADFs coincide with the timing of El Niño winters occurring during the cool AMO phase, resulting in enriched $\delta^{13} \mathrm{C}$ values. The 
additional precipitation may encourage tree growth, but subsequent dry periods may slow growth and cause the tree to employ water-conservation strategies. Tree growth is influenced by the major climate drivers and the control they exert over the timing of precipitation; however, growth is ultimately controlled by the microenvironment surrounding individual trees. The $\delta^{18} \mathrm{O}$ and $\delta^{13} \mathrm{C}$ values of the latewood cellulose were compared to tropical cyclone activity occurring within a $100 \mathrm{~km}$ radius of BPK. Tropical storms and depressions appeared as anomalously depleted values in the $\delta^{18} \mathrm{O}$ residual record, reflecting large amounts of tropical rain. The effects of hurricanes varied by storm; however, many of the major hurricanes (category 3-5) were preserved as an enrichments in the $\delta^{13} \mathrm{C}$ value of the following earlywood season. The application of stable isotope analyses greatly increases the breadth of paleoclimate information available from the trees. 


\section{TABLE OF CONTENTS}

CHAPTER

PAGE

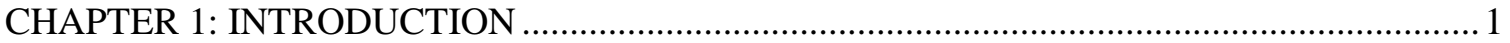

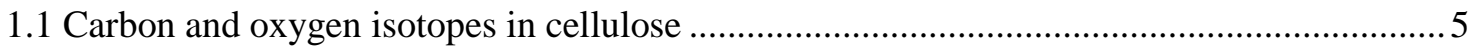

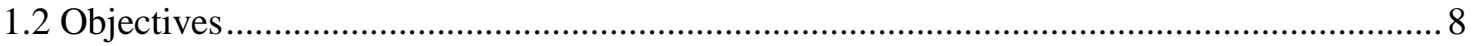

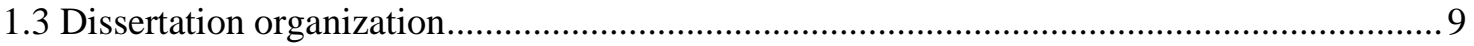

1.4 References

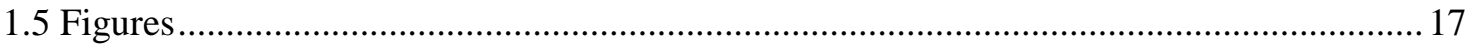

CHAPTER 2: DEVELOPING A CARBON ISOTOPE CHRONOLOGY FOR A SUBTROPICAL TREE SPECIES WITH VARIABLE SUB-ANNUAL TREE-RING

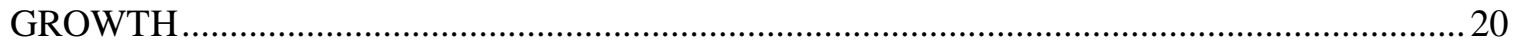

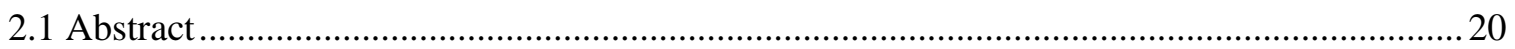

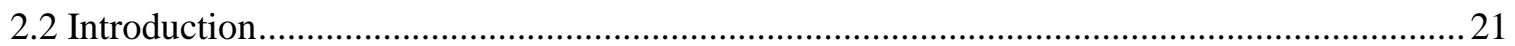

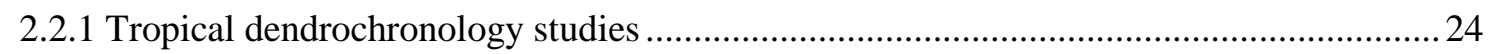

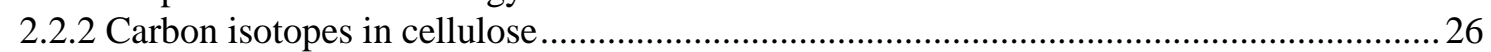

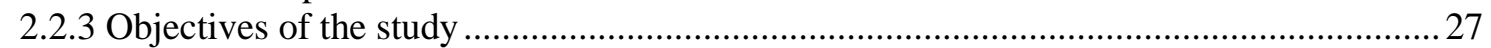

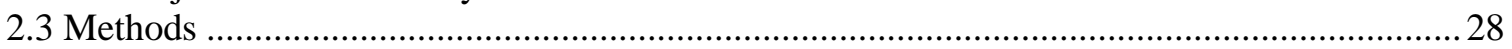

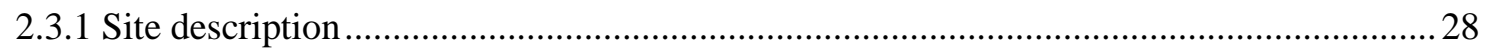

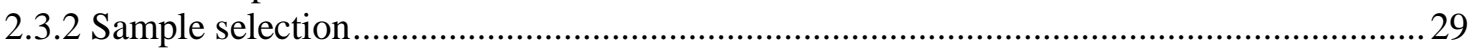

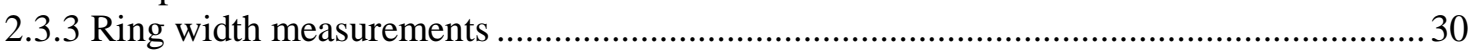

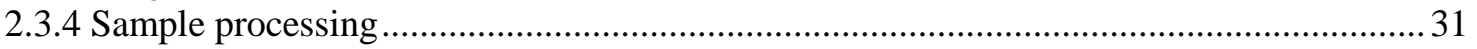

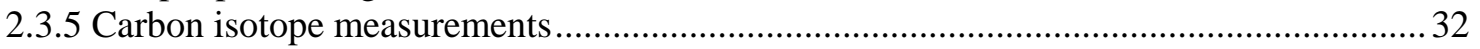

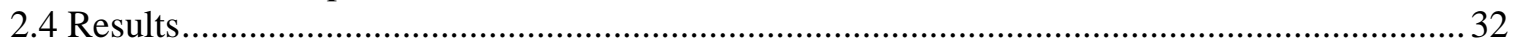

2.4.1 Building a chronology using standard dendrochronology techniques.............................. 32

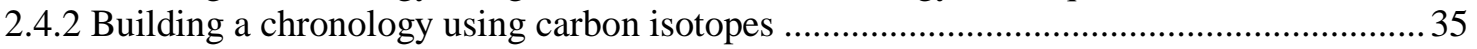

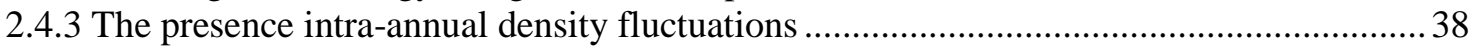

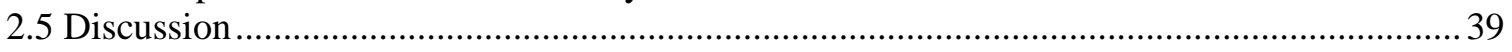

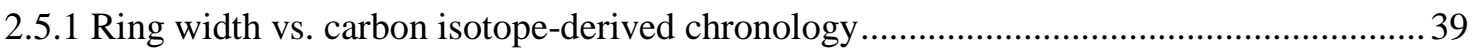

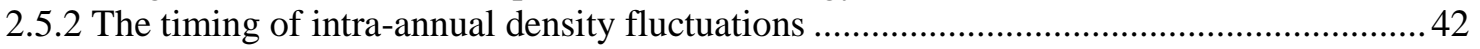

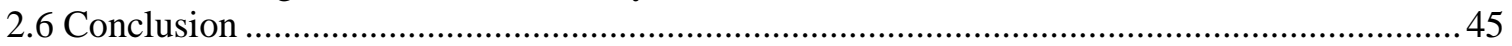

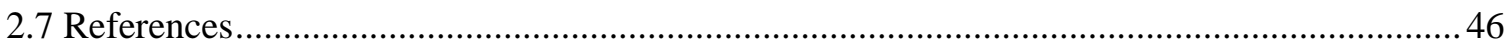

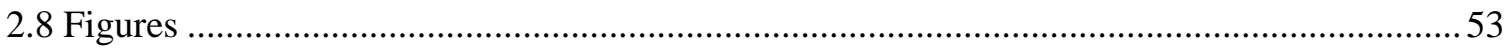

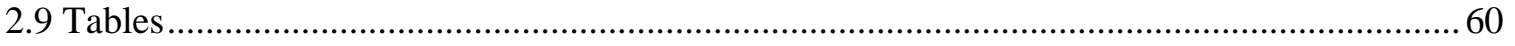

CHAPTER 3: CARBON ISOTOPES IN PINUS ELLIOTTII CELLULOSE AND THE RELATIONSHIP WITH SEASONAL PRECIPITATION AND CLIMATE OSCILLATIONS . 62

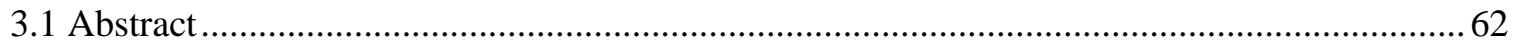

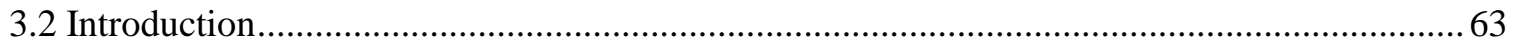

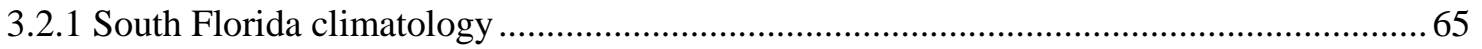

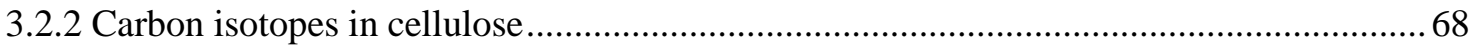

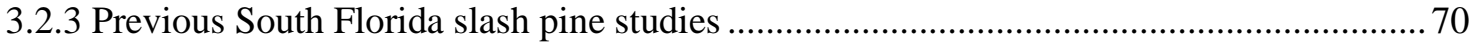

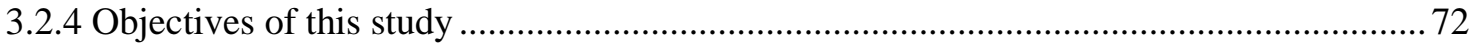

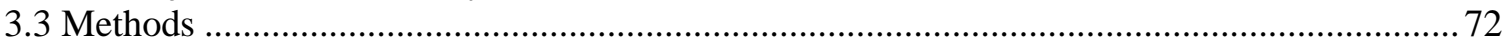

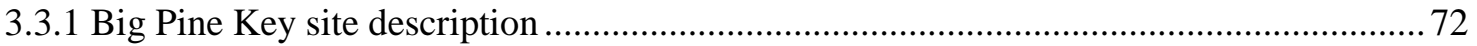




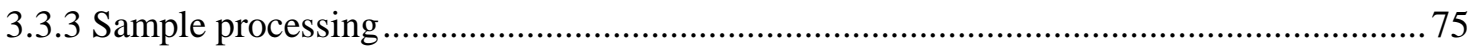

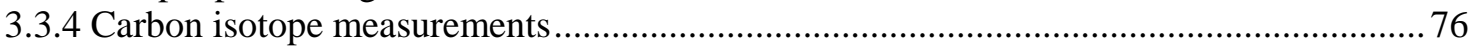

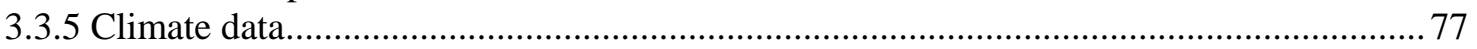

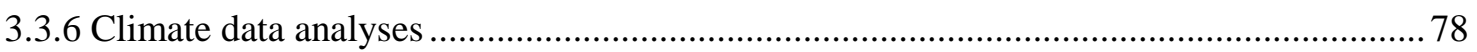

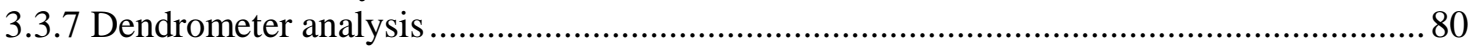

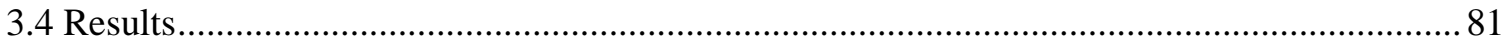

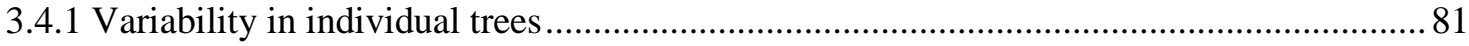

3.4.2 Comparison of the seasonal carbon isotope record and the climate parameters ...............82 82

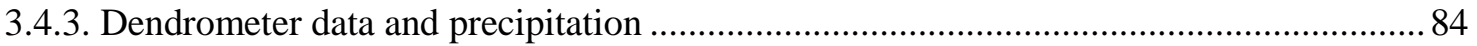

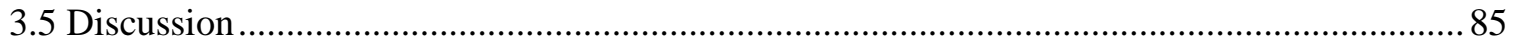

3.5.1 The landscape -scale picture: carbon isotopes and climate oscillations ............................85

3.5.2 The individual picture: variability of individual trees across a hydrologic transect...........88

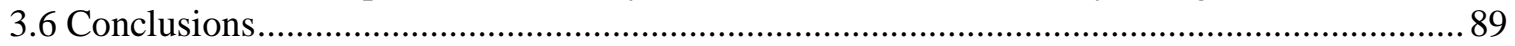

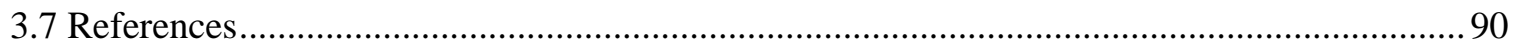

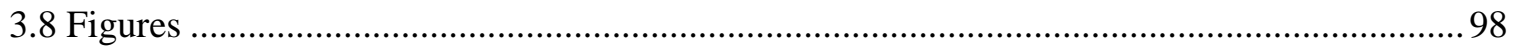

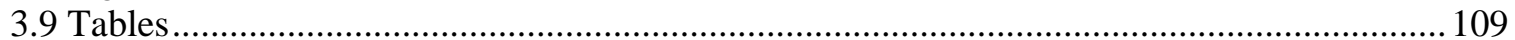

CHAPTER 4: TROPICAL CYCLONE ACTIVITY RECORDED IN PINUS ELLIOTTII TREE-RINGS ON A SUBTROPICAL ISLAND IN THE FLORIDA KEYS ............................. 111

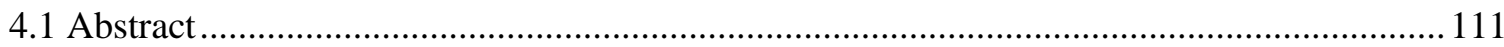

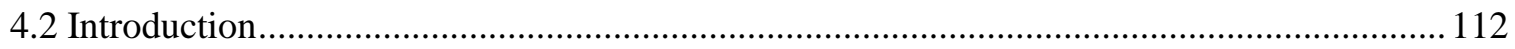

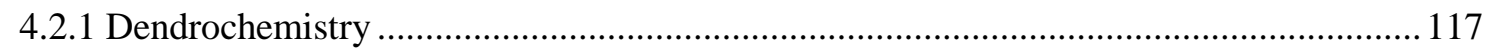

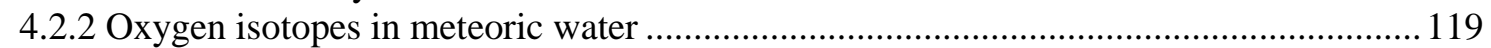

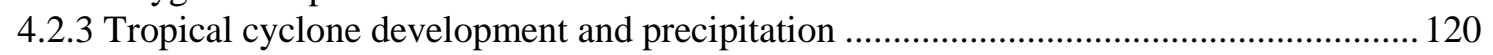

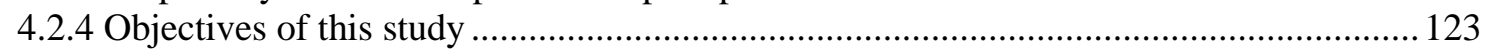

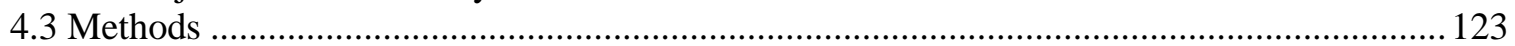

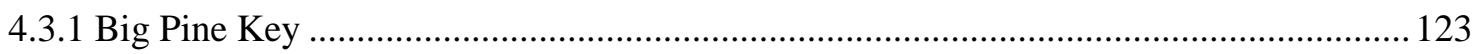

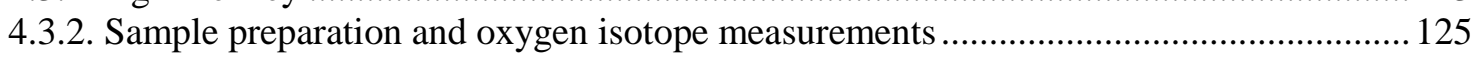

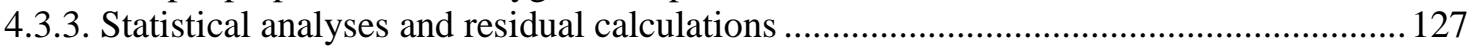

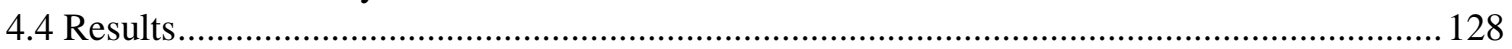

4.4.1 Variability in the oxygen isotopic record among individual trees.................................. 128

4.4.2 Comparison of the tropical cyclone activity in the $\delta^{18} \mathrm{O}$ and $\delta^{13} \mathrm{C}$ record ...................... 130

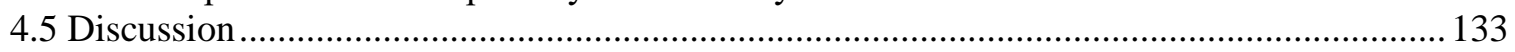

4.5.1 Variability in the oxygen isotope records among individual trees ............................... 133

4.5.2 Oxygen and carbon isotopes and the tropical cyclone record ........................................ 137

4.5.3 Explanation of false negatives and false positives in the oxygen isotope residual

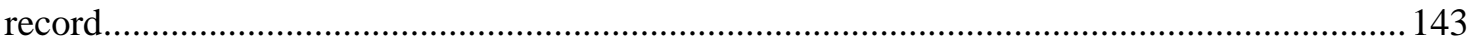

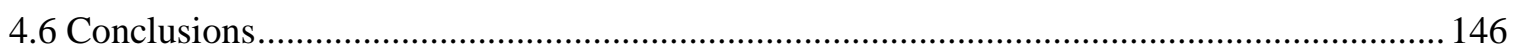

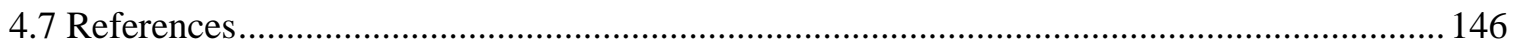

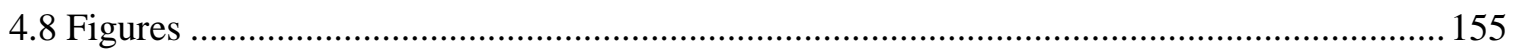

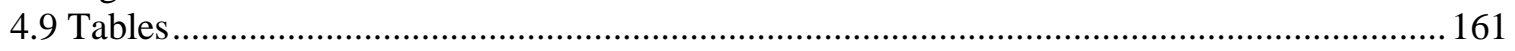

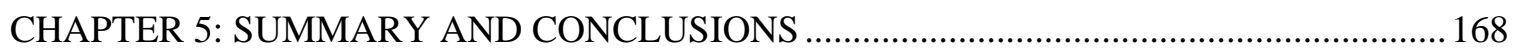

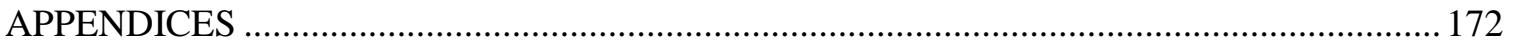

VITA 


\section{LIST OF TABLES}

Table 2.1 Ring Counts for WSL and SERC SIL. The calendar ages and number of rings counted for all P. elliottii var. densa tree disks measured. Annual tree-rings were counted and dated on the dendrochronology transects at the WSL (two left columns in the table) and on the isotope transects at the SERC SIL (4 columns on the right). The isotope-derived chronology includes oldest rings analyzed (the dates in parentheses), the number of intraannual density fluctuations (IADFs) removed from the datasets, and the number of missing rings. The SERC SIL tree-ring and IADF data combines the earlywood and latewood components into single annual rings. The values in the IADFs column denoted by asterisks reflect the removal of the latewood portions of the 2006 annual rings; they were shown to be part of the bark.

Table 2.2 Occurrence of Intra-Annual Density Fluctuations. Appearance of IADFs by tree, season, and climate variable. The precipitation data is from Key West, the closest, continuously recording station and is presented as more than average, "+," or less than average, "-," "precipitation. The ENSO and AMO data are divided into warm phase, "+," and cool phase, "-." All climate data is from the NOAA climate data inventories (NCDC, 2010).....61

Table 3.1 AMO Phase Interpretations and Sources. A list of sources and their respective methods used to define the phases of the AMO.

Table 3.2 Results of the Linear Mixed Effects Model. Results of the LME model used to compare changes in radial tree growth measured by dendrometers and cumulative precipitation at different intervals. Tree growth and precipitation were the fixed effects and tree ID was considered a random effect. Significance codes: 0 ' $* * *$ ' $0.001^{\prime \prime} * *$ ' $0.01^{\prime} *$.

Table 4.1 Saffir-Simpson Hurricane Intensity Scale. Classification of hurricane intensity by wind speed. *Actual storm surge inundation depends heavily on coastal morphology, the speed at which the hurricane is moving, and the angle of the wind direction relative to the coast. Table is modified from Rowlett (2004) and Schott et al. (2012)

Table 4.2 Potential Damage Characteristic of Each Hurricane Category. Table of hurricanes classified by the extent of possible damage. Modified from Rowlett (2004), Schott et al. (2012), and The National Hurricane Center (http://www.nhc.noaa.gov)

Table 4.3 Tropical Cyclone Activity for 1922-2005 within a 100km Radius of Big Pine Key. Bold font indicates that the eye of the hurricane passed within $25 \mathrm{~km}$ of Big Pine Key. * Record precipitation for that date, as of May 2016. - Instrumental data unavailable. Data from The National Hurricane Center (http://www.nhc.noaa.gov) and National Climate Data Center website (http://www.csc.noaa.gov/).....

Table 4.4 Paired T-Test Comparison of Individual Trees. Table contains data for all combinations of individual P. elliottii var. densa trees. All trees were compared over the years 1950-2005 with the exception of DBH2-DBH6, in which a longer time series, 1928-2005, 
was used. No combination of two trees was found to be statistically different from each other....

Table 4.5 Correlation values for individual and composite $\delta^{18} \mathrm{O}$ time series and monthly and seasonal Key West precipitation. Results of regression analyses between P. elliottii var. densa trees $\delta^{18} \mathrm{O}$ residual time series and monthly and seasonal precipitation recorded at the Key West weather station for the years 1950-2005. There were no strong correlations (r-values close to \pm 1 ) between recorded precipitation and any of the trees. However, there were some significant ( $\mathrm{p}$-value $\leq 0.05$ ) weak correlations observed in the record. The composite (the combined tree) and DBH1 indexes show very weak positive correlations to November precipitation and trees $\mathrm{DBH} 2$ and $\mathrm{DBH} 3$ have weak positive correlations to annual rainfall and January precipitation, respectively.

Table 4.6 Tropical cyclones recorded in the $\delta^{18} \mathrm{O}$ residual values. An " $\mathrm{X}$ " denotes that time series recorded an oxygen isotope residual value $<-0.01$ during years with reported tropical cyclone activity. The blue boxes indicate tropical cyclones with at least $5.0 \mathrm{~cm}$ of associated precipitation recorded at the Key West weather station...

Table 4.7 Anomalies in the Oxygen Residual Record. List of years with false negatives and false positives in the $\delta^{18} \mathrm{O}$ residuals in the combined tree time series. False negatives are years with reported tropical cyclones occurring within $100 \mathrm{~km}$ of Big Pine Key but the storms are not recorded in the $\delta^{18} \mathrm{O}$ residual values (residual values $>$ zero). False positives in the oxygen residual record are indicated by residual values less than -0.1 in years without tropical cyclone activity..... 


\section{LIST OF FIGURES}

Figure 1.1 Ring anomalies in Pinus elliottii var. densa trees from Big Pine Key, Florida. a) A high-resolution scan of a $P$. elliottii var. densa tree disk showing uneven concentric ring growth typical of trees growing in the Lower Florida Keys. b) Close-up of pinched rings. The arrows indicate the point where multiple rings pinch into a single narrow ring. c) Diffuse ring boundary. Ring boundaries without sharp contacts are a result of continuous annual growth. d) Intra-annual density fluctuations (IADFs). The arrows highlight several examples of periods of variable growth that are not related to the annual seasonal cycles. The black scale bars in the lower right corner of each picture represent one centimeter.

Figure 1.2 Diagram showing the factors that influence the $\delta^{13} \mathrm{C}$ values of tree-ring cellulose and the sources of fractionation as $\mathrm{CO}_{2}$ is fixed in the leaf. The environmental factors influencing the uptake of $\mathrm{CO}_{2}$ are in blue on the left half of the figure. The text in brown on the right describes the fractionation process. a) Atmospheric $\mathrm{CO}_{2}$ is the source for $\delta^{13} \mathrm{C}$ in the cellulose. There are two sources of fractionation: b) the discrimination against ${ }^{13} \mathrm{C}$ associated with the process of diffusion of $\mathrm{CO}_{2}$ through the stomata of the leaf, and c) the biological discrimination against ${ }^{13} \mathrm{C}$ as carbon is fixed into sucrose.................................. 18

Figure 1.3 Diagram showing the source water pools and the processes within the tree that influence the $\delta^{18} \mathrm{O}$ values of tree-ring cellulose. The pools of potential source water are in blue and appear on the left side of the figure and the processes are in brown on the right. Each water source has a distinct isotopic signature and trees generally utilize more than one source. a) There is no fractionation as the tree draws up water through the roots. b) The xylem water becomes slightly enriched in the leaf through transpiration. c) Sucrose produced in the leaf travels down the trunk where it exchanges with xylem water before being fixed within the cellulose.

Figure 2.1 Map of Big Pine Key, Florida showing the areal extent and depths of the two fresh water lenses during a typical wet season. The sampling transect is located inside the white box on the northeastern side of the island.

Figure 2.2 Average annual ring width index from 1920-2006 for the four P. elliottii var. densa disks measured at the WSL (black line). The index does not include the innermost juvenile rings (1901-1919) because their thicker ring widths may introduce a false trend in the index. The gray field indicates the spread between the maximum and minimum values among the

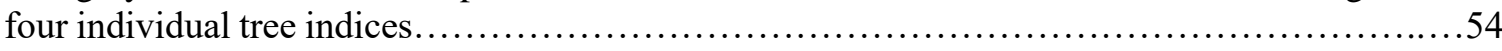

Figure 2.3 Average SERC SIL single transect measurements vs WSL multiple transect measurements ring width scatterplots for the four P. elliottii var. densa trees. The $\mathrm{r}^{2}$ values for each tree are displayed on their respective plots. Trees DBH3 and DBH6 (c and d) show weak correlations between ring width measurements taken at each lab; however, DBH1 and DBH2 ( $a$ and $b$ ) show almost no correlation between the two labs......................................

Figure 2.4 a) Model showing the expected relationship between ring width and $\delta^{13} \mathrm{C}$. The samples are expected to plot in the shaded regions. Fields 1 and 4 represent the range of growth 
conditions (optimal to stressed) that are expected if there is an inverse relationship between ring width and the $\delta^{13} \mathrm{C}$ value of the cellulose. b-e) Variance in $\delta^{13} \mathrm{C}$ and ring width for the $P$. elliottii var. densa trees. Plots show the distribution earlywood (light) and the latewood (dark) samples in the four quadrants of the model presented in part a. The percentage of total samples plotting within the combined quadrants 1 and 4 is displayed on each graph....................56

Figure $2.5 \delta^{13} \mathrm{C}$ chronologies for the four P. elliottii var. densa disks measured at SERC SIL: a) Individual $\delta^{13} \mathrm{C}$ for each of the four $P$. elliottii var. densa tree disks vs. ring number. The ring numbers increase from bark to pith. The black circles highlight the marker features used to crossdate the samples and to assist in the identification of IADFs in the dataset. The dashed lines connect identical features among samples. b) The final $\delta^{13} \mathrm{C}$ index for the site. This is an averaged value for DBH1, DBH2 and DBH3; the fourth sample, DBH6, was not included because its overall enriched signal dampens the data from the other three trees. The gray shaded field indicates the range of averaged values. The numbers highlight intervals of enriched $\delta^{13} \mathrm{C}$ or periods of sustained stress. These periods may be a result of hurricane activity within $100 \mathrm{~km}$ of Big Pine Key. The enrichment periods, their coincident hurricanes and respective intensities at the time of passage are as follows: $1=$ Unnamed hurricane, 1926 (Category 3), 2 = Labor Day Hurricane, 1935 (Category 5), 3 = Two unnamed hurricanes, 1948 (Categories 3 and 4), 4 = Hurricane Donna, 1960 (Category 4), 5 = Hurricane Wilma,

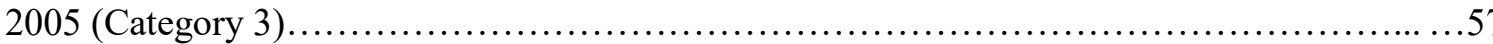

Figure 2.6 Comparisons between the chronologies derived from the $\delta^{13} \mathrm{C}$ data (blue lines) and the ring width data (gray lines). The biannual carbon isotope data have been condensed into annual measurments by calculating a weighted average for each year using the relative contributions for both the earlywood and latewood rings. a) Plot showing the variance from the respective means for each chronology. b) Plot showing the first order differences $\left(\mathrm{y}_{\mathrm{t}}-\mathrm{y}_{\mathrm{t}-1}\right)$ for both chronologies

Figure 2.7 The intra-annual density fluctuations (IADFs) removed from the isotope transects all four $P$. elliottii var. densa trees. a) IADFs identified over the $\delta^{13} \mathrm{C}$ chronology. A single circle is used to denote seasons when a tree had at least one occurrence of a density fluctuation; however, IADFs often occurred in multiples of two or three. For a total number of IADFs removed per tree, please refer to Table 2.1. b) The frequency of IADFs occurrence by season across the hydrologic transect. Tree DBH1 is closest to the deeper, more stable part of the freshwater lens, while DBH6 is located near the edge. c) Photograph of typical IAFDs. The arrows indicate two sets of density variations in a latewood ring.

Figure 3.1 Map of the Middle and Lower Florida Keys showing the sampling site on Big Pine Key (blue star) and the locations of the three nearest, historically continuous climate stations; Key West, Marathon, and Tavernier (red circles) ....................................... 98

Figure 3.2 Annual Climatologies for the Lower Florida Keys. a) The average monthly precipitation (in $\mathrm{cm}$ ) for the two long-term climate stations nearest to Big Pine Key: Key West (KW) and Marathon (Mar) (solid lines). The dashed lines show the running cumulative total percentage of monthly precipitation for each station. b) The average monthly maximum (red) and minimum (blue) temperatures for the Lower Keys. The data shown here is from the Key West station. The corresponding data for the Marathon station varies $\pm 0.5 \mathrm{C}^{\circ}$ except for temperature is $1 \mathrm{C}^{\circ}$ lower than Key West. c) Hours of daylight for the $15^{\text {th }}$ of each month.........99 
Figure 3.3 Time series for the climate variables used in the EOF analyses. All data have be converted into wet (May - October) and dry (November-following April) season values. The reported monthly sea surface temperature anomalies for each of the four large-scale climate oscillations (a-d) have been averaged into biannual values. Daily precipitation data from the two longest and most continuously recording climate stations (e-f) have been converted into monthly values. The monthly precipitation values were averaged over for the period 19502005 and the deviation from the mean was calculated for each month before data were averaged into seasonal values. The yearly data for Accelerated Cyclone Energy (g), have not been treated, but the values have been repeated to conform to the biannual scheme of the datasets. The Bermuda dust record (h) is from Prospero and Lamb (2006) and Prospero (2011). The gaps in the dust record were filled with a dummy constant for the analyses and the biannual values were calculated by summing the corresponding monthly totals

Figure 3.4 The first two EOFs for ring width (a-b) and $\delta^{13} \mathrm{C}$ values (c-d) for both the earlywood (EW) and latewood (LW) portions of each of the four P. elliottii var. densa trees. The percentage of the variance explained by each EOF is in the table to the right....

Figure 3.5 Pearson correlation coefficients for the $\delta^{13} \mathrm{C}$ values for a) earlywood and b) latewood and monthly precipitation from previous January ( $\mathrm{pJan}$ ) to current December. Black bars indicate months with statistically significant $\mathrm{p}$-values ( $\mathrm{p}$-value $\leq 0.05$ ).

Figure 3.6 The first two EOFs comparing the carbon isotope records for the individual tree to ENSO (a-b) and the AMO (c-d) for both the earlywood (EW) and latewood (LW) components of the tree-rings. The percentage of the variance explained by each EOF is in the table to the right.

Figure 3.7 The leading eigenvector a) and the secondary eigenvector b) comparing precipitation in the Florida Keys to the major climate cycles and hurricane records. The percent variance for each EOF is shown in the table. KW= Key West precipitation record. $\mathrm{TAV}=$ Tavernier precipitation records $. \mathrm{NAO}=$ North Atlantic Oscillation. $\mathrm{PDO}=$ Pacific Decadal Oscillation. ACE $=$ Accumulated Cyclone Energy.

Figure 3.8 Changes in radial growth for the three trees (black lines) used in the dendrometer study and the corresponding cumulative precipitation (blue bars) for each sampling interval. The change in radial growth is defined as the difference (in $\mathrm{mm}$ ) in the dendrometer readings between successive sampling periods. Precipitation values are the cumulative daily totals (in $\mathrm{mm}$ ) as reported by the Key West station. The dates have been converted to sampling days, where day zero (04/20/1990) represents the date of dendrometer installation and day 1275 is end of the study (10/07/1993). For reference, vertical gray lines have been added to show the

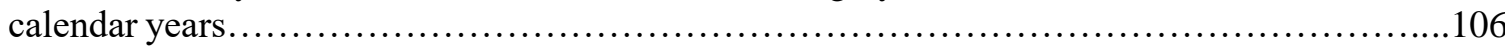

Figure 3.9 The major climate drivers of South Florida precipitation and the $\delta^{13} \mathrm{C}$ composite index from 1922-2005. The phases of a) the AMO (shown with a 7-point moving average) and b) ENSO (3-point moving average) are shown in red for the positive and blue for the negative phase. c.) Graph of the $\delta^{13} \mathrm{C}$ composite index (green line) and ENSO (blue line), both shown with a 3-point moving average. The warm (red) and cool (blue) phases of the AMO are represented by the colored bars. The white bars are the transitions between the positive and negative phases 
Figure 3.10 The relationship between ENSO and Key West precipitation under both phases of the AMO for the earlywood a) and the latewood seasons b). In both graphs, red indicates the positive phase of the AMO, while blue represents the negative phase.....................108

Figure 4.1 Map of the Lower Florida Keys showing the sampling site on Big Pine Key (blue star) and the location of the nearest, historically continuous climate station, Key West (red circle). The red box in the inset shows the area of the Florida Keys referenced...................155

Figure 4.2 Oxygen isotope values for the four P. elliottii var. densa trees. a) Latewood $\delta^{18} \mathrm{O}$ measurements for individual trees (\%o V-SMOW). Trees DBH1 and DBH3 span the period 1950-2005, while the time series for DBH2 and DBH6 extend to 1928 and 1922, respectively. b) The first-order difference values for each tree in per mil $\left(\delta^{18} \mathrm{Ot}_{2^{-}}-\delta^{18} \mathrm{O} \mathrm{t}_{1}\right)$. There are variations in the amplitudes of the annual values among individuals; however, the trees follow similar trends during several periods throughout the time series.............................156

Figure 4.3 Combined average carbon and oxygen residuals for the four P. elliottii var. densa trees from Big Pine Key over the period 1922 - 2005. A) Carbon isotope residuals for the latewood (solid black line) and the one season offset earlywood (dashed line) samples. The gray shaded area includes all residuals greater than zero; indicating enriched $\delta^{13} \mathrm{C}$ values and possible sustained periods of environmental stress. B) Oxygen isotope residual values for the latewood tree-rings. All residual values less than zero are included in the gray shaded box. Previous studies have defined the threshold for anomalously depleted oxygen residual values as $\geq-0.5$; however, that value may be too stringent for the Big Pine Key data. The solid vertical lines highlight all tropical cyclone events within $100 \mathrm{~km}$ of Big Pine Key occurring between the years 1922-2005 (See table 4.3). Blue lines are tropical depressions and tropical storms, orange lines are minor hurricanes (categories 1 and 2) and red lines are major hurricanes (categories $3-5$ ). In years with multiple tropical cyclone events, the color representing the strongest storm is used....

Figure 4.4 Plot showing the relationship between corresponding latewood carbon and oxygen isotope residuals for the years 1922-2005. The gray boxes represent years when there were no reported tropical cyclone activity within a $250 \mathrm{~km}$ radius of Big Pine Key, while the black circles indicate years with tropical cyclone activity. The data do not follow the predicted relationship of enriched carbon isotope residuals corresponding to depleted oxygen isotope residuals during tropical cyclone years. There is little difference in the relationship between the carbon and oxygen isotopes during tropical cyclone versus non-tropical cyclone seasons.....158

Figure 4.5 Carbon and oxygen isotope residuals by tropical cyclone type for the years 1922 2005. In all graphs, the circles represent the concurrent latewood (LW) residuals for both carbon isotopes and oxygen isotopes and the triangles show a one season offset where the current latewood oxygen isotope residual is plotted with carbon isotope residual for the next earlywood (EW) season. The hurricane seasons are labeled by year and, when possible, the label is placed between the two data points for each year. a) Tropical storms and tropical depressions. b) Minor hurricanes (categories 1-2). c) Major hurricanes (categories 3-5)..........159

Figure 4.6 Satellite images of two tropical cyclones from the 1973 hurricane season. A) Hurricane Brenda which formed near the Yucatan Peninsula in late August, arced westward and made landfall in the Yucatan. The rain bands are shown extending across the southern 
Gulf of Mexico to the Florida Keys. B) Tropical Storm Gilda formed in the Caribbean Sea and crossed central Cuba as it moved out into the Atlantic Ocean. The two storms could have contributed to the precipitation recorded by the Key West weather station and to the most depleted $\delta 180$ residual value in the tree-ring chronology. Image source: The National Hurricane Center Archive http://www.nhc.noaa.gov/archive. 


\section{LIST OF ABBREVIATIONS AND ACRONYMS}

ACE

AMO

$\mathrm{CO}_{2}$

$\mathrm{DBH}$

EA-IRMS

ENSO

EW

IADF

LME

LW

NAO

NOAA

PBK

PDO

PDSI

P. elliottii var. densa

ppm

RuBisCo

SERC SIL

SFWMD

V-PDB

V-SMOW
Accumulated Cyclone Energy

Atlantic Multidecadal Oscillation

Carbon dioxide

Diameter at breast height

Elemental analyzer isotope ratio mass spectrometry

El Niño - Southern Oscillation

Earlywood

Intra-annual density fluctuation

Linear mixed effects model

Latewood

North Atlantic Oscillation

National Ocean and Atmospheric Administration

Big Pine Key, Florida

Pacific Decadal Oscillation

Palmer Drought Severity Index

Pinus elliottii var. densa, Florida slash pine

Parts per million

Ribulose-1,5-Bisphosphate Carboxylase

Southeast Environmental Research Center Stable Isotope Laboratory

South Florida Water Management District

Vienna Pee Dee Belemnite

Vienna Standard Mean Ocean Water 


\section{CHAPTER 1: INTRODUCTION}

The observation that climate influences tree-ring production has been noted many times by several independent naturalists and scientists over the span of centuries. The ancient Greeks were the first to recognize that wood grows in sequential, concentric rings, and, in the following centuries, notes relating variations in tree-ring growth to a range of natural phenomena have been found in the writings of Leonardo da Vinci, Carl Linnaeus, Charles Babbage (the "father of the computer"), and John Muir, among many others (Speer, 2010). However, it was not until the work of Andrew Ellicott Douglass, a late $19^{\text {th }}$ century astronomer looking for evidence of the effects of the 11-year sunspot cycle on the Earth's weather, did dendrochronology emerge as an organized field of study (McGraw, 2003). Widely regarded as the "father of dendrochronology" (Schweingruber, 1988), Douglass discovered that patterns found in pine and sequoia tree-rings could be crossdated (matched among many samples of varying ages) and extended back in time to form centuries-long records of drought history (Douglass, 1909, 1920, and 1929). He then went on to apply his newly standardized techniques to the dating of wooden structures in several archaeological sites in the American Southwest (Douglass, 1929 and McGraw, 2003), thus propelling the interest and demand for tree-ring-derived chronologies across the globe and solidifying the legitimacy of the field of dendrochronology.

In a 1929 article he published in National Geographic about his work on the Pueblo Bonito archaeological site in New Mexico, Douglass described his view of trees as chronographers, dutifully recording their time on earth and how he, as a scientist, was simply reading their diaries (Douglass, 1929). Through dendroarchaeology, Douglass made significant contributions to the understanding of the timing of several Southwestern Native American civilizations (Douglass, 1929 and McGraw, 2003) and his observations of climate-related tree-ring growth have inspired a global network of dendrochronology studies. Since his time, chronologies spanning centuries have 
been developed for many regions including Central Europe (Becker, 1993, Spurk et al., 2002 and Friedrich et al., 2004), Northern Europe (Grudd et al., 2002), Asia (Zhang et al., 2003) and the western United States (Ferguson, 1968 and D'Arrigo and Jacoby, 1991).

The science of dendrochronology has also evolved, and it has become more than just counting the number of rings or recognizing patterns in their relative thicknesses. Dendrochronologists now have the capability of reading tree's "diaries" at much greater temporal resolutions and the breadth of information recovered from the rings is becoming increasingly diverse as new technologies are developed (Speer, 2010 and Cernusak and English, 2015). One such addition to the dendrochronology toolbox is the measurement of various stable isotopes in either the tree-ring whole wood or the extracted $\alpha$-cellulose component (McCarroll and Loader, 2004). The stable isotopes of carbon $\left(\delta^{13} \mathrm{C}\right)$, hydrogen $(\delta \mathrm{D})$, and oxygen $\left(\delta^{18} \mathrm{O}\right)$ have been used as proxies to infer more specific information on both the physiological controls and the ecological factors that influence tree growth. The assimilation of oxygen and hydrogen from water sources and carbon from the atmosphere into plant biomass records the stable isotopic composition of source material and environmental conditions under which the plant was photosynthesizing (Francey and Farquhar, 1982, Farquhar et al., 1989, Dawson et al., 1993, and Barbour et al., 2005). The measurement of stable isotope ratios in wood has shown that tree growth is sensitive to variability in precipitation (Saurer et al., 1997 and Mora et al., 2007), temperature (Libby and Pandolfi, 1974), humidity (Sternberg et al. 2007), large-scale ocean/atmospheric oscillations (Gray et al., 2004), and disturbance events (Anderson et al., 2005 and Miller et al., 2006). In addition, extremely highresolution measurements of $\delta^{13} \mathrm{C}$ and $\delta^{18} \mathrm{O}$ have allowed for the analysis of sub-seasonal growth dynamics (Loader et al., 1995, Poussart et al., 2004, and Verheyden et al., 2004) on a scale that would have been diluted if ring-width measurements were used alone (Managave and Ramesh, 2012). 
Advancements in analytic techniques have broadened the applicability of dendrochronology studies to the tropical and subtropical regions. Unlike the temperate zone, where the vast majority of treering studies occur, large gradients in annual temperature and solar insolation are not likely to be the limiting factors in tropical and subtropical tree growth (Worbes, 2002). The lack of well-defined seasonality dictated by average temperature fluctuations or day length can complicate the cycle of tree growth and may result in ring patterns that are difficult to interpret using traditional dendrochronology techniques (Tomlinson and Craighead, 1972, and Worbes, 2002). Trees in the tropics can be evergrowing (i.e., they grow continuously throughout the year; Glock, 1955), or they can exhibit episodic growth spurts with intermittent dormancy periods that occur at regular or irregular intervals depending on the tree species and the environment under which it is growing (Shukla and Ramakrishnan, 1986). Sporadic and inconsistent growth can lead to the production of ring anomalies which can emulate annual rings in appearance and confound a ring-width derived chronology. Common structural features that result from variable growth rates in tropical trees include micro rings (very thin rings that are only a few cells wide), diffuse ring boundaries (rings that indicate slowed growth, but no cessation), pinching rings (single or multiple rings that narrow into a single thin ring or disappear altogether), and false rings, or intra-annual density variations (IADFs), that look like annual rings but are produced sub-annually (Tomlinson and Craighead, 1972 and Speer, 2010). The dendrochronological interpretation of tree species that are known to have ring anomalies can be further complicated by the irregular periodicity of one or more environmental limiting factors that lead to the production of the anomalies. The appearance of IADFs, for example, may be a result of unseasonable wet or dry conditions (Schulman, 1938 and Leavitt et al., 2002), a disturbance event (such as an insect infestation; McCarroll and Loader, 2004), or a vegetational change in their localized environment (Copenheaver et al., 2004). 
Few dendrochronological studies have been conducted on tree species in the subtropical Florida Keys because many species have complicated, subannual ring structures or do not produce visible rings. One of the most promising candidates for dendrochronology-based paleoclimate research is the slash pine, Pinus elliottii Engelm. var. densa. As the dominant canopy species in the pine rockland ecosystem, $P$. elliottii var. densa has been shown to produce well-defined ring structures (Tomlinson and Craighead, 1972) that can be correlated to historical climate records with some success (Harley et al., 2011; Harley et al., 2012). The limited success in the correlation of P. elliottii var. densa ring width variations to the instrumental climatology is likely a result of the prevalence of many of the ring anomalies common in subtropical species. The tree-rings in P. elliottii var. densa growing on Big Pine Key do not have perfect circuit uniformity and they exhibit highly uneven concentric growth (Figure 1.1a). In addition, other inconsistent ring structures are also common in the $P$. elliottii var. densa trees, such as pinched rings, diffuse ring boundaries, and multiple IADFs (Figure 1.1b-d). The variability in ring width around the circumference of the tree and presence of other anomalous ring structures makes it difficult to build a site chronology using ring width measurements alone.

The research presented in the present dissertation was driven by the need for a high-resolution paleoclimate proxy for South Florida. Previous studies conducted in the Lower Florida Keys have shown that $P$. elliottii var. densa trees respond to solar insolation and precipitation (Harley et al., 2011; Harley et al., 2012); however, relationships between ring production and the strong teleconnections controlling South Florida precipitation (the Atlantic Multidecadal Oscillation, AMO, and the El Niño-Southern Oscillation, ENSO) have not been found. Decoding the "diaries" of the subtropical $P$. elliottii var. densa trees requires a technique that is capable of unlocking information on a chemical level that extends beyond what can be learned from the visible ring structures. The current study combines traditional dendrochronology techniques with the modern 
application of stable isotope analysis in an attempt to gain insight on the climate factors controlling P. elliottii var. densa growth over time and, ultimately, to contribute to the paleoclimate and hydrological history of the Florida Keys.

\subsection{Carbon and oxygen isotopes in cellulose}

Stable isotope-dendrochronology is one of the fastest growing subfields of modern dendrochronology (McCarroll and Loader, 2004). Stable isotopes are non-radiogenic and do not decay over time. The most common elements whose isotopes are used in ecosystem research are carbon, nitrogen, sulfur, hydrogen, and oxygen (Peterson and Fry, 1987); for these elements, the lighter isotope accounts for $95-99.9 \%$ of the natural abundance (Hoefs, 1997). The mass from the extra neutrons, as slight as it may be, influences the way the isotope moves through the environment in the process known as fractionation. Isotope fractionation is the partial separation of heavy and light isotopes through passive equilibrium or active kinematic processes (O'Leary, 1981). The relative distribution of the heavier isotopes in an ecosystem can provide a multitude of information about element cycles, biological reaction conditions, and the origin of resources used by organisms (Peterson and Fry, 1987).

In the field of isotope-dendrochronology, the isotopic ratios $\left({ }^{13} \mathrm{C} /{ }^{12} \mathrm{C}\right.$ or $\left.{ }^{18} \mathrm{O} /{ }^{16} \mathrm{O}\right)$ are measured in either tree-ring whole wood or extracted $\alpha$-cellulose. All isotope data in the present dissertation were measured in the $\alpha$-cellulose component of the tree-rings because the wood of the P. elliottii var. densa tree has a high resin content that may interfere with the annual climate signals. The $\alpha-$ cellulose extraction process reduces the wood to its main structural component by removing all resin, lignin, and other mobile constituents (Cullen and Grierson, 2006). A detailed description of the extraction process modified after Green (1963) can be found in Appendix 1. 
Carbon $\left(\delta^{13} \mathrm{C}\right)$ isotopes and oxygen $\left(\delta^{18} \mathrm{O}\right)$ isotopes were analyzed in both the earlywood (lighter, thin-walled cells growing in the spring and early summer) and the latewood (darker, thick-walled cells produced in the late-summer and fall) portions of the annual $P$. elliottii var. densa tree-rings and each analysis offers different insight into the variability of the environment in which the trees were growing over time. The following paragraphs provide an overview of the processes involved in the biologic assimilation of carbon and oxygen into the tree-rings and the environmental factors controlling their $\delta^{13} \mathrm{C}$ and $\delta^{18} \mathrm{O}$ composition. The chapters related to each type of isotopic analysis will include more in-depth descriptions of the calculations and the factors influencing the isotopic composition of the cellulose. Chapters 2 and 3 will discuss carbon isotopes and Chapter 4 will review oxygen isotopes in greater detail.

The variability in the carbon isotopic record may be attributed to changes in stomatal conductance in response to suboptimal growing conditions (O'Leary, 1981; Francey and Farquhar, 1982). Atmospheric carbon in $\mathrm{CO}_{2}$ is the sole source of carbon in terrestrial plants (O'Leary, 1981) and trees are sensitive to the anthropogenic $\delta^{13} \mathrm{C}$ enrichment of atmospheric carbon (Leavitt and Long, 1983), so all $\delta^{13} \mathrm{C}$ values in the time series must be corrected post-analysis (McCarroll et al., 2009). The carbon isotopic composition of cellulose is controlled by the fractionation of carbon dioxide as it diffuses through the stomata in the leaves during photosynthesis (O'Leary 1988). The isotopic signature of the assimilated carbon depends on: 1) the fractionation that occurs as the gas passes through the stomata and 2) the fractionation associated with the isotope discrimination of the Ribulose-1,5-Bisphosphate Carboxylase enzyme (RuBisCo) during carbon fixation (O'Leary 1988). If both the fractionation factors are considered to be constants, then the $\delta^{13} \mathrm{C}$ value of the cellulose is a result of the amount of $\mathrm{CO}_{2}$ taken in through the leaves (Farquhar et al., 1989). Trees will respond to periods of suboptimal growing conditions by altering their patterns of stomatal regulation, particularly if the tree has limited access to water. Therefore, the $\delta^{13} \mathrm{C}$ signature of a 
water stressed tree shows a relative enrichment in the amount of assimilated ${ }^{13} \mathrm{C}$ because the tree is transpiring less than it would in a more favorable setting (Farquhar et al., 1989). Figure 1.2 shows the environmental factors contributing to the $\delta^{13} \mathrm{C}$ of tree-ring cellulose.

The oxygen isotope composition of cellulose is controlled by three factors: 1 ) the combined isotopic composition of the source waters utilized by the tree, 2) the evaporative enrichment of water in the leaves due to transpiration (Dongmann et al., 1974), and 3) the biologic fractionation between cellulose and water and the exchange of oxygen atoms during the transfer of sucrose from the leaf to the cellulose production site (Sternberg et al., 1989). There is no fractionation associated with the uptake of source water by the roots; however, large fractionations can occur in the leaf causing the leaf water to be enriched in $\delta^{18} \mathrm{O}$ relative to the source water (Rodan et al., 2000; Anderson et al., 2002). Also, prior to cellulose synthesis, the isotopic composition of the sucrose is modified through oxygen exchange with the source water in the xylem (Sternberg et al., 1989). The above processes should be relatively constant for the trees in the same area, so any fluctuations in the oxygen isotope record should be a result of isotopic variability in the source waters (Anderson et al., 2002).

Trees may obtain their water from the soil, the groundwater supply, or a nearby body of surface water depending on their root structure (Figure 1.3). Groundwater tends to be more isotopically stable over time because it has a long residence time and represents the average of many rain events (Gat, 1996). On the other hand, the isotopic signature of soil water is constantly changing as a result of precipitation and enrichment in the upper soil column through evaporation (Tang and Feng, 2001). The isotopic composition of precipitation is highly variable and is controlled by many factors (Rozanski et al., 1993; Dansgaard, 1964). Most trees utilize a combination of available water reservoirs, and the relative contribution of each source may vary seasonally. In addition, 
tropical cyclones have depleted isotopic compositions, up to 10\%o (Lawrence et al., 2002) compared to typical summer rainfall (Price et al., 2008). Therefore, large $\delta^{18} \mathrm{O}$ depletions in the paleo-record may reflect tropical cyclone events (Miller et al., 2006), while intra-annual variability between the earlywood and latewood should be attributed to seasonal differences in precipitation.

\subsection{Objectives}

The work presented in the present dissertation was based on the following objectives. The main hypotheses for each objective are also provided.

1. To construct a stable isotope-derived sub-annual chronology in subtropical P. elliottii var. densa trees, a species known to produce intra-annual density fluctuations that are visibly indistinguishable from the annual growth rings.

H1a: The stable isotope-derived chronology will correlate to the traditionally constructed ring width chronology.

H1b: The narrowest rings will correlate with the most enriched carbon isotope cellulose values.

H1c: The stable isotope-derived chronology can be used to crossdate among trees in the same way ring-width patterns are crossdated in standard dendrochronology techniques.

2. To determine if the carbon isotopes within the $\alpha$-cellulose of individual P. elliottii var. densa earlywood and latewood rings can be used as paleoclimate proxies and recorders of disturbance events.

H2a: The P. elliottii var. densa tree-ring isotopic records will correlate with the recorded climatology of the Lower Keys, with severe drought years appearing in the record as relatively enriched carbon values. 
$\mathrm{H} 2 \mathrm{~b}$ : The carbon isotope site index will correlate to the major climate cycles, such as ENSO and the AMO, that influence the seasonal precipitation patterns in the Florida Keys. H2c: The appearance of intra-annual density fluctuations in the P. elliottii var. densa timeseries will correlate with seasons showing precipitation deficits.

3. To determine if the oxygen isotopes within the $\alpha$-cellulose of individual $P$. elliottii var. densa latewood rings can be used as recorders of hurricane events, and whether trees growing along a hydrologic transect show a gradient in carbon isotope enrichment from sea level rise.

H3a: The oxygen isotope signatures of the P. elliottii var. densa latewood rings will record a distinct signature that correlates to the elevated precipitation levels received during El Niño winters

H3b: Major disturbance events such as Hurricane Wilma will produce "stressed" signatures within the carbon isotope record, and the oxygen isotope record will reflect an extremely depleted $\delta^{18} \mathrm{O}$ value associated with tropical cyclones.

$\mathrm{H} 3 \mathrm{c}$ : Trees on the more coastal ends of the hydrologic transect will exhibit increasing stressed conditions over time as sea level rises and the areal extent of the freshwater lens decreases.

\subsection{Dissertation organization}

The individual body chapters (chapters 2-4) of the dissertation were written in manuscript format with the intention of submission to peer-reviewed scientific journals. All figures and tables referenced within the chapters are included after the reference sections of their respective chapters. The concluding chapter (chapter 5) is a brief summation of the overall conclusions of the dissertation research as a whole. The final section of the dissertation, the appendices, includes tables 
for all of the P. elliottii var. densa ring width and stable isotope data and a detailed description of the cellulose extraction method used to prepare all wood samples.

Chapter 2 (to be submitted to The Journal of Coastal Research) examines the feasibility of constructing a site chronology from the $\delta^{13} \mathrm{C}$-derived time series of four $P$. elliottii var. densa trees in Big Pine Key. The isotope chronology is compared and contrasted with a more traditional ring width analysis conducted on the same trees. The frequent appearance of IADFs led to discrepancies in the interpretation of the tree-rings between the two methods; however, the IADFs could be identified more easily by their $\delta^{13} \mathrm{C}$ signatures. Many of the visibly indistinct IADFs did not vary isotopically from the ring in which they appeared, although true latewood rings often showed a slight isotopic enrichment in comparison to their earlywood counterparts. In addition, the $\delta^{13} \mathrm{C}$ derived chronology revealed five periods of enrichment when the trees experienced extreme stress and the timing of each enrichment event is coincident with the passage of at least one category 3 or greater hurricane.

Chapter 3 (to be submitted to the Journal of Geophysical Research: Biogeosciences) is an analysis of the relationship between the $\delta^{13} \mathrm{C}$ time series (discussed in Chapter 2) for the four P. elliottii var. densa trees collected along a hydrologic gradient and various measured climate variables. Both the site-wide index and the $\delta^{13} \mathrm{C}$ time series for each individual tree were compared to precipitation records for the Florida Keys, sea surface temperature anomalies for several teleconnections (AMO, ENSO, the North Atlantic Oscillation (NAO) and the Pacific Decadal Oscillation (PDO)), the seasonal Accumulated Cyclone Energy for the Atlantic Basin, and the African dust record using empirical orthogonal functions (EOFs) over the period of 1950-2006. The carbon isotope records for the both the earlywood and latewood components of the four trees correlated well with each other in contrast to their ring widths, which had a complicated and inconsistent relationship. The 
P. elliottii var. densa trees respond to precipitation and ENSO cycles, but the nature of the relationship is complicated by the phase of the AMO. Tree growth is heavily influenced by regional patterns in precipitation; however, the microclimate and the localized hydrology surrounding individual trees ultimately controls the degree of response.

Chapter 4 (to be reformatted for submission to the Journal of Geophysical Research: Biogeosciences) examines the relationship between the $\delta^{18} \mathrm{O}$ values of the P. elliottii var. densa tree-ring cellulose and the hurricane record for the years 1922-2005. The trees showed some variability in their individual oxygen isotope chronologies; however, small differences in their overall average $\delta^{18} \mathrm{O}$ values indicated that the trees were utilizing the same source waters. A composite $\delta^{18} \mathrm{O}$ residual time series was constructed from the combined individual oxygen isotope chronologies of the four trees. The composite record documented $56 \%$ of the tropical cyclones that passed within a $100 \mathrm{~km}$ radius of Big Pine Key, as indicated by residual values $\leq-0.1$. Unlike previous studies, the carbon isotope residual records were also considered and the $\delta^{13} \mathrm{C}$ composite residual chronologies for the latewood samples and the earlywood samples of the following year were compared to the latewood $\delta^{18} \mathrm{O}$ residual time series. The intensity of the storms dictated which isotope residual captured the event; tropical depression and tropical cyclones had a limited impact on the $\delta^{13} \mathrm{C}$ residual values, but often appeared as depletions in the $\delta^{18} \mathrm{O}$ residual record. Several major hurricanes (categories 3-5) led to depletions in the $\delta^{18} \mathrm{O}$ residual record; however, half of them also showed enrichments in the $\delta^{13} \mathrm{C}$ residual values of the earlywood in the following year, suggesting that storm surge or high winds caused lasting damage to the trees. In addition, the depleted precipitation from the far-reaching rain bands of tropical cyclones in the western Gulf of Mexico was also recorded by the trees. 


\subsection{References}

Anderson, W. T., Bernasconi, S. M., McKenzie, J. A., Saurer, M., \& Schweingruber, F. (2002). Model evaluation for reconstructing the oxygen isotopic composition in precipitation from tree-ring cellulose over the last century. Chemical Geology, 182(2), 121-137.

Anderson, W. T., Sternberg, L. S. L., Pinzon, M. C., Gann-Troxler, T., Childers, D. L., \& Duever, M. (2005). Carbon isotopic composition of cypress trees from South Florida and changing hydrologic conditions. Dendrochronologia, 23(1), 1-10.

Barbour, M. M., Cernusak, L. A., \& Farquhar, G. D. (2005). Factors affecting the oxygen isotope ratio of plant organic material. Stable Isotopes and Biosphere-Atmosphere Interactions: Processes and Biological Controls, 9-28.

Becker, B. (1993). An 11,000-year German oak and pine dendrochronology for radiocarbon calibration. Radiocarbon, 35, 201-201.

Cernusak, L. A., \& English, N. B. (2015). Beyond tree-ring widths: stable isotopes sharpen the focus on climate responses of temperate forest trees. Tree physiology, 35(1), 1-3.

Copenheaver, C. A., Fuhrman, N. E., Stephens Gellerstedt, L., \& Gellerstedt, P. A. (2004). Tree encroachment in forest openings: a case study from Buffalo Mountain, Virginia. Castanea, 69(4), 297-308.

Cullen, L. E., \& Grierson, P. F. (2006). Is cellulose extraction necessary for developing stable carbon and oxygen isotopes chronologies from Callitris glaucophylla? Palaeogeography, Palaeoclimatology, Palaeoecology, 236(3), 206-216.

Dansgaard, W. (1964). Stable isotopes in precipitation. Tellus, 16(4), 436-468.

D'Arrigo, R. D., \& Jacoby, G. C. (1991). A 1000-year record of winter precipitation from northwestern New Mexico, USA: a reconstruction from tree-rings and its relation to El Niño and the Southern Oscillation. The Holocene, 1(2), 95-101.

Dawson, T. E., Ehleringer, J. R., Hall, A. E., \& Farquhar, G. D. (1993). Water sources of plants as determined from xylem-water isotopic composition: perspectives on plant competition, distribution, and water relations. In Stable isotopes and plant carbon-water relations. (pp. 465-496). Academic Press Inc.

Dongmann, G., Nürnberg, H. W., Förstel, H., \& Wagener, K. (1974). On the enrichment of $\mathrm{H}_{2}{ }^{18} \mathrm{O}$ in the leaves of transpiring plants. Radiation and environmental biophysics, 11(1), 41-52.

Douglass, A. E. (1909). Weather cycles in the growth of big trees. Monthly Weather Review, 37(6), 225-237.

Douglass, A. E. (1920). Evidence of climatic effects in the annual rings of trees. Ecology, 1(1), 2432. 
Douglass, A. E. (1929, December). The Secret of the Southwest Solved by Talkative Tree-rings: Horizons of American History Are Carried Back to A. D. 700 and a Calendar for 1,200 Years Established by National Geographic Society Expeditions. National Geographic Magazine, LVI (Six), 737+. Retrieved from http://tinyurl.galegroup.com/tinyurl/wrbC3

Farquhar, G. D., Hubick, K. T., Condon, A. G., \& Richards, R. A. (1989). Carbon isotope fractionation and plant water-use efficiency. In Stable isotopes in ecological research (pp. 21-40). Springer New York.

Ferguson, C. W. (1968). Bristlecone pine: science and esthetics a 7100-year tree-ring chronology aids scientists; old trees draw visitors to California mountains. Science, 159(3817), 839846.

Francey, R. J., \& Farquhar, G. D. (1982). An explanation of 13C/12C variations in tree-rings. Nature 297, 28-31.

Friedrich, M., Remmele, S., Kromer, B., Hofmann, J., Spurk, M., Kaiser, K. F., ... \& Küppers, M. (2004). The 12,460-year Hohenheim oak and pine tree-ring chronology from central Europe - a unique annual record for radiocarbon calibration and paleoenvironment reconstructions. Radiocarbon, 46(3), 1111-1122.

Gat, J. R. (1996). Oxygen and hydrogen isotopes in the hydrologic cycle. Annual Review of Earth and Planetary Sciences, 24(1), 225-262.

Glock, W. S. (1955). II. Growth rings and climate. The Botanical Review, 21(1-3), 73-188.

Gray, S. T., Graumlich, L. J., Betancourt, J. L., \& Pederson, G. T. (2004). A tree-ring based reconstruction of the Atlantic Multidecadal Oscillation since 1567 AD. Geophysical Research Letters, 31(12).

Green, J. W. (1963). Wood cellulose. In Whistler R. L. (ed.) Methods in Carbohydrate Chemistry, vol. iii. Academic Press, New York.

Grudd, H., Briffa, K. R., Karlén, W., Bartholin, T. S., Jones, P. D., \& Kromer, B. (2002). A 7400year tree-ring chronology in northern Swedish Lapland: natural climatic variability expressed on annual to millennial timescales. The Holocene, 12(6), 657-665.

Harley, G. L., Grissino-Mayer, H. D., \& Horn, S. P. (2011). The dendrochronology of Pinus elliottii in the lower Florida Keys: chronology development and climate response. Tree-Ring Research, 67(1), 39-50

Harley, G. L., Grissino-Mayer, H. D., Franklin, J. A., Anderson, C., \& Köse, N. (2012). Cambial activity of Pinus elliottii var. densa reveals influence of seasonal insolation on growth dynamics in the Florida Keys. Trees, 26(5), 1449-1459.

Hoefs, J., (1997). Stable isotope geochemistry (Vol. 201). Berlin: Springer.

Lawrence, J. R., Gedzelman, S. D., Gamache, J., \& Black, M. (2002). Stable isotope ratios: hurricane Olivia. Journal of Atmospheric Chemistry, 41(1), 67-82. 
Leavitt, S. W., \& Long, A. (1983). An atmospheric 13C/12C reconstruction generated through removal of climate effects from tree-ring 13C/12C measurements. Tellus B, 35(2), 92-102.

Leavitt, S. W., Wright, W. E., \& Long, A. (2002). Spatial expression of ENSO, drought, and summer monsoon in seasonal $\delta 13 \mathrm{C}$ of ponderosa pine tree-rings in southern Arizona and New Mexico. Journal of Geophysical Research: Atmospheres, 107(D18).

Libby, L. M., \& Pandolfi, L. J. (1974). Temperature dependence of isotope ratios in treerings. Proceedings of the National Academy of Sciences, 71(6), 2482-2486.

Loader, N. J., Switsur, V. R., \& Field, E. M. (1995). High-resolution stable isotope analysis of treerings: implications of 'microdendroclimatology' for palaeoenvironmental research. The Holocene, 5(4), 457-460.

Managave, S. R., \& Ramesh, R. (2012). Isotope dendroclimatology: A review with a special emphasis on tropics. In Handbook of Environmental Isotope Geochemistry (pp. 811-833). Springer Berlin Heidelberg.

McCarroll, D., \& Loader, N. J. (2004). Stable isotopes in tree-rings. Quaternary Science Reviews, 23(7), 771-801.

McCarroll, D., Gagen, M. H., Loader, N. J., Robertson, I., Anchukaitis, K. J., Los, S., ... \& Waterhouse, J. S. (2009). Correction of tree-ring stable carbon isotope chronologies for changes in the carbon dioxide content of the atmosphere. Geochimica et Cosmochimica Acta, 73(6), 1539-1547.

McGraw, D. J. (2003). Andrew Ellicott Douglass and the giant sequoias in the founding of dendrochronology. Tree-Ring Research.

Miller, D. L., Mora, C. I., Grissino-Mayer, H. D., Mock, C. J., Uhle, M. E., \& Sharp, Z. (2006). Tree-ring isotope records of tropical cyclone activity. Proceedings of the National Academy of Sciences, 103(39), 14294-14297.

Mora, C. I., Miller, D. L., \& Grissino-Mayer, H. D. (2007). Oxygen Isotope Proxies in Tree-Ring Cellulose: Tropical Cyclones, Drought, and Climate Oscillations. Terrestrial Ecology, 1, 63-75.

O'Leary, M. H. (1981). Carbon isotope fractionation in plants. Phytochemistry, 20(4), 553-567.

O'Leary, M. H. (1988). Carbon isotopes in photosynthesis. Bioscience, 38(5), 328-336.

Peterson, B. J., \& Fry, B. (1987). Stable isotopes in ecosystem studies. Annual review of ecology and systematics, 293-320.

Poussart, P. F., Evans, M. N., \& Schrag, D. P. (2004). Resolving seasonality in tropical trees: multidecade, high-resolution oxygen and carbon isotope records from Indonesia and Thailand. Earth and Planetary Science Letters, 218(3), 301-316. 
Price, R. M., Swart, P. K., \& Willoughby, H. E. (2008). Seasonal and spatial variation in the stable isotopic composition $\left(\delta^{18} \mathrm{O}\right.$ and $\left.\delta \mathrm{D}\right)$ of precipitation in south Florida. Journal of Hydrology, 358(3), 193-205.

Roden, J. S., Lin, G., \& Ehleringer, J. R. (2000). A mechanistic model for interpretation of hydrogen and oxygen isotope ratios in tree-ring cellulose. Geochimica et Cosmochimica Acta, 64(1), 21-35.

Rozanski, K., Araguás-Araguás, L., \& Gonfiantini, R. (1993). Isotopic patterns in modern global precipitation. Climate change in continental isotopic records, 1-36.

Saurer, M., Borella, S., \& Leuenberger, M. (1997). $\delta^{18} \mathrm{O}$ of tree-rings of beech (Fagus silvatica) as a record of $\delta 180$ of the growing season precipitation. Tellus $B, 49(1), 80-92$.

Schweingruber, F. H. (1988). Tree-rings. Springer Science \& Business Media.

Shukla, R. P., \& Ramakrishnan, P. S. (1986). Architecture and growth strategies of tropical trees in relation to successional status. The Journal of Ecology, 33-46.

Speer, J. H. (2010). Fundamentals of tree-ring research. University of Arizona Press.

Spurk, M., Leuschner, H. H., Baillie, M. G., Briffa, K. R., \& Friedrich, M. (2002). Depositional frequency of German subfossil oaks: climatically and non-climatically induced fluctuations in the Holocene. The Holocene, 12(6), 707-715.

Sternberg, L. da Silveira, L., Mulkey, S. S., \& Wright, S. J. (1989). Oxygen isotope ratio stratification in a tropical moist forest. Oecologia, 81(1), 51-56.

Sternberg, L da SL., Pinzon, M. C., Vendramini, P. F., Anderson, W. T., Jahren, A. H., \& Beuning, K. (2007). Oxygen isotope ratios of cellulose-derived phenylglucosazone: an improved paleoclimate indicator of environmental water and relative humidity. Geochimica et Cosmochimica Acta, 71(10), 2463-2473.

Schulman, E. (1938). Classification of false annual rings in Monterey pine. Tree-Ring Bulletin.

Tang, K., \& Feng, X. (2001). The effect of soil hydrology on the oxygen and hydrogen isotopic compositions of plants' source water. Earth and Planetary Science Letters, 185(3), 355367

Tomlinson, P. B., \& Craighead, F. C. (1972). Growth-ring studies on the native trees of sub-tropical Florida. Ghouse, A, K, M, Yunus, $M$ ed $(s)$. Research trends in plant anatomy. Reprint, 4894, 39-51.

Verheyden, A., Helle, G., Schleser, G. H., Dehairs, F., Beeckman, H., \& Koedam, N. (2004). Annual cyclicity in high-resolution stable carbon and oxygen isotope ratios in the wood of the mangrove tree Rhizophora mucronata. Plant, Cell \& Environment, 27(12), 1525-1536.

Worbes, M. (2002). One hundred years of tree-ring research in the tropics-a brief history and an outlook to future challenges. Dendrochronologia, 20(1), 217-231. 
Zhang, Q. B., Cheng, G., Yao, T., Kang, X., \& Huang, J. (2003). A 2,326-year tree-ring record of climate variability on the northeastern Qinghai-Tibetan Plateau. Geophysical Research Letters, 30(14). 


\subsection{Figures}
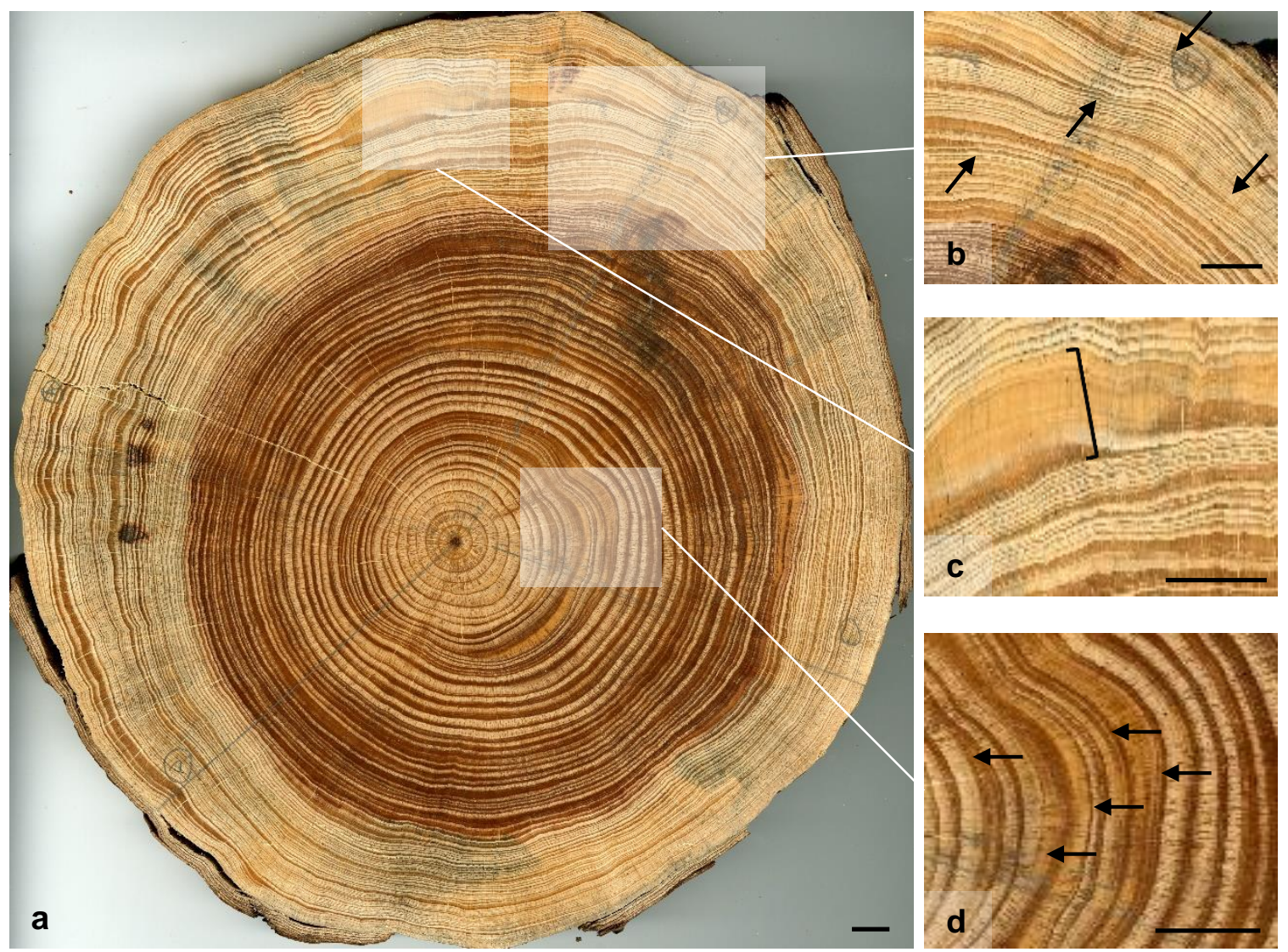

Figure 1.1 Ring anomalies in Pinus elliottii trees from Big Pine Key, Florida. a) A high-resolution scan of a $P$. elliottii var. densa tree disk showing uneven concentric ring growth typical of trees growing in the Lower Florida Keys. b) Close-up of pinched rings. The arrows indicate the point where multiple rings pinch into a single narrow ring. c) Diffuse ring boundary. Ring boundaries without sharp contacts are a result of continuous annual growth. d) Intra-annual density fluctuations (IADFs). The arrows highlight several examples of periods of variable growth that are not related to the annual seasonal cycles. The black scale bars in the lower right corner of each picture represent one centimeter. 


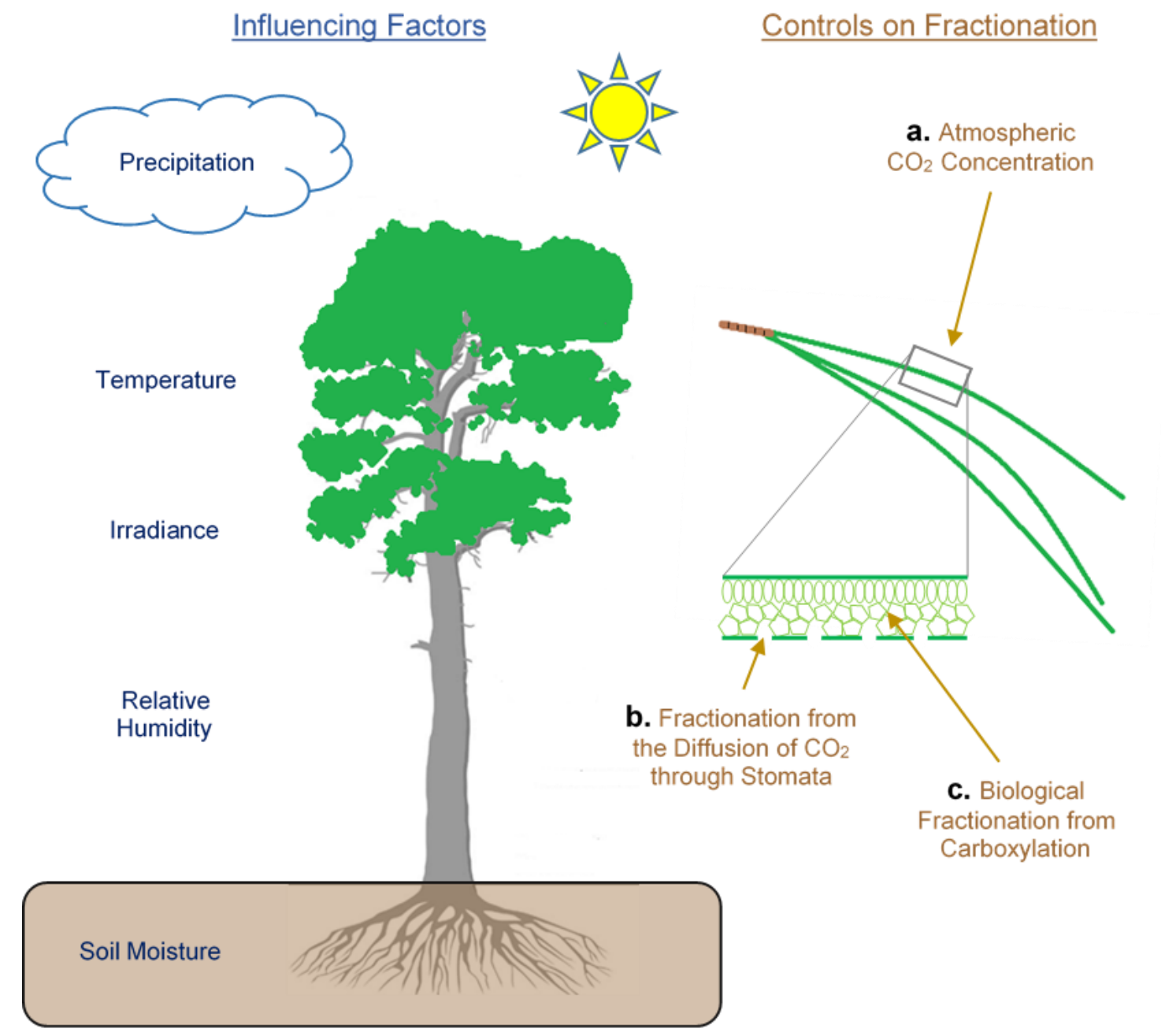

Figure 1.2 Diagram showing the factors that influence the $\delta^{13} \mathrm{C}$ values of tree-ring cellulose and the sources of fractionation as $\mathrm{CO}_{2}$ is fixed in the leaf. The environmental factors influencing the uptake of $\mathrm{CO}_{2}$ are in blue on the left half of the figure. The text in brown on the right describes the fractionation process. a) Atmospheric $\mathrm{CO}_{2}$ is the source for $\delta^{13} \mathrm{C}$ in the cellulose. There are two sources of fractionation: b) the discrimination against ${ }^{13} \mathrm{C}$ associated with the process of diffusion of $\mathrm{CO}_{2}$ through the stomata of the leaf, and c) the biological discrimination against ${ }^{13} \mathrm{C}$ as carbon is fixed into sucrose. Both fractionation factors are constants, so variations in the $\delta^{13} \mathrm{C}$ record are a result of the combined influence of the environmental conditions under which the tree is photosynthesizing. Chapters 2 and 3 provide a more detailed description of the carbon fixation process. (Modified from McCarroll and Loader, 2004). 


\section{Source Water Pools}

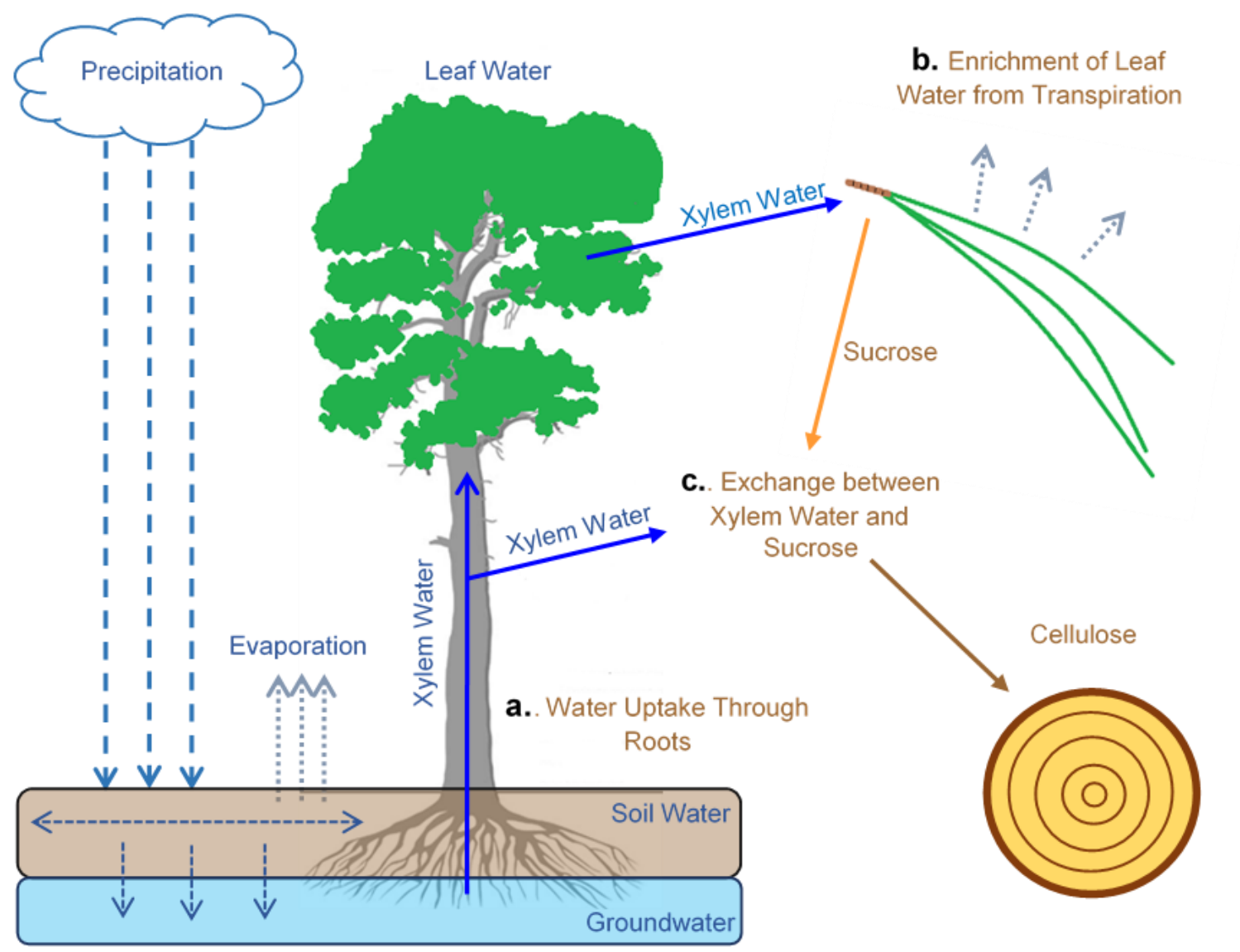

Figure 1.3 Diagram showing the source water pools and the processes within the tree that influence the $\delta^{18} \mathrm{O}$ values of tree-ring cellulose. The pools of potential source water are in blue and appear on the left side of the figure and the processes are in brown on the right. Each water source has a distinct isotopic signature and trees generally utilize more than one source. a) There is no fractionation as the tree draws up water through the roots. b) The xylem water becomes slightly enriched in the leaf through transpiration. c) Sucrose produced in the leaf travels down the trunk where it exchanges with xylem water before being fixed within the cellulose. For a more detailed description of the processes involved in the determination $\delta^{18} \mathrm{O}$ values of tree-ring cellulose, please refer to Chapter 4. (Modified from McCarroll and Loader, 2004). 


\section{CHAPTER 2: DEVELOPING A CARBON ISOTOPE CHRONOLOGY FOR A SUBTROPICAL}

\section{TREE SPECIES WITH VARIABLE SUB-ANNUAL TREE-RING GROWTH}

\subsection{Abstract}

The paucity of dendrochronological studies of climate variability in the subtropics is related to the challenge of developing ring width-derived chronologies in species that are notorious for irregular ring growth or for not producing annual rings as a result of the regional precipitation-driven seasonality. This study uses stable carbon isotopes to build a chronology in Pinus elliottii Engelm. var. densa (Little \& Dorman) growing along a hypothesized hydrologic gradient in the subtropical region of the Lower Florida Keys. Pinus elliottii exhibits distinct growth rings; however, the rings can show inconsistent growth around the circumference of a given tree. Additionally, the trees are known for having frequent intra-annual density fluctuations (IADFs), or false rings, that make crossdating the trees very difficult. The $\delta^{13} \mathrm{C}$ values of earlywood formed during the wet season, and latewood formed during the dry season) were used to both identify IADFs and crossdate the trees to build a site chronology (1922-2006). The formation of the IADFs is likely related to moisture availability and age of the tree, and their appearance varied temporally and spatially along the gradient. A traditionally derived ring-width chronology is compared and contrasted with one developed from the carbon isotopic composition if the $\alpha$-cellulose components of the tree-rings in four tree disks. The tree that showed the highest sensitivity and the tree living closer to the edge of the freshwater lens had a tendency to produce more IADFs during wetter than usual summers, while IADFs in the other two trees were more likely to appear in drier summers and wetter El Niño winters. Additionally, all four trees exhibited five seasons of prolonged stress that temporally corresponded to the passage of six major hurricane events ( $\geq$ category 3 ), the most recent of which, Hurricane Wilma in 2005, created a large storm surge in the Lower Keys that produced an enrichment response in the $\delta^{13} \mathrm{C}$. For the period 1922-2005, the $\delta^{13} \mathrm{C}$ chronology developed from tree-rings of one radius on the tree disk showed similar variability to a traditionally-derived ring 
width chronology that required the measurement of multiple radii on a tree disk to construct. This study shows this subtropical pine species to be a viable source of dendrochrologically-dervied paleoclimate inference, which has implications for improved water management in a system where freshwater input relies on precipitation.

\subsection{Introduction}

The recent focus on global climate trends has ignited the need for long-term, high-resolution paleoclimate datasets as a means of contextualizing the current state of climate change. Distinguishing and assessing the true effects of climate change from fluctuations in the inherently complex natural climate system require long paleoclimate records. The numerous controls on natural climate variability occur at different timescales, so several cycles of interrelated multi-scale global climate oscillations, such as the Atlantic Multidecadal Oscillation (AMO) and the El NiñoSouthern Oscillation (ENSO), are essential to the understanding of how the different phases of the predominant cycles interact with each other to influence climate patterns (Bradley, 1999). Therefore, continuous records must span the order of centuries so as to capture both the nuances of the Holocene natural climate system and the anthropogenically-induced warming trends of the last century (IPCC, 2014; Bradley, 1999).

While an understanding of global climate trends is necessary, the spatial heterogeneity of the projected effects, such as an increase in the expected annual precipitation or a greater likelihood of the occurrence of prolonged drought, demands a refinement to smaller scales. When the spectrum of potential warming and $\mathrm{CO}_{2}$ emissions reduction scenarios are factored in, policymaking organizations at all levels require localized data with which to make the most informed and economically feasible decisions (IPCC, 2014). The availability of high-resolution site-specific paleoclimate records could have important implications for future water management, more 
efficient farming practices, and the mediation of allergies and infectious disease control (IPCC, 2014; Epstein, 2005; Vörösmarty et al., 2000; Bradley, 1999).

The subtropical and tropical zones have important linkages to global climate regulation. Relatively small annual temperature gradients cause the characteristic ecosystems of the subtropics and tropics to be highly sensitive to increases in temperature; however, the degree of sensitivity is not fully understood (IPCC, 2014; Wang et al., 2014; Mora et al., 2013). A recent study by Mora et al., (2013) has shown that tropical and subtropical ecosystems are projected to experience greater climate-related stress than those located at the poles. Increased warming and enhanced acidification of the tropical oceans has led to higher-latitude migration of some marine species and to the initiation of the breakdown of coral reef communities (Walther et al., 2002). Terrestrially, the subtropical regions are likely to receive less annual precipitation then they do presently while evaporation is expected to increase (IPCC, 2014). Additionally, sea level rise in tandem with strained resources are forcing highly-vulnerable island states in the Pacific Ocean and Caribbean Basin to develop adaptation and mitigation strategies to protect both natural and human assets (IPCC, 2014). Yet, in spite of the important meteorological, ecological, and political implications, the subtropical region continues to be underrepresented in climate-related studies (IPCC, 2014; Mora et al., 2013; Rosenzweig and Neofotis, 2013).

Subtropical Florida faces the risk of immediate effects of global climate change. The nearly 3,700 $\mathrm{km}$ of tidal coastlines and relatively smooth topography make Florida susceptible to both sea level rise and climate-related terrestrial changes. Among the threatened coastlines is the South Florida coastal ecosystem that includes the Florida Everglades and Big Cypress National Preserve, as well as the heavily populated urban areas of Miami-Dade, Broward, and Monroe Counties. In an assessment of global port cities with high vulnerability to inundation as a result of climate change, Miami was ranked first in assets at risk to sea level rise and ninth in total population exposed to 
coastal flooding (Hanson et al., 2011). With a maximum natural surface elevation of about $7 \mathrm{~m}$ (5.5 $\mathrm{m}$ in the Florida Keys) above sea level and a highly permeable and shallow aquifer, the valuable freshwater resources of South Florida are at risk of salt water contamination (Schroeder et al., 1956; Hoffmeister and Multer, 1968; and Hoffmeister, 1974).

The freshwater resources of particular concern for South Florida are the low-lying Florida Everglades, where current restoration projects are underway, and the primary municipal water source for southeast Florida, the Biscayne Aquifer. Anthropogenic alterations to the historical freshwater flow through the Everglades watershed have greatly impaired the ability of the system to naturally mediate the landward encroachment of saline bay and coastal waters (Light and Dineen, 1994; Wanless et al., 1994; Price et al., 2006; among others). The installation of a network of canals and other drainage structures has diverted water from its natural southward course and created opportunities for further inland movement of the salt water / fresh water interface; therefore, these structures must be heavily managed by the South Florida Water Management District (SFWMD) (Light and Dineen, 1994; Wanless et al., 1994). The SFWMD must balance flood control with the hydrologic needs of the populated areas and the natural systems in the Everglades and, consequently, must rely on predictive hydrologic models (Light and Dineen, 1994; Huser, 1989).

The historical climate datasets available to the SFWMD and policymaking groups in South Florida are currently limited. There is a network of climate stations located throughout the Everglades, the metropolitan coastal areas, and the Florida Keys; however, very few of the stations have continuous historical data extending beyond the mid-1920s (NCDC, 2010). Access to long-term climate data is important because South Florida precipitation patterns have strong teleconnections to the ENSO and the AMO; however, the existing instrumental records do not even capture two complete cycles of the long-phase AMO (60-80 year cycles) (Gray et al., 2004; Enfield et al., 2001). The ability to 
supplement the instrumental records with data derived from high-resolution paleoclimate proxies provides insight into the intricacies of long-term climate cycles and may help to improve the predictive power of current models.

There have been many examples of paleoclimate research in South Florida using proxies such as paleolimnological studies (Watts and Hanson, 1988), diatoms (Wachnicka et al., 2010), pollen assemblage analysis from peat cores (Donders et al., 2005), and lipid biomarkers (Xu et al., 2007). The aforementioned studies have provided invaluable insight into the evolution of the South Florida ecosystem over the Quaternary Period; however, none of these proxies has the capability of subannual resolution. Unfortunately, South Florida offers very few options for high-resolution paleoclimate proxies, with the two main candidates being corals and tree-rings. Several studies relating coral growth bands to climate variables have been published throughout the region (Swart et al., 1996; Swart, Dodge and Hudson, 1996; Helmle et al., 2011), although the marine system may not capture the nuances of the terrestrial climate system. The tree-ring archive for South Florida has been lacking; however, recent research shows promise for its development.

\subsubsection{Tropical dendrochronology studies}

In spite of the demand for high-resolution tropical paleoproxies, the vast majority of the robust global dendrochronological archive is focused on the species residing in the temperate latitudes. Temperature extremes and significant variability in the length of the photoperiod impose limitations on cambial activity and lead to distinct growth rings defined by annual periods of dormancy in the temperate zone (Fritts, 1976). In contrast, seasonality in the subtropics is driven by changes in precipitation, as annual fluctuations in temperature and photoperiod are far less

pronounced than in their temperate counterparts (Worbes, 2002). A less rigidly-defined growing season may allow for everwet conditions ideal for year-long growth or irregular, punctuated 
cambial activity from inconsistent wet and dry periods (Worbes, 2002). Consequently, many tropical and subtropical tree species do not exhibit visible rings or have ring structures that may or may not represent annual growth (Poussart et al., 2004; Worbes, 2002; Tomlinson and Craighead, 1972).

In an assessment of subtropical trees, few tree species in South Florida, including the slash pine, Pinus elliottii Engelm. var. densa Little \& Dorman, show potential as candidates for dendrochronological studies (Tomlinson and Craighead, 1972). Although Tomlinson and Craighead (1972) determined that $P$. elliottii var. densa exhibited light and dark ring patterns that may represent annual growth, they also revealed that a more complicated annual ring pattern could be present as a consequence of the appearance of up to five false rings, so called intra-annual density fluctuations (IADFs) embedded within the true annual rings per year. Ultimately, Tomlinson and Craighead determined that each year may appear to have up to five successive growth flushes in a single growing season (1972). Research showed that the formation of the IADFs may be a result of a localized drought or other type of stress, such as insect infestation or a high-wind event (Tomlinson and Craighead, 1972).

Recently, Harley et al., (2011) conducted a dendrochronology study of P. elliottii var. densa trees in the lower Florida Keys. They discovered that the crossdating of tree-ring patterns among samples was difficult as a result of the uneven growth of the rings; to overcome this setback, they intentionally selected trees from sites with known burn histories. The fire scars could be used as site-wide marker rings representing a specific, documented date. However, the necessity of visible marker rings greatly limits the versatility of a ring width-based approach to dendrochronology in South Florida. Additionally, the development of very long paleoclimate datasets often require the utilization of partially complete samples from old snags in varying states of decay or from wooden 
beams in archaeological structures, potentially further reducing the usefulness of a species with complicated ring structures in dendrochronological reconstructions. A different approach, such as the use of stable isotopes in tree-ring cellulose, will allow for the increase in applicability of this type of study in subtropical South Florida.

\subsubsection{Carbon isotopes in cellulose}

Traditional dendrochronology studies may be taken a step beyond the physical measurement of tree-ring widths by using the stable isotope ratios within cellulose to infer information about physiological controls and environmental factors that affect the distribution of isotopes within the plant (Francey and Farquhar, 1982). It has been established that the stable isotope composition of tree-ring cellulose can be related to temperature (Libby and Pandolfi, 1974), precipitation (Saurer et al., 1997), drought (Mora et al., 2007), relative humidity (Sternberg et al., 2007), large-scale ocean/atmospheric oscillations (Gray et al., 2004), and disturbance events (Anderson et al., 2005; Miller et al., 2006).

The carbon isotopic composition of wood cellulose is controlled by the fractionation of carbon dioxide as it diffuses through the stomata in the leaves during photosynthesis (O'Leary, 1981, 1988). Fractionation is the partial separation of the heavier ${ }^{13} \mathrm{C}$ isotope from the lighter, more abundant ${ }^{12} \mathrm{C}$ isotope and it can occur through kinetic or equilibrium processes (O’Leary, 1981). In plants, the isotopic signature of the assimilated carbon depends on: 1) the fractionation that occurs as the source $\mathrm{CO}_{2}$ passes through the stomata, and 2) the fractionation associated with the isotope discrimination of Ribulose-1,5-Bisphosphate Carboxylase enzyme (RuBisCo) during carbon fixation (Farqhuar et al., 1989; O’Leary, 1988; Francey and Farquhar, 1982; O’Leary, 1981). The influences of these factors on the resultant $\delta^{13} \mathrm{C}$ of the plant can be expressed as (Francey and Farquhar, 1982): 


$$
\delta^{13} C=\delta^{13} C_{a}-a-(b-a) \frac{P_{i}}{P_{a}}
$$

where $\delta^{13} \mathrm{C}$ and $\delta^{13} \mathrm{C}_{\text {a }}$ are the $\delta^{13} \mathrm{C}$ values of the plant and atmospheric $\mathrm{CO}_{2}$, respectively; $a$ is the diffusion fractionation that occurs as $\mathrm{CO}_{2}$ passes through the leaf stomata $(\approx 4.4 \%$ ); $b$ is the biologic fractionation by the RuBisCo enzyme ( $\approx 27 \%$ ); and $P_{i}$ and $P_{a}$ are the internal and external partial pressures of $\mathrm{CO}_{2}$, respectively. The stomatal conductance is high and the plant is operating under more optimal conditions when $P_{a}$ is greater than $P_{i}$, which results in a strong discrimination against ${ }^{13} \mathrm{C}$ during carboxylation (Farqhuar et al., 1989). Conversely, when the gradient between $P_{a}$ and $P_{i}$ decreases, such as in times of water deficit when transpiration is limited, there is a decrease in the discrimination of ${ }^{13} \mathrm{C}$ leading to a relatively enriched $\delta^{13} \mathrm{C}$ value (Farquhar et al., 1989). The variations of $\delta^{13} \mathrm{C}$ can be attributed to adjustments in stomatal conductance relating to changes in temperature, precipitation, and relative humidity, or to environmental disturbances, such as hurricanes or saltwater intrusion, that cause the tree to enter a stressed state (McCarroll and Loader, 2004; Leavitt and Long, 1991; Farquhar et al., 1988; Pearman et al., 1976). Therefore, the carbon isotope signal in cellulose may indicate periods of sustained site-wide stress, which could be analogous to narrow growth-rings characterizing sub-optimal growing conditions in traditional dendrochronology studies.

\subsubsection{Objectives of the study}

This present study seeks to develop a paleoclimate chronology in a subtropical tree species from South Florida, Pinus elliottii Engelm. var. densa (Little \& Dorman), which is known for having intra-annual density variations that may be indistinguishable in appearance from the annual rings. Both traditional ring width measurements and carbon stable isotope techniques will be used on samples from the same trees to determine if a crossdateable chronology can be developed for trees without fire scars or other visual marker rings. The long-term goal is to provide a source of highresolution paleoclimate data that could potentially be extended back several hundred years for a 
region that is highly susceptible to the effects of climate change and requires immediate mediation planning.

\subsection{Methods}

\subsubsection{Site description}

Big Pine Key is the largest island in the lower Florida Keys, with an area of approximately $25 \mathrm{~km}^{2}$ and a maximum elevation of $3 \mathrm{~m}$ (Figure 2.1). A majority of the central region of the island is part of the National Key Deer Refuge, home to the endangered key deer, Odocoileus virginianus clavium (Barret and Stiling, 2006). Ecosystems represented on the island range from pine rockland forests and rockland hammocks at higher elevations to supratidal scrub and mangrove forests along the lower elevation gradients (Ross et al., 1992). The hydrology of the island consists of two separate shallow freshwater lenses: a large northern lens with a maximum depth of $8 \mathrm{~m}$, and a smaller, shallower southern lens (Wightman, 1990; Wightman et al., 1990). Both lenses exhibit seasonally-variable areal extents that fluctuate depending on recharge from rainfall (Wightman, 1990; Wightman et al., 1990). The freshwater lenses are a key factor in the distribution of the saltintolerant pine rockland community.

The endangered, fire-dependent pine rockland ecosystem is unique to southern Florida, although similar rockland ecosystems occur in the Bahamas (Noss et al., 1995). It is dominated by a single canopy species, the Florida slash pine (P. elliottii var. densa), with a palm and hardwood subcanopy and a rich herbaceous groundcover layer (USFWS, 1999). The limestone bedrock substrate is at or very near the surface, with small shallow pockets of sand, marl and organic material $(3-5 \mathrm{~cm}$ average depth range) dispersed across a karstic landscape that supports vegetation (Ross et al., 1994; USFWS, 1999). As noted above, the pine rocklands are dependent on the freshwater lenses and the resident botanical species are tolerant of short storm surge flooding events; however, most 
species will senesce and die if exposed to salt water for long periods of time (USFWS, 1999; Ross et al., 2009). A widespread P. elliottii var. densa mortality event occurred on Big Pine Key several months after the October 2005 passage of Hurricane Wilma as a result of flooding and subsequent salt stress (Ross et al., 2009; Sah et al., 2010). The northeastern track of the hurricane over peninsular Florida piled the water of Florida Bay along the northern shorelines of the islands in the lower Keys, creating a 1.8 - 2.4 m storm surge (Ross et al., 2009). The detrimental influence of the saltwater surge event was intensified by an uncharacteristically dry winter season which prevented the removal of the residual salts left in the soils by the overwash. About $80 \%$ of pines growing in the storm surge zone located at an elevation of less than a meter died within months of the flooding, while the loss of pines at elevations greater than a meter was significantly lower (Ross et al., 2009).

\subsubsection{Sample selection}

The four primary P. elliottii var. densa samples used in this study were collected by staff at the National Key Deer Refuge in April of 2006 along a proposed hydrologic gradient from the high mortality region on the northeastern portion of the island (Figure 2.1). The dead trees were cut down with a chainsaw and a 4.5-8 $\mathrm{cm}$ thick disk was removed at breast height. Three of the trees (DBH1, DBH2, and DBH3) are clustered together ( $\leq 30 \mathrm{~m}$ apart) and are growing on the inland edge of the sampling transect, while the fourth tree (DBH6) is located $160 \mathrm{~m}$ in the eastern direction towards the coast. A hydrologic survey completed by Wightman (1990) indicates that trees DBH1, DBH2, and DBH3 are growing in an area located over a deeper, more stable part of the northern freshwater lens and DBH6 is closer to the less stable periphery of the lens. None of the samples show visible evidence of fire scars, nor were the samples located in any of the known historical burn units described in Bergh and Wisby (1996). 


\subsubsection{Ring width measurements}

The four $P$. elliottii var. densa tree disks were divided transversely into two nearly identical disks and each was sanded using increasingly finer grits (beginning with 80 grit and ending with 400 grit) until the surface was completely smooth and all the rings were clearly visible. One disk from each tree was analyzed at the Swiss Federal Institute for Forest, Snow and Landscape Research (WSL), where ring width was measured in $1-4$ radii per tree disk, depending on the characteristics of the rings and the extend of termite damage to the tree disk, to the nearest $0.01 \mathrm{~mm}$ using the Time Series Programme (RinnTech, Heidelberg, Germany). The results of these analyses will be distinguished from the ring width measurements conducted on the stable isotope transects by referring to them as the "dendrochronology data" or the "dendrochronology transects" from this point forward.

From the second set of disks, a single, roughly inch-wide transect extending from bark to pith was cut from each disk and used for isotope analysis. The individual transects for each tree were selected from the group of 1-4 radii measured at the WSL and they represented the most complete view of the rings (a location where the bark was still attached, had the least occurrence of ring compression, and were distant from visible termite damage). Standard dendrochronology techniques were used to count the rings in each disk sample following the guidelines described in Fritts (1976) and Cook and Kairiukstis (1990). During the initial visual analysis of the isotope transects, every distinct ring was assigned a consecutive number that correlated to the position of the ring from the bark. The last ring formed before death was assigned the label "ring 1" and the numbers increase inward towards the pith, with the innermost ring having the highest number for that tree. All alternating

light and dark bands were counted and individually separated as a sub-annual rings. When an obvious visual IADF (a very faint ring a few cells thick) was encountered, a best estimation was 
used to determine if the IADF was part of the earlywood or latewood growth and it was homogenized with that ring. A total of $754 \alpha$-cellulose samples were analyzed for $\delta^{13} \mathrm{C}$.

The samples were photographed, examined under a microscope, and the locations of the ring boundaries were manually recorded within the digital images using Adobe Photoshop CS2. In this preliminary stage, all light and dark bands that appeared to be separate rings were counted and obvious IADFs were grouped with their respective rings.

Once each sample was divided into distinct growth rings, the average width of every earlywood and latewood ring and the width of the entire annual ring as a whole were measured with the image processing and analysis program ImageJ, which uses a simple ratio system to compare a known distance within an image with unknown distances. Conversions of the ImageJ ratios to millimeters were calculated in a Microsoft Excel worksheet. All visually identifiably IADFs were measured as part of their respective rings.

\subsubsection{Sample processing}

Each early- and latewood ring defined during the dendrochronological analysis portion of the study was individually separated into ring shavings under a microscope at $15 \mathrm{x}$ magnification using an $\mathrm{X}$ Acto knife. Special care was taken when dividing the rings to accommodate for wood curvature and uneven vertical growth, so that each sample contained only material from that growth period. The samples were then homogenized into a semi-fine powder using a stainless steel vial and ball set in a Spex 8000M Mixer/Mill. The time required to homogenize each sample varied depending on the thickness of the ring shavings, the overall amount of sample, and the resin content of the wood. Samples from the heartwood took an average of 90 minutes to homogenize, whereas samples from thinner rings in the sapwood required around 30 minutes in the ball mill. A subset of the powdered samples underwent a chemical extraction process to isolate the $\alpha$-cellulose component 
of the wood using a method modified after Green (1963) (see Appendix 1 for a detailed description of the revised process). The extraction process removed the mobile resin component and other elements in the wood that can jeopardize the integrity of the climate signal of the isotope analysis by introducing unnecessary noise among samples (Cullen and Grierson, 2006; Loader et al., 2007).

\subsubsection{Carbon isotope measurements}

Carbon isotope measurements were completed in the Southeast Environmental Research Center Stable Isotope Laboratory (SERC SIL) at Florida International University on a Carlo Erba NA1500 II coupled to a Finnigan MAT Delta C mass spectrometer via a ConFlo II interface using standard elemental analyzer isotope ratio mass spectrometry (EA-IRMS) techniques. All isotopic values will be expressed as $\delta \%$, which will be calculated using the following formula (Coplen, 1994):

$$
\delta \%=\left[\left(\frac{R_{\text {sample }}}{R_{\text {standard }}}\right)-1\right] 1000
$$

where $\mathrm{R}_{\text {sample }}$ is the ratio of ${ }^{13} \mathrm{C} /{ }^{12} \mathrm{C}$ in the sample and $\mathrm{R}_{\text {standard }}$ is the ratio ${ }^{13} \mathrm{C} /{ }^{12} \mathrm{C}$ in the V-PDB (Vienna Pee Dee Belemnite) standard for carbon.

\subsection{Results}

2.4.1 Building a chronology using standard dendrochronology techniques

Tree-ring series were constructed using measurements taken along the sampling radii analyzed in each individual tree disk at the WSL and along a single $2-2.5 \mathrm{~cm}$ wide radius on the samples used for isotope analysis at the SERC SIL. As described in previous studies (Harley et al., 2011; 2012), the four P. elliottii var. densa samples displayed concentrically complicated ring growth and all transects measured had examples of IADFs that were, at times, difficult to visually distinguish from the annual rings. Additionally, locally absent rings were found along many of the transects; these "missing" rings were identified as a single narrow latewood ring on one side of the disk that would thicken and divide into several light and dark "rings" on the other side of the tree. Also, there were 
many examples of latewood rings that gradually transitioned into the next earlywood ring, appearing more like a smear than a sharp contact, and indicating that a complete cessation of growth may not have occurred during the corresponding dry season. The occasional lack of sharp contacts, the locally absent rings, and the presence of IADFs complicated the ring identification and counting process.

Crossdating among trees was challenging in the absence of fire scars or another type of visible marker ring. Crossdating transects measured within the same tree was also problematic because of the locally absent rings and the frequent appearance of IADFs. There was not a consensus between the two labs on the definition of ring boundaries or the number of annual rings represented in each disk. One reason for this discrepancy may be that the two disks collected from the same tree show slight differences in their ring patterns. For example, a latewood ring might appear as a single ring in one disk and the same ring may be split into multiple IADFs in the other disk. The tracheid growth within these trees is inconsistent around the circumference of the trunk and can also vary vertically over relatively short distances (on the scale of several centimeters).

The average ring width index compiled from the combined dendrochronology transects from all four trees is shown in Figure 2.2. The gray shaded region indicates the variability among the individual tree's series used to construct the index. The spread between the minimum and maximum values varies considerably and there are relatively few years when the trees all show the same magnitude and type of growth dynamic. Some variation in annual ring width among the trees is expected since growth is ultimately controlled by the immediate conditions around the tree and no forest has perfectly homogenous soil and nutrient distribution, water and light availability, etc. (McCarroll and Loader, 2004). A ring width chronology developed from the isotope transect is not 
shown in Figure 2.2 because crossdating the samples with such limited data is challenging and a single transect does not fully capture the variability introduced by the complicated ring structures.

The scatterplots comparing the tree-ring series developed from the multiple dendrochronology transects and the single isotope transects are provided in Figures 2.3b-e. Linear relationships between the two sets of measurements were expected; however, the different measuring techniques utilized by each lab is potentially responsible for large discrepancies in the ring width analyses for all four trees. The SERC SIL transects used for isotope analyses were as close to parallel as possible with one of the dendrochronology transects analyzed in the WSL disk (with a 3.8-7 cm vertical displacement in the trunk). The ring width data for the isotope transects are averaged from five measurements along a single, inch-wide transect, while the dendrochronology data is an average of the measurements of multiple transects taken at different locations around the disks. Trees DBH3 and DBH6 (Figures 2.3d and e, respectively) are weakly correlated $\left(\mathrm{r}^{2}=0.31\right.$ and 0.47 , respectively) in their measured ring widths, while DBH1 and DBH2 (Figures 2.3b and c, respectively) show no relationship $\left(r^{2} \leq 0.03\right)$ between lab analyses. There are discrepancies between the total numbers of rings counted by the WSL and by the SERC SIL and the lack of a strong correlation between the two datasets can be explained by the different interpretations of ring boundary definitions (Table 2.1and Figure 2.3). Slight disagreements between the two tree-ring series would propagate throughout the dataset and result in offsets in numerically corresponding rings.

Comparisons of the high-resolution digital scans of the two sets of tree disks from each tree confirmed differences in the visual appearances of the parallel transects. The inconsistent nature of P. elliottii var. densa growth under the variability of a precipitation-driven seasonality in the subtropics can result in the appearance of ring structures that are not necessarily annual by nature (Cherubini et al., 2003). The presence of these sub-annual structures contributed to discrepancies 
in ring boundaries definitions among the two labs and reinforces the need for an additional technique to extract meaningful climate data from this species.

\subsubsection{Building a chronology using carbon isotopes}

A relatively enriched $\delta^{13} \mathrm{C}$ value indicates a period of stressful growth for the tree where discrimination against ${ }^{13} \mathrm{C}$ is decreased; thus, it is expected that the most enriched values correspond to the narrowest rings and depleted $\delta^{13} \mathrm{C}$ values are found in samples from relatively wider rings produced under optimal growing conditions. Comparisons between variance in ring width and variance in the corresponding $\delta^{13} \mathrm{C}$ value were predicted to plot in quadrants 1 and 4 in the model shown in Figure 2.4a; however, no consistent inverse relationship between $\delta^{13} \mathrm{C}$ and width was found (Figure 2.4b-e). Between 45-54\% of the samples for each tree exhibit the expected pattern of ${ }^{13} \mathrm{C}$ enrichment in narrow rings and the depletion of ${ }^{13} \mathrm{C}$ in the wider rings. Once the yearly chronology was established, additional scatterplots were constructed by subdividing the data into years of extreme precipitation and drought, ENSO phases, strong ENSO phases, and AMO phases. The analyses were repeated using a one season offset to account for any potential lag in growth response to the climate variables. No significant relationship was found between $\delta^{13} \mathrm{C}$ and ring width under any of the climate variables tested: Key West precipitation, Palmer's Severity Drought Index, ENSO, AMO, or maximum temperature. This is likely a result of measuring ring width from a single transect; better correlations may have been achieved if multiple transects had been used to build a ring width index.

A site index for the years 1922-2006 was developed using patterns in the $\delta^{13} \mathrm{C}$ time-series for the four trees. Figure 2.5a shows the plots of $\delta^{13} \mathrm{C} \%$ versus ring number for the entire bark to the pith span of the isotope transects. Similar patterns were noted among the samples; however there was an offset among the corresponding ring numbers. Crossdating the trees was accomplished by using 
the four most striking similarities (black circles in Figure 2.5a) in the same way visible marker rings, such as fire scars, would be used to align the samples. The IADFs were isotopically similar to the sub-annual ring in which they were embedded because they were part of the same ring; alternatively, the method used to analyze the samples may have been too coarse to capture the individual signatures of the IADFs (De Micco et al., 2012). All IADFs incorrectly identified as rings were detected by counting the number of rings in each sample between the anchor marker rings intervals. Once suspected IADFs were identified, the original digital images or the remaining tree disk was consulted for further scrutiny. Samples were candidates for removal from the carbon isotope data set only if they could be confirmed as IADFs in the digital images or there was no change in the isotopic value within a span of three or four consecutive samples. A total of 115 samples were removed from the dataset. Additionally, two trees, DBH1 and DBH6, appear to have a missing ring for the years 1936 and 1988, respectively. In both cases, the ring was so narrow at the point where it intersected the sampling transect that it was mistakenly grouped in with the next season's sample.

Calendar years were assigned to each ring under the assumption that the lighter rings were earlywood and correspond to wet season cambial activity (May to October) and the dark rings were formed as latewood during the dry season (November to the following April). The data were corrected to the pre-industrial standard value of atmospheric $\mathrm{CO}_{2}(-6.4 \%)$ using the method described in McCarroll et al. (2009) and the annual historical values of $\delta^{13} \mathrm{C}$ of atmospheric $\mathrm{CO}_{2}$ published in McCarroll and Loader (2004). The average index for the three trees from the deeper section of the hydrological sampling transect (DBH1, DBH2 and DBH3) is shown in Figure 2.5b. The fourth tree, DBH6, was not included in the site index because, given its proximity to the edge of the seasonally changing fresh water lens, it showed an overall enriched, possibly water-stressed, signature compared to the other trees. However, DBH6 appears to have adapted to its environment, 
because it shows the same extremes in amplitude and overall trends exhibited by the three interior trees, suggesting that it is living in equilibrium under more its restricted hydrologic conditions (Figure 2.5a). When the DBH6 data was incorporated in the average $\delta^{13} \mathrm{C}$ chronology, it dampened the signal of the other three trees.

There are several notable periods of enrichment in the carbon isotope chronology that are indicative of seasons of prolonged, extreme stress (denoted by the numbers above the enrichment peaks in Figure 2.5b). These events do not correspond to anomalously dry seasons with drought-like conditions, with the exception of peak 1 that occurs during the very the dry winter season of 20052006. All of the most isotopically-enriched stress events occurred following the passage of a major hurricane within a $100 \mathrm{~km}$ radius of Big Pine Key. The five enrichment peaks coincide with the timing of six hurricanes that were category 3 or greater at the time of passage (Figure $2.5 \mathrm{~b}$ ). The hurricanes and their respective intensities at the time of passage are as follows: Hurricane Wilma, 2005 (Category 3), Hurricane Donna, 1960 (Category 4), two unnamed hurricanes, 1948 (Categories 3 and 4), Labor Day Hurricane, 1935 (Category 5), and an unnamed hurricane, 1926 (Category 3) (NCDC, 2012).

Hurricane events are a possible explanation for the periods of prolonged states of stress within the trees. In addition to the coincident timing of hurricanes and enrichment events, it has been documented that hurricanes can cause long-term damage in South Florida trees through structural damage from wind and storm surge (Duryea et al., 1996, Everham and Brokaw, 1996; Koptur et al., 2002; Sah et al., 2010). Enrichment peak 1 occurs in the dry season of 2005-2006, just after the October impact of Hurricane Wilma. The Florida Keys were not in the direct path of the hurricane; however, the hurricane caused a storm surge in Florida Bay that flooded the northern portions of the Lower Keys islands and deposited a layer of marine salts that persisted in the soil long after the 
water subsided (Sah et al., 2010). The combination of residual salts and an abnormally dry winter is likely what caused the demise of the trees used in this study; therefore, a peak in $\delta^{13} \mathrm{C}$ during the corresponding dry season is expected (Sah et al., 2010).

The $\delta^{13} \mathrm{C}$ site index is compared to the site index developed from the traditional ring width measurements for the period of 1920-2005 in Figure 2.6. The sub-annual carbon isotope data was combined into annual values using weighted averages from the relative contributions of each earlywood ring and its corresponding latewood ring. Figure $2.6 \mathrm{a}$ is a plot of the variance from the respective mean for each chronology, while the first order differences for the two chronologies is shown in Figure 2.6b. The two indices do not show a perfect correlation; however, there are similarities in their variance, although the nature of their relationship fluctuates over the time period. The first order difference is a way of illustrating changes between successive time intervals and it is calculated by subtracting the variance of the previous year from that of the current year (Hamilton, 1994). There are periods (1923-1930 and 1981-1995, for example) when the $\delta^{13} \mathrm{C}$ chronology and the ring width chronology are coincident and trend together. At other times in the record, the response recorded by the two proxies is reversed (1930-1943 and 1998-2005) or inconsistent from period to period. The expected relationship between ring width and $\delta^{13} \mathrm{C}$ is depicted in Figure 2.4a. Years when narrow rings are produced are expected to show a corresponding enrichment in ${ }^{13} \mathrm{C}$, whereas wider rings indicate an environment of optimal growth and should show a relative depletion in $\delta^{13} \mathrm{C}$.

\subsubsection{The presence intra-annual density fluctuations}

The IADFs that were indistinguishable from the annual rings over the length of the P. elliottii var. densa isotope-derived chronologies is shown in Figure 2.7a. Overall, the trees exhibited little overlap in the occurrence of IADFs and there is only a single period, 1978, in the 84-year 
chronology when all four trees simultaneously produced density variations. Of the 36 seasons with IADF production, 32 appeared in single trees and 3 seasons had density variations in at least two trees. There is a lack a consistency among trees over which season shows the greatest occurrence of IADFs (Figure 2.7b). In total, $60 \%$ of the IADFs were formed in the latewood, during the dry season (November-following April); however, the trend in seasonal production is opposite of what is expected across the hydrologic transect. The frequency of dry seasonal density fluctuation production is greatest (73\%) in DBH1, the tree located the furthest away from the coast, and it decreases across the sampling transect, while the frequency of wet season IADFs increases. The tree nearest to the unstable edge of the freshwater lens, DBH6, recorded the largest percentage of individual appearances of wet season IADFs, 60\%. Tree DBH2 has the highest recorded appearances of IAFDs, with the majority (58\%) of them forming in earlywood growth; this tree also showed the greatest sensitivity in the $\delta^{13} \mathrm{C}$ record (Figure 2.5a). All trees demonstrated the tendency to produce multiple sets of density variations within one season. Nearly $70 \%$ of the IDAFs appeared as multiples of two to three light and dark bands with gradational contacts within a seasonal growth ring, suggesting that normal cell production was interrupted more than once during that season (Figure 2.7c). Lastly, three of the five years corresponding to potential hurricane impacts (the numbered events in Figure 2.5b) have density variations appearing in the concurrent season or the season following the tropical activity: the 1935 hurricane in DBH2, 1948 hurricanes in DBH3, and Hurricane Donna (1960) in DBH2. Additionally, DBH1 is missing the ring for the season following the 1935 hurricane.

\subsection{Discussion}

\subsubsection{Ring width vs. carbon isotope-derived chronology}

Traditional dendrochronology methods that rely on the visual appearance of ring structures to construct a ring width-derived chronologies may be limited in subtropical trees; however those 
limitations do not extend to the biochemical composition of the ring cellulose. The differences in ring width measurements between the dendrochronology and isotope transects likely occurred because of the complicated ring structures of these very southern P. elliottii var. densa trees. Although the samples analyzed by each lab were transversally cut from the same disk, the ring patterns look slightly different and were difficult to visually compare. The difference is most noticeable in the mid-to-later years of growth, as the rings progressively form farther away from the pith. The prevalence of complicated ring structures, such as irregular IADFs and locally absent rings (rings that are visible in parts of the disk, but not in others), can make crossdating transects measured within centimeters of each other in the same disk difficult. Additionally, the appearance of IADFs is not consistent among the trees, so they do not make good candidates as visible marker rings. Similar results were found in a multi-lab blind test study of olive trees growing in the Mediterranean with frequent IADFs and notoriously difficult rings to interpret; five different labs using various dendrochronological techniques could not reach a consensus on the age of the trees (Cherubini et al., 2013). In addition, because the rings are counted and assigned a calendar year, discrepancies in the ring definitions will compound and errors in annual ring definitions will propagate throughout the disk.

A reliable ring width-derived chronology could never be developed with confidence from a single transect in P. elliottii var. densa from this site, but the $\delta^{13} \mathrm{C}$ in the cellulose from that same single transect was successfully used to assist in the identification of IADFs and to date the tree-rings. The intervals of four or more consecutive $\delta^{13} \mathrm{C}$ samples with almost identical carbon isotope values were flagged because they were often revealed to be single rings that expanded into a series of density variations where they intersected the transect. The subannual rings containing the IADFs were isotopically similar to density variations, making them easily identifiable. De Micco et al. (2012) found that the $\delta^{13} \mathrm{C}$ values of the IADFs and the rings containing them were not statistically 
different and a high-resolution in continuum method using laser-ablation was required to isotopically distinguish the IADFs. The high number of samples (6-17\% of the sub-annual rings identified in the SERC SIL transect) discounted as IADFs is likely a result of being overly-cautious when individual rings were identified before the isotope analysis. The suspect IADFs were easily identifiable after using the patterns in the isotope data to isolate areas of potential density variations and revisiting the digital images.

The ring width chronologies developed independently by the WSL and SERC SIL did not strongly correlate with each other (Figure 2.3). However, the carbon isotope site index created from single transects in each of the four trees shows promise as an alternative method for developing a chronology for the Lower Florida Keys. The variability in the $\delta^{13} \mathrm{C}$ index is similar to that of the WSL ring width chronology derived from traditional dendrochronology methods (Figure 2.6), although the character of their variability is not consistent. Enrichment of ${ }^{13} \mathrm{C}$ occurs during both the expected anomalously narrow rings and during times when ring growth was not restricted. The shifts in type of responses presented by the chronologies do seem to occur at irregular intervals over the length of the time series, suggesting that some external forcing or limiting factor may be exhibiting varying degrees of control over carbon fixation and radial tree growth. Other studies comparing the relationship between $\delta^{13} \mathrm{C}$ and ring width in multiple tree species have reported varying results. For example, Gebrekirstos et al. (2009) reported a significant negative correlation between $\delta^{13} \mathrm{C}$ and ring width in trees growing in tropical Africa, while Brooks et al. (1998) reported no relationship between ring width variation and $\delta^{13} \mathrm{C}$ in spruce and pine species growing in boreal forests. Pinus elliottii growth in Big Pine Key may be controlled by a complex interplay of multiple climate variables and the degree to which certain climate factors affect tree growth could vary with time. Chapter 3 will discuss in greater detail the environmental factors and climate variables 
contributing to the nature of the relationship between ring width and the carbon isotope composition of the cellulose.

This study had the benefit of working with the whole tree disk, which allowed for the observation of the ring growth around the entire circumference of the tree; however, a $360^{\circ}$ view is not always available. When it is not practical to remove 5-6 cores from a single tree, or if only a small sample is available, such as in a rotting, old snag or in an archeological sample, for example, the carbon stable isotope signatures may be used in the same way as standard ring widths to build a site chronology. A $\delta^{13} \mathrm{C}$ chronology can be achieved with a single transect because the carbon assimilated into the structure of the ring $\alpha$-cellulose originated from the same source $\mathrm{CO}_{2}$ and was incorporated over the same time period under the same conditions throughout the whole ring, although there may be a small degree of fractionation within the circumference of the ring itself (McCarroll and Loader, 2004). Homogenization and the $\alpha$-cellulose extraction process help to lessen the effects of any unevenly distributed ${ }^{13} \mathrm{C}$ within individual rings (Cullen and Grierson, 2006; Loader et al., 2007).

\subsubsection{The timing of intra-annual density fluctuations}

Intra-annual density fluctuations can occasionally be indistinguishable from true annual rings and are described as cells characteristic of latewood growth (smaller and denser with thick cell walls) appearing in seasonal earlywood rings (larger, thinner-walled cells), and vice versa (Fritts, 1976). The formation of IADFs is indicative of some kind of environmental change that has interrupted or encouraged cell production out of season (Schulman, 1938; Fritts, 1976; Cherubini et al., 2003). In many species in the Mediterranean, the formation of IADFs can be linked to water stress in trees from site-wide drought conditions (Cherubini et al., 2003; Olivar et al., 2011); however, in certain environments, the production of density variations may be caused by wetter than normal conditions (Vieira at al., 2009; De Micco et al., 2012). The presence of IADFs within trees at a specific site 
can vary both temporally and spatially (Cherubini et al., 2003), as they did in this study. Even though DBH1, DBH2 and DBH3 were growing within 33 meters of each other, only $8 \%$ (3 seasons) of occurrences of visibly indistinguishable IADFs were recorded in more than one tree, showing a high variability in microsite ecological conditions. A13-month micro-coring study of $P$. elliottii var. densa trees in the Lower Florida Keys reported the concurrent formation of density variations in four of the six trees studied and determined that the timing of their appearance correlated to changes in solar insolation (Harley et al., 2012).

The landscape scale factors controlling tree growth (precipitation, disturbance events, etc.) appear to exhibit control on all four trees in this study, as the overall patterns in $\delta^{13} \mathrm{C}$ are similar. However, the degrees of individual response to the climatic and environmental stimuli vary greatly among trees, even though they are growing less than 30 meters from each other. For example, during each of the periods of prolonged extreme stress (numbered peaks in Figure 2.5b), DBH2 showed a much more dramatic response than the other three trees (Figure 2.5a). This enhanced sensitivity must be a result of the localized conditions around DBH2. Perhaps this tree had more limited access to a water source, or it sustained some type of damage to its canopy, or it was subjected to an insect infestation that led to a decrease in stomatal activity (Farquhar et al., 1989). Limitations present in the immediate site conditions under which individual trees grow ultimately dictate the tree's ecophysiological response to climate or disturbance events (Fritts, 1976; Saurer et al., 1995; McCarroll and Loader, 2004; Anderson et al., 2005; Vieira et al., 2009; De Micco et al., 2012).

The hydrological gradient along which the $P$. elliottii var. densa trees were collected seems to play an important role in the health of the trees. With the exception of $\mathrm{DBH} 2$, there is a trend in the timing and appearance of IADFs in trees across the freshwater lens transect. Tree DBH1 (more centrally positioned over the lens) had a greater occurrence of density variations during the dry 
season, whereas DBH6 (near the periphery of the lens) was more prone to wet season IADF development. This relationship between seasonal density variation production and proximity to the freshwater lens was unexpected, and, logically, it should be the inverse, as the tree growing in the most water-limited environment should be less productive under drier conditions. This suggests that these trees have optimized their growth processes under their individual conditions. The carbon isotope chronology for tree DBH6 further supports this; although its $\delta^{13} \mathrm{C}$ values were consistently more enriched, it did not show the same type of variability in the amplitude between periods of enrichment and depletion as in the other trees. DBH6 also had the lowest number of IADFs in all four trees (less than half of the next lowest value). It appears that this individual has adapted its stomatal regulation to the unstable conditions associated with living close to the boundary of the salt water/ fresh water interface.

The trends in $\delta^{13} \mathrm{C}$ and in IADF production for tree $\mathrm{DBH} 2$ did not follow the expected gradient across the hydrologic transect. The $\delta^{13} \mathrm{C}$ record of $\mathrm{DBH} 2$ showed the greatest variance in amplitude across the time series and this tree had the most frequent appearance of IADFs that are visibly indistinguishable from seasonal rings. The pattern of density variation formation in $\mathrm{DBH} 2$ mirrored that of the tree living on the edge of the freshwater lens, DBH6; the majority of the IADFs appeared in the wet season under wetter than average conditions and very few occurred during the dry season. The variability in the degree of response to regional climate regimes can give insight into highly localized, site-scale conditions. Individual trees that show high sensitivity in comparison to those growing around them provide valuable, additional information at multiple scales, from landscape down to the microenvironment scale (Leavitt and Long, 1989; McCarroll and Loader, 2004).

Lastly, P. elliottii var. densa in the Lower Florida Keys show promise as a subject for the reconstruction of past seasons of pronounced tropical cyclone activity in the region. The event 
peaks in Figure $2.5 \mathrm{~b}$ represent sustained periods where the trees were not transpiring at their optimal potential. The known effects of the 2005 storm surge from the passage of Hurricane Wilma were captured as one of the enrichment peaks (Event 1 in Figure 2.5b) and timing of the peaks 2-5 corresponds to the passage of several major hurricanes that could have imposed similar types of damage. Unfortunately, the historical records on the effects of hurricane impacts in the sparsely populated islands in the Lower Keys are extremely limited. Future work on these P. elliottii var. densa samples will include an oxygen isotope analysis that may provide more insight into the potential of hydrologic stress as a cause of the enrichments in the carbon record. Tropical cyclones have depleted isotopic compositions, up to $10 \%$ (Lawrence et al., 2002) compared to typical summer rainfall (Price et al., 2008). Therefore, large $\delta^{18} \mathrm{O}$ depletions in the paleo-record may reflect tropical cyclone events (Miller et al., 2006), while intra-annual variability between the earlywood and latewood should be attributed to seasonal differences in precipitation.

\subsection{Conclusions}

Stable carbon isotopes in tree-ring cellulose can be used to build a chronology in a subtropical pine species known for producing intra-annual density variations, particularly when there are no visible marker rings or crossdateable ring width patterns. Adding stable isotope analyses to traditional dendrochronological techniques may help extend the applicability of dendrochronology as a viable paleoproxy into other subtropical areas where ring-width chronologies are difficult to crossdate. Areas like South Florida, where the options for high-resolution paleoclimate proxies are limited, yet vital for such applications as the development of climate models used to make informed water management decisions, would benefit greatly from stable isotope-dendrochronology studies. South Florida is in the position where the need to adapt and to mediate the effects of climate change is becoming a necessity. Its freshwater resources are heavily managed to maintain a balance between the natural systems and human need and, as population increases and sea level continues to rise, 
this balance will become increasingly strained. Access to a high-resolution paleoclimate proxy, such as the one developed here, could mean the difference between proactive mitigation and reactive measures.

Stable isotope-derived dendrochronology studies have the potential for extending the highresolution paleoclimate record well beyond the available instrumental record. As mentioned in the South Florida example above, the ability to lengthen the regional climate history has major implications for untangling the interrelated effects of multiple climate oscillations, such as ENSO and the AMO, from the actual climate change trends. However, the applicability of such records goes beyond the regional scale and can, perhaps more importantly, provide information on much smaller scales; for example, records of the terrestrial impacts of historical hurricane and storm surge events for much of the Florida Keys are lacking. A study of trees across the island of Big Pine Key, similar to the one conducted here, could help reconstruct the extent of historical storm surges and, thus, provide information about the characteristics of seasonal tropical cyclone activity before sophisticated monitoring equipment was in place.

\subsection{References}

Anderson, W. T., Sternberg, L. S. L., Pinzon, M. C., Gann-Troxler, T., Childers, D. L., \& Duever, M. (2005). Carbon isotopic composition of cypress trees from South Florida and changing hydrologic conditions. Dendrochronologia, 23(1), 1-10.

Barrett, M. A., \& Stiling, P. (2006). Effects of Key deer herbivory on forest communities in the lower Florida Keys. Biological Conservation, 129(1), 100-108.

Bergh, C., \& Wisby, J. (1996). Fire history of lower Keys pine rocklands. Nature Conservancy, Florida Keys Initiative.

Bradley, R. S. (1999). Paleoclimatology: reconstructing climates of the Quaternary (Vol. 68). Academic Press. 
Brooks, J. R., Flanagan, L. B., \& Ehleringer, J. R. (1998). Responses of boreal conifers to climate fluctuations: indications from tree-ring widths and carbon isotope analyses. Canadian Journal of Forest Research, 28(4), 524-533.

Cherubini, P., Gartner, B. L., Tognetti, R., Braeker, O. U., Schoch, W., \& Innes, J. L. (2003). Identification, measurement and interpretation of tree-rings in woody species from Mediterranean climates. Biological Reviews, 78(01), 119-148.

Cherubini, P., Humbel, T., Beeckman, H., Gärtner, H., Mannes, D., Pearson, C., Schoch, W., Tognetti, R., \& Lev-Yadun, S. (2013). Olive tree-ring problematic dating: a comparative analysis on Santorini (Greece). PloS one, 8(1), e54730.

Cook, E. R., \& Kairiukstis, L. A. (Eds.). (1990). Methods of dendrochronology: applications in the environmental sciences. Springer Science \& Business Media

Coplen, T. B. (1994). Reporting of stable hydrogen, carbon, and oxygen isotopic abundances. Pure and Applied Chemistry, 66, 273-273.

Cullen, L. E., \& Grierson, P. F. (2006). Is cellulose extraction necessary for developing stable carbon and oxygen isotopes chronologies from Callitris glaucophylla? Palaeogeography, Palaeoclimatology, Palaeoecology, 236(3), 206-216.

De Micco, V., Battipaglia, G., Brand, W. A., Linke, P., Saurer, M., Aronne, G., \& Cherubini, P. (2012). Discrete versus continuous analysis of anatomical and $\delta 13 \mathrm{C}$ variability in treerings with intra-annual density fluctuations. Trees, 26(2), 513-524.

Donders, T. H., Wagner, F., Dilcher, D. L., \& Visscher, H. (2005). Mid-to late-Holocene El NinoSouthern Oscillation dynamics reflected in the subtropical terrestrial realm. Proceedings of the National Academy of Sciences of the United States of America, 102(31), 1090410908.

Duryea, M. L., Blakeslee, G. M., Hubbard, W. G., \& Vasquez, R. A. (1996). Wind and trees: A survey of homeowners after Hurricane Andrew. Journal of Arboriculture, 22, 44-50.

Enfield, D. B., Mestas-Nuñez, A. M., \& Trimble, P. J. (2001). The Atlantic multidecadal oscillation and its relation to rainfall and river flows in the continental US. Geophysical Research Letters, 28(10), 2077-2080.

Epstein, P. R. (2005). Climate change and human health. New England Journal of Medicine, 353(14), 1433-1436.

Everham, E. M., \& Brokaw, N. V. (1996). Forest damage and recovery from catastrophic wind. The botanical review, 62(2), 113-185.

Farquhar, G. D., Ehleringer, J. R., \& Hubick, K. T. (1989). Carbon isotope discrimination and photosynthesis. Annual review of plant biology, 40(1), 503-537.

Francey, R. J. and B. D. Farquhar. (1982). An explanation of ${ }^{13} \mathrm{C} /{ }^{12} \mathrm{C}$ variation in tree-rings. Nature 297. 28-31. 
Fritts, H. C. (1976). Tree-rings and Climate. Academic Press, New York.

Gebrekirstos, A., Worbes, M., Teketay, D., Fetene, M., \& Mitlöhner, R. (2009). Stable carbon isotope ratios in tree-rings of co-occurring species from semi-arid tropics in Africa: patterns and climatic signals. Global and Planetary Change, 66(3), 253-260.

Gray, S. T., Graumlich, L. J., Betancourt, J. L., \& Pederson, G. T. (2004). A tree-ring based reconstruction of the Atlantic Multidecadal Oscillation since 1567 AD. Geophysical Research Letters, 31(12).

Green, J. W. (1963). Wood cellulose. In Whistler R. L. (ed.) Methods in Carbohydrate Chemistry, vol. iii. Academic Press, New York.

Hanson, S., Nicholls, R., Ranger, N., Hallegatte, S., Corfee-Morlot, J., Herweijer, C., \& Chateau, J. (2011). A global ranking of port cities with high exposure to climate extremes. Climatic change, 104(1), 89-111.

Hamilton, J. D. (1994). Time series analysis (Vol. 2). Princeton: Princeton university press.

Harley, G. L., Grissino-Mayer, H. D., \& Horn, S. P. (2011). The dendrochronology of Pinus elliottii in the lower Florida Keys: chronology development and climate response. Tree-Ring Research, 67(1), 39-50

Harley, G. L., Grissino-Mayer, H. D., Franklin, J. A., Anderson, C., \& Köse, N. (2012). Cambial activity of Pinus elliottii var. densa reveals influence of seasonal insolation on growth dynamics in the Florida Keys. Trees, 26(5), 1449-1459.

Helmle, K. P., Dodge, R. E., Swart, P. K., Gledhill, D. K., \& Eakin, C. M. (2011). Growth rates of Florida corals from 1937 to 1996 and their response to climate change. Nature Communications, 2, 215.

Hoffmeister, J. E. (1974). Land from the sea: The geologic story of South Florida (p. 143). Coral Gables, Florida: University of Miami Press.

Hoffmeister, J. E., \& Multer, H. G. (1968). Geology and origin of the Florida Keys. Geological Society of America Bulletin, 79(11), 1487-1502.

Huser, T. (1989). Into the Fifth Decade: the first forty years of the South Florida Water Management District. Special Publication South Florida Water Management District, West Palm Beach, FL.

Intergovernmental Panel on Climate Change, IPCC (2014). Climate Change 2014: Impacts, Adaptation, and Vulnerability. Part B: Regional Aspects. Contribution of Working Group II to the Fifth Assessment Report of the Intergovernmental Panel on Climate Change [Barros, V.R., C.B. Field, D.J. Dokken, M.D. Mastrandrea, K.J. Mach, T.E. Bilir, M. Chatterjee, K.L. Ebi, Y.O. Estrada, R.C. Genova, B. Girma, E.S. Kissel, A.N. Levy, S. MacCracken, P.R. Mastrandrea, and L.L. White (eds.)]. Cambridge University Press, Cambridge, United Kingdom and New York, NY, USA. 
Koptur, S., Rodriguez, M. C., Oberbauer, S. F., Weekley, C., \& Herndon, A. (2002). HerbivoreFree Time? Damage to New Leaves of Woody Plants after Hurricane Andrew1. Biotropica, 34(4), 547-554.

Langdon, O. G. (1963). Growth Patterns of Pinus elliotti var. densa. Ecology, 44(4) 825-827.

Lawrence, J. R., Gedzelman, S. D., Gamache, J., \& Black, M. (2002). Stable isotope ratios: hurricane Olivia. Journal of Atmospheric Chemistry, 41(1), 67-82.

Leavitt, S. W., \& Long, A. (1989). Intertree variability of $\delta 13 \mathrm{C}$ in tree-rings. In Stable isotopes in ecological research (pp. 95-104). Springer New York.

Leavitt, S. W., \& Lone, A. (1991). Seasonal stable-carbon isotope variability in tree-rings: possible paleoenvironmental signals. Chemical Geology: Isotope Geoscience section, 87(1), 59-70.

Libby, L. M., \& Pandolfi, L. J. (1974). Temperature dependence of isotope ratios in treerings. Proceedings of the National Academy of Sciences, 71(6), 2482-2486.

Light, S. S., \& Dineen, J. W. (1994). Water control in the Everglades: a historical perspective. Everglades: The ecosystem and its restoration, 47-84.

Loader, N. J., D. McCarroll, M. Gagen, I. Roberson and R. Jalkanen. (2007). Extracting climatic information from stable isotopes in tree-rings. In Dawson, T. E. and R. T. W. Siegwolf (Eds.) Stable Isotopes as Indicators of Ecological Change. Academic Press, New York.

McCarroll, D., \& Loader, N. J. (2004). Stable isotopes in tree-rings. Quaternary Science Reviews, 23(7), 771-801.

McCarroll, D., Gagen, M. H., Loader, N. J., Robertson, I., Anchukaitis, K. J., Los, S, Young, G. H. F., Jalkanen, R., Kirchhefer, A. and Waterhouse , J. S. (2009). Correction of tree-ring stable carbon isotope chronologies for changes in the carbon dioxide content of the atmosphere. Geochimica et Cosmochimica Acta, 73(6), 1539-1547.

Miller, D. L., Mora, C. I., Grissino-Mayer, H. D., Mock, C. J., Uhle, M. E., \& Sharp, Z. (2006). Tree-ring isotope records of tropical cyclone activity. Proceedings of the National Academy of Sciences, 103(39), 14294-14297.

Mora, C., Frazier, A. G., Longman, R. J., Dacks, R. S., Walton, M. M., Tong, E. J. J. Sanchez, J.J., Kaiser, L. R., Stender, Y. O., Anderson, J. M., Ambrosino, C. M., Fernandez-Silva, I., Giuseffi, L. M. and Giambelluca, T. W. (2013). The projected timing of climate departure from recent variability. Nature, 502(7470), 183-187.

Mora, C. I., Miller, D. L., \& Grissino-Mayer, H. D. (2007). Oxygen Isotope Proxies in Tree-Ring Cellulose: Tropical Cyclones, Drought, and Climate Oscillations. Terrestrial Ecology, 1, 63-75.

National Climate Data Center (NCDC). (2012). Historical Hurricane Tracks Satellite and Information Service, web. http://www.csc.noaa.gov/ 
National Climate Data Center (NCDC). (2010). NOAA climate data inventories for Florida. NOAA Satellite and Information Service, web. http://www.csc.noaa.gov/

Noss, R. F., LaRoe, E. T., \& Scott, J. M. (1995). Endangered ecosystems of the United States: a preliminary assessment of loss and degradation (Vol. 28). Washington, DC, USA: US Department of the Interior, National Biological Service.

Ogden, J. C., Davis, S. M., Jacobs, K. J., Barnes, T., \& Fling, H. E. (2005). The use of conceptual ecological models to guide ecosystem restoration in South Florida. Wetlands, 25(4), 795809.

O'Leary, M. H. (1981). Carbon isotope fractionation in plants. Phytochemistry, 20(4), 553-567.

O'Leary, M. H. (1988). Carbon isotopes in photosynthesis: fractionation techniques may reveal new aspects of carbon dynamics in plants. Bioscience 38(5), 328-336.

Olivar, J., Spiecker, H., \& Bravo, F. (2011) Climate impact on growth dynamics and intra-annual density fluctuations in Mediterranean pine species (Pinus halepensis, Pinus pinaster and Pinus sylvestris). Modelling Forest Ecosystems-Concepts, Data and Application, 117.

Pearman, G. I., Francey, R. J., \& Fraser, P. J. B. (1976). Climatic implications of stable carbon isotopes in tree-rings. Nature, 260(5554), 771-773

Poussart, P. F., Evans, M. N., \& Schrag, D. P. (2004). Resolving seasonality in tropical trees: multidecade, high-resolution oxygen and carbon isotope records from Indonesia and Thailand. Earth and Planetary Science Letters, 218(3), 301-316.

Price, R. M., Swart, P. K., \& Fourqurean, J. W. (2006). Coastal groundwater discharge-an additional source of phosphorus for the oligotrophic wetlands of the Everglades. Hydrobiologia, 569(1), 23-36.

Price, R. M., Swart, P. K., \& Willoughby, H. E. (2008). Seasonal and spatial variation in the stable isotopic composition $\left(\delta{ }^{18} \mathrm{O}\right.$ and $\left.\delta \mathrm{D}\right)$ of precipitation in south Florida. Journal of Hydrology, 358(3), 193-205

Rosenzweig, C., \& Neofotis, P. (2013). Detection and attribution of anthropogenic climate change impacts. Wiley Interdisciplinary Reviews: Climate Change, 4(2), 121-150.

Ross, M. S., O'Brien, J. J., \& Flynn, L. J. (1992). Ecological site classification of Florida Keys terrestrial habitats. Biotropica, 488-502.

Ross, M. S., O'Brien, J. J., \& Sternberg, L. D. S. L. (1994). Sea-level rise and the reduction in pine forests in the Florida Keys. Ecological Applications, 144-156.

Ross, M. S., O'Brien, J. J., Ford, R. G., Zhang, K., \& Morkill, A. (2009). Disturbance and the rising tide: the challenge of biodiversity management on low-island ecosystems. Frontiers in Ecology and the Environment, 7(9), 471-478. 
Sah, J. P., Ross, M. S., Snyder, J. R., \& Ogurcak, D. E. (2010). Tree mortality following prescribed fire and a storm surge event in slash pine (Pinus elliottii var. densa) forests in the Florida Keys, USA. International Journal of Forestry Research, 2010.

Saurer, M., Borella, S., \& Leuenberger, M. (1997). $\delta^{18} \mathrm{O}$ of tree-rings of beech (Fagus silvatica) as a record of $\delta^{18} \mathrm{O}$ of the growing season precipitation. Tellus $B, 49(1), 80-92$.

Saurer, M., Siegenthaler, U., \& Schweingruber, F. (1995). The climate-carbon isotope relationship in tree-rings and the significance of site conditions. Tellus B, 47(3), 320-330.

Schroeder, M. C., Klein, H., \& Hoy, N. D. (1956). Biscayne aquifer in Dade and Broward Counties, Florida. State of Florida State Board of Conservation Report of Investigations No. 17.

Schmidt, N., Lipp, E. K., Rose, J. B., \& Luther, M. E. (2001). ENSO influences on seasonal rainfall and river discharge in Florida. Journal of Climate, 14(4), 615-628.

Schulman, E. (1938). Classification of false annual rings in Monterey pine. Tree-Ring Bulletin.

Sternberg, L. D. S. L., Pinzon, M. C., Vendramini, P. F., Anderson, W. T., Jahren, A. H., \& Beuning, K. (2007). Oxygen isotope ratios of cellulose-derived phenylglucosazone: an improved paleoclimate indicator of environmental water and relative humidity. Geochimica et cosmochimica acta, 71(10), 2463-2473.

Swart, P. K., Healy, G. F., Dodge, R. E., Kramer, P., Hudson, J. H., Halley, R. B., \& Robblee, M. B. (1996). The stable oxygen and carbon isotopic record from a coral growing in Florida Bay: a 160 year record of climatic and anthropogenic influence. Palaeogeography, Palaeoclimatology, Palaeoecology, 123(1), 219-237.

Swart, P. K., Dodge, R. E., \& Hudson, H. J. (1996). A 240-year stable oxygen and carbon isotopic record in a coral from South Florida: Implications for the prediction of precipitation in southern Florida. Palaios, 362-375.

Taylor, W. 2000. Change-Point Analyzer 2.0 shareware program, Taylor Enterprises, 11 Libertyville, Illinois. Web: http://www.variation.com/cpa

Tomlinson, P. B., \& Craighead, F. C. (1972). Growth-ring studies on the native trees of sub-tropical Florida. Ghouse, A, K, M, Yunus, $M$ ed $(s)$. Research trends in plant anatomy. Reprint, 4894, 39-51.

United States Fish and Wildlife Service (USFWS). (1999). South Florida Multi-Species Recovery Plan: Pine Rocklands. United States Fish and Wildlife Service, Atlanta.

Vieira, J., Campelo, F., \& Nabais, C. (2009). Age-dependent responses of tree-ring growth and intra-annual density fluctuations of Pinus pinaster to Mediterranean climate. Trees, 23(2), 257-265.

Vörösmarty, C. J., Green, P., Salisbury, J., \& Lammers, R. B. (2000). Global water resources: vulnerability from climate change and population growth. Science, 289(5477), 284-288. 
Wachnicka, A., Gaiser, E., Collins, L., Frankovich, T., \& Boyer, J. (2010). Distribution of diatoms and development of diatom-based models for inferring salinity and nutrient concentrations in Florida Bay and adjacent coastal wetlands of south Florida (USA). Estuaries and Coasts, 33(5), 1080-1098.

Walther, G. R., Post, E., Convey, P., Menzel, A., Parmesan, C., Beebee, T. J., Fromentin, J., HoeghGuldberg, O., \& Bairlein, F. (2002). Ecological responses to recent climate change. Nature, 416(6879), 389-395.

Wang, X., Piao, S., Ciais, P., Friedlingstein, P., Myneni, R. B., Cox, P., Heimann, M., Miller, J., Peng, S., Wang T., Yang, H., \& Chen, A. (2014). A two-fold increase of carbon cycle sensitivity to tropical temperature variations. Nature, 506(7487), 212-215.

Wanless, H. R., Parkinson, R. W., \& Tedesco, L. P. (1994). Sea level control on stability of Everglades wetlands. Everglades: the Ecosystem and Its Restoration. St. Lucie Press, Delray Beach, FL, USA, 199-223.

Watts, W. A., \& Hansen, B. C. (1988). Environments of Florida in the late Wisconsin and Holocene. Wet site archaeology, 307-323.

Wightman, M. J. (1990). Geophysical analysis and Dupuit-Ghyben-Herzberg modeling of freshwater lenses on Big Pine Key, Florida. (Master of Science Thesis. University of South Florida).

Wightman, M. J., M. T. Stewart, and H. L. Vacher. (1990). Geophysical mapping and hydrological analysis of fresh-water lenses at Big Pine Key, Florida. Tropical Hydrogeology and Caribbean Water Resources: American Water Resources Association July: 301-309.

Worbes, M. (2002). One hundred years of tree-ring research in the tropics-a brief history and an outlook to future challenges. Dendrochronologia, 20(1), 217-231.

Xu, Y., Holmes, C. W., \& Jaffé, R. (2007). Paleoenvironmental assessment of recent environmental changes in Florida Bay, USA: A biomarker based study. Estuarine, Coastal and Shelf Science, 73(1), 201-210. 


\subsection{Figures}

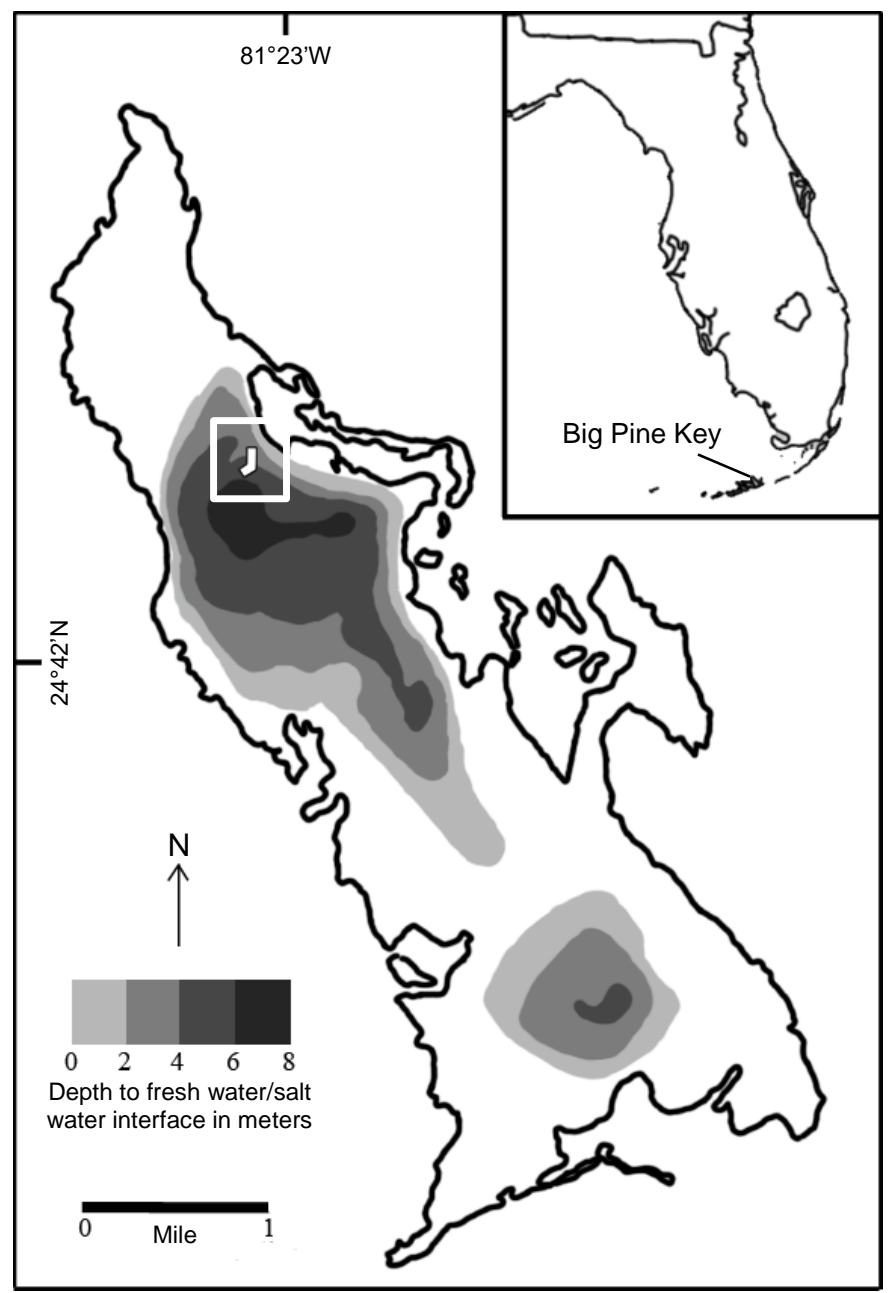

Figure 2.1 Map of Big Pine Key, Florida showing the areal extent and depths of the two fresh water lenses during a typical wet season. The sampling transect is located inside the white box on the northeastern side of the island. Image modified from Wightman, 1990. 


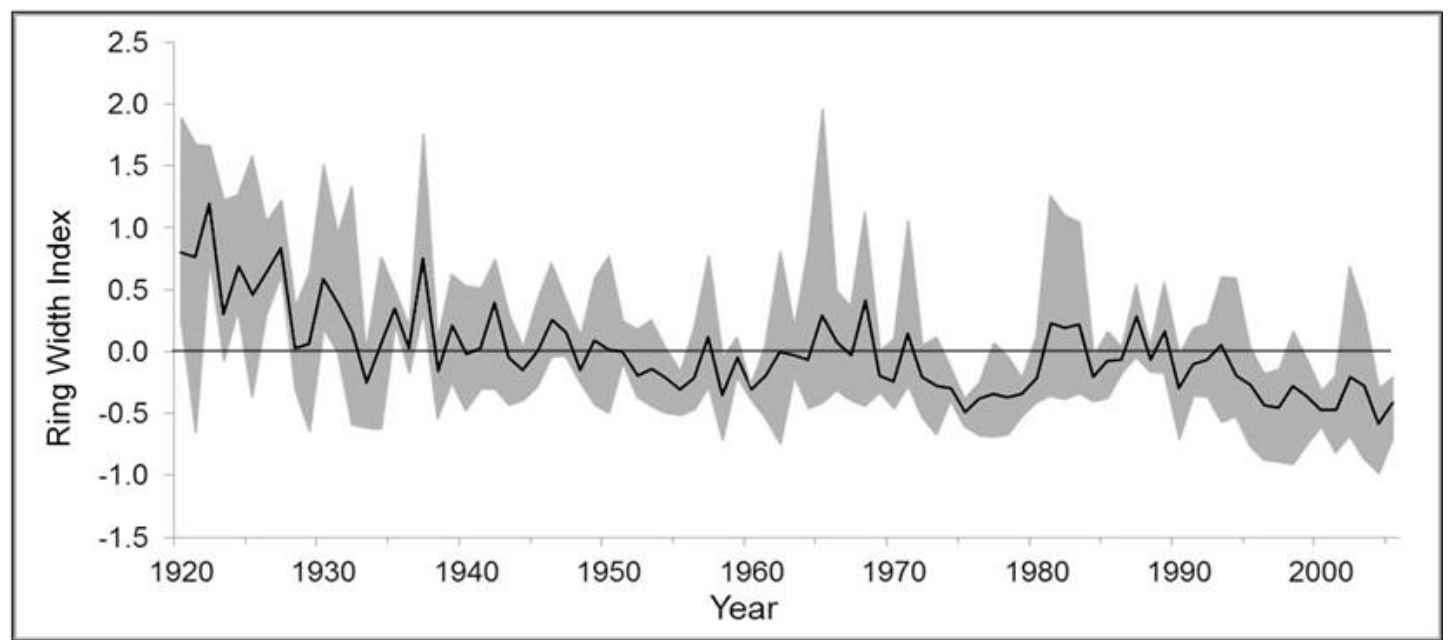

Figure 2.2 Average annual ring width index from 1920-2006 for the four P. elliottii var. densa disks measured at the WSL (black line). The index does not include the innermost juvenile rings (19011919) because their thicker ring widths may introduce a false trend in the index. The gray field indicates the spread between the maximum and minimum values among the four individual tree indices. 


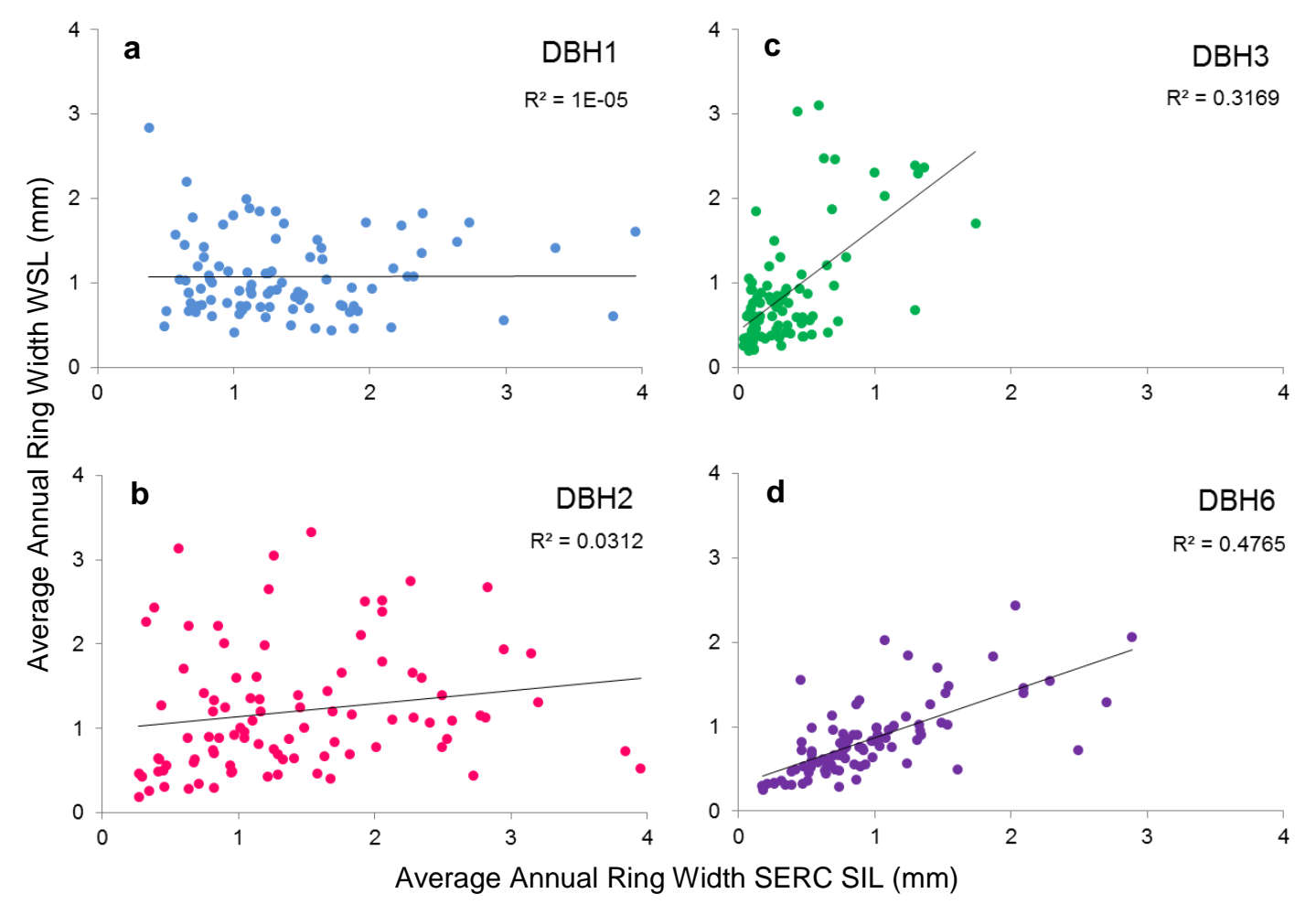

Figure 2.3 Average SERC SIL single transect measurements vs WSL multiple transect measurements ring width scatterplots for the four P. elliottii var. densa trees. The $\mathrm{r}^{2}$ values for each tree are displayed on their respective plots. Trees DBH3 and DBH6 (c and d) show weak correlations between ring width measurements taken at each lab; however, DBH1 and DBH2 (a and b) show almost no correlation between the two labs. 


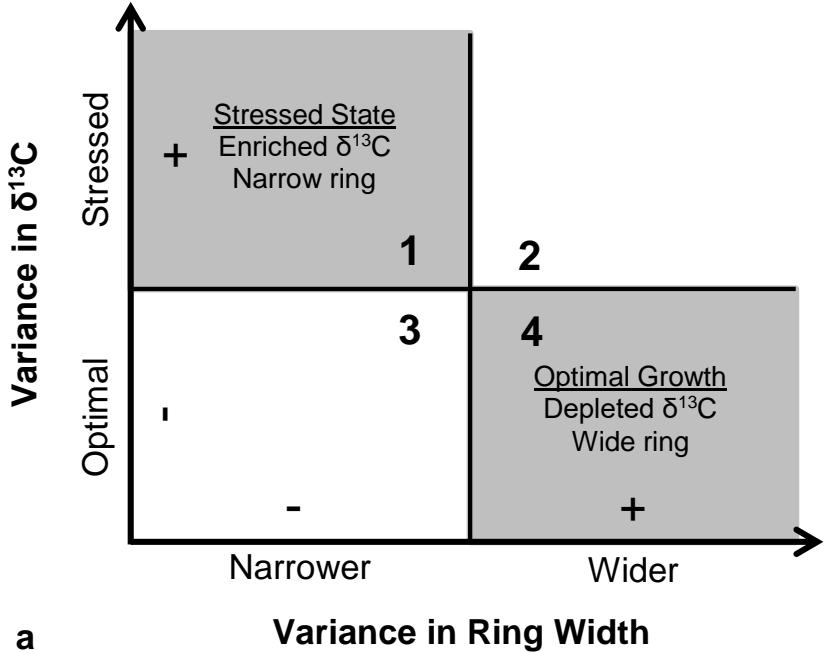

a
Figure 2.4 a) Model showing the expected relationship between ring width and $\delta^{13} \mathrm{C}$. The samples are expected to plot in the shaded regions. Fields 1 and 4 represent the range of growth conditions (optimal to stressed) that are expected if there is an inverse relationship between ring width and the $\delta^{13} \mathrm{C}$ value of the cellulose. b-e) Variance in $\delta^{13} \mathrm{C}$ and ring width for the $P$. elliottii trees. Plots show the distribution earlywood (light) and the latewood (dark) samples in the four quadrants of the model presented in part a. The percentage of total samples plotting within the combined quadrants 1 and 4 is displayed on each graph.

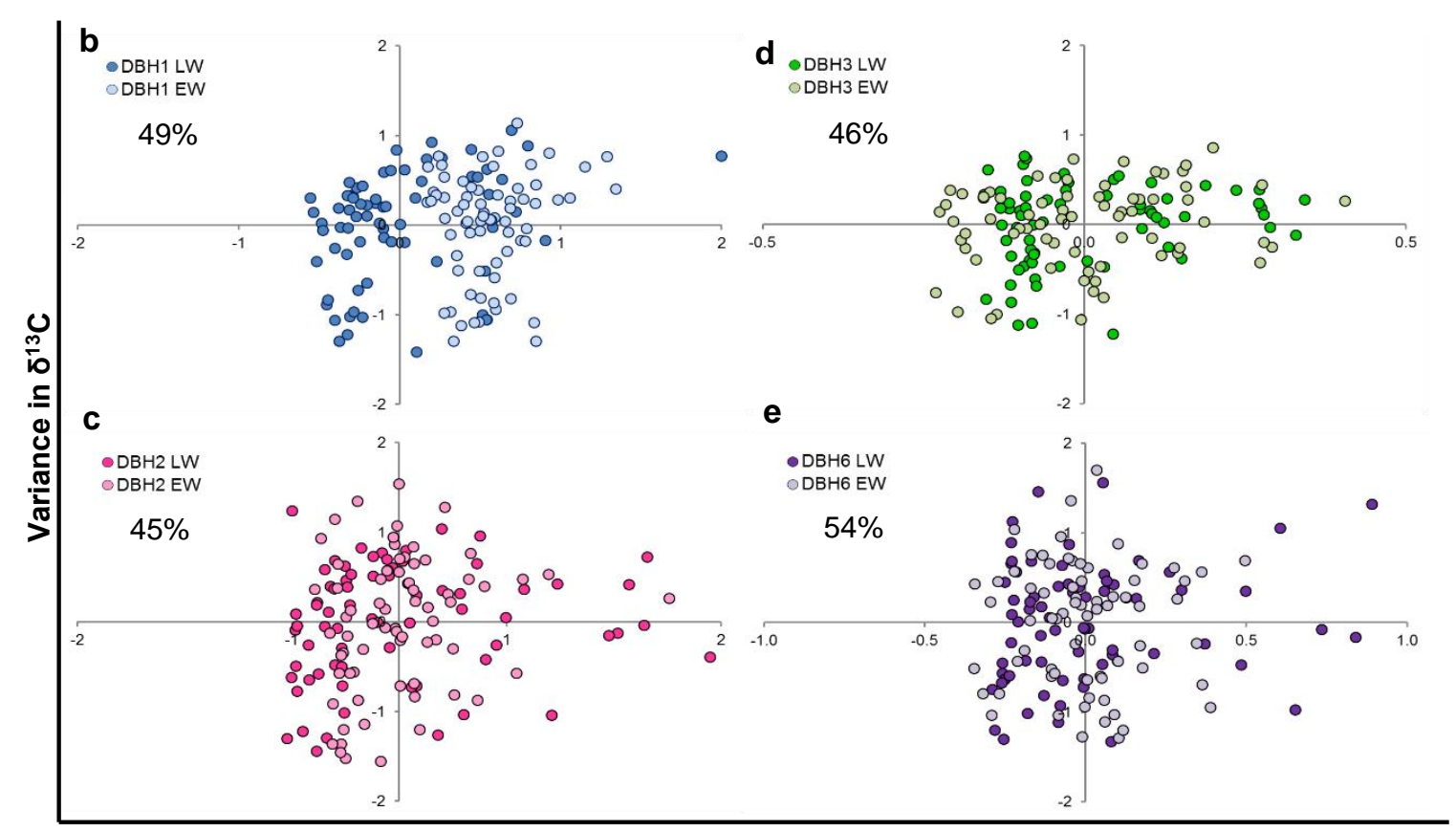

Variance in Ring Width 

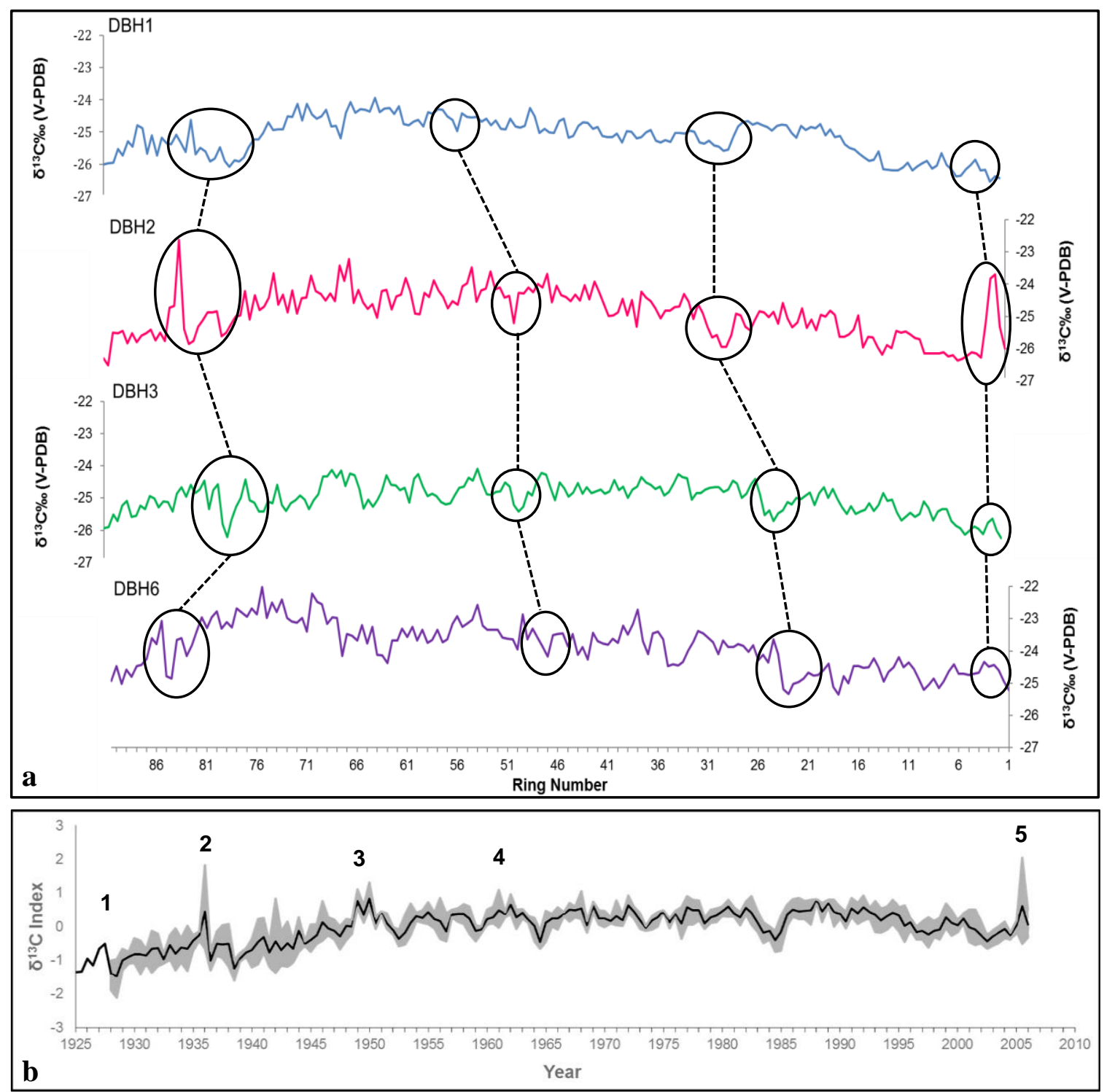

Figure $2.5 \delta^{13} \mathrm{C}$ chronologies for the four $P$. elliottii var. densa disks measured at SERC SIL: a) Individual $\delta^{13} \mathrm{C}$ for each of the four $P$. elliottii var. densa tree disks vs. ring number. The ring numbers increase from bark to pith. The black circles highlight the marker features used to crossdate the samples and to assist in the identification of IADFs in the dataset. The dashed lines connect identical features among samples. b) The final $\delta^{13} \mathrm{C}$ index for the site. This is an averaged value for DBH1, DBH2 and DBH3; the fourth sample, DBH6, was not included because its overall enriched signal dampens the data from the other three trees. The gray shaded field indicates the range of averaged values. The numbers highlight intervals of enriched $\delta^{13} \mathrm{C}$ or periods of sustained stress. These periods may be a result of hurricane activity within 100km of Big Pine Key. The enrichment periods, their coincident hurricanes and respective intensities at the time of passage are as follows: 1 = Unnamed hurricane, 1926 (Category 3), 2 = Labor Day Hurricane, 1935 (Category 5), 3 = Two unnamed hurricanes, 1948 (Categories 3 and 4), 4 = Hurricane Donna, 1960 (Category 4), 5 = Hurricane Wilma, 2005 (Category 3). (Hurricane data from NCDC, 2012) 

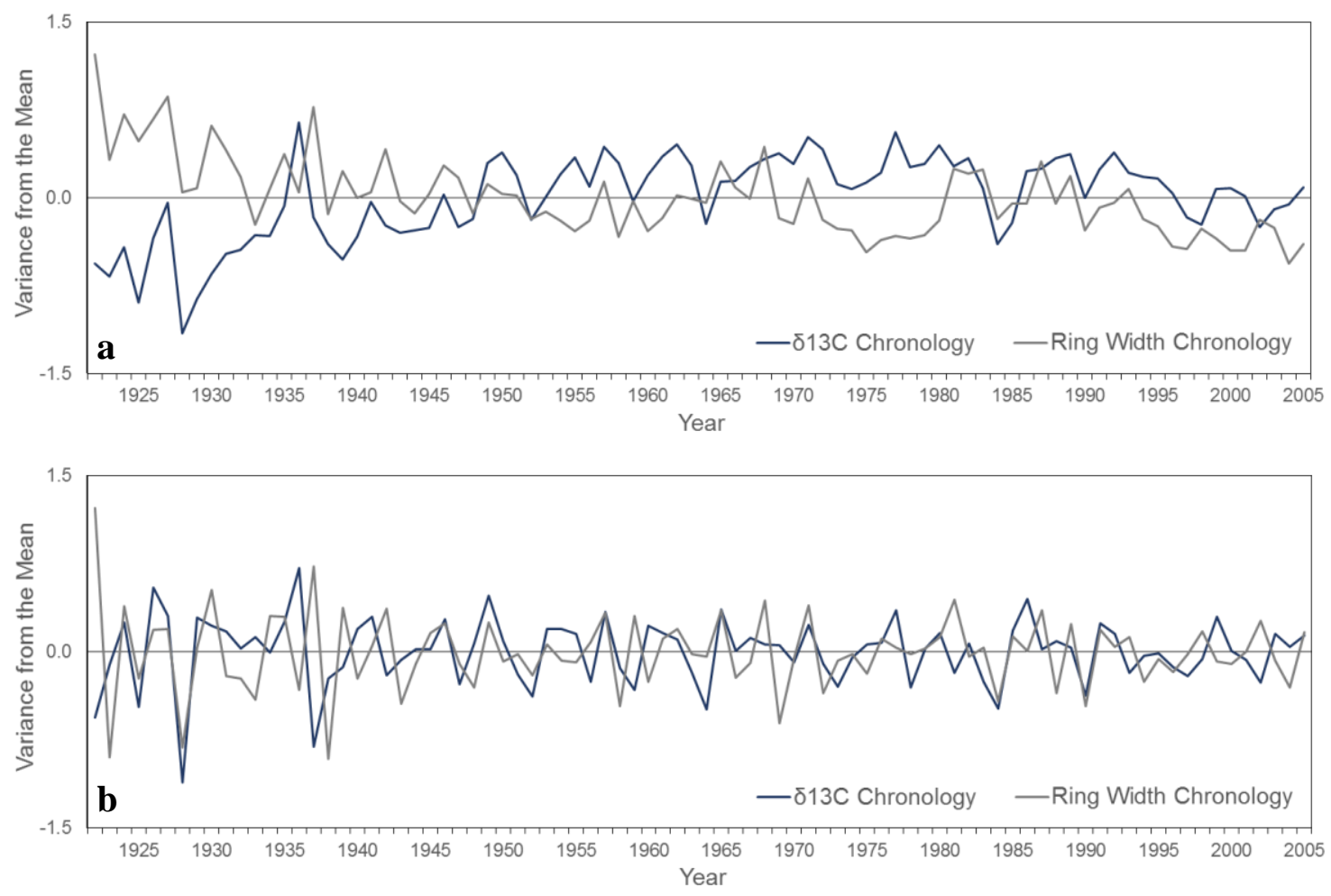

Figure 2.6 Comparisons between the chronologies derived from the $\delta^{13} \mathrm{C}$ data (blue lines) and the ring width data (gray lines). The biannual carbon isotope data have been condensed into annual measurments by calculating a weighted average for each year using the relative contributions for both the earlywood and latewood rings. a) Plot showing the variance from the respective means for each chronology. b) Plot showing the first order differences $\left(\mathrm{y}_{\mathrm{t}}-\mathrm{y}_{\mathrm{t}-1}\right)$ for both chronologies. The first order difference calculates the change in variance betweeen consecultive years. While the relationship is not perfect, both chronologies show similar patterns in their variance over the course of the time series. 

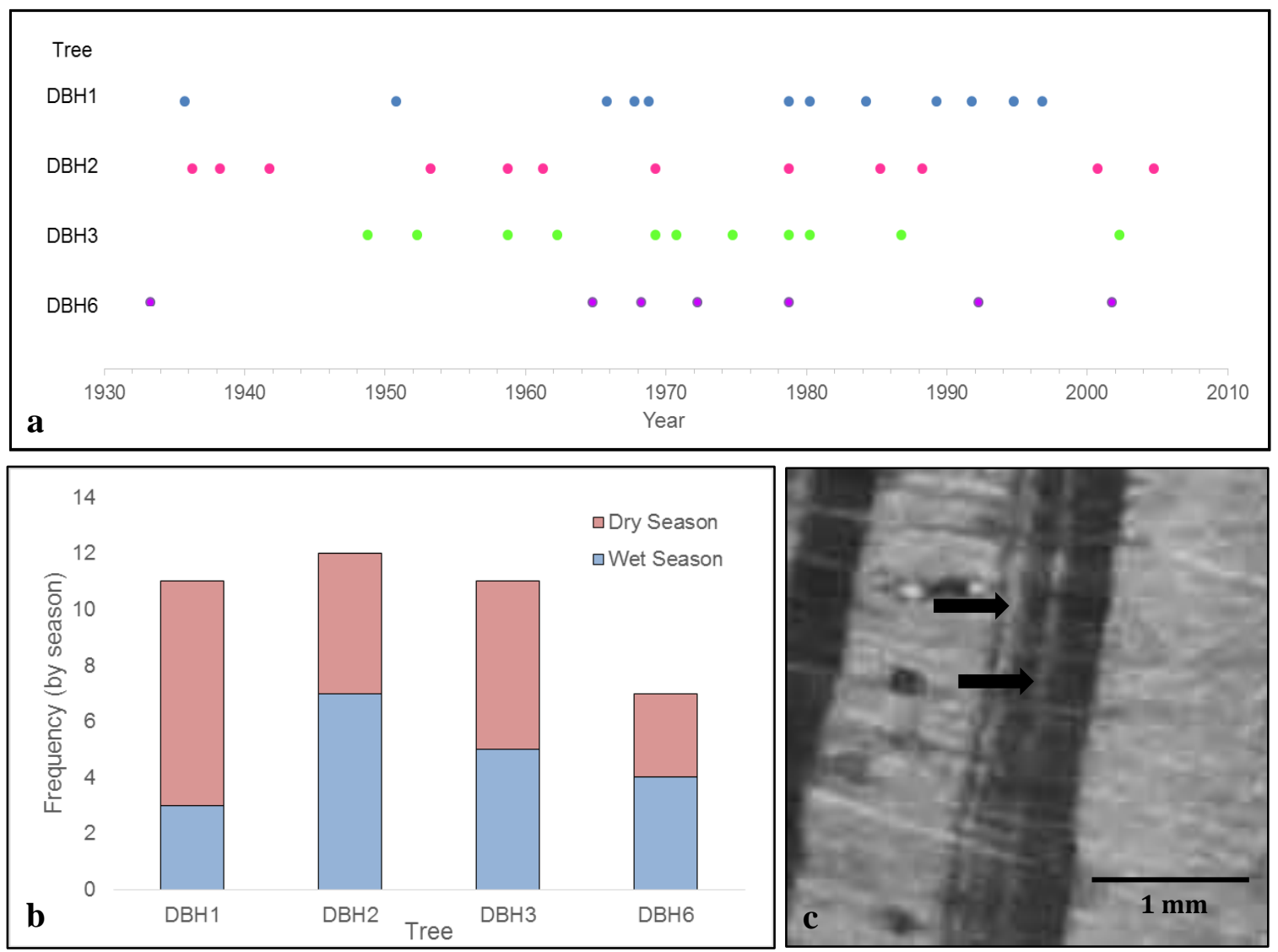

Figure 2.7 The intra-annual density fluctuations (IADFs) removed from the isotope transects all four $P$. elliottii var. densa trees. a) IADFs identified over the $\delta^{13} \mathrm{C}$ chronology. A single circle is used to denote seasons when a tree had at least one occurrence of a density fluctuation; however, IADFs often occurred in multiples of two or three. For a total number of IADFs removed per tree, please refer to Table 2.1. b) The frequency of IADFs occurrence by season across the hydrologic transect. Tree DBH1 is closest to the deeper, more stable part of the freshwater lens, while DBH6 is located near the edge. c) Photograph of typical IAFDs. The arrows indicate two sets of density variations in a latewood ring. Most of the IAFDs removed from the dataset post-stable isotope analysis were not as visually obvious as the examples shown here. 
Table 2.1: Ring Counts for WSL and SERC SIL

\begin{tabular}{|c|c|c|c|c|c|c|}
\hline Tree & $\begin{array}{c}\text { WSL } \\
\text { (Annual) }\end{array}$ & Oldest Ring & $\begin{array}{l}\text { SERC SIL } \\
\text { (Annual) }\end{array}$ & $\begin{array}{c}\text { Oldest Ring } \\
\text { (Oldest Analyzed) }\end{array}$ & $\begin{array}{l}\text { IADFs } \\
\text { Removed }\end{array}$ & Missing Rings \\
\hline DBH1 & 99 & 1907 & 79 & 1926 (1928) & $15.5^{*}$ & 1 \\
\hline $\mathrm{DBH} 2$ & 104 & 1902 & 80 & 1926 (1928) & $17.5^{\star}$ & 0 \\
\hline DBH3 & 101 & 1905 & 83 & 1923 (1925) & $17.5^{\star}$ & 0 \\
\hline DBH6 & 96 & 1910 & 84 & $1921(1922)$ & 7 & 1 \\
\hline
\end{tabular}

Table 2.1 Ring Counts for WSL and SERC SIL. The calendar ages and number of rings counted for all P. elliottii var. densa tree disks measured. Annual tree-rings were counted and dated on the dendrochronology transects at the WSL (two left columns in the table) and on the isotope transects at the SERC SIL (4 columns on the right). The isotope-derived chronology includes oldest rings analyzed (the dates in parentheses), the number of intra-annual density fluctuations (IADFs) removed from the datasets, and the number of missing rings. The SERC SIL tree-ring and IADF data combines the earlywood and latewood components into single annual rings. The values in the IADFs column denoted by asterisks reflect the removal of the latewood portions of the 2006 annual rings; they were shown to be part of the bark. 
Table 2.2: Occurrence of Intra-Annual Density Fluctuations

\begin{tabular}{llllllll}
\hline \multirow{2}{*}{ Tree } & \multirow{2}{*}{ Season } & \multicolumn{2}{c}{ Precipitation } & \multicolumn{2}{c}{ ENSO } & \multicolumn{3}{c}{ AMO } \\
\hline \hline \multirow{2}{*}{ DBH1 } & wet & 1 & 2 & 0 & 1 & 0 & 3 \\
& dry & 3 & 5 & 5 & 2 & 4 & 4 \\
DBH2 & wet & 1 & 4 & 1 & 2 & 2 & 3 \\
& dry & 2 & 2 & 1 & 1 & 3 & 1 \\
DBH3 & wet & 2 & 3 & 2 & 1 & 3 & 2 \\
& dry & 3 & 3 & 1 & 2 & 2 & 4 \\
DBH6 & wet & 2 & 1 & 2 & 0 & 2 & 2 \\
& dry & 0 & 3 & 1 & 1 & 2 & 1 \\
\hline
\end{tabular}

Table 2.2 Occurrence of Intra-Annual Density Fluctuations. Appearance of IADFs by tree, season, and climate variable. The precipitation data is from Key West, the closest, continuously recording station and is presented as more than average, "+," or less than average, "-, "precipitation. The ENSO and AMO data are divided into warm phase, "+," and cool phase, "-." All climate data is from the NOAA climate data inventories (NCDC, 2010). 
CHAPTER 3: CARBON ISOTOPES IN PINUS ELLIOTTII CELLULOSE AND THE RELATIONSHIP WITH SEASONAL PRECIPITATION AND CLIMATE OSCILLATIONS

\subsection{Abstract}

Previous dendrochronological studies of Florida slash pine (Pinus elliottii Engelm. var. densa) in the pine rocklands of the Lower Florida Keys have not found correlations between ring width and the major climate oscillations (the Atlantic Decadal Oscillation, AMO, and the El Niño-Southern Oscillation, ENSO) that are strongly tied to regional precipitation patterns. The lack of correlation may be a result of the complicated ring structures exhibited by the subtropical tree species, but an analysis of the stable carbon isotopes within the tree-ring cellulose can reveal paleoclimate signals while overcoming the challenges of the physical appearance of the rings. The carbon isotope records $\left(\delta^{13} \mathrm{C}\right)$ of four $P$. elliottii var. densa trees were examined at different timescales relative to potential climate drivers affecting precipitation in the Lower Florida Keys. Monthly dendrometer data were compared to cumulative precipitation at 30 and 60 day periods corresponding to the sampling intervals using a linear mixed effects model. The 30 day period was found to be statistically significant $(\mathrm{p}$-value $=8.2 \mathrm{E}$-), while the 60 day interval was not significant $(\mathrm{p}$-value $=$ 0.1265), indicating that the trees have an immediate response to precipitation, particularly in the dry season. The $\delta^{13} \mathrm{C}$ composition of latewood tree-ring cellulose correlated positively to precipitation received in the previous December and the current November, whereas, there was a negative correlation between the $\delta^{13} \mathrm{C}$ composition of earlywood and previous December and April precipitation ( $p$-values $\leq 0.05$ ). Empirical orthogonal function (EOFs) were used to identify the direction and magnitude of correlations between the $\delta^{13} \mathrm{C}$ records for the individual trees and the major climate oscillations driving South Florida climate. The EOFs revealed a complicated relationship between the $\delta^{13} \mathrm{C}$ values of tree-ring cellulose and ENSO that is dependent on the prevailing phase of AMO. An increase in latewood precipitation during El Niño years of the cool AMO phase resulted in enriched $\delta^{13} \mathrm{C}$ values and may provide the mechanism for the formation of 
intra-annual density fluctuations (IADFs). The AMO and ENSO exert first-order control over the isotopic composition of the tree-rings; however, the localized hydrology of the site plays an important role in the ultimate growth response of the trees.

\subsection{Introduction}

Subtropical and tropical ecosystems are predicted to be greatly impacted by climate-related stresses in the coming decades; the relative stability of the equatorial and subequatorial climates makes them the most sensitive to change (Mora et al., 2013). Yet, the subtropics have an underrepresentation of high-resolution terrestrial paleoclimate records, such as those derived from the tree-ring archives. Tropical tree-ring research has been ongoing for over a century; however, the seasonality defined by precipitation characteristic of this region contributes to the relatively low number of studies (Worbes, 2002). At higher latitudes, where the majority of dendrochronology studies are conducted, tree growth is limited by seasonally-driven reductions in ambient temperature and solar insolation. In contrast, the subtropical region exhibits a much less extreme annual temperature gradient and seasonality is instead defined by the timing and yearly distribution of precipitation (Worbes, 2002) Consequently, the growth periodicity may be such that trees experience multiple flushes of growth throughout the year, giving rise to complex subannual ring formations, or that the growth rate simply may be too consistent to encourage the production of visibly detectable rings (Glock, 1955; Worbes, 2002; Poussart et al., 2004).

Dendrochronology is a favored proxy for terrestrial paleoclimate reconstructions and has been utilized with much success in many regions of the world. Unlike many other popular terrestrial proxies, trees have a wide distribution and can produce perfectly resolved annual chronologies spanning centuries; in addition, it is relatively easy and inexpensive to obtain and analyze multiple replicates of each sample to produce a robust site index (McCarroll and Loader, 2004; Managave 
and Ramesh, 2011). However, standard dendrochronology practices that analyze ring width alone may not be feasible for many subtropical tree species because of the potentially complicated ring patterns characteristic of many subtropical trees (Worbes, 2002). Stable isotope analyses may be used as tools to enhance dendrochronology studies by providing insight into the variations of biochemical processes involved in tree-growth over time. This allows for the inference of additional information about physiological controls and environmental factors that affect the distribution of isotopes within the plant. Many studies have shown that the stable isotopic composition of cellulose can be related to precipitation (Saurer et al., 1997; Gebrekirstos et al., 2009; Fichtler et al., 2010), relative humidity (Sternberg et al., 2007), temperature (Libby and Pandolfi, 1974), large-scale ocean/atmospheric oscillations (Gray et al., 2004) and disturbance events (Anderson et al., 2005; Miller et al., 2006).

Several studies employing techniques of the combined field of stable-isotope dendrochronology have produced promising results for the future of tropical dendrochronology in species where physical tree-ring measurements are difficult or impossible to obtain. Among these, Poussart et al., (2004) used $\delta^{18} \mathrm{O}$ and $\delta^{13} \mathrm{C}$ to detect seasonal cycles in trees with indistinct growth bands from Indonesia and Thailand and Evans and Schrag (2004) used high-resolution $\delta^{18} \mathrm{O}$ measurements in trees lacking a physical ring structures to develop a chronology and a model for rainfall and growth rate estimates. More recently the work presented in Chapter 2 showed that the $\delta^{13} \mathrm{C}$ measurements of cellulose in individual tree-rings could be used as an alternative to traditional ring width measurements to build a chronology for a subtropical South Florida species that gives the appearance of distinct growth rings, but whose interpretation is confounded by the occurrence of inter-annual density fluctuations (IADFs), or false rings. 
South Florida, like many areas of the subtropics, has few tree species that are suitable candidates for dendrochronological studies as a result of non-visible or seasonally inconsistent ring production. However, several long-term paleoclimate datasets of varying temporal resolutions have been derived from other terrestrial proxies, such as pollen assemblage analysis in peat cores (Winkler et al., 2001; Donders et al., 2005; Saunders et al., 2006; Willard and Bernhardt, 2011; Donders, 2014), paleolimnological cores (Watts and Hanson, 1988), diatom assemblages (Wachnicka et al., 2010; Sanchez et al., 2013), and lipid biomarkers (Xu et al., 2007). Each of these proxies contributes valuable information to the paleoclimatological history of South Florida; yet, none of the aforementioned studies were able to achieve the sub-annual resolution that tree-ring analyses provide and that is required for resolving complicated climate patterns at a seasonal scale.

\subsubsection{South Florida climatology}

South Florida exhibits characteristics of a tropical monsoon climate, according to the KöppenGeiger classification system, where average monthly temperatures rarely fall below $18^{\circ} \mathrm{C}$ and the seasonality is driven by a distinct annual cycle of rainfall (Peel et al., 2007). During the summer months, average temperatures are consistently above $27^{\circ} \mathrm{C}$, and the winter months are mild, with average temperatures around $20.5^{\circ} \mathrm{C}$; however, occasional cold fronts may drop temperatures to near-freezing (Duever et al., 1994; NCDC, 2014). The average dry season (November - following April) precipitation accounts for roughly $25 \%$ of the total annual precipitation, with extratropical frontal rainfall being the primary source (Ali at al., 2000; NCDC, 2014). Precipitation in the more pronounced wet season originates from tropical sources such as daily convective rainfall, tropical depressions, and hurricanes (Ali at al., 2000). In addition, there are defined geographical precipitation gradients (i.e. the east coast receives relatively more precipitation in the wet season, and the west coast dry season is slightly more wet compared to the east coast) and high-resolution 
spatial variations that cause rainfall events and resultant quantities to be heterogeneous across the South Florida landscape (Ali at al., 2000; Moses et al., 2013).

Strong teleconnections exist between South Florida climate and the El Niño-Southern Oscillation (ENSO) phases. Variations in seasonal precipitation and their relationship to Niño-3.4 sea surface temperature anomalies (SSTA) have been well-documented. Under positive ENSO phase (El Niño) conditions, there is an equatorial displacement of the jet stream, which increases the occurrence of frontal precipitation in the Southeastern United States leading to cooler and wetter winters in South Florida (Hanson and Maul, 1991, Schmidt et al., 2001, and others). The southeastern coast of Florida and the Lower Keys show the strongest statewide responses to the El Niño phase (Sittel, 1994; Livezey et al., 1997; Schmidt et al., 2001) and report up to $150 \%$ of the normal winter precipitation (Schmidt et al., 2001). The springs and summers of La Niña (negative ENSO phase) years have a high probability of being drier than normal (Sittel, 1994; Livezey et al., 1997; Schmidt et al., 2001) and, as a consequence, result in an increase in the incidence of natural wildfires (Beckage et al., 2003). The Lower Florida Keys may experience up to 50\% less than normal rainfall in the winter (January-March), spring (April-June), and autumn (October-December) months during La Niña years, although the degree of the seasonal anomalies in precipitation can vary among episodes of ENSO cold phases (Schmidt et al., 2001). Additionally, hurricane formation is reduced during El Niño years in response to an increase in upper tropospheric westerly winds over the Atlantic basin that create wind shear conditions that are unfavorable for sustained organized cyclonic activity (Gray, 1984).

The connection between ENSO and precipitation is well pronounced, however, the climate of South Florida is further influenced by complicated over-lapping cycles of other multi-scale climate oscillations and the interplay of these factors are not constant with time. For example, in a study 
designed to understand the variability of the Florida wet seasons over time, Misra and DiNapoli (2013) reported that ENSO variability affects the length of the wet season over South Florida; however, the dominance of that effect varied throughout time. They found that longer wet seasons occurred after El Niño winters and shorter wet seasons followed La Niña winters, but the strength of that influence has diminished since 1976 when the intensity of the Bermuda High and the size of the Atlantic Warm Pool increased, becoming the primary drivers of precipitation (Misra and DiNapoli, 2013). The larger-scale AMO has contrasting controls on precipitation throughout the United States and, unlike a majority of the country, Central Florida receives significantly less rainfall during the negative cycles (Enfield et al., 2001). However, winter El Niño months experience above average precipitation regardless of the corresponding AMO phase (Enfield et al., 2001).

The strength and effects of climate cycles can vary on small geographic scales as revealed in a high-resolution spatial analysis of twelve climatological stations scattered across South Florida by Moses et al., (2013). According to their study, the nature of the teleconnections between South Florida precipitation patterns and the ENSO, the AMO, and the Pacific Decadal Oscillation (PDO) were heterogeneous both in time and across the landscape down to a distance of as little as $10 \mathrm{~km}$ (Moses et al., 2013). Regionally, the AMO had no effect on winter precipitation; however, summer rainfall was shown to have a positive correlation, except along the southwest coastal and interior areas (Moses et al., 2013). Conversely, summer precipitation was unaffected by the ENSO, but rainfall occurring during the winter months of December, January and February was positively correlated to the ENSO phases, although the correlation was not significant along the southeast coast (Moses et al., 2013). The PDO showed a positive correlation to winter rainfall at some of the stations and a negative correlation with winter temperature was shown along the west coast and the Florida Keys (Moses et al., 2013). The demonstrated heterogeneity and gradients of South Florida 
climate and the effects of the teleconnections to global climate oscillations further highlights the need for more high-resolution paleoclimate proxies that not only extend the present records, but also capture the climate intricacies of the natural landscape.

\subsubsection{Carbon isotopes in cellulose}

The carbon isotopic composition of cellulose is controlled by the fractionation of carbon dioxide as it diffuses through the stomata in the leaves during photosynthesis (O'Leary, 1988). In nature, the two stable isotopes of carbon, ${ }^{12} \mathrm{C}$ and ${ }^{13} \mathrm{C}$, are found in the abundance 99:1. Plants will naturally discriminate against the heavier ${ }^{13} \mathrm{C}$ isotope because the slight addition of mass from the extra neutron imparts small differences in its chemical and physical properties compared to the lighter ${ }^{12} \mathrm{C}$ isotope (O’Leary, 1988). Consequently, under optimal conditions, plants will selectively assimilate fewer ${ }^{13} \mathrm{C}$ for two reasons: (1) they form slightly stronger bonds than their lighter ${ }^{12} \mathrm{C}$ counterpart, and (2) the diffusion of ${ }^{13} \mathrm{CO}_{2}$ through the stomata is slower than ${ }^{12} \mathrm{CO}_{2}$ (O'Leary, 1988).

Atmospheric carbon dioxide is the sole source of carbon in terrestrial plants; however, it is not consistent in atmospheric concentration or carbon isotopic composition over time. The current isotopic value of atmospheric $\mathrm{CO}_{2}$ is around $-8.3 \%$ (CDIAC, 2014); however this value is becoming increasingly more negative over time as the atmospheric concentration of $\mathrm{CO}_{2}$ increases. The current atmospheric concentration of $\mathrm{CO}_{2}$ is 401 ppm, up from 360 ppm in 1960 (Tans and Keeling, 2016). The anticorrelation trend between increasing $\mathrm{CO}_{2}$ concentration and decreasing $\delta^{13} \mathrm{C}$ depletion is referred to as the "13 $\mathrm{C}$ Seuss Effect" and is a result of the burning of ${ }^{13} \mathrm{C}$ depleted fossil fuels (Friedli et al., 1986). To remove this trend from the tree-ring carbon isotope record, McCarroll et al., (2009) offers a post-analysis correction that normalizes the data to the preindustrial standard value of atmospheric $\mathrm{CO}_{2}(-6.4 \%$ ) . 
With the variability of the source removed, the isotopic signature of the assimilated carbon in C3 plants is dependent upon two stages of fractionation; first, equilibrium fractionation occurs as $\mathrm{CO}_{2}$ diffuses through the stomata and secondly, biological fractionation associated with the isotopic discrimination of Ribulose-1,5-Bisphosphate Carboxylase enzyme (RuBisCo) during carbon fixation (Francey and Farquhar, 1982; O’Leary, 1988; Farqhuar et al., 1989). The influences of these factors on the $\delta^{13} \mathrm{C}$ of the plant can be expressed as:

$$
\delta^{13} \mathrm{C}=\delta^{13} C_{a}-a-(b-a) \frac{P_{i}}{P_{a}}
$$

where $\delta^{13} \mathrm{C}$, and $\delta^{13} C_{a}$ are the $\delta^{13} \mathrm{C}$ values of the plant and atmospheric $\mathrm{CO}_{2}$ respectively, $a$ is the diffusion fractionation that occurs as $\mathrm{CO}_{2}$ passes through the leaf stomata $(\approx 4.4 \%$ o), $b$ is the biologic fractionation by the RuBisCo enzyme $(\approx 27 \%)$, and $P_{i}$ and $P_{a}$ are the internal and external partial pressures of $\mathrm{CO}_{2}$, respectively (Francey and Farquhar, 1982). Stomatal conductance increases when $P_{i} / P_{a}$ increases and there will be a strong discrimination against ${ }^{13} \mathrm{C}$ during carboxylation (Farquhar et al., 1989). Conversely, when $P_{i} / P_{a}$ is reduced, such as in times of conservative stomatal conductance imposed by an environmental stress, there is a decrease in the discrimination of ${ }^{13} \mathrm{C}$, resulting in relatively enriched $\delta^{13} \mathrm{C}$ value (Farquhar et al., 1989). The variations of $\delta^{13} \mathrm{C}$ in treering cellulose are the effect of changes in stomatal aperture patterns; however, when the tree is transpiring, there must always be a balance between carbon gain and leaf water loss. Therefore, the changes in $\delta^{13} \mathrm{C}$ may be attributed the influence of external forcing factors such as temperature, precipitation, relative humidity, or disturbance events, such as hurricanes, depending on the limiting factors on tree growth for a particular environment (Pearman et al., 1976; Farquhar et al., 1989a and b; Leavitt and Long, 1991; and many others). Additionally, the characteristics (availability of soil moisture, competition for resources, etc.) of the specific location where the tree is growing can be equally as important to the carbon isotope record as the broad scale climate factors (Saurer et al., 1995; Anderson at al., 2005). 


\subsubsection{Previous South Florida slash pine studies}

The Florida slash pine, Pinus elliottii Engelm. var. densa, is the southernmost native subtropical pine in the United States (Little and Dorman, 1952). Pine rocklands once dominated the higher elevations of the South Florida landscape, extending from the east to the west coast and from Lake Okeechobee to the Lower Florida Keys (Duncan and Duncan, 1988). At present, the areal distribution of $P$. elliotti has been significantly reduced to isolated tracts in Long Pine Key in Everglades National Park and the Cypress National Preserve, as well as pockets of pine rocklands scattered throughout southern Florida and the Lower Keys (USFWS, 1999).

One of the first $P$. elliottii var. densa studies from South Florida was conducted by Langdon (1963). He installed vernier growth bands on ten P. elliottii var. densa trees at a site in Southwest Florida and took bi-weekly incremental radial growth readings for a period of four years. These results showed that the trees grew continuously throughout the year, with two main flushes of growth occurring in the spring and the fall (Langdon, 1963). Spring growth started in early February and continued through April, followed by a slight decrease in the growth rate until the second, smaller, period of increased growth beginning in September and tapering off by November. Langdon did not report a cessation in growth at any point in his four year study, and he remarked on the significance of the continued, albeit much reduced ( $3 \%$ contribution to annual change in diameter), growth observed in December and January (1963). Less than decade later, Tomlinson and Craighead (1972) published a study of their observations of wood anatomy for several South Florida tree species. They concluded that P. elliottii var. densa was one of fifteen South Florida trees species that produces annual rings (Tomlinson and Craighead, 1972). However, Tomlinson and Craighead did acknowledge that $P$. elliottii var. densa has a high incidence of false rings (indicating up to 5 successive spurts of seasonal growth), yet they do not propose a mechanism for their formation or guidelines on identifying their characteristics (Tomlinson and Craighead, 1972). 
A recent study by Harley et al., (2011) used traditional dendrochronology techniques and wildfire scars in several living and remnant $P$. elliottii var. densa trees from the Lower Keys to develop a cross-datable tree-ring chronology from 1871-2009. They determined, like Tomlinson and Craighead (1972), that slash pine form anatomically distinct annual growth rings and that, as expected, tree growth was influenced primarily by precipitation (Harley et al., 2011). However, they could not find statistically significant correlations between ring width and the ENSO or the AMO (Harley et al., 2011). In a later study published by the same group, Harley et al., (2012) extracted micro-cores from six living $P$. elliottii var. densa trees for a period of 13 months. Monthly cambial growth was quantified by counting the number cells at different stages in the growth process; this approach allowed for the comparison of ring growth to monthly climate data at a much higher resolution than was previously attainable. Their analysis indicated that the growing season for P. elliottii var. densa in the Florida Keys extends from February to December and that solar radiation was the primary control on cell production (Harley et al., 2012). The study tracked growth from March 2010 through March 2011 and found that the trees produced earlywood cells from March to June and latewood growth occurred between June through December or January (Harley et al., 2012). Additionally, there was a period from mid-July to mid-August when four of the six trees produced inter-annual density fluctuations (IADFs) that indicates a period of punctuated growth (Harley et al., 2012). Unlike the Langdon (1963) study where continuous growth was observed, Harley et al., (2012) witnessed a period of cambial dormancy from December to February.

The Langdon (1963) and Harley at al., (2011; 2012) studies provide general insight into the growth dynamics of the only native subtropical pine species in the United States; however, the results showed a surprising absence of correlation between tree-ring growth and major climate oscillations. The Langdon (1963) study measured biweekly changes in radial diameter between December 1955 
and December 1959, a sampling period that included a La Niña year (1956) and two El Niño years (1957 and 1958). The bimodal spring growth peaks observed in 1957 and 1958 and the pronounced fall growth peaks of 1956 and 1957 may have been influenced by their respective co-occurring ENSO phase. Harley et al., (2012) did not find any correlations to precipitation in their 13-month micro-core analysis, and they did not discuss the possible influence that the corresponding El Niño year may have had on the results of their data. In addition, their sampling period included both the driest May in five decades and driest February in over 65 years, which may have contributed to the production of IADFs and encouraged the 2-month period of dormancy observed in their trees (NOAA, 2013). The lack of relationship between the ring width-derived climatologies and largescale climate drivers, may indicate that traditional dendrochronology techniques are not on their own sufficient proxies for South Florida climate.

\subsubsection{Objectives of this study}

The objectives of this study are to determine the relationship between carbon isotopes within the $\alpha$-cellulose of individual Pinus elliottii earlywood and latewood rings and localized precipitation and large-scale climate oscillations at several scales. Sub-annual $\delta^{13} \mathrm{C}$ values are compared to biannual climate data and to monthly precipitation data. Monthly dendrometer data are compared to precipitation over several intervals to determine the radial growth response to precipitation as a modern day analogue for growth.

\subsection{Methods}

\subsubsection{Big Pine Key site description}

Big Pine Key is the largest and easternmost island in the lower Florida Keys, with a maximum elevation of $3 \mathrm{~m}$ and an areal extent of approximately $25 \mathrm{~km}^{2}$ (Figure 2.1). Geologically, the island is composed of an oolitic facies of the Miami limestone underlain by the coralline Key Largo 
limestone (Hoffmeister and Multer, 1968). The Pleistocene-aged limestones were formed under different nearshore marine settings during the sea level high of the last Pleistocene interglacial period (Hoffmeister and Multer, 1968). The Key Largo limestone is an ancient reef tract of variable thickness (with a maximum thickness of about $61 \mathrm{~m}$ ) that is main structural component of the elongated and linearly oriented Upper and Middle Florida Keys (Hoffmeister and Multer, 1968). The Lower Keys are primarily composed of the Miami oolite, cemented calcium carbonate ooid sand deposited in the form of a marine tidal bar system (Hoffmeister and Multer, 1968; Hoffmeister, 1974; Halley and Harris, 1979). The two facies of the Miami Limestone intersect on Big Pine Key, where the ooilite has been found to overlay the Key Largo limestone at a contact depth of 4-6 meters (Hoffmeister and Multer, 1968; Coniglio and Harrison, 1983) The juxtaposition of the oolite with the more transmissive Key Largo limestone allows the island to support two freshwater lenses with the bases extending to just below the contact of the two limestone units (Vacher et al., 1992). The larger northern lens has a maximum depth of $8 \mathrm{~m}$, and the southern lens is both smaller and shallower (Wightman, 1990). Both lenses are recharged primarily by precipitation and, therefore, exhibit variable areal extents in response to seasonal rainfall.

The oolitic limestone bedrock is at or very near the surface and contains small, shallow pockets of sand, marl and organic material dispersed across a karstic landscape that supports vegetation (Ross et al., 1994; USFWS, 1999). The environments on the island transition from the lowest elevation mangrove forests to the pine rocklands and hardwood hammocks found at comparatively higher elevations (Ross et al., 1992). The pine rocklands are a disturbance-driven community dominated by $P$. elliottii var. densa as the single canopy species and several species of palm in the understory (Ross et al., 1992; Oberbauer et al., 1997). Under natural conditions, pine rocklands rely on lightning-induced fires 2-3 times a decade to clear the understory of successional hardwood species; however, most fires within the last 50 years have been prescribed by the management at the 
National Key Deer Refuge (Taylor, 1981; Bergh and Wisby, 1996; Ross and Ruiz, 1996). The slash pine are saltwater intolerant and their distribution on the island is dictated by the freshwater lenses; however, they can withstand short hurricane-induced storm surge flooding events, although most species will senesce and die if exposed to salt water for longer periods of time (USFWS, 1999; Ross et al., 2009). The P. elliottii var. densa trees have a limit to their resiliency as witnessed by a major die off in the northern Big Pine Key in early 2006 after two storm surges flooded the island during the passage of Hurricane Wilma in October 2005. The detrimental influence of the saltwater surges was intensified by an uncharacteristically dry winter which prevented the removal of the residual salt deposit from the overwash (Ross et al., 2009; Sah et al., 2010).

The adjacency of the lower Florida Keys to two warm, buffering water bodies, the Gulf Stream and the Gulf of Mexico, gives them a mild, tropical-maritime climate (NOAA, 2013). Their position of about $24.67^{\circ} \mathrm{N}$ latitude results in a relatively small annual maximum and minimum temperature gradient of $24^{\circ} \mathrm{F}$, (NCDC, 2013) and a three hour difference in daylight hours between solstices (USNO, 2014). Seasonality in the Florida Keys, like mainland South Florida, is defined by annual precipitation patterns. The dry season is generally considered to be November through April; it accounts for about $29 \%$ of annual precipitation $(\sim 30 \mathrm{~cm})$ (NCDC, 2013). Conversely, $71 \%$ of the annual precipitation $(\sim 70 \mathrm{~cm})$ for the Lower Keys falls during the wet season months of May through October (NCDC, 2013).

The four $P$. elliottii var. densa samples used in this study were collected by staff at the National Key Deer Refuge in April of 2006. Disks were recovered from trees along a proposed hydrologic gradient on the northern freshwater lens from a post-Hurricane Wilma high mortality region on the northeastern portion of Big Pine Key the (Figure 3.1). A cluster of three disk samples were collected from trees less than $30 \mathrm{~m}$ from each other over a deeper, more stable part of the northern freshwater 
lens (approximately $900 \mathrm{~m}$ from the coast). An additional tree was sampled from the less stable periphery of the lens about $160 \mathrm{~m}$ from the cluster (approximately $750 \mathrm{~m}$ from the coast).

\subsubsection{Sample processing}

The $P$. elliottii var. densa tree disks were sanded using increasingly finer sandpapers (beginning with 80 grit and ending with 400 grit) until all the rings were clearly visible. A single, roughly inchwide radius extending from bark to pith was cut out from each disk from an area in the disk free of physical damage and showing the least amount of ring compression anomalies. Standard dendrochronology techniques were used to count and identify the rings in each of the radaii following the guidelines described in Cook and Kairiukstis (1990) and Fritts (1976). The samples were photographed and examined under a microscope. Adobe Photoshop CS2 was used to distinguish and record the locations of the ring boundaries on the images. ImageJ, an image processing and analysis program that uses a simple ratio system to compare a known distance within an image with unknown distances, was used to determine the average width of every earlywood, latewood, and whole ring sample. To accommodate for the variability in width of individual rings, multiple measurements ( 5 each for the early- and latewood and 7 for the whole ring) were taken along every ring. The measurements were then averaged to obtain the ring width values.

Every seasonal (early- and latewood) ring was individually separated under a microscope at $15 \mathrm{x}$ magnification using an X-Acto knife. Special care was taken when dividing the rings to accommodate for curvature and uneven vertical growth of the tree-rings, so that every sample contained only material from that growth period. The samples were then homogenized in a Spex 8000M Mixer/Mill using stainless steel vial and ball sets. On average, an $80-90 \mathrm{mg}$ (with as little as $20 \mathrm{mg}$ for very thin rings) aliquot of each powdered sample underwent a chemical extraction 
process to isolate the $\alpha$-cellulose component of the wood using a method modified after Green, 1963 (see Appendix 1 for a detailed description of the revised process). These P. elliottii var. densa samples were highly resinous and the extraction process removes the mobile resin component and any other wood elements that may interfere with the climate signal in the isotope analysis (Loader et al. 2007).

\subsubsection{Carbon isotope measurements}

Every earlywood and latewood cellulose sample from each of the four P. elliottii var. densa trees was analyzed for $\delta^{13} \mathrm{C}$ individually. All carbon isotope measurements were completed on a Carlo Erba NA1500 II coupled to a Finnigan MAT Delta C mass spectrometer via a ConFlo II interface using standard elemental analyzer isotope ratio mass spectrometry (EA-IRMS) techniques at the SERC Stable Isotope Laboratory (SERC SIL) at Florida International University. Variations of isotopic values are expressed in $\delta \%$, which is calculated using the following formula (Coplen, 1994):

$$
\delta^{13} C \%=\left[\left(\frac{R_{\text {sample }}}{R_{\text {standard }}}\right)-1\right] 1000
$$

Where $\mathrm{R}$ is the ratio of ${ }^{13} \mathrm{C} /{ }^{12} \mathrm{C}$ in the sample $\left(R_{\text {sample }}\right)$ and in the V-PDB (Vienna Pee Dee Belemnite) standard for carbon $\left(R_{\text {standard }}\right)$.

A biannual chronology using the carbon isotope signature for the four trees was developed and all inter-annual density fluctuations were flagged and removed from the dataset using the methods described in Chapter 2. Additionally, a correction was applied to normalize the time-series to the historical value of $\delta^{13} \mathrm{C}$ of atmospheric $\mathrm{CO}_{2}$ following the methods in McCarroll et al. (2009) and McCarroll and Loader (2004) so comparisons could be made to historical climate measurements. 


\subsubsection{Climate data}

The majority of the long-term climate datasets used here come from the National Climate Data Center website (http://www.csc.noaa.gov/). Data for the Atlantic Multidecadal Oscillation (AMO), North Atlantic Oscillation (NAO), and the Pacific Decadal Oscillation (PDO) were downloaded from the Climate Indices page of the National Oceanic and Atmospheric Administration website (NOAA, 2013a). There is not a consensus concerning the timing of the AMO phase shifts; the definition of the AMO phases used here may be found in Table 3.1. The El Niño - Southern Oscillation (ENSO) dataset is from the Ocean Niño Index of sea surface temperature anomalies (SSTA) from the Niño 3.4 region (NOAA, 2013b). Accumulated Cyclone Energy (ACE), which is an index used to classify the energy from individual tropical cyclones, as well as entire hurricane seasons, was downloaded from the NOAA Hurricane Research Division webpage (NOAA, 2013c).

Although there is currently an operational station on Big Pine Key that was installed after the trees used in this study were sampled, temperature and precipitation records were used from the weather station on Key West (approx. $40 \mathrm{~km}$ distance) because it has the longest historical record of consistent data collection in the Lower Keys. In addition, data from the next closest long-term weather station (approx. $94 \mathrm{~km}$ distance), Tavernier in the Upper Keys, was also included in the climate analysis for the sake of completeness; however, the precipitation and temperature data from Key West is used in most of the analyses. Although there are some minor variations in the timing and the amount of monthly precipitation received between the Key West station and the next closest station to the sampling site, Marathon (Figure 3.1), the running annual totals for the two stations are nearly identical (Figure 2.2). The monthly differences in average temperatures and monthly hours of daylight are also nearly identical between Key West and Marathon (Figure 2.2); therefore, it can be assumed that the monthly historical record for Key West is a good representation of Big Pine Key climate. The Palmer Drought Severity Index (PDSI), which quantifies the intensity and 
duration of long-term drought conditions, is for the regional Florida Climate Division 7 (NOAA, 2013a). The aerosol dust record is modified from Prospero and Lamb (2006) and Prospero (2011), and is a measure of aerosol African dust concentrations collected on Barbados. The University of Miami Aerosol Research Station in Barbados is located approximately 2,636 km from the $P$. elliottii var. densa sampling site in Big Pine Key; however, aerosol dust collected in the Miami showed similarities to the influx pattern, but with lower volumes of dust recorded in Barbados (Trapp et al., 2010; Prospero, 2011).

The tree-ring chronology extends from 1922-2006; however, the period between 1950 and 2006 was selected for many of the analyses because it is the interval of time containing the most complete instrumental records for almost all the climate parameters analyzed. All datasets were averaged into two annual points, wet season (May-October) and dry season (November to the following April), except in the case of ACE, in which the annual value was repeated for both seasons. Before being converted into biannual values, the precipitation datasets were normalized by converting each point to a variance from the mean by subtracting the monthly means calculated for the period 19502006 from the observed monthly values. The gaps in the Bermuda dust record were filled in with a dummy constant (15 $\mu \mathrm{g} \mathrm{m-3)}$ and the monthly values were summed into seasonal totals. The carbon isotope values and ring width measurements for each of the four P. elliottii var. densa trees were also analyzed as variances from the respective mean of each tree. Unless otherwise noted, the trees were normalized to the $\delta^{13} \mathrm{C}$ values averaged over the period of 1950-2006.

\subsubsection{Climate data analyses}

The simultaneous comparison between the various climate variables and the individual tree carbon isotope variables were calculated in MATLAB using empirical orthogonal functions (EOFs) to compare the $\delta^{13} \mathrm{C}$ values of individual ring cellulose to multiple climate and environmental 
variables at the same time. Tree growth is likely influenced by a complex interplay of interrelated, nonlinear, and multi-scale climate drivers, which exhibit varying degrees of control at scales that range from regional down to the microclimate conditions surrounding individual trees. An analytical method that can detect the variability in multiple, concurrent factors is required to discern the intricacies of the interactions both among the climate drivers themselves and the nature of their elicited response in cellular production within trees. The EOFs breaks down a suite of complicated time series into a matrix of eigenvectors that show the covariance of the individual components (Hannachi, 2004). The MATLAB EOF program used here first detrends the individual datasets before calculating a covariance matrix.

Only the leading and secondary eigenvectors (EOF1 and EOF2) will be presented for all the data. In general, the first two eigenvectors explain at least half of the variance in EOFs comparing $\leq 8$ datasets. The addition of more datasets to the EOF analyses will result in smaller variances explained by the leading eigenvectors because the relationships become increasingly more complex as more time series are considered. The variance is quantified as a percent in a table accompanying all graphs. It is important to note that EOFs simply show the directional (+ or -) quality and the strength of the variability (numerical departure from zero) among the independent and unweighted time series being analyzed. They allow a series of complicated datasets to be viewed as a series of nested relationships, with the leading eigenvector showing the primary covariance of the dataset and the next eigenvector exposing the secondary pattern (Hannachi et al., 2007).

Simple Pearson product-moment correlation coefficient (r) calculations were used to specifically assess the relationships between the composite $\delta^{13} \mathrm{C}$ time series and monthly historical precipitation values collected by the Key West weather station following the methods in Harley et al. (2011) and Grogan, and Schulze (2012). Pearson values measure the linear dependence between an 
independent (precipitation amount) and a dependent variable $\left(\delta^{13} \mathrm{C}\right.$ value $)$. The results are given as a number between -1 and +1 , with the end members indicating a prefect negative or positive linear relationship, respectively, between the variables. Monthly precipitation data for the concurrent season and the previous season were compared to the mean adjusted earlywood and the latewood $\delta^{13} \mathrm{C}$ index values independently.

\subsubsection{Dendrometer analysis}

Monthly dendrometer data collected from three $P$. elliottii var. densa trees growing in $10 \mathrm{x} 60$ meter permanent sampling plots on Big Pine Key and nearby Sugarloaf Key (Ross, unpublished) were used to determine the effects of environmental drivers on tree growth. The permanent sampling plot on Big Pine Key is located on the northeastern quadrant of the island, approximately $1.25 \mathrm{~km}$ away from the dendrochronology transect. Spring-loaded vernier growth bands were fixed to three of the largest $P$. elliottii var. densa trees $(\geq 26.9 \mathrm{~cm}$ diameter) at standard breast height (Cattelino et al., 1986) in April of 1990 and readings were collected at monthly intervals until October, 1993. Growth was initially recorded as departures (in $\mathrm{mm}$ ) from the starting position on the dendrometer band and it was converted to incremental changes in diameter between subsequent sampling periods. The data was compared to cumulative Key West precipitation occurring between each sampling period.

A linear mixed effects model (LME) was used to analyze the relationship between radial growth and precipitation using the LME package (Bates et al., 2015) in the statistics program, $\mathrm{R}$ (R Core Team, 2016), through the RStudio interface (RStudio Team, 2015). Cumulative precipitation and tree growth were the fixed effects and the tree ID was considered as a random effect to remove any potential influence of resampling the same trees over the course of the study period. Originally, hours of sunlight was also included as a fixed effect in the model; however, as expected for such a 
southern latitude, it was not considered to be significant ( $\mathrm{p}$-value was not $\leq 0.05$ ). The model was run under three precipitation scenarios, the cumulative precipitation over the true sampling interval (from actual sampling date to the following sampling date), the precipitation accumulated over a static 30 day period before the sampling date and the total precipitation occurring in a static 60 day period prior to each dendrometer reading. The different precipitation intervals were designed to test whether there is a lag in the trees' growth response to rainfall.

\subsection{Results}

\subsubsection{Variability in individual trees}

Previous studies for slash pine in the Lower Florida Keys have used ring width measurements to determine the relationship between tree growth and climate variables. The tree-rings in slash pine are concentrically variable, which may introduce unnecessary error into the dataset and may not provide the most accurate correlations with the climate parameters of interest. Empirical orthogonal functions were used to assess the relationships in ring width versus $\delta^{13} \mathrm{C}$ values among the four trees sampled. Figure 3.4 shows the first and second EOFs for ring widths (a-b) and $\delta^{13} \mathrm{C}$ values $(\mathrm{c}-$ d) in both the earlywood, EW (blue), and the latewood, LW (pink), components of each annual ring. The data shown is for 1950-2005. For ring width, the first EOF (EOF1) explains $31.7 \%$ of the variance among earlywood tree growth and $33.2 \%$ variance in the latewood. The second EOF (EOF2) accounts for $27.2 \%$ and $26.5 \%$ of the variance in earlywood and latewood ring width, respectively. The variance in the carbon isotope records of the trees is $43.1 \%$ (EW) and $39.3 \%$ (LW) for EOF1 and $28.9 \%(\mathrm{EW})$ and $26.4 \%(\mathrm{LW})$ in EOF2.

The ring width patterns do not display consistent patterns in either the EW or the LW datasets. For example, both earlywood and latewood rings in DBH6 and the latewood portion of DBH2 have an inverse trend compared to the other trees (Figure 3.4a), whereas all four trees show the same 
response in the $\delta^{13} \mathrm{C}$ values in both seasonal components (Figure 3.4c). The pattern in the carbon isotopes in EOF2, indicates that the trees growing adjacent to each other are more similar than the trees farther away. In addition, the proposed hydrologic gradient may play a role in the overall carbon isotope signatures of the trees; an inverse relationship exists between trees at either end of the sampling transect. The relationship between the trees is more consistent in the carbon isotope records in comparison to the ring width records, making the $\delta^{13} \mathrm{C}$ values a better choice for climate analysis.

\subsubsection{Comparison of the seasonal carbon isotope record and the climate parameters}

The composite carbon isotope record was compared to monthly Key West precipitation data for the period 1922-2005 using a Pearson product-moment correlation coefficient analysis (Figure 3.5). The analysis was completed using the monthly precipitation from the previous year ( $\mathrm{pJan}-\mathrm{pDec}$ ) through the 12 months of the current years (Jan-Dec). Earlywood $\delta^{13} \mathrm{C}$ values are negatively correlated to the precipitation received in the previous December ( $\mathrm{p}$-value $=0.021)$ and the April $(p$-value $=0.042)$ and positively correlated to the January rainfall in the previous year $(p$-value $=$ 0.035). The inverse correlation between dry season precipitation and carbon isotope values, particularly for the typically very dry month of April, may indicate that rainfall received during this time is crucial in the initiation of sustained earlywood growth. More rainfall at the end of the dry season leads to less enriched $\delta^{13} \mathrm{C}$ values in the earlywood. The carbon isotope values of the latewood were significantly positively correlated to the precipitation received in the previous December $(\mathrm{p}$-value $=0.035)$ and the current November $(\mathrm{p}$-value $=0.050)$. The positive relationship between November precipitation and latewood $\delta^{13} \mathrm{C}$ values is counterintuitive and indicates that additional precipitation at the beginning of the dry season leads to more cellulose enriched in ${ }^{13} \mathrm{C}$. It is possible that a spike in dry season rainfall, encourages tree growth that cannot be sustained in the subsequent dry months of December and January, leading to enrichment. 
The first and second EOFs comparing the individual carbon isotope records of the P. elliottii var. densa trees to the major climate oscillations controlling South Florida precipitation are shown in Figure 3.6a-d. In the case of ENSO, EOF1 explains 34.5\% of the variance in the EW and $32.1 \%$ of the variance in the LW records, while EOF2 accounts for $23.8 \%$ (EW) and $22.6 \%$ (LW) of the variance. The carbon isotope values in the latewood of all four trees respond positively to the added precipitation in El Niño winters and negatively during wet season years, although the influence of El Niño in the wet season is close to zero (eigenvalue $=0.053$ ). The trees show the effect of the hydrologic transect gradient in EOF2 (Figure 3.5b), where DBH1 and DBH6 have inverse secondary responses to ENSO. La Niña phases coincident with LW production result in relatively more depleted $\delta^{13} \mathrm{C}$ values in DBH6, a relationship not present in the other trees. The EW cellulose in DBH1 is isotopically enriched during El Niño years.

All trees have an inverse correlation with the positive phase of the AMO in the carbon isotope value of both their EW and LW components (Figure 3.6c); however, the second eigenvector shows a more complicated relationship (Figure 3.6d). In EOF2, the trees, with the exception of DBH1, have depleted carbon isotope values during the cool phase of the AMO in their EW and enrichments in ${ }^{13} \mathrm{C}$ during the positive $\mathrm{AMO}$ phase. The percent variance explained by EOF1 is $37.9 \%$ in the EW and $34.0 \%$ in the LW and $26.3 \%(\mathrm{EW})$ and $23.5 \%(\mathrm{LW})$.

The first two EOFs comparing Florida Keys precipitation with the major climate oscillations (ENSO, AMO, and PDO) and concurrent hurricane activity (ACE) is shown in Figure 3.7. EOF1 explains $26.0 \%$ of the variance in the EW and $39.2 \%$ of the variance in the LW records, while EOF2 accounts for $22.9 \%$ (EW) and $20.5 \%$ (LW) of the variance. In EOF1, the precipitation from both stations, ENSO, the NAO, and the PDO are positively correlated with each other and negatively correlated to the AMO and ACE in both the EW and the LW (Figure 3.7a). EOF2 shows 
seasonal differences among the climate parameters (Figure 3.7b). The EW phase of the NAO is positively correlated to precipitation and negatively correlated to all other climate variables, while the LW phase of the NAO is negatively correlated to all other datasets. The negative relationship between the NAO and winter Caribbean precipitation has been documented (Jury et al., 2007), but it appears to have a limited effect on precipitation in the Florida Keys. The PDO and ENSO have been reported to positively correlate with winter precipitation at some historical climate stations in South Florida (Moses et al., 2013); this agrees with the relationships seen in EOF1. However, the positive correlation between summer rainfall and the AMO found for mainland South Florida (Moses et al., 2013) is not replicated in the Lower Florida Keys. The EOFs for the remaining climate variables may be found in the Appendices.

\subsubsection{Dendrometer data and precipitation}

Figure 3.8 shows the changes in radial growth for the three trees (solid, dashed, and dotted black lines) used in the dendrometer study and the corresponding cumulative precipitation (blue bars) for each sampling interval. The change in radial growth is defined as the difference (in $\mathrm{mm}$ ) in the dendrometer readings between successive sampling periods. Precipitation values are the cumulative daily totals (in $\mathrm{mm}$ ) as reported by the Key West station. For the purpose of the model, the dates have been converted from calendar days into sampling days, where day zero (04/20/1990) represents the date of dendrometer installation and day 1275 is end of the study (10/07/1993). Vertical gray lines have been added for reference to illustrate the calendar years. A LME model was used to determine the relationship between tree growth and three different precipitation scenarios while removing any bias from possible resampling effects.

The results of the LME model analyses are shown in Table 4.2. The interval (Interval Precip) between dendrometer readings was inconsistent and ranged from 20 to 44 days, so a static 30 day period (30 Day Precip) was also analyzed. Additionally, a static 60 day precipitation (60 Day 
Precip) period was included to identify any potential lag between precipitation and tree growth. Both the Interval Precip and the 30 Day Precip LME results were considered statistically significant (p-values $=4.10 \mathrm{E}-06$ and 8.2E-06, respectively); however the 60 Day Precip was not significant (p-value $=0.1265)$. The results of the LME analyses suggest that tree diameter growth is responding immediately to precipitation and that there is not a lag or cumulative effect of rainfall received in previous months. The time of day the samplings occurred is unknown and it may affect the results of the LME models as tropical trees are known to have appreciable fluctuations in stem diameter throughout the day (Sheil, 2003). Inconsistency in the timing of the dendrometer samplings could account for the negative changes in growth diameter (Figure 3.8). However, the P. elliottii var. densa trees of Big Pine Key have access to the freshwater lens all year round and have been observed to opportunistically modify their water acquisition strategies to incorporate recent precipitation from the soil pore spaces, particularly in the dry season (Ogurcak, 2015). The occurrence of precipitation during typically dry months could result in episodic tree growth and lead to the formation of IADFs.

\subsection{Discussion}

3.5.1 The landscape -scale picture: carbon isotopes and climate oscillations

The four $P$. elliottii var. densa trees showed uniform patterns in their carbon isotope compositions (EOF1 Figure 3.4c), indicating that the trees have similar overall responses to the landscape-scale drivers that control the timing of precipitation. Previous dendrochronology studies using slash pine in the Lower Florida Keys were unable to find a relationship between ring width measurements and ENSO (Harley et al., 2011; 2012). The absence of correlation between tree growth and the strongest teleconnection impacting South Florida dry season precipitation (Enfield et al., 2001; Moses et al., 2013) is unexpected, as precipitation is likely to be the primary driver of P. elliottii var. densa growth (Langdon, 1963, Fichtler et al., 2010, and Harley et al., 2011). There are two possible explanations for the quantitative lack of correlation between the physical characteristics of the $P$. 
elliottii var. densa tree-rings and the large-scale climate oscillations. The first could be a result of using ring width measurements as the tree response parameter in climate correlation analyses. The tree-rings of $P$. elliottii var. densa display variable widths around the circumference of the tree disk and the interpretation of ring boundaries is complicated by the presence of IADFs (Tomlinson and Craighead, 1972; Harley et al., 2011; Chapter 2). The leading EOF comparing the ring width measurements among the four trees (Figure 3.4a) shows very complicated relationships in the EW and LW portions of the trees. The variability in the concentric ring thickness may introduce error into the index chronology, and reduce the likelihood of finding statistically significant correlations with climate. The dendrochemistry of the structural tree-ring cellulose may provide more accurate results in paleoclimate studies because the isotopic composition of the cellulose is controlled by the physiologic responses of the tree to the local climate (McCarroll and Loader 2004).

The second reason for the quantitative lack of correlation between tree growth and the large-scale climate oscillations is that there is variability in the nature of the interrelated interactions among the climate drivers themselves. The trees show strong and well-defined responses in their carbon isotope records to both the AMO and ENSO (Figure 3.6 a and c); however, when considering the entire span of the $\delta^{13} \mathrm{C}$ time series, there is a statistically significant correlation for the AMO (pvalue $=0.032)$, but not for ENSO (p-value $=0.396)$. Figure 3.9c graphically shows relationship between ENSO and the $\delta^{13} \mathrm{C}$ composite index from 1922-2005. There is a direct relationship between ENSO and $\delta^{13} \mathrm{C}$ over the periods 1922-1938 and 1956-1985; however, the remainder of the times series (1939-1955 and 1986-2005) show inverse correlations between the two variables. The timing of the transition between the nature of the correlation between ENSO and $\delta^{13} \mathrm{C}$ seems to correspond with a phase shift in the AMO. There is not a consensus among the scientific literature about the temporal definitions of the AMO phases (Table 3.1) and there is likely an extended period of time (possibly up to a decade) where the AMO wavers between phases before reversing (Enfield 
et al., 2001; Grey et al., 2004; Knudsen et al., 2011). In general, the relationship between ENSO and $\delta^{13} \mathrm{C}$ values of $P$. elliottii var. densa cellulose is roughly inverse to the prevailing AMO phase. A similar trend was observed in Key West sea level anomalies and ENSO, the sign of their correlation reverses with a change in the AMO phase (Karamperidou et al., 2013).

Under a cool AMO phase, both the El Niño and the La Niña earlywood and the El Niño latewood seasons have the potential of being wetter than normal (Figure 3.10). The latewood $\delta^{13} \mathrm{C}$ values are more enriched during El Niño seasons occurring during the negative AMO phase; a counterintuitive relationship where the trees are assimilating more ${ }^{13} \mathrm{C}$ during times of increased rainfall. The $P$. elliottii var. densa trees have an immediate response to available precipitation, as demonstrated by the dendrometer data (Table 3.2) and previous observations (Ogurcak, 2015). Dry season precipitation in the Lower Florida Keys may be up to $150 \%$ greater than the average amount typically received during December, January, and February (Schmidt et al., 2001; Moses et al., 2013). It is possible that the addition of early dry season rain promotes tree growth; however, the sporadic contribution of precipitation, may cause the tree to become water stressed in between rain events.

The correlation between the $\delta^{13} \mathrm{C}$ values of subannual cellulose and the prevailing concurrent phases of the AMO and ENSO is complicated, but there is a distinct relationship between the timing of precipitation and the resulting carbon isotope signature. The EOFs show that the climate oscillations are the primary drivers of tree growth (EOF1 Figure 3.6); however, the localized environmental conditions specific to individual trees are also important to growth (EOF2 Figure 3.6). Trees growing within tens of meters from each other may have different growth responses to the same climate drivers. 
3.5.2 The individual picture: variability of individual trees across a hydrologic transect

The location of a tree on the proposed hydrologic transect has an effect on the way the tree responds to the climate oscillations and the input of precipitation. The trees exhibit a strong gradient along the transect in the relationship between the carbon isotope records of the four trees. For reference, tree DBH1 is on inland side of the hydrologic transect, while tree DBH6 is closest to the coast. When compared to the other trees, DBH6 has been shown to have overall more enriched $\delta^{13} \mathrm{C}$ values throughout the chronology (Chapter 2) and it has an inverse relationship with DBH1 in the carbon isotope EOF2 analysis (Figure 3.4d), implying that it resides in a more water-limited environment. The two trees in the middle of the sampling transect, $\mathrm{DBH} 2$ and DBH3, show intermediate responses to the climate variables and, together, the four trees show a gradient pattern in all of the EOF2 analyses (Figure 3.4d and 3.6b and d).

The effect of the position along the gradient was expected and it was initially hypothesized that seasonal changes in the size and shape of the freshwater lens would have negative effects on the trees closest to its periphery. However, the areal extent of the northern fresh water lens on Big Pine Key does not change from wet to dry season, but there is a seasonal cycle in the depth of the freshwater lens (Ogurcak, 2015). It is possible that slight increases in salinity near the edges of the lens could cause water stress in the trees near the periphery. An increase in salinity may explain why tree DBH6 has a positive response to El Niño rainfall and it had the fewest number of IADFs (Chapter 2).

The pattern of receiving atypical volumes of precipitation intermittently during a normally very dry period (i.e. during a $-\mathrm{AMO}$ and $+\mathrm{ENSO}$ dry season) may be a contributing mechanism to the formation of IADFs. Although not noted in their publication, the IADFs observed in a study of $P$. elliottii var. densa cambial activity by Harley et al. (2012) corresponded to an in influx of 
precipitation. The limited dendrometer data also supports the assumption that the growth of South Florida P. elliottii var. densa is strongly tied to moisture availability (Langdon 1963; Fichtler et al. 2010; Harley et al. 2011), suggesting that the trees will have a rapid and positive response to the addition of precipitation. This opportunistic growth response could contribute to the appearance of IADFs during unusually wet winters, when cell production may be triggered by unexpected moisture input (Vieira at al. 2009). The increase in water availability encourages growth and cell differentiation and leads to the production of earlywood cells within the latewood tree-ring (Wimmer et al., 2000; De Micco et al, 2007).

\subsection{Conclusions}

The dendrochemistry of tree-rings can provide more information about physiologic responses to climate drivers and individual tree site conditions than ring width measurements, particularly in trees that have complicated ring structures. The $\delta^{13} \mathrm{C}$ composition of the $P$. elliottii var. densa cellulose had strong first-order responses to the major climate oscillations controlling seasonal precipitation, but the microenvironment surrounding the tree, ultimately dictated the scale of that response. The dynamics and salinity of the fresh water lens, the most significant source of water for the P. elliottii var. densa trees, is primarily controlled by precipitation patterns influenced by global teleconnections and the tree's position relative to the most variable edge of the lens will affect its seasonal transpiration.

Trees contain a breadth of information and finding ways to decode the dendrochemical data grants access to a greater array of climate information. The relationship between environmental conditions and the nature of the assimilated carbon can have important implications for studying the interrelated effects of the teleconnections of multi-scale climate oscillations and their resultant precipitation patterns over timescales that transcend the instrumental records. Future work with the 
P. elliottii var. densa trees on Big Pine Key could focus on extending the high-resolution carbon isotope chronology and constructing a site-specific model to predict precipitation patterns under different combinations of the climate oscillations at telescoping scales. For example, a mircocoring study could be used to measure responses to precipitation on biweekly or monthly scales and the results could help refine the interpretation of a biannual dendrochronology study, such as this one.

\subsection{References}

Ali, A., Abtew, W., Van Horn, S. \& Kahanl, N. (2000). Temporal and spatial characterization of rainfall over Central and South Florida. Journal of the American Water Resources Association, 36(4), $833-848$.

Anderson, W. T., Sternberg, L. S. L., Pinzon, M. C., Gann-Troxler, T., Childers, D. L., \& Duever, M. (2005). Carbon isotopic composition of cypress trees from South Florida and changing hydrologic conditions. Dendrochronologia, 23(1), 1-10.

Bates, D., Maechler, M., Bolker, B., \& Walker, S. (2015). Fitting Linear Mixed-Effects Models U sing lme4. Journal of Statistical Software, 67(1), 1-48.

Beckage, B., Platt, W. J., Slocum, M. G., \& Panko, B. (2003). Influence of the El Nino Southern Oscillation on fire regimes in the Florida Everglades. Ecology, 84(12), 3124-3130.

Bergh, C., \& Wisby, J. (1996). Fire history of Lower Keys pine rocklands. Nature Conservancy, Florida Keys Initiative.

Carbon Dioxide Information Analysis Center. (2014). Carbon-13 in CO ${ }^{2}$. U.S. Department of Energy and Oak Ridge National Laboratory, web. http://cdiac.esd.ornl.gov/

Cattelino, P. J., Becker, C. A., \& Fuller, L. G. (1986). Construction and installation of homemade dendrometer bands. Northern Journal of Applied Forestry, 3(2), 73-75.

Coniglio, M., \& Harrison, R. S. (1983). Facies and diagenesis of late Pleistocene carbonates from Big Pine Key, Florida. Bulletin of Canadian Petroleum Geology, 31(3), 135-147.

Cook, E. R., \& Kairiukstis, L. A. (Eds.). (1990). Methods of dendrochronology: applications in the environmental sciences. Springer Science \& Business Media

Coplen, T. B. (1994). Reporting of stable hydrogen, carbon, and oxygen isotopic abundances. Pure and Applied Chemistry, 66, 273-273.

De Micco, V., Saurer, M., Aronne, G., Tognetti, R., \& Cherubini, P. (2007). Variations of wood anatomy and $\delta 13 \mathrm{C}$ within-tree-rings of coastal Pinus pinaster showing intra-annual density fluctuations. Iawa Journal, 28(1), 61-74. 
Donders, T. H., Wagner, F., Dilcher, D. L., \& Visscher, H. (2005). Mid-to late-Holocene El NinoSouthern Oscillation dynamics reflected in the subtropical terrestrial realm. Proceedings of the National Academy of Sciences of the United States of America, 102(31), 1090410908.

Donders, T. H. (2014). Middle Holocene humidity increase in Florida: Climate or sealevel? Quaternary Science Reviews, 103, 170-174.

Duever, M. J., Meeder, J. F., Meeder, L. C., \& McCollom, J. M. (1994). The climate of south Florida and its role in shaping the Everglades ecosystem. Everglades: The ecosystem and its restoration, 225-248.

Duncan, W. H., \& Duncan, M. B. (1988). Trees of the southeastern United States (Vol. 18). University of Georgia Press.

Enfield, D. B., Mestas-Nuñez, A. M., \& Trimble, P. J. (2001). The Atlantic multidecadal oscillation and its relation to rainfall and river flows in the continental US. Geophysical Research Letters, 28(10), 2077-2080.

Evans, M. N., \& Schrag, D. P. (2004). A stable isotope-based approach to tropical dendroclimatology. Geochimica et Cosmochimica Acta, 68(16), 3295-3305.

Farquhar, G. D., Ehleringer, J. R., \& Hubick, K. T. (1989a). Carbon isotope discrimination and photosynthesis. Annual review of plant biology, 40(1), 503-537.

Farquhar, G. D., Hubick, K. T., Condon, A. G., \& Richards, R. A. (1989b). Carbon isotope fractionation and plant water-use efficiency. In Stable isotopes in ecological research (pp. 21-40). Springer New York.

Fichtler, E., Helle, G., \& Worbes, M. (2010). Stable-carbon isotope time series from tropical treerings indicate a precipitation signal. Tree-Ring Research, 66(1), 35-49.

Francey, R. J., \& Farquhar, G. D. (1982). An explanation of 13C/12C variations in tree-rings. Nature 297, 28-31.

Friedli, H., Lötscher, H., Oeschger, H., Siegenthaler, U., \& Stauffer, B. (1986). Ice core record of the C-13/C-12 ratio of atmospheric CO2 in the past two centuries. Nature, 324, 237.

Gebrekirstos, A., Worbes, M., Teketay, D., Fetene, M., \& Mitlöhner, R. (2009). Stable carbon isotope ratios in tree-rings of co-occurring species from semi-arid tropics in Africa: patterns and climatic signals. Global and Planetary Change, 66(3), 253-260.

Glock, W. S. (1955). II. Growth rings and climate. The Botanical Review,21 (1-3), 73-188.

Gray, S. T., Graumlich, L. J., Betancourt, J. L., \& Pederson, G. T. (2004). A tree-ring based reconstruction of the Atlantic Multidecadal Oscillation since 1567 AD. Geophysical Research Letters, 31(12). 
Gray, W. M. (1984). Atlantic seasonal hurricane frequency. Part I: El Niño and $30 \mathrm{mb}$ quasibiennial oscillation influences. Monthly Weather Review, 112(9), 1649-1668.

Green, J. W. (1963). (3) Wood Cellulose. In Methods in carbohydrate chemistry, vol. 3: cellulose (pp. 9-20). Academic Press.

Grogan, J., \& Schulze, M. (2012). The impact of annual and seasonal rainfall patterns on growth and phenology of emergent tree species in southeastern Amazonia, Brazil. Biotropica, 44(3), 331-340.

Halley, R. B., \& Harris, P. M. (1979). Fresh-water cementation of a 1,000-year-old oolite. Journal of Sedimentary Research, 49(3).

Hannachi, A. (2004). A primer for EOF analysis of climate data. Department of Meteorology, University of Reading. UK.

Hannachi, A., Jolliffe, I. T., \& Stephenson, D. B. (2007). Empirical orthogonal functions and related techniques in atmospheric science: A review. International Journal of Climatology, 27(9), 1119-1152.

Hanson, K., \& Maul, G. A. (1991). Florida precipitation and the Pacific El Niño, 19851989. Florida Scientist FLSCAQ, 54(3/4).

Harley, G. L., Grissino-Mayer, H. D., Franklin, J. A., Anderson, C., \& Köse, N. (2012). Cambial activity of Pinus elliottii var. densa reveals influence of seasonal insolation on growth dynamics in the Florida Keys. Trees, 26(5), 1449-1459.

Harley, G. L., Grissino-Mayer, H. D., \& Horn, S. P. (2011). The dendrochronology of Pinus elliottii in the lower Florida Keys: chronology development and climate response. Tree-Ring Research, 67(1), 39-50.

Hoffmeister, J. E., \& Multer, H. G. (1968). Geology and origin of the Florida Keys. Geological Society of America Bulletin, 79(11), 1487-1502.

Hoffmeister, J. E. (1974). Land from the sea: the geologic story of South Florida. University of Miami Press.

Jury, M., Malmgren, B. A., \& Winter, A. (2007). Subregional precipitation climate of the Caribbean and relationships with ENSO and NAO. Journal of Geophysical Research: Atmospheres, 112(D16).

Karamperidou, C., Engel, V., Lall, U., Stabenau, E., \& Smith III, T. J. (2013). Implications of multi-scale sea level and climate variability for coastal resources. Regional Environmental Change, 13(1), 91-100.

Knudsen, M. F., Seidenkrantz, M. S., Jacobsen, B. H., \& Kuijpers, A. (2011). Tracking the Atlantic Multidecadal Oscillation through the last 8,000 years. Nature Communications, 2, 178.

Langdon, O. G. (1963). Growth Patterns of Pinus elliotti Var. densa. Ecology, 44(4), 825-827. 
Leavitt, S. W., \& Long, A. (1991). Seasonal stable-carbon isotope variability in tree-rings: possible paleoenvironmental signals. Chemical Geology: Isotope Geoscience section, 87(1), 59-70.

Libby, L. M., \& Pandolfi, L. J. (1974). Temperature dependence of isotope ratios in treerings. Proceedings of the National Academy of Sciences, 71(6), 2482-2486.

Little, E. L., \& Dorman, K. W. (1952). Slash pine (Pinus elliottii), its nomenclature and varieties. Journal of Forestry, 50(12), 918-923.

Livezey, R. E., Masutani, M., Leetmaa, A., Rui, H., Ji, M., \& Kumar, A. (1997). Teleconnective response of the Pacific-North American region atmosphere to large central equatorial Pacific SST anomalies. Journal of Climate, 10(8), 1787-1820.

Loader, N. J., McCarroll, D., Gagen, M. H., Robertson, I., \& Jalkanen, R. (2007). Extracting climatic information from stable isotopes in tree-rings. Stable isotopes as indicators of ecological change. Terrestrial Ecology Series/Ed. Dawson, T. \& Siegwolf, R. Academic Press, New York

Managave, S. R., \& Ramesh, R. (2012). Isotope dendroclimatology: A review with a special emphasis on tropics. In Handbook of Environmental Isotope Geochemistry (pp. 811-833). Springer Berlin Heidelberg.

McCarroll, D., \& Loader, N. J. (2004). Stable isotopes in tree-rings. Quaternary Science Reviews, 23(7), 771-801.

McCarroll, D., Gagen, M. H., Loader, N. J., Robertson, I., Anchukaitis, K. J., Los, S., ... \& Waterhouse, J. S. (2009). Correction of tree-ring stable carbon isotope chronologies for changes in the carbon dioxide content of the atmosphere. Geochimica et Cosmochimica Acta, 73(6), 1539-1547.

Miller, D. L., Mora, C. I., Grissino-Mayer, H. D., Mock, C. J., Uhle, M. E., \& Sharp, Z. (2006). Tree-ring isotope records of tropical cyclone activity. Proceedings of the National Academy of Sciences, 103(39), 14294-14297.

Misra, V., \& DiNapoli, S. M. (2013). Understanding the wet season variations over Florida. Climate dynamics, 40(5-6), 1361-1372.

Mora, C., Frazier, A. G., Longman, R. J., Dacks, R. S., Walton, M. M., Tong, E. J., ... \& Ambrosino, C. M. (2013). The projected timing of climate departure from recent variability. Nature, 502(7470), 183-187.

Moses, C. S., Anderson, W. T., Saunders, C., \& Sklar, F. (2013). Regional climate gradients in precipitation and temperature in response to climate teleconnections in the Greater Everglades ecosystem of South Florida. Journal of paleolimnology, 49(1), 5-14.

National Climate Data Center (NCDC). (2010). NOAA climate data inventories for Florida. NOAA Satellite and Information Service, web. http://www.csc.noaa.gov/ 
National Oceanic and Atmospheric Administration (NOAA). (2013a). Climate indices: monthly atmospheric and ocean time series. Earth System Research Laboratory, web. http://www.esrl.noaa.gov/

National Oceanic and Atmospheric Administration (NOAA). (2013b). El Niño / Southern Oscillation cold and warm episodes by season. National Weather Service Climate Prediction Center, web. http://www.cpc.ncep.noaa.gov/

National Oceanic and Atmospheric Administration (NOAA). (2013c). Tropical cyclones records page. Hurricane Research Division Atlantic Oceanography and Meteorological Laboratory, web. http://www.aoml.noaa.gov

National Oceanic and Atmospheric Administration (NOAA). (2014). Florida Keys climatology. National Weather Service Weather Forecast Office, web. http://www.srh.noaa.gov/

Oberbauer, S. F., Kariyawasam, P. S., \& Burch, J. N. (1997). Comparative analysis of growth, nutrition, carbon isotope ratios, and hurricane-related mortality of slash pines in south Florida. Florida Scientist, 60(4), 210-222.

Ogurcak, D. E. (2015). The effect of disturbance and freshwater availability on Lower Florida Keys' coastal forest dynamics (Unpublished doctoral dissertation). Florida International University, Miami, Florida.

O'Leary, M. H. (1988). Carbon isotopes in photosynthesis: fractionation techniques may reveal new aspects of carbon dynamics in plants. Bioscience, 38(5), 328-336.

Pearman, G. I., Francey, R. J., \& Fraser, P. J. B. (1976). Climatic implications of stable carbon isotopes in tree-rings. Nature, 260(5554), 771-773.

Peel, M. C., Finlayson, B. L., \& McMahon, T. A. (2007). Updated world map of the Köppen-Geiger climate classification. Hydrology and earth system sciences discussions, 4(2), 439-473.

Poussart, P. F., Evans, M. N., \& Schrag, D. P. (2004). Resolving seasonality in tropical trees: multidecade, high-resolution oxygen and carbon isotope records from Indonesia and Thailand. Earth and Planetary Science Letters, 218(3), 301-316.

Prospero, J. M., \& Lamb, P. J. (2003). African droughts and dust transport to the Caribbean: Climate change implications. Science, 302(5647), 1024-1027.

Prospero, J. (2011). Long-term trends in African dust transport to the Caribbean: African sources, changing climate, and future scenarios. Welcome to Bremen!!! 10, 17.

R Core Team (2016). R: A language and environment for statistical computing. R Foundation for Statistical Computing, Vienna, Austria. URL https://www.R-project.org/.

RStudio Team (2015). RStudio: Integrated Development for R. RStudio, Inc., Boston, MA URL h ttp://www.rstudio.com/. 
Ross, M. S., O'Brien, J. J., \& Flynn, L. J. (1992). Ecological site classification of Florida Keys terrestrial habitats. Biotropica, 488-502.

Ross, M. S., O'Brien, J. J., \& da Silveira Lobo Sternberg, L. (1994). Sea-Level Rise and the Reduction in Pine Forests in the Florida Keys. Ecological Applications, 4(1), 144-156.

Ross, M. S., \& Ruiz, P. (1996). A study of the distribution of several South Florida endemic plants in the Florida Keys. Unpublished report to the US Fish and Wildlife Service. Southeast Environmental Research Program, Florida International University, Miami.

Ross, M. S., O'Brien, J. J., Ford, R. G., Zhang, K., \& Morkill, A. (2009). Disturbance and the rising tide: the challenge of biodiversity management on low-island ecosystems. Frontiers in Ecology and the Environment, 7(9), 471-478.

Sah, J. P., Ross, M. S., Snyder, J. R., \& Ogurcak, D. E. (2010). Tree mortality following prescribed fire and a storm surge event in slash pine (Pinus elliottii var. densa) forests in the Florida Keys, USA. International Journal of Forestry Research, 2010.

Sanchez, C., Gaiser, E. E., Saunders, C. J., Wachnicka, A. H., Oehm, N., \& Craft, C. (2013). Challenges in using siliceous subfossils as a tool for inferring past water level and hydroperiod in Everglades marshes. Journal of paleolimnology, 49(1), 45-66.

Saunders, C. J., Gao, M., Lynch, J. A., Jaffé, R., \& Childers, D. L. (2006). Using soil profiles of seeds and molecular markers as proxies for sawgrass and wet prairie slough vegetation in Shark Slough, Everglades National Park. Hydrobiologia, 569(1), 475-492.

Saurer, M., Siegenthaler, U., \& Schweingruber, F. (1995). The climate-carbon isotope relationship in tree-rings and the significance of site conditions. Tellus B, 47(3), 320-330.

Saurer, M., Borella, S., \& Leuenberger, M. (1997). $\delta^{18} \mathrm{O}$ of tree-rings of beech (Fagus silvatica) as a record of $\delta 18 \mathrm{O}$ of the growing season precipitation. Tellus $B, 49(1), 80-92$.

Schmidt, N., Lipp, E. K., Rose, J. B., \& Luther, M. E. (2001). ENSO influences on seasonal rainfall and river discharge in Florida. Journal of Climate, 14(4), 615.

Sheil, D. (2003). Growth assessment in tropical trees: large daily diameter fluctuations and their concealment by dendrometer bands. Canadian Journal of Forest Research, 33(10), 2027 2035 .

Sittel, M. C. (1994). Marginal probabilities of the extremes of ENSO events for temperature and precipitation in the southeastern United States. Center for Ocean-Atmosphere Prediction Studies. Florida State University.

Sternberg, L. D. S. L., Pinzon, M. C., Vendramini, P. F., Anderson, W. T., Jahren, A. H., \& Beuning, K. (2007). Oxygen isotope ratios of cellulose-derived phenylglucosazone: an improved paleoclimate indicator of environmental water and relative humidity. Geochimica et Cosmochimica Acta, 71(10), 2463-2473. 
Tans, G. \& Keeling, R. (2016). Trends in atmospheric carbon dioxide from Earth System Research Laboratory Global Monitoring System. http://www.esrl.noaa.gov/gmd/ccgg/trends/

Tomlinson, P. B., \& Craighead, F. C. (1972). Growth-ring studies on the native trees of sub-tropical Florida. Ghouse, A, K, M, Yunus, $M$ ed $(s)$. Research trends in plant anatomy. Reprint, 4894, 39-51.

Trapp, J. M., Millero, F. J., \& Prospero, J. M. (2010). Temporal variability of the elemental composition of African dust measured in trade wind aerosols at Barbados and Miami. Marine Chemistry, 120(1), 71-82.

United States Fish and Wildlife Service (USFWS). (1999). South Florida Multi-Species Recovery Plan: Pine Rocklands. United States Fish and Wildlife Service, Atlanta.

United States Naval Observatory (USNO). 2014. Sun or moon rise/set table for one year. Astronomical Applications Department, web. http://aa.usno.navy.mil/.

Vacher, H. L., Wightman, M. J., \& Stewat M. T. (1992). Hydrology of meteoric diagenesis: effect of Pleistocene stratigraphy on freshwater lenses of Big Pine Key, Florida. In Quaternary coasts of the United States: marine and lacustrine systems v 48. (pp. 213-219). Society of Economic Paleontologists and Mineralogists Special Publications.

Wachnicka, A., Gaiser, E., Collins, L., Frankovich, T., \& Boyer, J. (2010). Distribution of diatoms and development of diatom-based models for inferring salinity and nutrient concentrations in Florida Bay and adjacent coastal wetlands of south Florida (USA). Estuaries and Coasts, 33(5), 1080-1098.

Watts, W. A., and B. C. S. Hanson. (1988). Environments of Florida in the Late Wisconsin and Holocene. In Burdy, B. (ed) Wet site archeology. Telford Press, NJ Caldwell. 307-323.

Wightman, M. J. (1990). Geophysical analysis and Dupuit-Ghyben-Herzberg modeling of freshwater lenses on Big Pine Key, Florida (Unpublished Master of Science thesis). University of South Florida, Tampa, Florida.

Willard, D. A., \& Bernhardt, C. E. (2011). Impacts of past climate and sea level change on Everglades wetlands: placing a century of anthropogenic change into a late-Holocene context. Climatic Change, 107(1-2), 59-80.

Wimmer, R., Strumia, G., \& Holawe, F. (2000). Use of false rings in Austrian pine to reconstruct early growing season precipitation. Canadian Journal of Forest Research, 30(11), 16911697.

Winkler, M. G., Sanford, P. R., \& Kaplan, S. W. (2001). Hydrology, vegetation, and climate change in the southern Everglades during the Holocene. Bulletins of American Paleontology, $57-$ 100 .

Worbes, M. (2002). One hundred years of tree-ring research in the tropics-a brief history and an outlook to future challenges. Dendrochronologia, 20(1), 217-231. 
Xu, Y., Holmes, C. W., \& Jaffé, R. (2007). Paleoenvironmental assessment of recent environmental changes in Florida Bay, USA: A biomarker based study. Estuarine, Coastal and Shelf Science, 73(1), 201-210. 


\subsection{Figures}

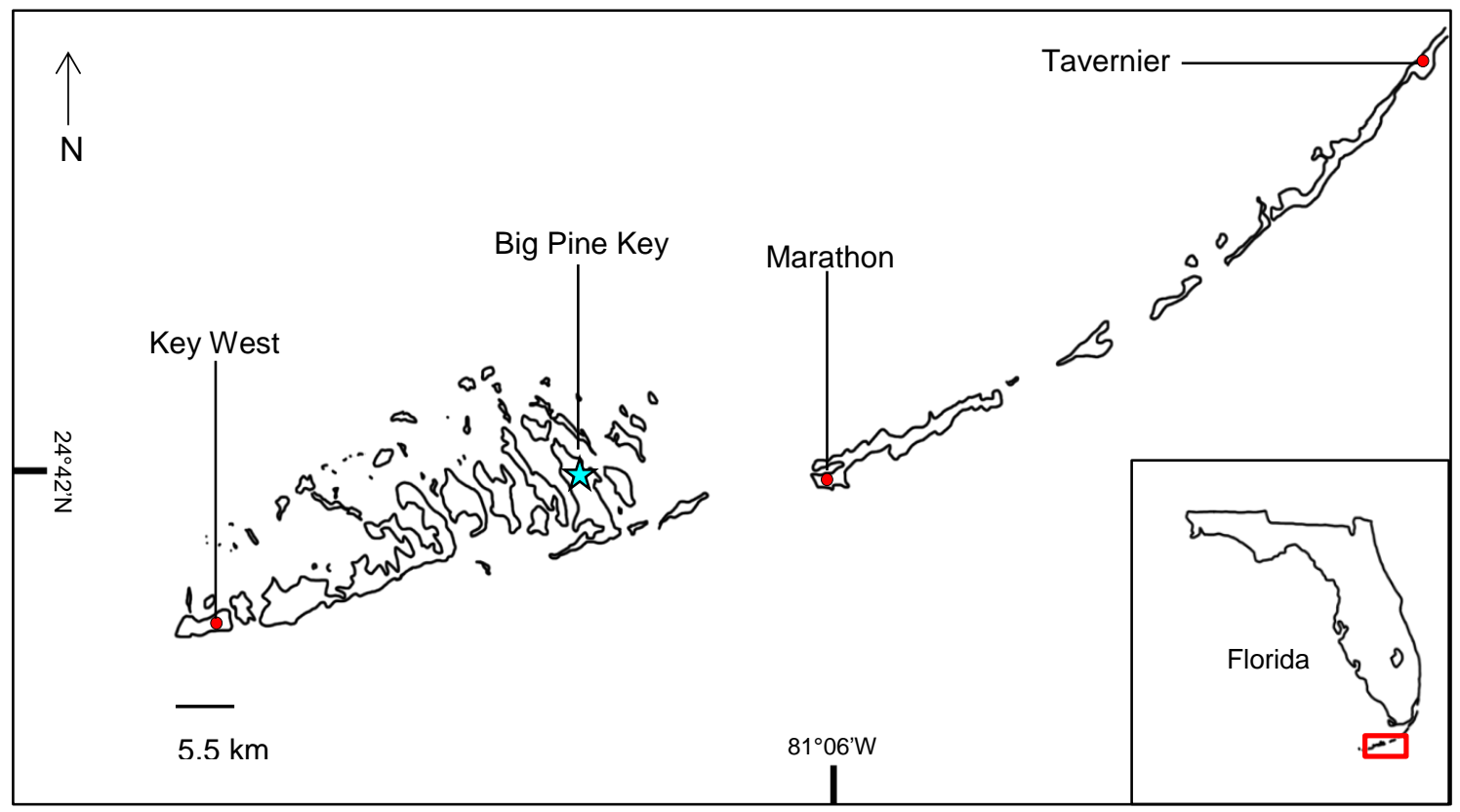

Figure 3.1 Map of the Middle and Lower Florida Keys showing the sampling site on Big Pine Key (blue star) and the locations of the three nearest, historically continuous climate stations; Key West, Marathon, and Tavernier (red circles). The red box in the inset shows the area of the Florida Keys referenced. 

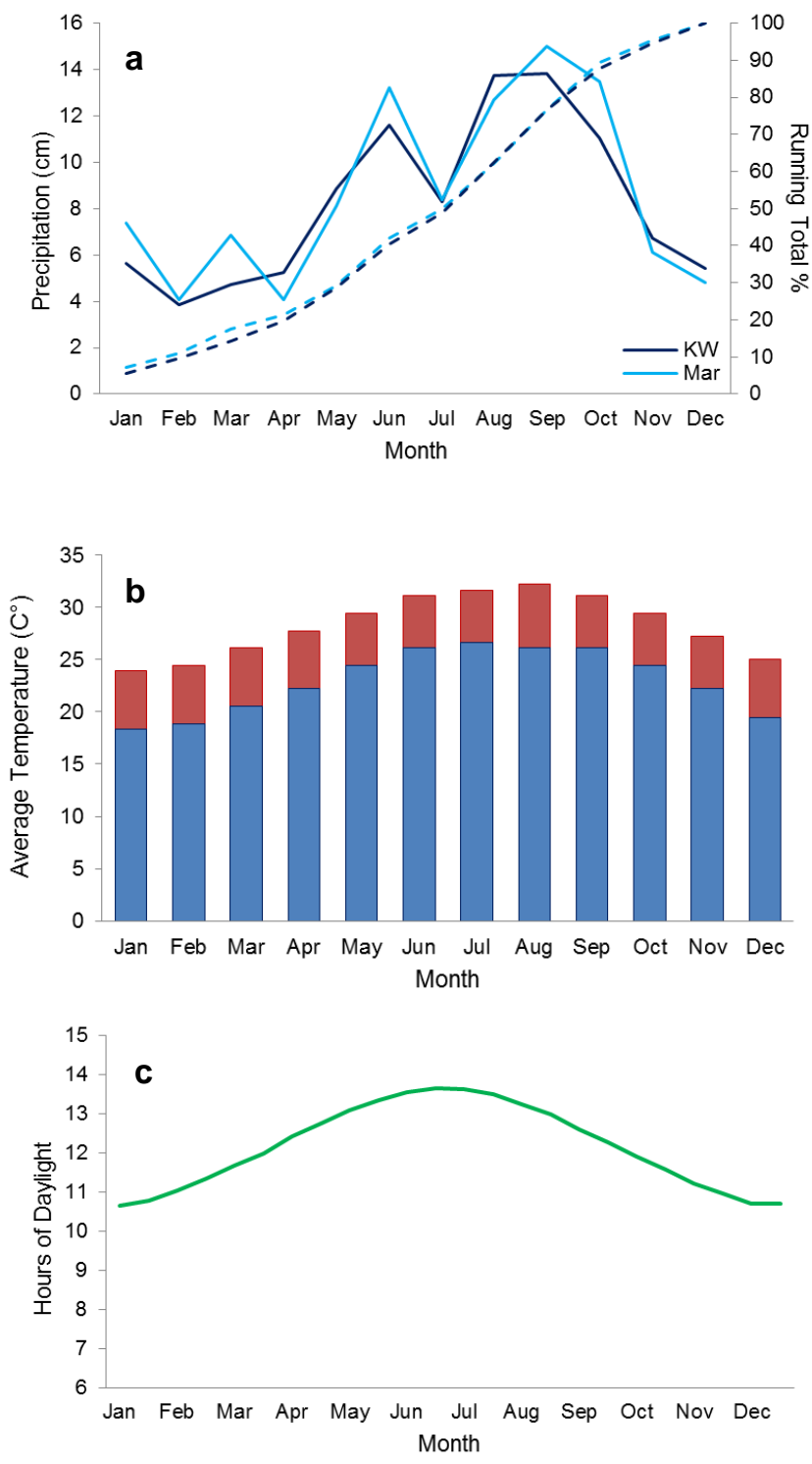

Figure 3.2 The Average Annual Climatologies for the Lower Florida Keys. (1970-2010) a) The average monthly precipitation (in $\mathrm{cm}$ ) for the two long-term climate stations nearest to Big Pine Key: Key West (KW) and Marathon (Mar) (solid lines). The dashed lines show the running cumulative total percentage of monthly precipitation for each station. b) The average monthly maximum (red) and minimum (blue) temperatures for the Lower Keys. The data shown here is from the Key West station. The corresponding data for the Marathon station varies $\pm 0.5 \mathrm{C}^{\circ}$ except for January when minimum temperature is $1 \mathrm{C}^{\circ}$ lower than Key West. c) Hours of daylight for the $15^{\text {th }}$ of each month. The maximum difference in daylight hours between Key West and Marathon is \pm 1 minute. Precipitation and temperature data from NOAA and daylight data are from the USNO. 

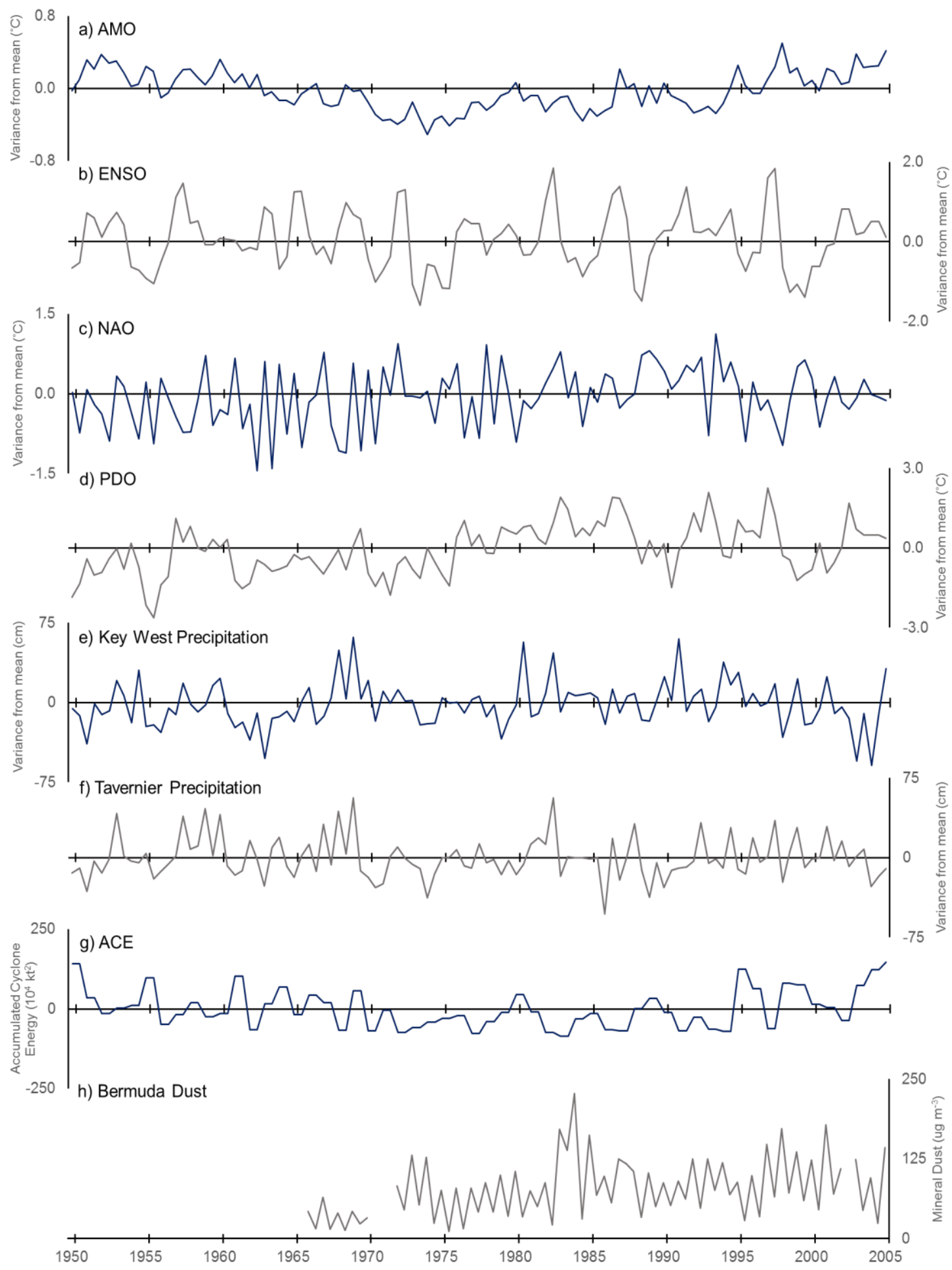

Figure 3.3 See caption on the following page. 
Figure 3.3 Time series for the climate variables used in the EOF analyses. All data have be converted into wet (May - October) and dry (November-following April) season values. The reported monthly sea surface temperature anomalies for each of the four large-scale climate oscillations (a-d) have been averaged into biannual values. Daily precipitation data from the two longest and most continuously recording climate stations (e-f) have been converted into monthly values. The monthly precipitation values were averaged over for the period 1950-2005 and the deviation from the mean was calculated for each month before data were averaged into seasonal values. The yearly data for Accelerated Cyclone Energy (g), have not been treated, but the values have been repeated to conform to the biannual scheme of the datasets. The Bermuda dust record (h) is from Prospero and Lamb (2006) and Prospero (2011). The gaps in the dust record were filled with a dummy constant for the analyses and the biannual values were calculated by summing the corresponding monthly totals. 
a. 1.0

Ring Width

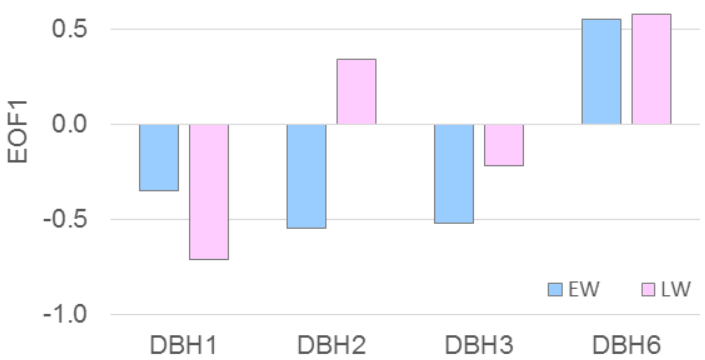

b. 1.0

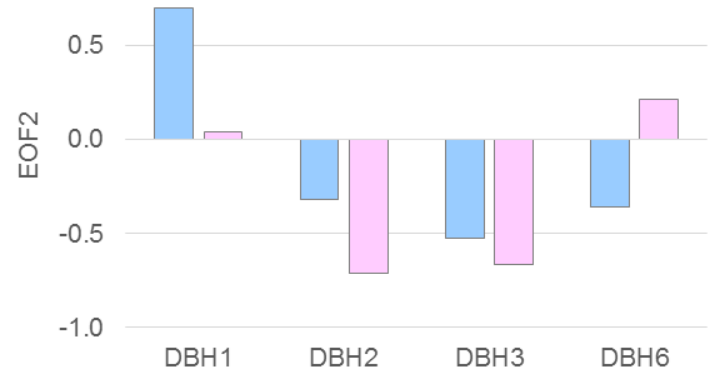

C. 1.0

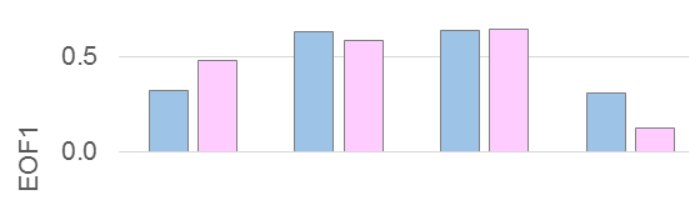

$-0.5$

$-1.0$

$\begin{array}{llll}\text { DBH1 } & \text { DBH2 } & \text { DBH3 } & \text { DBH6 }\end{array}$

d. 1.0

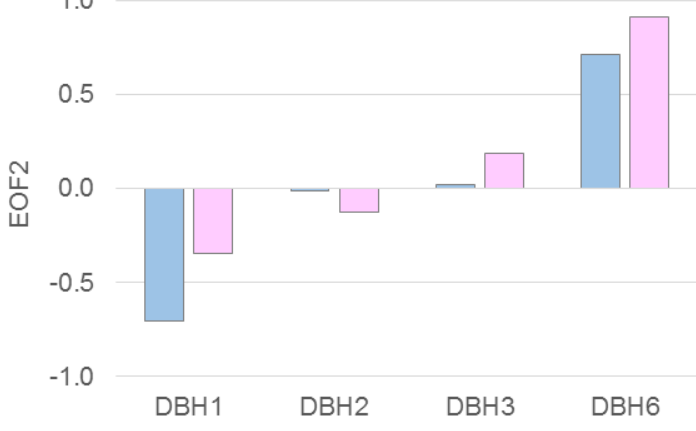

\begin{tabular}{lcc}
\hline \% Variance & EOF1 & EOF2 \\
\hline \hline EW Ring Width & 31.7 & 27.2 \\
LW Ring Width & 33.2 & 26.5 \\
EW $\delta 13 C$ & 43.1 & 28.9 \\
LW $\delta 13 C$ & 39.3 & 26.4 \\
\hline
\end{tabular}

$\delta^{13} \mathrm{C}$ Values

Figure 3.4 The first two EOFs for ring width (a-b) and $\delta^{13} \mathrm{C}$ values (c-d) for both the earlywood (EW) and latewood (LW) portions of each of the four P. elliottii var. densa trees. The percentage of the variance explained by each EOF is in the table to the right. 
a.

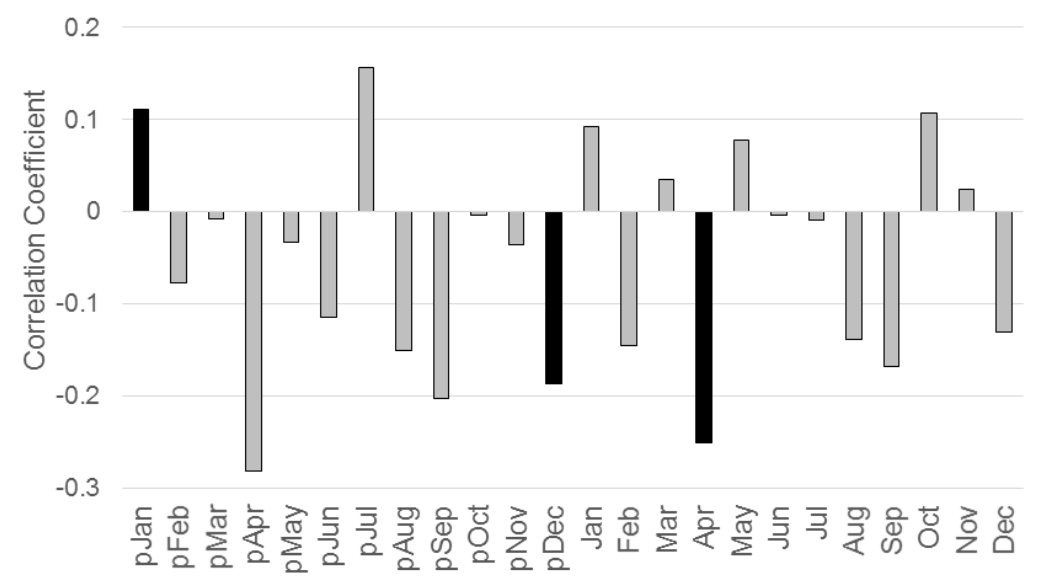

0.3 b.

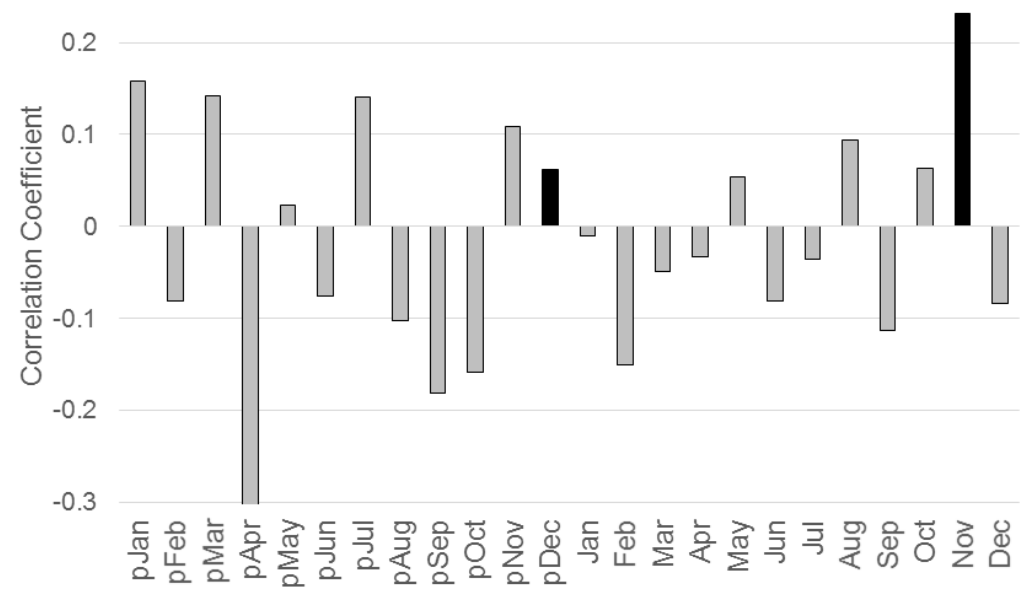

Figure 3.5 Pearson correlation coefficients for the $\delta^{13} \mathrm{C}$ values for a) earlywood and $\mathbf{b}$ ) latewood and monthly precipitation from previous January ( $\mathrm{pJan}$ ) to current December. Black bars indicate months with statistically significant $p$-values ( $p$-value $\leq 0.05)$. 
a. 1.0

ENSO

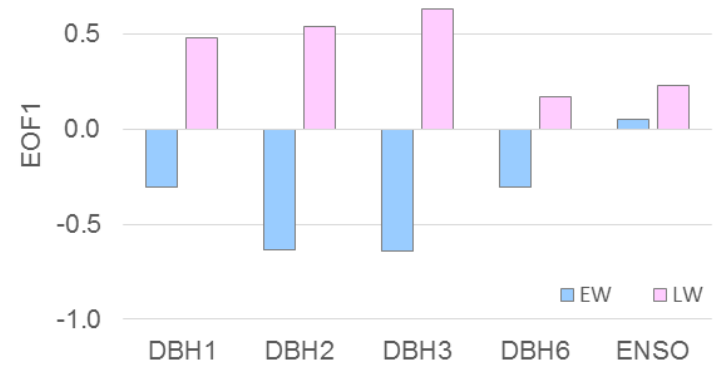

b.

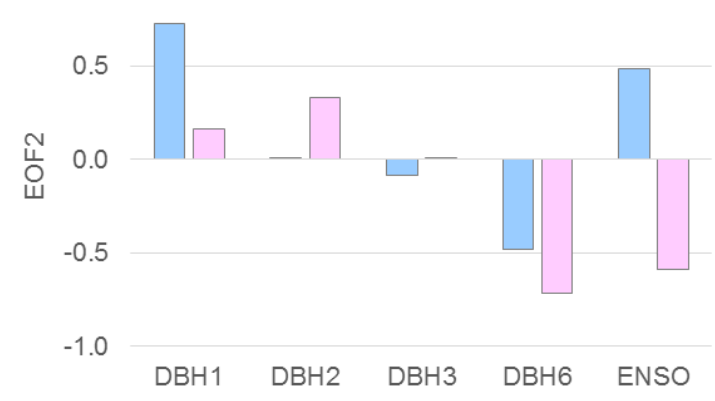

C. 1.0

AMO

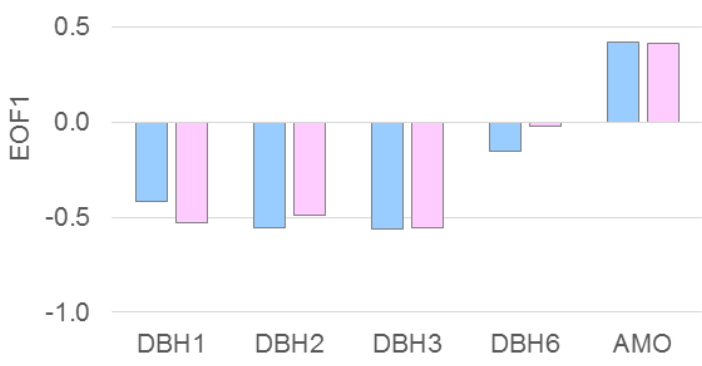

d. 1.0

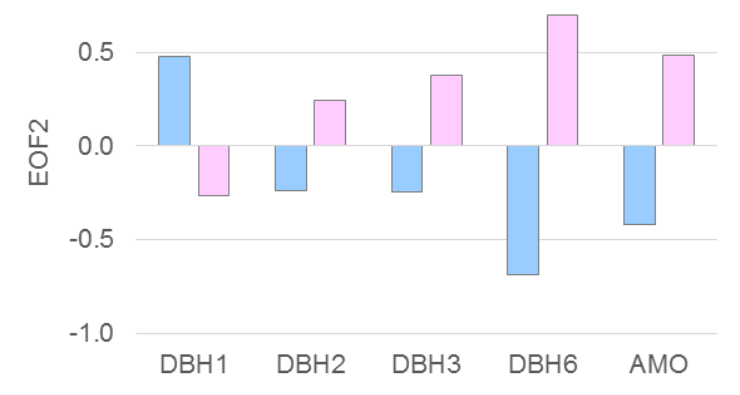

Figure 3.6 The first two EOFs comparing the carbon isotope records for the individual tree to ENSO (a-b) and the AMO (c-d) for both the earlywood (EW) and latewood (LW) components of the tree-rings. The percentage of the variance explained by each EOF is in the table to the right.

\begin{tabular}{lcc}
\hline \% Variance & EOF1 & EOF2 \\
\hline \hline EW ENSO & 34.5 & 23.8 \\
LW ENSO & 32.1 & 22.6 \\
EW AMO & 37.9 & 26.3 \\
LW AMO & 34.0 & 23.5 \\
\hline
\end{tabular}




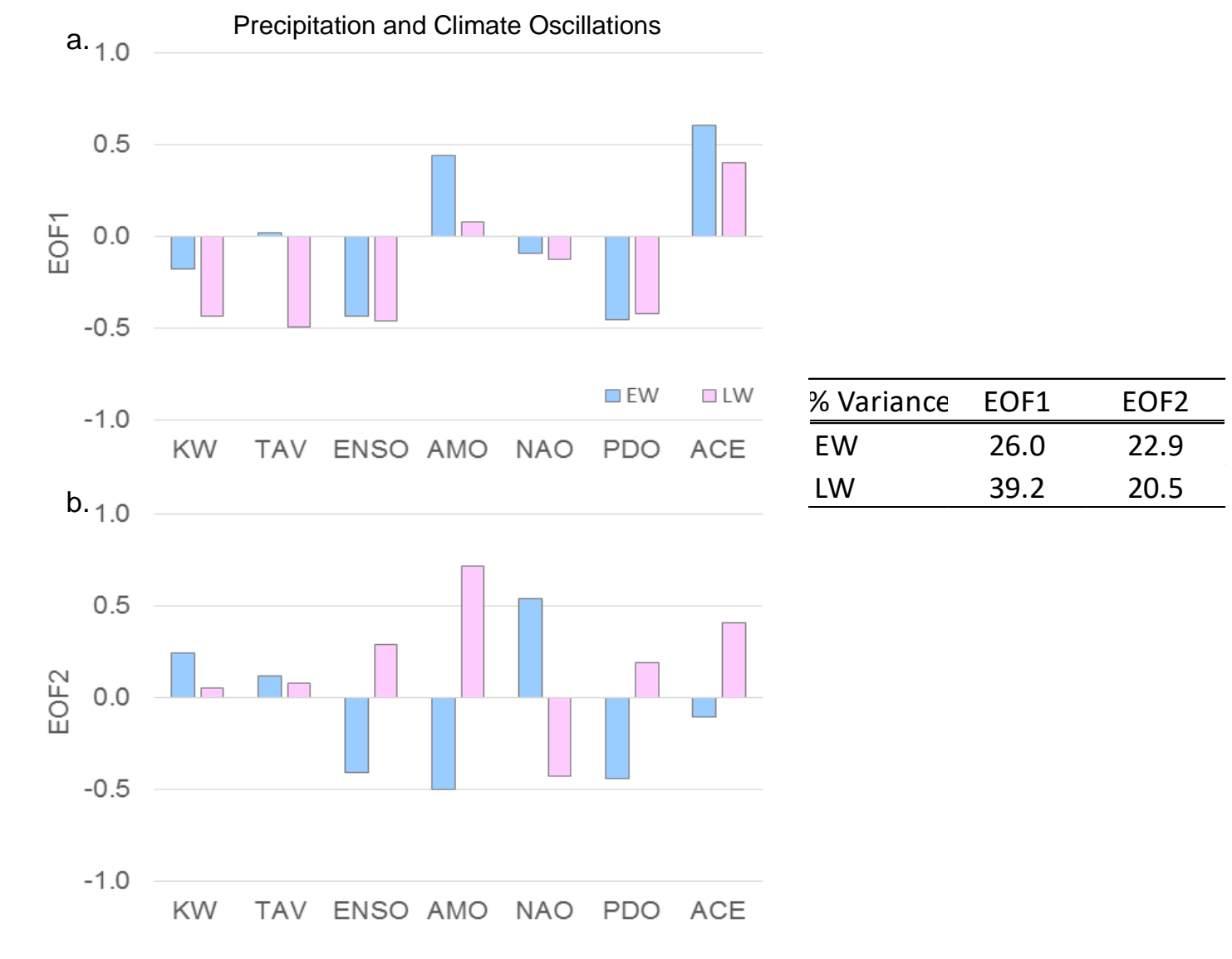

Figure 3.7 The leading eigenvector a) and the secondary eigenvector b) comparing precipitation in the Florida Keys to the major climate cycles and hurricane records. The percent variance for each EOF is shown in the table. KW= Key West precipitation record. TAV = Tavernier precipitation records. $\mathrm{NAO}=$ North Atlantic Oscillation. $\mathrm{PDO}=$ Pacific Decadal Oscillation. ACE =Accumulated Cyclone Energy. 


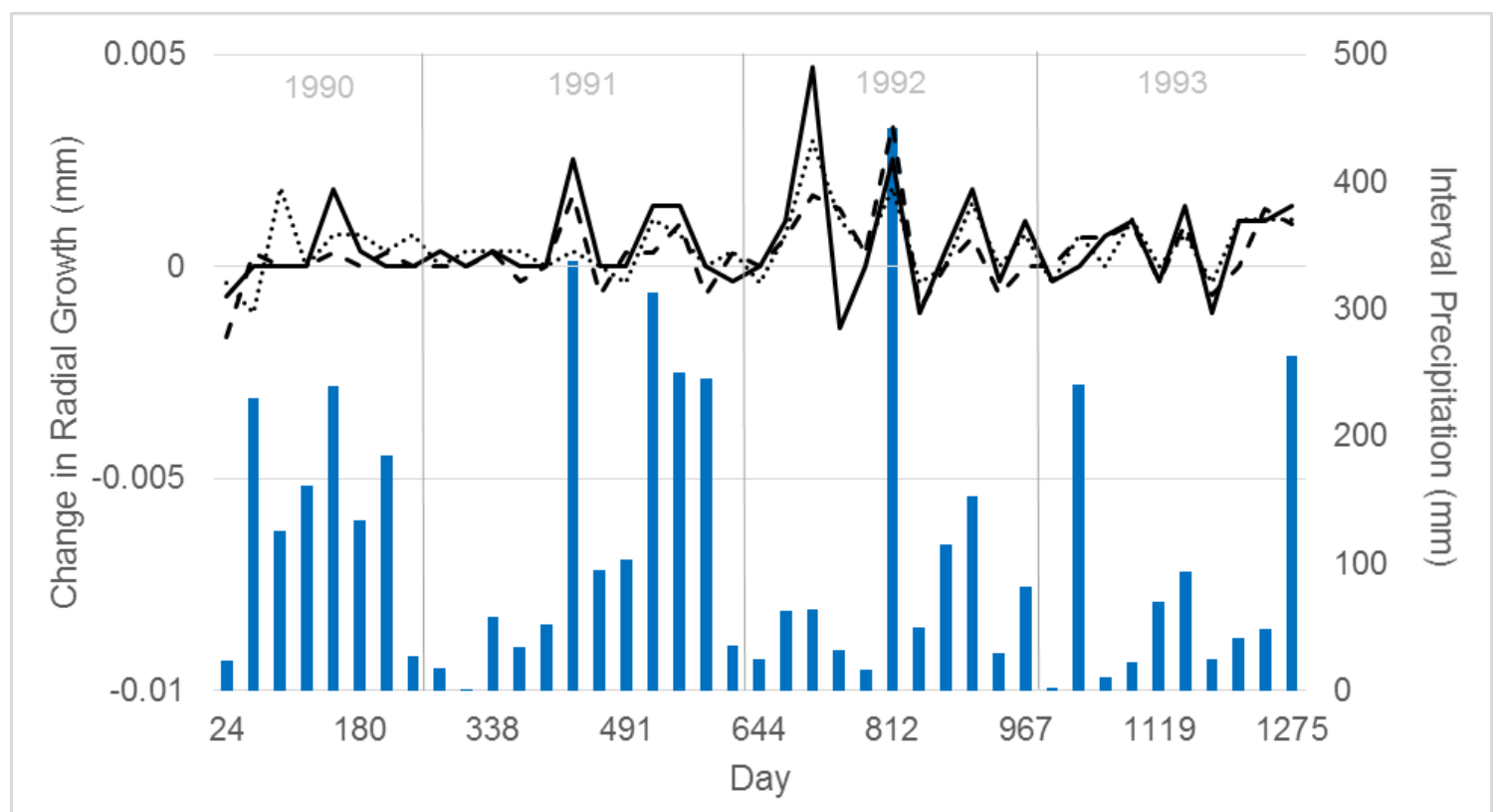

Figure 3.8 Changes in radial growth for the three trees (black lines) used in the dendrometer study and the corresponding cumulative precipitation (blue bars) for each sampling interval. The change in radial growth is defined as the difference (in $\mathrm{mm}$ ) in the dendrometer readings between successive sampling periods. Precipitation values are the cumulative daily totals (in $\mathrm{mm}$ ) as reported by the Key West station. The dates have been converted to sampling days, where day zero $(04 / 20 / 1990)$ represents the date of dendrometer installation and day 1275 is end of the study $(10 / 07 / 1993)$. For reference, vertical gray lines have been added to show the calendar years. 

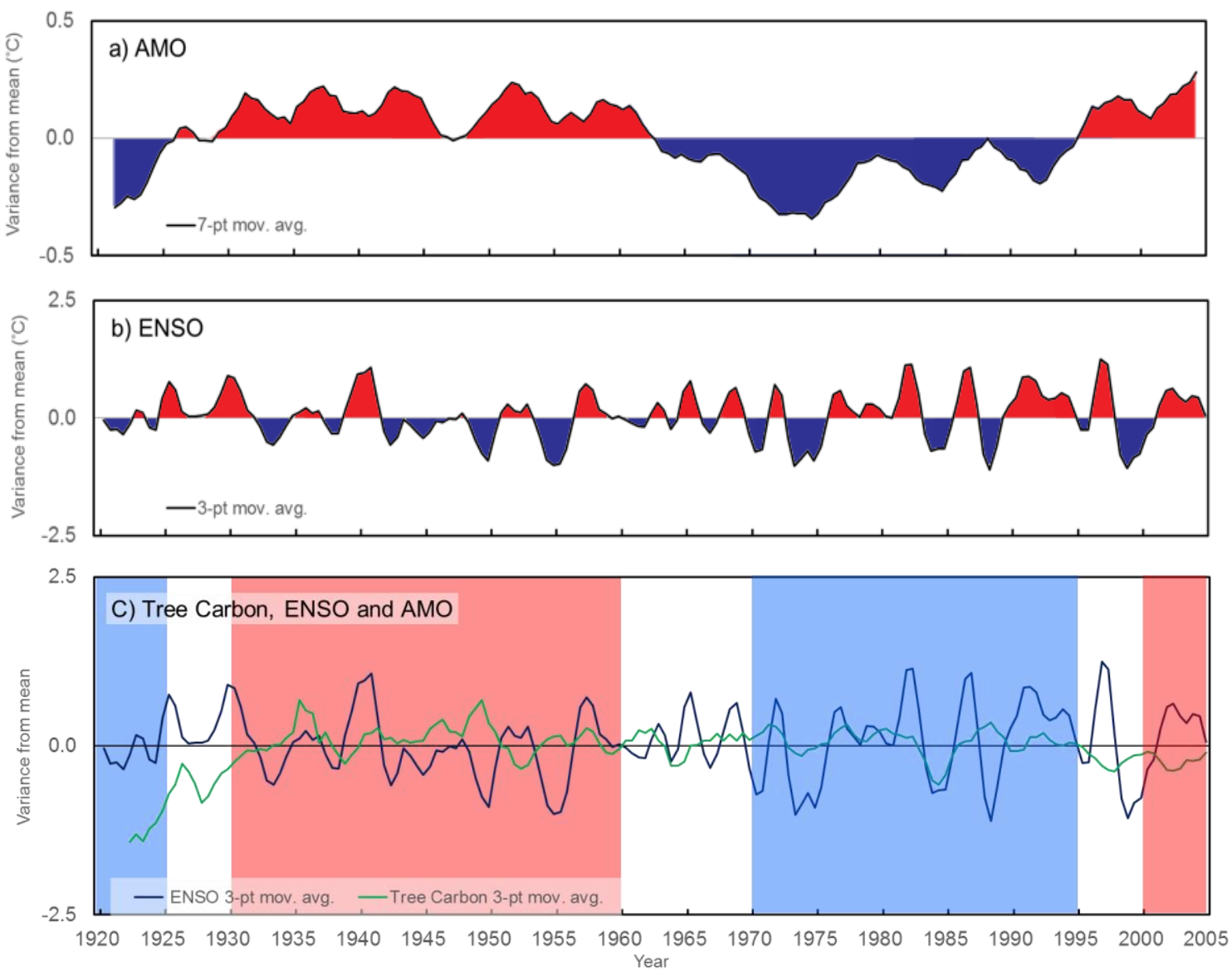

Figure 3.9 The major climate drivers of South Florida precipitation and the $\delta^{13} \mathrm{C}$ composite index from 1922-2005. The phases of a) the AMO (shown with a 7-point moving average) and b) ENSO (3-point moving average) are shown in red for the positive and blue for the negative phase. c) Graph of the $\delta^{13} \mathrm{C}$ composite index (green line) and ENSO (blue line), both shown with a 3-point moving average. The warm (red) and cool (blue) phases of the AMO are represented by the colored bars. The white bars are the transitions between the positive and negative phases (See table 3.1 for definition). The nature of the relationship between the $\delta^{13} \mathrm{C}$ composite index and ENSO is variable and may depend on prevailing phase of the AMO. 
a) Earlywood

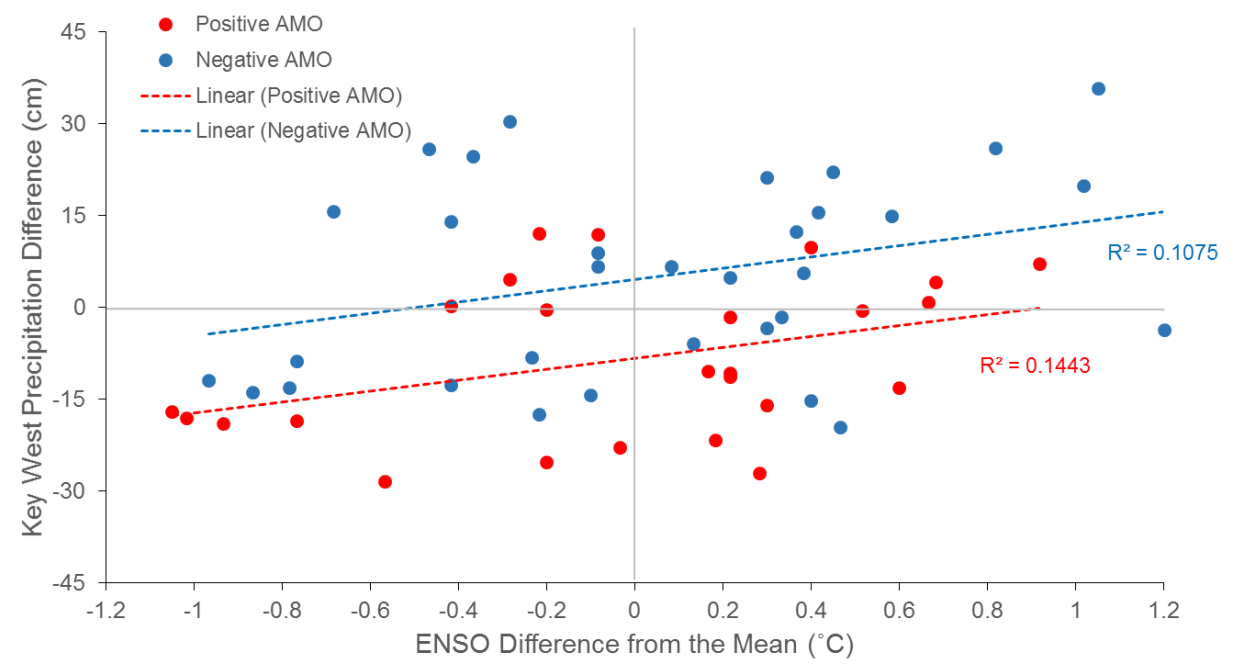

b) Latewood

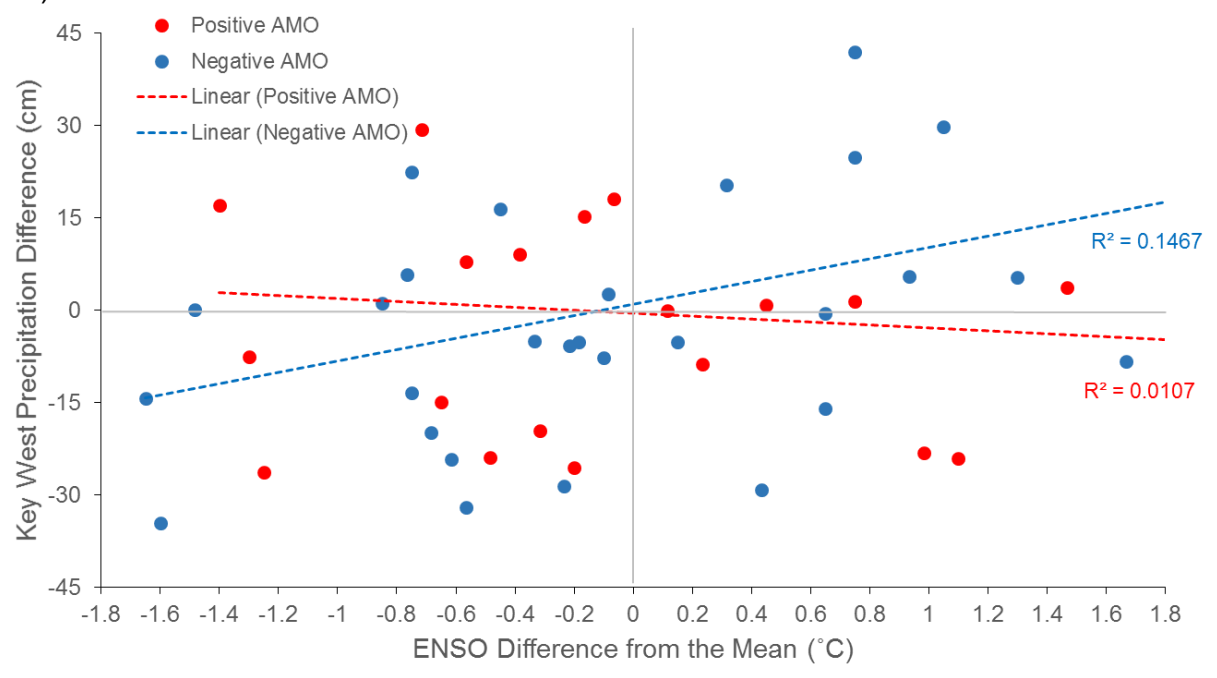

Figure 3.10 The relationship between ENSO and Key West precipitation under both phases of the AMO for the earlywood a) and the latewood seasons $\mathbf{b}$ ). In both graphs, red indicates the positive phase of the AMO, while blue represents the negative phase. 


\subsection{Tables}

Table 3.1: AMO Phase Interpretations and Sources

\begin{tabular}{|c|c|c|}
\hline Source & Phases & Method \\
\hline Enfield et al., 2001 & $\begin{array}{l}-1965-1994 \\
+1930-1959\end{array}$ & $\begin{array}{l}\text { Constructed a } 10 \text { year running mean of global SST } \\
\text { anomalies from Kaplan et al., } 1998 \text { for the period } \\
1920-1995 .\end{array}$ \\
\hline Grey et al., 2004 & $\begin{array}{l}-1971-1979 \\
+1925-1970 \\
-1903-1924\end{array}$ & $\begin{array}{l}1567-1990 \text { proxy record derived from tree-ring } \\
\text { chronologies }\end{array}$ \\
\hline Knudsen et al., 2011 & $\begin{array}{c}\text { + 1998- present } \\
\text { - 1956-1997 } \\
+1925-1964 \\
+1880-1924\end{array}$ & $\begin{array}{l}\text { Subtracted the annual global mean SST anomalies } \\
\text { from HadISST from the annual mean North Atlantic } \\
\text { SST for the period } 1870-2008 \text {. }\end{array}$ \\
\hline Figure 3.9 & $\begin{array}{c}\text { + 1996- present } \\
\text { - 1963-1995 } \\
+1929-1963 \\
\text { - } 1920-1926\end{array}$ & $\begin{array}{l}\text { Monthly Kaplan SST V2 anomaly data for 1920- } \\
2006 \text { from the NCDC, grouped into wet (May-Oct) } \\
\text { and dry seasons (Nov-following Apr) and smoothed }\end{array}$ \\
\hline
\end{tabular}

Table 3.1 AMO Phase Interpretations and Sources. A list of sources and their respective methods used to define the phases of the AMO. 
Table 3.2 Results of the Linear Mixed Effects Model

\begin{tabular}{lccccc}
\hline Fixed Effects & Estimate & Std. Error & df & t-value & p-value \\
\hline Interval Precip & $9.82 \mathrm{E}-05$ & $2.03 \mathrm{E}-05$ & $1.21 \mathrm{E}+02$ & 4.826 & $4.10 \mathrm{E}-06^{* * *}$ \\
30 Day Precip & $9.90 \mathrm{E}-05$ & $2.13 \mathrm{E}-05$ & $1.21 \mathrm{E}+02$ & 4.659 & $8.2 \mathrm{E}-06^{* * *}$ \\
60 Day Precip & $2.44 \mathrm{E}-05$ & $1.58 \mathrm{E}-05$ & $1.21 \mathrm{E}+02$ & 1.539 & 0.1265 \\
\hline
\end{tabular}

Table 3.2 Results of the Linear Mixed Effects Model. Results of the LME model used to compare changes in radial tree growth measured by dendrometers and cumulative precipitation at different intervals. Tree growth and precipitation were the fixed effects and tree ID was considered a

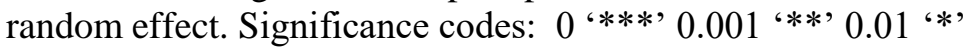


CHAPTER 4: TROPICAL CYCLONE ACTIVITY RECORDED IN PINUS ELLIOTTII TREERINGS ON A SUBTROPICAL ISLAND IN THE FLORIDA KEYS

\subsection{Abstract}

The science of extreme event attribution is an emerging field; however, the lack of high-resolution spatial and temporal paleoclimate data greatly reduces the applicability of the science to the field of tropical cyclone research. The slash pine, Pinus elliottii Engelm. var. densa, of the Lower Florida Keys are potentially invaluable repositories of past tropical cyclone activity; the nature of tree-ring growth allows for perfect annual to sub-annual resolution and the trees are in a prime location to record storms originating from the Atlantic Ocean, the Caribbean Sea, and the Gulf of Mexico. Previous studies for trees along the Atlantic Coastal Plain and the Gulf Coast of the United States have shown that coastal pines integrate tropical cyclone-derived precipitation as depletions in their oxygen isotope $\left(\delta^{18} \mathrm{O}\right)$ records. In order to determine if this relationship between tree-ring cellulose $\delta^{18} \mathrm{O}$ values and tropical cyclone activity extends to South Florida, I conducted a stable isotopedendrochronological study of four trees from Big Pine Key. Latewood cellulose samples were analyzed for $\delta^{18} \mathrm{O}$ over the period 1922-2005. The trees showed some variability in their individual oxygen isotope chronologies; however, small differences in their overall average $\delta^{18} \mathrm{O}$ values $( \pm$ $1 \%$ ) indicated that the trees were utilizing the same source waters. Applying a $100 \mathrm{~km}$ radius around Big Pine Key, the composite $\delta^{18} \mathrm{O}$ residual record successfully associated $56 \%$ of the depleted residual values $(\leq-0.1)$ with known tropical cyclone activity. The percentage increased to $66 \%$ when the radius was increased to $225 \mathrm{~km}$. Carbon isotopes were also considered in both the latewood samples and the earlywood samples of the following year. Storm intensity dictated which isotope residual captured the event. Tropical depressions and cyclones can produce significant amounts of rain and resulted in the overall most depleted $\delta^{18} \mathrm{O}$ residuals in the record (up to -0.6). The minor (categories 1-2) and major hurricanes (categories 3-5) could potentially show a depleted $\delta^{18} \mathrm{O}$ residual value; but, instead, were more likely to have an enriched $\delta^{13} \mathrm{C}$ residual value in the 
earlywood of the following year. These enrichments could be the result of storm surge, such as in 2005, but, lack of evidence of storm surges during the corresponding years, suggests that wind damage is the cause. Of the 25 tropical cyclones that occurred from 1922-2005, six were not recorded by the tree-ring cellulose. The lack of representation in the $\delta^{18} \mathrm{O}$ residual record was likely an effect of a mild tropical cyclone impact or, as in the case of Hurricane Wilma (2005), the dampening of the precipitation signature by subsequent evaporative-enrichment of the soil water. Additionally, four years appeared as false positives (residual value $\leq-0.1$ ) in the $\delta^{18} \mathrm{O}$ residual record, but were lacking documentation of nearby tropical cyclone activity. Three of these years occurred during the positive phase of El Niño Southern Oscillation (ENSO) and the depleted oxygen isotope values could be a result of changes in atmospheric circulation pattern from El Niño or they could be the result of precipitation from far-reaching rain bands of tropical cyclones situated over the Yucatan Peninsula.

\subsection{Introduction}

Recently, several studies have been published on the emerging field of extreme event attribution. The relatively new science aims to conclusively link individual extreme and record-setting weather events such as floods, heat-waves, and superstorms to atmospheric forcings brought about by global climate change. For example, in the first study of its kind, Schaller et al. (2016) found that changes in atmospheric composition related to human activity increased the probability of a low pressure area coupled with increased zonal flow forming in the North Atlantic. The greater likelihood of these factors occurring concurrently led to extreme precipitation and subsequent property damage in England in 2014 (Schaller et al., 2016). Complications in attributing the occurrence of extreme weather events to climate change arise when there are uncertainties in the definition of what would be considered the natural climate variability of a system versus anthropogenically-induced climate change (Trenberth et al., 2015; Stott et al., 2016). Erraticism in the magnitude and frequency of 
some extreme weather events, such as anomalously low and high temperatures or precipitation, influenced by climate change can be distinguished from normal climate fluctuations (Cornwall, 2016; NASEM, 2016). Yet, highly destructive hurricanes and typhoons are relatively small on a global scale and too complex to model as a result of incomplete and historically limited records (Cornwall, 2016; NASEM, 2016).

While all extreme weather events can result in significant damage and property loss, hurricanes and tropical cyclones accounted for over $47 \%$ of the weather and climate related damage in the United States between 1980 and 2011 (Smith and Katz, 2013). The impacts of coastal hazards (sea level rise and hurricanes) are expected to increase as the population increases and additional people relocate to coastal settings (Nicholls et al., 2007; Crossett et al., 2013). At present, the coastlines, which account for $10 \%$ of the land area in the United States, are home to $39 \%$ of the population and that number is expected to continue to increase over the next several decades (Crossett et al., 2013). Excessive urbanization along the coasts has resulted in a disproportionally high percentage of people and property exposed to the immediate effects of climate change. Miami and New York City are among the top three world coastal cities with assets vulnerable to climate and weather related damage, with the combined present-day values exceeding $\$ 335$ billon (Hanson et al., 2011). There is an immediate need for risk-reduction planning for several of the major cities along the Eastern coast of the United States (Hanson et al., 2011); however, the challenges in predicting the future behavior of destructive tropical cyclone activity make it difficult to construct accurate models (Cornwall, 2016).

There does not seem to be a consensus on how the frequency and intensity of tropical cyclone activity will be affected by climate change. The tropical Atlantic has warmed over several tenths of a degree Celsius in the last few decades, but it is unknown how this increase in temperature will 
affect cyclogenesis (Santer et al., 2006). There have been conflicting reports on the frequency, intensity, duration, rainfall projections, and track probability of future hurricane seasons under the projected warmer sea surface temperature scenarios (Mann and Emanuel, 2006; Landsea, 2007; Mann et al., 2009; Knutson et al., 2010). The specific details aside, many forecasting models converge to indicate a shift to lower frequency, but higher intensity storms in an atmosphere with projected 2100 greenhouse gas concentrations (Knutson et al., 2010). Disagreements among scientists concerning the uncertainties in Atlantic Basin tropical cyclone behavior are likely related to the quality and availability of the source data used in model calculations.

Many of the issues with forecasting future trends of tropical cyclone activity and with the attribution of changes in tropical cyclone behavior to climate change stem from incomplete historical data before the era of aircraft reconnaissance and satellite-based meteorology. Without an established baseline of tropical cyclone cyclicity under multiple climate oscillation regimes, it is difficult to extract current trends in activity. It has been argued that the number of tropical cyclones occurring before 1940 may have been underestimated, particularly if the storm made landfall near a sparsely populated area, and that current estimates of historical tropical cyclone counts may not represent the true multidecadal variability (Landsea, 2007; Vecchi and Knutson, 2008). Pre-1940 records of tropical cyclone data are limited temporally and spatially and rely on the historical record keeping in ship logs, newspaper reports, and diaries. Some areas, such as South Carolina, have very detailed and complete records and allow for local reconstruction back to the 1770's (Mock, 2004); however, this level of detail appears to be an exception for the Gulf Coast and Atlantic Seaboard (Landsea, 2007; Mann et al., 2009; Hippensteel, 2010).

The historical instrumental records have been supplemented and extended through the analysis of geologic proxy archives in marginal marine settings (Liu and Fearn, 2000; Hippensteel, 2010). The 
science of paleotempestology (Emanuel, 2003) utilizes the appearance of marine overwash deposits (tempestites) in coastal ponds and marshes (Liu, 2007; Wang and Horwitz, 2007; Liu and Fearn, 2000; Hippensteel, 2010) and beach ridge storm deposits (Nott and Hayne, 2001) to reconstruct past tropical cyclone landfalls. Tempestite deposits have been useful in reconstructing millennial scale variability in tropical cyclone impacts; however, they are limited in number, must be carbon dated, and require relatively large storms that are powerful enough to push detectable volumes of sediment inland (Liu and Fearn, 2000; Liu, 2007; Mann et al., 2009). Speleothems (Frappier et al, 2007), corals (Hetzinger et al., 2008) and tree-rings (Miller et al., 2006) have been used to refine the resolution to decadal and multidecadal timescales. It is possible to achieve annual resolution in the growth bands of speleothems and corals; however, both are restricted to specific geographic areas. Therefore, tree-rings may provide the best option for a widespread, high-resolution proxy for past tropical cyclone impact reconstructions.

Recent isotope-dendrochronology studies along the Atlantic Coastal Plain and the Gulf of Mexico have shown that anomalies in the oxygen isotope composition of tree-ring cellulose correlate to the passage of tropical cyclones (Miller et al., 2006; Nelson, 2008; Lewis, 2009). In a proof of concept study, Miller et al., 2006, compared the occurrence of ${ }^{18} \mathrm{O}$-depleted oxygen isotope values in seasonally-resolved tree-ring cellulose with the available historical records for a site in southern Georgia. A strong correlation was found between negative oxygen isotope residuals and hurricanes occurring within $400 \mathrm{~km}$ of the sampling site with documented localized rainfall over the period 1940-1997 (Miller et al., 2006). The 220-year study also compared well with the historical documentation for southern Georgia before the era of modern instrumental records and discovered potential evidence of previously undocumented tropical cyclone activity in the region. One such event, the Great Hurricane of 1780, one of the most deadly Atlantic hurricanes on record, passed through the Eastern Caribbean and was suspected to have impacted the United States; however, no 
prior evidence had been found (Sandrik and Landsea 2003; Miller et al., 2006). Subsequent studies conducted in the Florida Panhandle and South Carolina (Nelson, 2008) and Texas (Lewis, 2009) have had similar success in detecting historical tropical cyclone activity, as well as, showing decadal to multidecadal variability in precipitation and seasonal moisture stress (Miller et al., 2006; Brienen et al, 2012) The degree to which the trees at each site corresponded to the instrumental record varied; however, this new method shows promise as a viable addition to the tropical cyclone proxy archive.

The subtropical region, particularly around the Caribbean Sea, is notoriously underrepresented in dendrochronology studies; however, it holds promise as a vast repository of paleotempestology archives. Just to the north, on the boundary of the Caribbean Sea region, lies the Florida Keys archipelago, which extends roughly $200 \mathrm{~km}$ southeast into the Straits of Florida between the United States mainland and the island of Cuba. The Florida Keys are in a unique geographical location because their adjacency to two warm, regulatory water bodies, the Gulf Stream and the Gulf of Mexico, gives them a mild, tropical-maritime climate and an increased likelihood of experiencing tropical cyclone activity originating from the Atlantic Ocean, the Gulf of Mexico, or the Caribbean Sea. The dominant pine rockland canopy species found in the Lower Florida Keys is the slash pine, Pinus elliottii Engelm. var. densa, which has been shown to produce visible dateable rings (Tomlinson and Craighead, 1972; Harley et al., 2011). The subtropical P. elliottii var. densa trees have the potential of recording tropical cyclone activity occurring in both the Atlantic and Gulf of Mexico basins. Not all hurricanes have equal effects on the land they pass depending on a multitude of variables, i.e. the distance, speed, and direction of the storm at its closest approach, and some storms produce damaging winds but very little precipitation. Therefore, combining both the carbon and oxygen isotope records in $P$. elliottii var. densa tree-rings could provide a more complete picture of the tropical cyclone activity around the northern Caribbean Sea region. 


\subsubsection{Dendrochemistry}

Trees are potentially invaluable sources of paleoclimate data. They have a wide spatial distribution, offer data in perfect annual resolution, and many species are sensitive to small changes in their environment. Andrew Douglass, the "father of dendrochronology" (Schweingruber, 1988), was one of the first researchers to recognize and explore the potential of using tree-ring width as a proxy for the reconstruction of variability in past climate (Fritts, 1976). He observed that radial growth in pines was frequently limited by climate; specifically, that pines growing in the American Southwest produced narrow rings in the years experiencing regional drought conditions (Douglass, 1909; 1920). Douglass developed the method of crossdating, where distinct patterns in tree-ring growth are matched in increasingly older samples, to allow for the construction of annually-resolved chronologies that extend beyond the age of the oldest living trees sampled (Fritts, 1976). However, individual and site-wide index data derived from ring width measurements alone may not capture the nuances of the tree-environment interactions, particularly in environments such as the tropics where seasonality may not be characterized by a regular dormancy period (Worbes, 2002; McCarroll and Loader, 2004). The addition of stable isotope analyses to dendrochronology studies can provide insight into the biochemical cycles governing tree growth during each season in the life of a tree and can be used to infer multi-scale variability in the paleoclimate record (Saurer et al., 1997).

The oxygen isotope composition of cellulose is largely controlled by three factors: 1) the combined isotopic composition of the source waters utilized by the tree over time (Epstein et al., 1977), 2) the evaporative enrichment of leaf water from transpiration (Dongmann et al., 1974), and 3) the biological fractionation between cellulose and water and the exchange of oxygen atoms during the transfer of sucrose from the leaf to the cellulose production site (Sternberg et al., 1989). There is no fractionation associated with the uptake of source water by the roots; however, during 
transpiration, large fractionations can occur in the leaf causing the leaf water to be enriched in $\delta^{18} \mathrm{O}$ relative to the source water (Rodan et al., 2000; Anderson et al., 2002). The oxygen isotope composition of the sucrose produced in the $\delta^{18} \mathrm{O}$ enriched environment of the leaves is further modified through oxygen exchange with the unfractionated source water in the xylem prior to cellulose synthesis (Sternberg et al. 1989). The physiological effects of oxygen fixation should be relatively constant for the trees growing in the same area, so any fluctuations in the oxygen isotope record should reflect isotopic variability in the source waters and, therefore, not require a correction factor (Anderson et al. 2002). When looking for tropical cyclone activity preserved in tree-rings, the absolute values of the oxygen isotopes are less important than the relative relationships among the values from season to season.

The carbon isotope composition of cellulose records regulatory responses by the plant to changes in the environment (Francey and Farquhar, 1982; O'Leary, 1988) and it may be used to determine sustained periods of sub-optimal growth experienced by the tree. The carbon isotopic composition of cellulose is controlled by the fractionation of atmospheric carbon dioxide (the source of carbon in plants) as it diffuses through the stomata of leaves during photosynthesis (O'Leary, 1988). Variations in $\delta^{13} \mathrm{C}$ values of tree-ring cellulose reflect temporal changes in environmental conditions or climate patterns, such as fluctuations in available soil moisture content, temperature, or precipitation (Pearman et al., 1976; Farquhar et al., 1989; Leavitt and Long, 1991). Chapter 3 gives a detailed description of the process of carbon fixation and the potential causes of variability in the $\delta^{13} \mathrm{C}$ record. The addition of the carbon isotope record to the oxygen isotope-derived tropical cyclone identification method establish by Miller et al. (2006) may provide additional information about the nature of the storm at the time of impact. For example, a tropical cyclone may have high winds or cause a damaging storm surge on Big Pine Key without producing significant amounts of precipitation. The oxygen isotope record may not record the event; however, if the tree was 
damaged in such a way that would require it to enter a mode of increased water use efficiency for a sustained period in time, the stress response would stand out in the carbon isotope record.

\subsubsection{Oxygen isotopes in meteoric water}

The oxygen isotope value of cellulose is a result of the isotopic compositions of the source waters accessed by the plant (Epstein et al., 1977). Trees may obtain their water from the soil, the groundwater supply, a nearby body of surface water, or any combination of these. The dynamics of the hydrologic cycle dictates the distribution of the oxygen isotopes among its phases and each water source has a distinct and characteristic isotopic signature (Dansgaard, 1964; Gat, 1996). The oceans are the largest reservoirs of surface water and are thus the main contributors to global evaporation (Dansgaard, 1964). Given its primary role in the global hydrologic cycle, ocean water was chosen as the reference standard for oxygen isotope analysis (Craig, 1961).

There are three naturally occurring isotopes of oxygen, ${ }^{16} \mathrm{O},{ }^{17} \mathrm{O}$ and ${ }^{18} \mathrm{O}$, with relative abundances of $99.76 \%, 0.04 \%$ and $0.20 \%$, respectively (Dole, 1949; Hoefs, 1997). Traditionally, the ratio between ${ }^{18} \mathrm{O}$ and ${ }^{16} \mathrm{O}$ is measured during isotope analysis and, most commonly, VSMOW (Vienna Standard Mean Ocean Water) is used as the international standard to which all samples are compared (Craig, 1961; Coplen, 1994). The strength of the chemical bonds vary slightly among the isotopes and differences in the amount of energy required to break the bonds results in fractionation, or the partial separation of the heavy isotope, ${ }^{18} \mathrm{O}$, from the light isotope, ${ }^{16} \mathrm{O}$ (Hoefs, 1997). Equilibrium fractionation of ${ }^{18} \mathrm{O}$ isotopes is temperature dependent (Majoube, 1971) and the process follows the rule of thermodynamics where systems in equilibrium will maintain a state of minimum energy with the ${ }^{18} \mathrm{O}$ molecules occupying the medium where they are most heavily bound (Urey, 1947; Gat, 1996). Kinetic fractionation occurs when the chemical bonds of the lighter ${ }^{16} \mathrm{O}$ are broken more easily through unidirectional diffusion (Gat et al., 2001). 
The strongly coupled oceanic and atmospheric circulation patterns are responsible for the distribution of ${ }^{18} \mathrm{O}$ in reservoirs around the planet. The kinetic fractionation process of evaporation results in water vapor that is isotopically depleted in ${ }^{18} \mathrm{O}$ compared to the source water body (Dansgaard, 1964). The vapor cools and condenses into clouds that are isotopically enriched relative to the vapor surrounding them and Rayleigh distillation controls the isotopic composition of precipitation throughout the lifecycle of a cloud (Dansgaard, 1964). The proportion of heavier isotopes in precipitation decreases with condensation temperature and ${ }^{18} \mathrm{O}$ is more likely to be "rained out" leaving the remaining cloud condensate increasingly more depleted with each rain event over time (Dansgaard, 1964). As a result, precipitation is isotopically variable ( +5 to $-55 \%$, globally, Rozanski et al., 1993; Helsen, 2006) spatially and temporally depending on the distance and latitudinal gradient from the evaporative source, the topography of the land, seasonality, and the amount effect (Rozanski et al., 1993; Dansgaard, 1964). The isotopic signature of soil water is constantly changing in response to cycles of precipitation and subsequent enrichment in the upper soil column through evaporation (Tang and Feng, 2001). Groundwater tends to be more temporally isotopically stable because it generally has a long residence time and represents the average of rain events over several seasons (Gat, 1996).

\subsubsection{Tropical cyclone development and precipitation}

The nature of tropical cyclone development and their propagation across large expanses of warm, subtropical ocean water results in precipitation that is characteristically depleted in ${ }^{18} \mathrm{O}$ (Lawrence and Gedzelman, 1996). Tropical cyclones (i.e. tropical depressions, tropical storms, and hurricanes) are large, 250-600 $\mathrm{km}$ in diameter, convective storms that are characterized by low pressure cores and counter-clockwise (in the northern hemisphere) spiraling rotation (Neumann, 1993; NHC, 2016). Atlantic systems generally originate between $10^{\circ}$ and $20^{\circ} \mathrm{N}$ latitude as disturbances or waves in tropical waters off the coast of Africa that move in a westerly track (with varying degrees of 
northwesterly movement, depending on the steering current) across the Atlantic Ocean (DeMaria et al., 2001; NHC, 2016). Tropical cyclones may also develop from systems present in the Gulf of Mexico and the Caribbean Sea (NHC, 2016). Sea surface temperatures above $26.5^{\circ} \mathrm{C}$ to a depth of 50-60 $\mathrm{m}$ are favorable for cyclogenesis as long as the accompanying vertical wind shear is low enough to allow for sustained rotation (Gray, 1968). Tropical cyclone development is also affected by the June-September rainfall in the western African Sahel and by the prevailing phases of ENSO (El Niño years have increased vertical wind shear that discourages hurricane development), the AMO (Atlantic Decadal Oscillation) and other large-scale climate oscillations, although the full extent the role of interrelated climate oscillations have on cyclogenesis is not yet fully understood (Goldenberg et al., 2001; Landsea, 2007).

The Atlantic hurricane season officially begins on June $1^{\text {st }}$ and ends on November $30^{\text {th }}$, with the peak of the season occurring between mid-September and mid-October (NHC, 2016). Tropical cyclones are classified by their wind speed and surface pressures and, throughout the lifetime of the storm, it can strengthen and abate through multiple stages of the intensity scale. Tropical depressions form as low pressure areas associated with thunderstorms and circular winds with sustained speeds below $33 \mathrm{kts}$ (NHC, 2016). A storm is upgraded to a tropical cyclone when the sustained winds intensify to 34-63 kts; storms with wind speeds greater than 64 kts are categorized by numbers (Categories $1-5$ ) on the Saffir-Simpson hurricane intensity scale (Table 4.1). Much of the damage associated with the passage of a tropical cyclone is from the winds, particularly the wind gusts and storm surge for coastal areas (Table 4.2).

The maximum sustained wind speed is a defining characteristic for tropical cyclones; however, the amount and distribution of precipitation depends on a multitude of factors and can vary from storm to storm. Structurally, tropical cyclones differentiate into the central eye, the surrounding eyewall 
and the outer rain bands, which can extend for tens to hundreds of kilometers from the center of the storm (Holland, 1993; NHC, 2016). The amount of precipitation produced by a hurricane is not related to the intensity of the storm (Rappaport et al., 1999). Precipitation within a tropical cyclone is asymmetrically distributed depending on storm's intensity, the speed and location of the storm, moisture distribution within the system, and windshear; the amount of rain a location receives also depends on the distance from the tropical cyclone and the direction of approach (Lonfat et al., 2004). The most intense rainfall occurs in the front quadrant of tropical cyclones; however, the intensity of the storm dictates whether the maximum rainfall is from the front-left quadrant (tropical storms) or the front-right quadrant (Categories 3-5) (Lonfat et al., 2004). Heavy rain also occurs around the eyewall and in the rain bands that spiral outward from the center of the tropical cyclone. The rain bands can extend hundreds of kilometers from the center of the storm, although their maximum radius decreases as the storm intensifies (Lonfat et al., 2004).

The precipitation associated with tropical cyclones has been found to have a characteristically depleted $\delta^{18} \mathrm{O}$ signature (Nicolini et al., 1989; Lawrence and Gedzelman, 1996). Tropical cyclones are very efficient rain generators, acting as fractionation chambers, as they constantly rain out the heavier ${ }^{18} \mathrm{O}$ water molecules leading to more isotopically depleted precipitation over time (Gedzelman, 2003). Rain from tropical cyclones can be $>10 \%$ more depleted in ${ }^{18} \mathrm{O}$ (Lawrence et al., 2002) compared to typical summer rainfall (Price et al., 2008). Precipitation is more isotopically depleted near the eyewall; however, rain with depleted values has been recorded several hundred kilometers from the eye (Lawrence and Gedzelman, 1996). Areas well outside of the cone of trajectory can receive large amounts of tropical cyclone-related rain. As Hurricane Wilma stalled over the Yucatan Peninsula in 2005, isotopically depleted precipitation $\left(\delta^{18} \mathrm{O}<-10 \%\right)$ was recorded in South Florida, over $1000 \mathrm{~km}$ away (Price et al., 2008). Other studies have reported similar results without the hurricane making landfall near the study site. Rain bands from Hurricane Opal (1995) 
produced precipitation low in ${ }^{18} \mathrm{O}$ in Houston, Texas (Lawrence et al., 1998) and the Florida Keys received depleted rain from Hurricane Gabrielle (2001) while the storm was stalled in the Gulf of Mexico (Lawrence et al., 2004).

\subsubsection{Objectives of this study}

The objectives of this study are as follows: (1) to compare the $\delta^{18} \mathrm{O}$ measurements of latewood rings among the four individual Pinus elliottii trees, and (2) to determine the relationship between oxygen and carbon isotopes within the $\alpha$-cellulose of latewood rings and the following season's earlywood rings with the historical hurricane records for the Lower Florida Keys.

\subsection{Methods}

\subsubsection{Big Pine Key}

The Florida Keys are located at the southernmost tip of the eastern United States, extending in a southwesterly arc from mainland Florida (Figure 4.1). The islands are the remnants of two interglacial Pleistocene nearshore carbonate marine deposits; the Key Largo limestone, an ancient coral reef tract, and the Miami oolite, the relics of a calcium carbonate sand tidal bar system (Hoffmeister and Multer, 1968; Halley and Harris, 1979). The Key Largo limestone is the surficial bedrock in the Upper and Middle Keys and is overlain by the Miami oolite in the Lower Keys (Hoffmeister and Multer, 1968). Big Pine Key is largest island in the Lower Keys and is located at the junction where the two facies meet with a contact depth of 4-6 m (Hoffmeister and Multer, 1968; Coniglio and Harrison, 1983). Both limestone formations are permeable but the juxtaposition of the oolite overlying the more transmissive Key Largo limestone allows Big Pine Key to support two GhybenHerberg freshwater lenses (Vacher et al., 1992). 
The Lower Florida Keys exhibit the characteristics typical of a tropical monsoon climate where average monthly temperatures rarely fall below $18^{\circ} \mathrm{C}$ and the seasonality is driven by an annual cycle of precipitation (Peel et al., 2007). The wet season, with $71 \%$ of the total annual precipitation, is generally considered to fall between mid-May through mid-October, with the dry season accounting for the remainder of the year (NCDC, 2013). There are strong teleconnections between the timing and volume of precipitation and the AMO and ENSO climate oscillations, with El Niño winters and positive AMO phases receiving above average precipitation (Enfield et al., 2001; Moses et al. 2013). Peak hurricane season for the Florida Keys occurs between September and October with occasional storms in August and November (Table 4.3). Monroe County as a whole, including both the Florida Keys and the mainland section of the county, has received 32 direct hurricane strikes, 15 of which are considered major, between 1900 and 2010; making it the most vulnerable coastal county from Maine to Texas (Jarrell et al., 1992, with updates from the National Hurricane Center, http://www.nhc.noaa.gov). The island of Big Pine Key has experienced a total of 29 tropical cyclone events (depressions, tropical storms and hurricanes) passing within a $100 \mathrm{~km}$ radius around the island between the years 1992 and 2005 (Table 4.3).

The slash pine, P. elliottii var. densa, is the dominant tree species of the Big Pine Key pine rocklands. The pine rocklands are a disturbance-driven community that occupy the highest elevations ( 3 m) of the lower Florida Keys (Ross et al., 1992). The karstic landscape results in shallow pockets of sand, marl, and organic material that support vegetation (Ross et al., 1994; USFWS, 1999), and the slash pine growing there have been shown to access both ground water and utilize soil water from storm events, when available (Ogurcak, 2015). As a species that opportunistically utilizes soil water, $P$. elliottii var. densa should contain oxygen isotopic records within their tree-ring cellulose that reflect changes in climate and preserve tropical cyclone events associated with heavy rainfall. 
The response of slash pine to an extreme hurricane-related event was witnessed on Big Pine Key in late 2005 and early 2006. In October of 2005, a 2 m storm surge flooded the Lower Keys as Hurricane Wilma passed to the northwest of Florida Bay as it made landfall in central Florida (Ross et al., 2009). The receding surge led to areas of widespread P. elliottii var. densa mortality as the salinity of the freshwater lens increased and the Florida Bay salt deposits persisted in the soil into June of the following year (Ross et al., 2009; Sah et al., 2010; Ogurcak, 2015). The storm surge had devastating and lasting effects on the upland vegetation; however, Hurricane Wilma did not produce significant amounts of precipitation $(2.5-4.5 \mathrm{~cm})$ in the Lower Keys (NCDC Climate Data Online, https://www.ncdc.noaa.gov/cdo-web/) and, therefore, is not likely to be recorded in the oxygen isotope record. However, the event was captured in the carbon record as a peak in ${ }^{13} \mathrm{C}$ enrichment (Chapter 2) and ultimately led to the demise of the trees used in this study, as they could not recover from the prolonged salt stress (Ross et al., 2009; Sah et al., 2010).

The four P. elliottii var. densa trees analyzed here were collected along a proposed hydrologic gradient by staff at the National Key Deer Refuge in April of 2006 from the Hurricane Wilma pine mortality zone. A cluster of three tree disk samples were collected less than $30 \mathrm{~m}$ from each other (approximately $900 \mathrm{~m}$ from the coast) from a deeper, more stable part of the northern freshwater lens and an additional single sample was selected from the more coastward side of the lens about $160 \mathrm{~m}$ away from the cluster (approximately $750 \mathrm{~m}$ from the coast).

\subsubsection{Sample preparation and oxygen isotope measurements}

The tree disks were sanded with increasingly finer grit sandpaper to clearly expose the tree-rings. A single inch-wide transect from bark to pith was selected and cut from each disk to be used for analysis. The transects were carefully chosen to avoid any ring structure anomalies (i.e. compressed or highly expanded rings) and termite damage. The samples were photographed and standard 
dendrochronology techniques following the guidelines described in Cook and Kairiukstis (1990) and Fritts (1976) were used to count and identify the rings in each transect. The early- and latewood rings were individually separated using an X-Acto knife under a microscope at 15x magnification. The samples were powdered in a Spex 8000M Mixer/Mill until the wood was homogenized and the $\alpha$-cellulose component of the wood was isolated using a method modified after Green, 1963 (see Appendix 1 for a detailed description of the revised process).

The individual $P$. elliottii var. densa samples were dated and crossdated using the $\delta^{13} \mathrm{C}$ method described in Chapter 2. Only the latewood samples were analyzed for $\delta^{18} \mathrm{O}$ because they correspond to late summer and fall growth and should represent the height of hurricane season for South Florida (August - November). Trees DBH1 and DBH3 were analyzed for the time period 1950-2005 and a longer time series, 1922-2005, was analyzed for DBH2 and DBH6 because both trees showed the most sensitivity in their $\delta^{13} \mathrm{C}$ records. The latewood samples were analyzed in duplicates $(0.8-0.9$ mg, each) on a Finnigan High Temperature Conversion Elemental Analyzer (TC/EA) coupled to a Thermo Scientific Delta V isotope ratio mass spectrometer (IRMS) via a Conflo IV continuous flow interface. A TC/EA uses high-temperature pyrolysis $\left(1390^{\circ} \mathrm{C}\right)$ to covert solid cellulose samples into $\mathrm{CO}$ gas in the absence of oxygen. A total of 23 secondary standards were included in each run of 13 duplicate samples to ensure the integrity of the data, including IAEA-CH3 $\left(\delta^{18} \mathrm{O}=\right.$ $32.4 \%$, with a standard deviation $\leq 0.4 \%$, $n=75$ ). The raw data was corrected to the Sigma-Aldrich $\alpha$-cellulose, $\delta^{18} \mathrm{O}=31.4 \%$ o (V-SMOW), with a standard deviation $\leq 0.3 \%$, $\mathrm{n}=190$, and expressed in standard delta notation (Craig, 1961; Coplen, 1994). At times, the fibrous nature of $\alpha$-cellulose led to issues with homogeneity and samples that were found to have a very large standard deviation $(\geq 0.75 \%$ ) between their duplicates were reanalyzed. The duplicate latewood samples were averaged and the combined error for all sample replicates was $\pm 0.17 \%, n=274$. 


\subsubsection{Statistical analyses and residual calculations}

Residual values for the four $\delta^{18} \mathrm{O}$ and $\delta^{13} \mathrm{C}$ time series and the combined site index were calculated using the methods described in Miller et al. (2006) and by The Laboratory of Tree-Ring Research at the University of Arizona (http://ltrr.arizona.edu/). The process removes short-term autocorrelation from the time series and makes the recorded isotopic value for each point independent of the previous measurement. A one-year autoregressive-moving-average model (AR1) was applied to each dataset to detect anomalies in the isotopic records. First, the data was meanadjusted, where the individual means of each dataset were subtracted from the original data. Then, the expected values derived from the AR-1 model were subtracted from the observed values in the isotopic time series to calculate the individual residual values (residual $=$ observed - modelled expected value).

The residual calculations were compared to historical hurricane track records for the years 19222005 within a $100 \mathrm{~km}$ radius around Big Pine Key (NOAA Office of Coastal Management, https://coast.noaa.gov/hurricanes/). The $100 \mathrm{~km}$ radius around the sampling site is an arbitrary value that was selected as an initial starting point to try to describe the effects of the hurricanes that pass nearest to the sampling location. Previous studies (Miller et al., 2006; Nelson, 2008; Lewis, 2009; Lewis et al., 2011) have used 200-250 km starting radii with success, but some have had to expand up to $400 \mathrm{~km}$ in order to explain all of the depleted $\delta^{18} \mathrm{O}$ residual anomalies (Miller et al., 2006). In addition, to assess the likelihood that a passing hurricane would be recorded in the $\delta^{18} \mathrm{O}$ cellulose record, precipitation values were obtained from the National Climate Data Center historical instrumental climatology database for the closest weather station at Key West (NCDC Climate Data Online, https://www.ncdc.noaa.gov/cdo-web/). 


\subsection{Results}

4.4.1 Variability in the oxygen isotopic record among individual trees

Trees DBH1 and DBH3 were analyzed over the period 1950-2005 and the chronologies for trees DBH2 and DBH6 extend back to 1928 and 1922, respectively. Longer chronologies were analyzed for DBH2 and DBH6 because they showed the greatest sensitivity to environmental changes in their $\delta^{13} \mathrm{C}$ records. Variability was observed in the absolute values (measured oxygen isotope values) of $\delta^{18} \mathrm{O}$ in the latewood cellulose for all four individual $P$. elliottii var. densa trees over the period 1922-2005; however, all four P. elliottii var. densa trees followed similar trends over the span of the time series, particularly between the years 1958-1982 and 1990-2005 (Figure 4.2a-b). Discrepancies in the timing of the peaks among the four trees occur throughout the chronology and may be a result of differences in individual, localized environments, such as soil depth. The standard deviations for individual trees ranged from 0.66 to 0.68 , with $\mathrm{DBH} 1$ being the least variable and DBH6 showing slightly more instability in $\delta^{18} \mathrm{O}$ values over the time series. The mean for the absolute $\delta^{18} \mathrm{O}$ values among all four trees was $31.2 \%$. Tree DBH6 showed the overall most enriched mean (31.76\%o), while DBH2 was the overall most depleted (30.77\%).

Paired t-tests were used to compare and contrast the individual trees with one another. To account for the variability among the absolute cellulose values, the time series were normalized by calculating the first order differences in consecutive $\delta^{18} \mathrm{O}$ values, highlighting the year to year trends (Figure 4.2b). All trees were compared over the years 1950-2005 with the exception of DBH2-DBH6, in which a longer time series, 1928-2005, was used. No combination of two trees (DBH1-DBH2, DBH1-DBH3, DBH1-DBH6, DBH2-DBH3, DBH2-DBH6, and DBH3-DBH6) was found to be statistically different from each other at the 95\% confidence level (Table 4.4). 
The oxygen isotope residual time series for individual trees and the composite chronology were compared to historical monthly and seasonal precipitation records from the Key West weather station (Table 4.5). Pearson coefficients and associated p-values were calculated for each chronology using only the data for the years 1950-2005. The Key West weather station has the most compete monthly precipitation records over this in interval and the monthly average values were substituted when data was missing from the record. There is not a clear relationship between the amount of precipitation received and the $\delta^{18} \mathrm{O}$ latewood values. The amount of precipitation received in the November was very weakly positively correlated with the oxygen isotope values in tree $\mathrm{DBH} 2$ and the average composite chronology ( $\mathrm{p}$-values $=0.022$ and 0.049 , respectively). Tree DBH2 showed very weak positive correlations with August precipitation and the seasonal total (pvalues $=0.063$ and 0.020 , respectively) and tree $\mathrm{DBH} 3$ has a very weak positive correlation to the amount of precipitation in the following January $(\mathrm{p}$-value $=0.024)$. Tree DBH6 did not have significant correlations with any monthly or seasonal precipitation. A previous study by Lewis (2009) showed statistically significant positive correlations between precipitation and the latewood $\delta^{18} \mathrm{O}$ values of trees in the southeastern Texas Coastal Plain; however, this relationship may not translate to the Lower Florida Keys. The amount of precipitation may not be as important as the precipitation source and the contribution of the evaporatively enriched soil water.

The success rate for capturing tropical cyclone events varied among individual trees and the composite record (Table 4.6). Tropical cyclone events are defined as depleted residual values $\leq-$ 0.1 occurring in years with a corresponding reported storm (Table 4.3). Of the individual trees, DBH6 recorded the least number of tropical cyclones, 20\%, while DBH3 had the highest percentage of storms in its $\delta^{18} \mathrm{O}$ residual record, 44\%. Trees DBH1 and DBH2 each recorded around a third of the tropical cyclones, $38 \%$ and 33\%, respectively. The composite record captured 56\% tropical cyclones. There were 14 tropical cyclones with at least $5 \mathrm{~cm}$ of storm-related rain recorded 
by the Key West weather station (blue boxes in Figure 4.6), of these, 10 were captured in the composite $\delta^{18} \mathrm{O}$ residual record $(71 \%)$.

\subsubsection{Comparison of the tropical cyclone activity in the $\delta^{18} \mathrm{O}$ and $\delta^{13} \mathrm{C}$ record}

The two carbon isotope residual time series were calculated individually using the absolute values for the latewood (solid line) and earlywood (dashed line) components of the combined site $\delta^{13} \mathrm{C}$ chronology developed for the four P. elliottii var. densa trees in chapter 2 (Figure 4.3a). The carbon isotope residual latewood values are concurrent to the latewood oxygen isotopes residuals and were analyzed from the same cellulose latewood samples. The earlywood carbon isotope residuals are also included to more accurately assess the lasting effects of tropical cyclones that may have affected the trees into the subsequent growth period. The next season's $\delta^{13} \mathrm{C}$ earlywood values are paired with the previous $\delta^{18} \mathrm{O}$ isotope latewood season. For example, the earlywood carbon values for 1936 are compared to the latewood oxygen isotope residuals for 1935. The residual values greater than 0 have been highlighted in a gray box and may represent prolonged periods of stressful growing conditions for the trees. The p-value for the combined $\delta^{13} \mathrm{C}$ residual index is less than 0.01 .

The residual values were calculated for each individual tree and for the combined site index. The p-values for the residual time series ranged from $0.001-0.645$ and only trees DBH2 and DBH6 and the combined site index were considered statistically significant $(\mathrm{p} \geq 0.05)$. The combined site index residual $\delta^{18} \mathrm{O}$ values will be reported in this paper and the resulting chronology is shown in figure $4.3 \mathrm{~b}$. The definition of the threshold for anomalously depleted $\delta^{18} \mathrm{O}$ residual values has been somewhat arbitrary in the previous literature and is likely heavily dependent on the site-specific environment conditions. Miller et al. (2006) determined that residual values $\leq-0.5$ could be attributed to tropical cyclone related precipitation with confidence; however, that definition would exclude the majority of the Big Pine Key data. To assess the tropical cyclone record for the lower 
Florida Keys, a less stringent threshold of oxygen residual values $\leq-0.1$ was applied to the data (gray shaded area in figure $4.3 \mathrm{~b}$ ).

The carbon and oxygen residual data sets were compared to the historical tropical cyclone records in figure 4.3a-b. There were 29 tropical cyclone-related storms that passed within $100 \mathrm{~km}$ of Big Pine Key between 1922 and 2005 (Table 4.3). The storms have been divided by intensity into three groups: tropical depressions and tropical storms, minor hurricanes (categories 1 and 2), and major hurricanes (categories 3-5). Previous studies have excluded tropical depressions from their analyses; however, they have been included here because they can produce large amounts of rain in South Florida and may influence the $\delta^{18} \mathrm{O}$ record. The colored vertical lines in figure 4.3 show the timing of tropical cyclone events; the major hurricanes are red, the minor hurricanes are orange, and the tropical storms and depressions are blue. In years with more than one tropical cyclone, the storm with the greatest intensity was chosen to represent that season. Specific data for each storm may be found in table 4.3. There were seven reported storms that appeared as false negatives (residuals values $\geq 0.1$ ) in the oxygen isotope record and 11 years with depleted $\delta^{18} \mathrm{O}$ values $(\leq 0.1)$ without corresponding storm (false positive). The most depleted $\delta^{18} \mathrm{O}$ value $(-0.644)$ in the composite oxygen isotope record is a false positive in 1973 (Table 4.7). The years 1924 and 1984 also have relatively depleted false positive values: -0.356 and -0.359 , respectively.

Figure 4.4 shows the relationship between corresponding latewood carbon and oxygen isotope residuals for the entire length of the time series. The black circles indicate years with reported tropical cyclone activity and the gray boxes are years without storms occurring in a $100 \mathrm{~km}$ radius of Big Pine Key. The data do not follow the predicted relationship of enriched carbon isotope residuals corresponding to depleted oxygen isotope residuals during tropical cyclone years. There is little difference in the relationship between the carbon and oxygen isotopes during tropical 
cyclone versus non-tropical cyclone seasons. Only data for the non-tropical cyclone years are significant ( $\mathrm{p}$-value $=0.0012$ ); the $\mathrm{p}$-value for the tropical cyclone data is 0.5386 .

The carbon and oxygen isotope residuals for years with reported tropical cyclone activity are presented in scatterplots by intensity to better show the nature of individual storms (Figure 4.5a-c). In all plots, the circles represent the concurrent latewood residuals for both carbon isotopes and oxygen isotopes and the triangles show a one season offset where the current latewood oxygen isotope residual is plotted with carbon isotope residual for the next earlywood season. The seasons with tropical depressions or tropical storms (Figure 4.5a) showed the most consistently depleted $\delta^{18} \mathrm{O}$ residual values. The years 1941 and 1994 have enriched $\delta^{18} \mathrm{O}$ residuals. There was very little rain $(2.39 \mathrm{~cm})$ recorded at the Key West Station for Tropical Storm Gordon in 1994 and the unnamed tropical depression in 1941 may have also had very little rain, although there are no precipitation records for that year. The $\delta^{13} \mathrm{C}$ residual data for both the latewood and the offset earlywood appear to be unaffected by the passage of tropical depressions and tropical storms. The relatively enriched $\delta^{13} \mathrm{C}$ residual value in the 1941 offset earlywood sample is likely a response to some type of stress occurring during that growing season and not a result of the unnamed tropical depression in the previous year.

The seven minor hurricanes that occurred during 1922-2005 did not result in depleted $\delta^{18} \mathrm{O}$ residual values or relatively enriched $\delta^{13} \mathrm{C}$ latewood residual value (Figure 4.5b). There were two seasons, 1987 and 2005, with enriched $\delta^{13} \mathrm{C}$ offset earlywood residual values. In 2005, Hurricane Katrina had record precipitation $(24.54 \mathrm{~cm})$ recorded by the Key West weather station and Hurricane Rita was also a very wet storm $(9.74 \mathrm{~cm})$; however the signatures of their depleted ${ }^{18} \mathrm{O}$ precipitation were likely dampened by the enrichment of soil water and the trees transitioning to groundwater during three drier than normal months during that growing season. The relatively large enrichment 
in the $2005 \delta^{13} \mathrm{C}$ offset earlywood residual has been attributed to Hurricane Wilma (Chapter 2). Hurricane Wilma did not pass within 100 km of Big Pine Key; however, it created a storm surge in Florida Bay that led to a large area of P. elliottii var. densa trees that were unable to recover to the salt stress (Ross et al., 2009; Sah et al., 2010).

All major hurricane seasons but three, 1929, 1935, and 1965, resulted in a significantly depleted oxygen isotope residuals (Figure 4.5c). The concurrent latewood carbon isotope residuals for all storms did not show any significant enrichment; however, positive values in the offset earlywood carbon isotope residuals for the 1935,1948 , and, to a lesser extent, 1926 storms indicate that the trees may have been damaged by the storms and were still recovering throughout the following spring and early summer months.

\subsection{Discussion}

4.5.1 Variability in the oxygen isotope records among individual trees

The oxygen isotope composition of tree-ring cellulose is a result of the combined oxygen isotope signatures of all the water sources utilized by the tree over time (Epstein et al., 1977); however, the relative proportions of available water reservoirs accessed by trees may vary within a stand. The pine rocklands in the Lower Florida Keys are a heterogeneous landscape, where the exposed limestone bedrock is interrupted by shallow pockets of soil that support patches of vegetation. The areal extent of the soil coverage and the soil depth are variable throughout the rocklands. The average soil depth for pine rocklands in the Lower Florida Keys has been reported to be $7.67 \pm 0.32$ cm (Ogurcak, 2005); however, this value can vary between $1 \mathrm{~cm}$ and $10 \mathrm{~cm}$ (Ross et al., 1992). The rooting depth of $P$. elliottii var. densa on average is 2 to $3 \mathrm{~m}$ (van Rees and Comerford, 1986), and the trees are known to opportunistically use channels and solution holes in the limestone to extend their roots through the bedrock to gain access to the water table (Querejeta et al., 2007). The 
depth to the northern freshwater lens on Big Pine Key is $1.5 \mathrm{~m}$ at the highest elevations on the island and it should be accessible to the P. elliottii var. densa trees in the pine rocklands (Wightman, 1990; Ogurcak, 2005). Water source partitioning by P. elliottii var. densa trees on Big Pine Key has been observed to vary with season and groundwater is an important source throughout the year; although, the $P$. elliottii var. densa trees can quickly adapt their water conservation strategies to take advantage of soil water after a rain event, particularly during the dry season (Ross et al., 1994; Ogurcak, 2015).

The variability in the $\delta^{18} \mathrm{O}$ records among the four $P$. elliottii var. densa trees suggests that the extent to which trees utilize different water sources is controlled by their individual site conditions. While all four trees demonstrated periods of extreme enrichment and depletion in their individual $\delta^{18} \mathrm{O}$ records, the timing of these events didn't always coincide among the trees (Figure 4.2). Assuming that all four trees use the same groundwater source and that precipitation and soil water are an important contributors to the oxygen isotope signature of the cellulose, the differences among the four trees in their isotope time series should be related to the characteristics of the soil surrounding each tree. The heterogeneity of the soil distribution throughout the pine rocklands may significantly alter the oxygen isotope compositions of precipitation and soil water available to the trees. The isotopic signature of soil water is constantly changing in response to the addition of precipitation and the subsequent dampening of that precipitation signal through evaporation (Tang and Feng, 2001). This cycle of precipitation and evaporation may be amplified in shallow soils; particularly during the dry season when the relative humidity decreases.

Analysis of stem water in P. elliottii var. densa trees on Big Pine Key shows that the relative contributions of each source water end member at the end of the wet season in November are $30 \%$ groundwater, 20\% soil water, and 50\% precipitation (Ogurcak, 2015). The reported annual $\delta^{18} \mathrm{O}$ 
values of each water reservoir utilized by P. elliottii var. densa on Big Pine Key is $-3.8 \%$ for the mean weighted precipitation, $-3.2 \%$ to $-3.8 \%$ for groundwater, and the highly variable soil water values are between $-3.2 \%$ and $-0.2 \%$ (Ogurcak, 2015). On average, the absolute oxygen isotope values for the four $P$. elliottii var. densa trees did not vary significantly $( \pm 1 \%)$, suggesting that they are accessing the same source waters. However, while contributing the lowest percentage, the oxygen isotope input of the altered localized soil water could account for the variability among trees in the absolute oxygen isotope time series. Similar results were reported by Lewis (2009), whose work is the only other study, to date, to use more than one tree per site to construct an oxygen isotope residual chronology. Inconsistencies in the absolute oxygen isotope records of four individual longleaf pines in Texas were attributed to variation in soil moisture available to the trees (Lewis, 2009).

The four trees used in the Texas study exhibited significant, but variable, correlations to historical precipitation measurements, with the differences being the most significant in the years with the least precipitation (Lewis, 2009). No strong relationships were found between the amount of precipitation recorded by the Key West station and the $\delta^{18} \mathrm{O}$ values of individual Big Pine Key trees or the composite residual chronologies (Table 4.5). It is possible that the historical Key West weather station is too far away from sampling site and it does not accurately represent precipitation falling $40 \mathrm{~km}$ away on Big Pine Key. The spatial heterogeneity of South Florida precipitation has been well documented and precipitation patterns are strongly tied to ENSO and the AMO (Tokay et al., 2003; Moses et al., 2013). Rainfall in the Lower Keys follows a south to north and west to east gradient, with the northern and western portions of the islands receiving the most rainfall; however, the average difference between precipitation amounts at different locations was less than 10\% (Tokay et al., 2003). The $P$. elliottii var. densa trees have access to groundwater year round, unlike the longleaf pines in Texas (Lewis, 2009), but they take advantage of late wet season - early 
dry season precipitation (Ogurcak, 2015), so it is possible that quantity is less important than the isotopic composition of the incoming precipitation in the determination of the absolute oxygen isotope values of the cellulose. Although not quantitatively considered here, the relative humidity may play a role in determining the $\delta^{18} \mathrm{O}$ value of cellulose, as has been found in trees growing in the monsoon climate of India (Managave et al., 2010). The timing of precipitation may also be important in determining the assimilated tree-ring $\delta^{18} \mathrm{O}$ values; three of the five time series, DBH1, DBH6 and the composite chronology, had very weak, but statistically significant, positive correlations to November and January precipitation. The trees appear to take advantage of uncharacteristic precipitation in the early dry season, but the soil water is unlikely to be associated with a depleted tropical cyclone source and evaporation would occur rapidly resulting in a relatively enriched $\delta^{18} \mathrm{O}$ cellulose value.

The success rate of capturing tropical cyclone events in the $\delta^{18} \mathrm{O}$ residual records varied among individual trees. The average success rate for all four trees is $32 \%$; however, the composite $\delta^{18} \mathrm{O}$ residual chronology identified $56 \%$ of the tropical cyclones occurring within a $100 \mathrm{~km}$ radius around Big Pine Key (Table 5.6). Lewis (2009) reported better results for individual longleaf pine in Texas, 42\%; although, the composite $\delta^{18} \mathrm{O}$ residual chronology only recorded $50 \%$ of tropical cyclones. The lower success rates measured in the Big Pine Key trees compared to the Texas pines are likely a result of differences in site conditions. The trees in Texas are not reported to have access to groundwater, so the $\delta^{18} \mathrm{O}$ values of the cellulose reflect solely the isotopic values of soil water and precipitation (Lewis, 2009). Additionally, the P. elliottii var. densa trees of Big Pine Key could potentially have a longer growing season compared to the Texas longleaf pines. The P. elliottii var. densa trees may experience cambial dormancy in December and January, although there may not be a cessation in growth if there is anomalously high precipitation in the dry season, as suggested by the presence of diffuse ring boundaries and IADFs (Harley et al., 2012; Chapter 3). The addition 
of more precipitation received during December, January, and February of El Niño years, for example, may promote cell production and cause the $\delta^{18} \mathrm{O}$ signature of a homogenized tree-ring to skew towards a more enriched value.

The addition of more trees to the composite oxygen residual chronology may increase the success rate of detecting tropical cyclone signals in the $\delta^{18} \mathrm{O}$ residual values. As an alternative, a more highresolution method of measuring the $\delta^{18} \mathrm{O}$ values in tree-rings could be employed to analyze much smaller increments of growth; this may reduce the dampening effect of homogenizing the rings and highlight tropical cyclone activity that appears to be missing. Nevertheless, the chance a storm event will be preserved in the tree-ring record is dependent on the nature and effects of the storm and the environment in which the tree is growing. Significant between-tree variability implies that very-localized site conditions control the biochemistry of the $P$. elliottii var. densa trees in the pine rocklands of Big Pine Key; however, a meaningful site chronology can still be developed from as few as four individual trees in the Lower Keys.

\subsubsection{Oxygen and carbon isotopes and the tropical cyclone record}

The composite oxygen isotope residual time series recorded 14 of the 25 (56\%) documented years with tropical cyclone storms that passed within $100 \mathrm{~km}$ of Big Pine Key. Previous studies from several sites along the Gulf Coast and the Atlantic Coastal Plain have reported 24\% (Nelson, 2008) to $83 \%$ (Miller at al., 2006) accuracy in detecting tropical cyclones in tree-ring cellulose over the time frame encompassing the most complete instrumental records for their respective sites. The $\delta^{18} \mathrm{O}$ residual method has proven to be successful in reconstructing past tropical cyclone activity; however, no previous studies have examined the concurrent carbon isotope residuals. The carbon isotope values of tree-ring cellulose can highlight periods of depressed and stressful growth for individual trees and it may be useful in the identification of historical tropical cyclone events. 
Precipitation in tropical cyclones is unevenly distributed throughout the structure of the storm and some storms produce very little precipitation (Lonfat, 2014) but, the sustained winds from a category 2 hurricane are enough to cause lasting damage to a tree (Duryea et al., 1996) (Table 4.2). In addition, the Lower Keys are susceptible to wind-induced storm surge, which can be caused by a category 1 hurricane, depending on coastal morphology and the angle of approach of the storm. The carbon isotope residual records have the potential to capture the tropical cyclones as peaks of ${ }^{13} \mathrm{C}$ enrichment from significant and lasting damage to trees that may persist into the subsequent earlywood season.

There is no significant relationship between carbon and oxygen isotope residuals during years with reported tropical cyclone activity (Figure 4.4). This lack of relationship is expected, as there are many factors (i.e. available soil moisture, the localized effects of the storm, and the nature of the damage to the tree) that are specific to trees as individuals and may influence the both the carbon and oxygen composition of the cellulose (McCarroll and Loader, 2004). Storm intensity appears to play a role in determining the relationship between concurrent carbon and oxygen residuals and the latewood oxygen and the earlywood carbon residuals for the following season (Figure 4.5). Tropical storms and tropical depressions can contribute significant amounts of isotopicallydepleted rain which are preserved in the $\delta^{18} \mathrm{O}$ residual values of the cellulose (Lawrence and Gedzelman, 1996; Miller et al., 2006) (Figure 4.5a). Of the nine tropical storm and depression years with instrumental precipitation data, six years $(1945,1952,1976,1981,1990$, and 1991) have significant amounts of storm-associated rainfall (precipitation $\geq 5 \mathrm{~cm}$ ). Two of the three years with little to no storm-associated precipitation, 1969 and 1970, produced significantly depleted oxygen residual values. It is possible that they received tropical cyclone-related rain from a tropical cyclone occurring outside the $100 \mathrm{~km}$ radius defined in this study. Overall, the oxygen residual values in the tree-ring cellulose occurring during tropical storms and depressions are the most depleted in 
both the individual and composite residual records. The concurrent latewood and offset earlywood carbon isotope residuals do not indicate that the tropical storms imposed any long-term damage to the trees. The possible exception appears as an enrichment in the earlywood $\delta^{13} \mathrm{C}$ value for the growing season following the 1941 tropical depression. The ${ }^{13} \mathrm{C}$ enrichment in the 1942 earlywood samples may be the result of sustained drought conditions; July 1942 is the driest month on record for Key West (NWS, 2016), or, less likely, the enrichment may have been caused by damage from a relatively small unnamed category 3 hurricane that made landfall just south of Miami (NHC, 2016). While precipitation data for this period in the Key West climatology is unavailable, the hurricane reportedly caused severe and destructive thunderstorms in the Lower Florida Keys (Brooks, 1945).

The effects of the passage of the minor (categories 1-2) and the major (categories 3-5) hurricanes varied by storm. The minor hurricanes, in general, did not imprint a distinct depleted precipitation signature in the oxygen isotope record, with the exception of the 1933 and 1999 seasons, which both had residual values $<-0.1$ in the tree-ring record (Figure $4.5 \mathrm{~b}$ ). Both hurricanes are associated with record amounts of precipitation for their respective dates of passage in the Key West climatology: the unnamed 1933 hurricane (category 2) deposited $34.39 \mathrm{~cm}$ of rain and $21.82 \mathrm{~cm}$ of rain accumulated during Hurricane Irene (category 1) (NCDC, 2016). Hurricane Georges also set record rainfall in September, $1998(21.28 \mathrm{~cm})$ and was followed by $4.45 \mathrm{~cm}$ of precipitation from Hurricane Mitch in November (NCDC, 2016); however, the depleted precipitation signal was not retained in the oxygen isotope record of the cellulose. The signature of the depleted precipitation was likely dampened through evaporative enrichment of the soil water and a possible transition by the trees to a larger proportion of groundwater input during a relatively dry period lasting from mid-November well into December (NWS, 2016). The signatures of Hurricane Rita $(9.47 \mathrm{~cm})$ and Hurricane Katrina's record-setting $24.54 \mathrm{~cm}$ of rainfall were also dampened in the tree-ring record 
and, interestingly, the year 2005 showed the most enriched $\delta^{18} \mathrm{O}$ value among all the tropical cyclone years. In late October, a storm surge caused by the passing of Hurricane Wilma to the northwest flooded the rocklands of Big Pine Key (Ross et al., 2009; Sah et al., 2010); this event was followed by the most severe drought on record from mid-November through December, with 29 days in December receiving no precipitation (NWS, 2016). The concurrent 2005 latewood $\delta^{13} \mathrm{C}$ value shows minor enrichment; however, the $\delta^{13} \mathrm{C}$ residual value for the following earlywood season is significantly enriched. The earlywood $\delta^{13} \mathrm{C}$ value for 2006 is the second most enriched measurement in the entire carbon isotope chronology (Chapter 2) and it documents the decline of the $P$. elliottii var. densa trees as they struggled to recover from the storm surge and subsequent drought until their deaths in early 2006.

The major hurricanes also resulted in variable signatures in the carbon and oxygen residual records of the four P. elliottii var. densa trees on Big Pine Key (Figure 4.5c). Two storms left no impression in either isotope residual record: the unnamed hurricane of 1929 and Hurricane Betsy (1965). Hurricane Betsy holds the record volume of precipitation for September 8 in the Key West climatology, but enrichment of soil water during the drier than average months of November and December seems to have overpowered the effect of the hurricane-related precipitation in the oxygen isotopic record (NCDC, 2016). Hurricane Isabell (1964), Hurricane Donna and Tropical Depression Florence (1960), and the two unnamed hurricanes of 1948 all resulted in significant precipitation in Key West (NCDC, 2016) and their $\delta^{18} \mathrm{O}$ residual records reflect the input depleted precipitation. The 1926 hurricane season was the third most depleted $\delta^{18} \mathrm{O}$ residual value observed in the time series (Figure 4.3). An unnamed hurricane of 1926 made landfall in central Cuba as a category 4 and skirted the Florida Keys as it moved northeast (NHC, 2016). As with many of pre1950 tropical cyclones, it is difficult to find documentation of the impact the storm had on the sparsely populated Lower Florida Keys, although, a newspaper from northern Florida reported rains 
and high winds in Key West (Bradford County Telegraph, 1926). The well-documented Labor Day Hurricane was the strongest storm to make landfall in the western hemisphere and caused significant destruction in the Middle Keys from a 5-6 m storm surge (Emanuel, 2005; Henson, 2007). The compact, category 5 hurricane had an eye that was less than $13 \mathrm{~km}$ in diameter, the third lowest barometric pressure recorded for an Atlantic tropical cyclone, and is estimated to have produced wind gusts exceeding 100 km/hr near Big Pine Key (Barnes, 1998 and Emanuel, 2005). There is no available record of precipitation in Key West and the weather station in the Middle Keys was washed away in the storm (Barnes, 1998; NCDC, 2016). A Key West newspaper reported localized tropical storm conditions associated with the passing of the hurricane, but precipitation appears to have been minimal (The Key West Citizen, 1935). The $\delta^{18} \mathrm{O}$ residual value for 1935 is very close to zero $(-0.005)$ and does not reflect the influence of a significant amount of depleted precipitation; however, both the concurrent and offset earlywood $\delta^{13} \mathrm{C}$ residual values show enrichment. The earlywood $\delta^{13} \mathrm{C}$ value for 1936 is the most enriched throughout the time series (Chapter 2).

The relative enrichment of $\delta^{13} \mathrm{C}$ residual values in the earlywood following a major hurricane appears seven times in the residual records of the 14 major and minor hurricanes $(1926,1935,1948$, 1960, 1987, 1998, and 2005). In 2005, Hurricane Wilma produced a storm surge that increased the salinity of the freshwater lens for several months (Ross et al., 2009; Sah et al., 2010). Slash pine have a low salt tolerance and the prolonged exposure to more saline groundwater caused the trees to employ water conservation strategies that were recorded as enrichments in the $\delta^{13} \mathrm{C}$ value of the tree-ring cellulose. A 1.4 m storm surge was recorded in Big Pine Key during Hurricane Georges (1998) that flooded the coastal hammock communities, but is not thought to have affected the higher-elevation pine rocklands (Sea Systems Corporation, 1998; Ogurcak, 2015). The damage to the $P$. elliottii var. densa trees was attributed to high winds (Ogurcak, 2015); Hurricane Georges 
produced wind speeds greater than $165 \mathrm{~km} / \mathrm{h}$ as it made landfall to the west of Key West (NHC, 2016). Florida slash pine have a medium wind-resistance and wind damage from hurricanes may not be outwardly apparent, but can cause death several months after the storm (Duryea and Kampf, 2007). One quarter of slash pines in Central Florida that appeared unscathed by the passage of category 4 Hurricane Charley (2004) died from internal storm-related damage three months later and the same phenomenon was witnessed after Hurricane Andrew (Duryea et al, 1996; Duryea and Kampf, 2007). The reason for the delayed mortality is not well-understood, but it has been attributed to the bending and twisting motion of the tree under sustained high winds (Duryea and Kampf, 2007). The wind-related damage and subsequent recovery may also explain the uneven concentric growth of the tree-rings.

The elevated $\delta^{13} \mathrm{C}$ residual values in the earlywood of post-hurricane years may indicate a recovery period from high wind damage. In 1948, two category 3 hurricanes passed within $25 \mathrm{~km}$ of Big Pine Key two weeks apart (NHC, 2016). The late September storm had winds in excess of 193 $\mathrm{km} / \mathrm{h}$ and caused severe damage around Key West (The Canberra Times, 1948) and high winds and flooding were reported on the island of Key West for the October storm (The Key West Citizen, 1948). Big Pine Key may have also experienced flooding from one or both storms, but the associated enriched offset earlywood $\delta^{13} \mathrm{C}$ residual value is more likely a result of wind damage. The Labor Day Hurricane of 1935 and Hurricane Donna (1960), which had nearly identical northwesterly tracks across Florida Bay, and the unnamed hurricane of 1926 were powerful hurricanes (categories 4-5) at the time of impact (NHC, 2016). There is no 1935 wind data for Big Pine Key; however, there was likely some type of wind-related impact because the greatest ${ }^{13} \mathrm{C}$ enrichment over the entire 1922-2005 chronology appeared in the 1936 earlywood samples. Hurricane Donna had sustained winds greater than $90 \mathrm{~km} / \mathrm{h}$ (Houston and Powell, 2003) and the 1926 hurricane had 200-220 km/h winds in the vicinity of Big Pine Key (NHC, 2016). There may 
have been some flooding associated with the passage of Hurricane Donna, but the most destructive storm surges occurred on the southwestern coast of the mainland (Houston and Powell, 2003). Flooding was reported $32 \mathrm{~km}$ south of the eye of the storm and the tidal gauge at Key West recorded a 1.1 m surge (Dunn and Miller, 1961), while the high water benchmark on Big Pine Key was estimated to be just over a meter for the northern portion of the island (Harris, 1963). Whether the damage was caused by storm surge or high winds, the recovery period for the trees may have been prolonged by record droughts in the 1927 and 1961 (NWS, 2016).

\subsubsection{Explanation of false negatives and false positives in the oxygen isotope residual record}

No site is going to capture $100 \%$ of historical tropical cyclone activity because there are a host of factors that contribute to the likelihood that an isotopically depleted tropical cyclone precipitation signature will be preserved in the tree-ring record. For example, the nature of the storm (tropical cyclones are not homogenous and their effects are not uniform across the entirety of the storms) and the coarse sampling resolution (the latewood samples each represent several months of time when the tropical cyclone signal may have been dampened through the input of other water sources utilized by the tree) can have a significant impact on the final $\delta^{18} \mathrm{O}$ value of the cellulose. False negatives are defined as years when tropical cyclones passed within $100 \mathrm{~km}$ of Big Pine Key, but were not recorded in the oxygen isotope record as a depleted residual value $(\leq 0.01)$. False negatives appeared throughout the chronology and under all tropical cyclone intensity classifications (Table 4.7). Previous studies report multiple occurrences of tropical cyclones being absent in their oxygen isotope residuals records (Miller et al., 2006; Nelson, 2008; Lewis, 2009). The missing active tropical cyclone years may be explained by the dampening of the depleted precipitation signal through evaporative enrichment of the soil water or, simply, that the storm did not produce significant amounts of rain at the study site. In addition, the position of the sampling location relative to the track of a hurricane can dictate the isotopic quality of the precipitation received 
(Munksgaard et al., 2015), so, if water vapor making up the rain has not undergone repetitive fractionation, it will not have the characteristic isotopically depleted signature.

Key West precipitation data is not available for three of the seven years with false negatives (1929, 1941, and 1947). The tropical cyclone events in 1965, 1987, 1998, and 2005 all produced greater than $9 \mathrm{~cm}$ of precipitation, but, with the exception of 2005, the months of September and December were drier than normal (NCDC, 2016 and NWS, 2016). Interestingly, only one tree, DBH2, recorded depleted $\delta^{18} \mathrm{O}$ residual values in 1987 and 1998; this tree may rely on a larger percentage of precipitation and soil water compared to the other three trees. As mentioned, 2005 was the $7^{\text {th }}$ wettest year in Key West history (1871-2011); however, December 2005 is the driest on record, with a monthly cumulative total of $0.127 \mathrm{~cm}$ of rainfall (NWS, 2016). The effect of the extremely dry December, drier than normal following January and February, and added salt stress may have been enough to dilute the depleted signal of the tropical cyclone precipitation from the 2005 latewood ring.

The small $100 \mathrm{~km}$ radius of tropical cyclone activity was intentionally chosen to determine the effects of tropical cyclones in the immediate vicinity of Big Pine Key and, as a consequence of this rigid restriction, several false positives were recorded. False positives occur when depleted oxygen isotope residual values are recorded during years when there is no tropical cyclone activity within the defined area around the sampling location. Under the $100 \mathrm{~km}$ radial restriction, there were 11 years with depleted $\delta^{18} \mathrm{O}$ tree-ring cellulose residuals (Table 4.7). When the radius is widened to $225 \mathrm{~km}$, a value comparable to the previous studies (Miller et al., 2006; Nelson, 2008; Lewis, 2009), the number of false positives is reduced to just 4 years; 1923, 1934, 1973, and 1983. There were 15 additional storms whose tracks passed within $225 \mathrm{~km}$ from Big Pine Key, 14 of which were tropical storms or depressions and one major hurricane, an unnamed storm in 1924 (NHC, 2016). 
The most depleted $\delta^{18} \mathrm{O}$ value in the residual record (-0.644) occurred in the 1973 tree-ring; however, there are no tropical cyclones reported within the expanded radius. The rain bands of tropical cyclones can extend hundreds of kilometers from the center of the storm (Lonfat et al., 2004) and the tropical cyclone-related isotope depletions can be significant even in the most distal reaches of the cyclone (Lawrence and Gedzelman, 1996). In South Florida, tropical cyclones originating from the west tend to have precipitation with more depleted isotopic values, and the center of the storm can be on the western side of the Gulf of Mexico basin and still produce characteristically depleted precipitation in Florida through the far-reaching rain bands (Price et al., 2008). In addition, lower latitude locations have more rainfall and more depleted precipitation, in general (Lawrence, 1998).The hurricane season of 1973 produced fewer storms than normal because it was an El Niño year and it was the first year in over a decade when a hurricane did not make landfall in the United States (Herbert and Frank, 1974). However, there were four tropical cyclones that developed in the western Caribbean, an unnamed tropical depression, Tropical Storms Delia and Gilda, and Hurricane Brenda (NHC, 2016) with rain bands resulting in some precipitation recorded by Key West (NCDC, 2016) (Figure 4.6). Similar tropical cyclones formed near the Yucatan Peninsula in 1923 and 1934, and Hurricane Barry (1983) traversed Central Florida en route to Mexico (NHC, 2016). It is possible that the four false positives in $\delta^{18} \mathrm{O}$ the residual record resulted from the tropical cyclone-derived precipitation originating from storms occurring several hundreds of kilometers away. As an alternative explanation, three of the four years were under the El Niño phase of ENSO (1923, 1973, and 1983) and the isotopic value of the precipitation may have become more depleted from the addition of continentally-sourced air masses to the southern atmospheric circulation patterns (Nelson, 2008). Nelson (2008) reported a similar relationship between false positives and El Niño years, including the years 1973 and 1983, in trees along the Atlantic Coastal Plain. 


\subsection{Conclusions}

The oxygen and carbon isotope records of the P. elliottii var. densa trees of the Lower Florida Keys have been shown to record the influences of tropical cyclone activity occurring both on local and regional scales. The $\delta^{18} \mathrm{O}$ residuals record episodes of tropical cyclone-derived rain and the $\delta^{13} \mathrm{C}$ residuals highlight periods of stress when the trees are recovering from prolonged damage potentially caused by storm surge or high winds. Generally, the study of paleotempestology can only record the activity of storms that made landfall or skirted the coast before dissipating or making a northeasterly turn back into the Atlantic Ocean. However, the isotopic analysis of treerings may allow for the expansion of those boundaries. As more studies like this one are conducted along the Gulf Coast, the Atlantic Coastal Plain, and throughout the Caribbean Sea, regional and site-specific maps of past tropical cyclone activity could simultaneously be created for hundreds of years into the past. There is great potential for analyzing the regional impacts and temporal patterns of the major climate oscillations, such as ENSO and the AMO, superimposed on the changes brought about by true climate change, all on an annual scale. The science of extreme event attribution would greatly benefit from such archives and it could contribute to a better understanding of the past, present, and the future of global circulation patterns.

\subsection{References}

Anderson, W. T., Bernasconi, S. M., McKenzie, J. A., Saurer, M., \& Schweingruber, F. (2002). Model evaluation for reconstructing the oxygen isotopic composition in precipitation from tree-ring cellulose over the last century. Chemical Geology, 182(2), 121-137.

Barnes, J. (1998). Florida's hurricane history. UNC Press Books.

Bradford County Telegraph (1926, October, 22). Hurricane hits lower east coast. Bradford County Telegraph. Retrieved from http://ufdc.ufl.edu/.

Brienen, R. J., Helle, G., Pons, T. L., Guyot, J. L., \& Gloor, M. (2012). Oxygen isotopes in treerings are a good proxy for Amazon precipitation and El Niño-Southern Oscillation variability. Proceedings of the National Academy of Sciences, 109(42), 16957-16962. 
Brooks, E. M. (1945). An analysis of an unusual rainfall distribution in a hurricane (Unpublished doctoral dissertation). Massachusetts Institute of Technology.

Chadwick, R., Good, P., Martin, G., \& Rowell, D. P. (2015). Large rainfall changes consistently projected over substantial areas of tropical land. Nature Climate Change.

Coplen, T. B. (1994). Reporting of stable hydrogen, carbon, and oxygen isotopic abundances (technical report). Pure and Applied Chemistry, 66(2), 273-276.

Cook, E. R., \& Kairiukstis, L. A. (Eds.). (1990). Methods of dendrochronology: applications in the environmental sciences. Springer Science \& Business Media

Coniglio, M., \& Harrison, R. S. (1983). Facies and diagenesis of late Pleistocene carbonates from Big Pine Key, Florida. Bulletin of Canadian Petroleum Geology, 31(3), 135-147.

Cornwall, W. (2016). Efforts to link climate change to severe weather gain ground. Science, 351(6279), 1249-1250.

Craig, H. (1961). Isotopic variations in meteoric waters. Science, 133(3465), 1702-1703.

Crossett, K., Ache, B., Pacheco, P., \& Haber, K. (2013). National coastal population report, population trends from 1970 to 2020. NOAA State of the Coast Report Series, US Department of Commerce, Washington.

Dansgaard, W. (1964). Stable isotopes in precipitation. Tellus, 16(4), 436-468.

DeMaria, M., Knaff, J. A., \& Connell, B. H. (2001). A tropical cyclone genesis parameter for the tropical Atlantic. Weather and Forecasting, 16(2), 219-233.

Dole, M. (1949). The history of oxygen. Science, 109(2822), 77-96.

Dongmann, G., Nürnberg, H. W., Förstel, H., \& Wagener, K. (1974). On the enrichment of H2 180 in the leaves of transpiring plants. Radiation and environmental biophysics, 11(1), 41-52.

Douglass, A. E. (1909). Weather cycles in the growth of big trees. Monthly Weather Review, 37(6), 225-237.

Douglass, A. E. (1920). Evidence of climatic effects in the annual rings of trees. Ecology, 1(1), 2432

Dunn, G. E., \& Miller, B. I. (1961). The hurricane season of 1960. Monthly Weather Review, 89(3), 99-108.

Duryea, M. L., Blakeslee, G. M., Hubbard, W. G., \& Vasquez, R. A. (1996). Wind and trees: A survey of homeowners after Hurricane Andrew. Journal of Arboriculture, 22, 44-50.

Duryea, M. L., \& Kampf, E. (2007). Wind and Trees: Lessons Learned from Hurricanes. University of Florida, IFAS Extension. 
Emanuel, K. (2003). Tropical cyclones. Annual Review of Earth and Planetary Sciences, 31(1), 75.

Emanuel, K. (2005). Divine wind: the history and science of hurricanes. Oxford University Press.

Enfield, D. B., Mestas-Nuñez, A. M., \& Trimble, P. J. (2001). The Atlantic multidecadal oscillation and its relation to rainfall and river flows in the continental US. Geophysical Research Letters, 28(10), 2077-2080.

Epstein, S., Thompson, P., \& Yapp, C. J. (1977). Oxygen and hydrogen isotopic ratios in plant cellulose. Science, 198(4323), 1209-1215.

Farquhar, G. D., Ehleringer, J. R., \& Hubick, K. T. (1989). Carbon isotope discrimination and photosynthesis. Annual review of plant biology, 40(1), 503-537.

Francey, R. J., \& Farquhar, G. D. (1982). An explanation of 13C/12C variations in tree-rings. Nature 297, 28-31.

Frappier, A. B., Sahagian, D., Carpenter, S. J., González, L. A., \& Frappier, B. R. (2007). Stalagmite stable isotope record of recent tropical cyclone events. Geology, 35(2), 111114.

Fritts, H. C. (1976) Tree-rings and Climate. Academic Press, New York.

Gat, J. R. (1996). Oxygen and hydrogen isotopes in the hydrologic cycle. Annual Review of Earth and Planetary Sciences, 24(1), 225-262.

Gat, J. R., Mook, W. G., \& Meijer, H. A. J. (2001). Environmental Isotopes in the Hydrological Cycle, Volume II: Atmospheric Water 55, 56.

Gedzelman, S., Lawrence, J., Gamache, J., Black, M., Hindman, E., Black, R., ... \& Zhang, X. (2003). Probing hurricanes with stable isotopes of rain and water vapor. Monthly Weather Review, 131(6), 1112-1127.

Goldenberg, S. B., Landsea, C. W., Mestas-Nuñez, A. M., \& Gray, W. M. (2001). The recent increase in Atlantic hurricane activity: Causes and implications. Science, 293(5529), 474479 .

Gray, W. M. (1968). Global view of the origin of tropical disturbances and storms. Monthly Weather Review, 96(10), 669-700.

Green, J. W. (1963). (3) Wood Cellulose. In Methods in carbohydrate chemistry, vol. 3: cellulose (pp. 9-20). Academic Press.

Halley, R. B., \& Harris, P. M. (1979). Fresh-water cementation of a 1,000-year-old oolite. Journal of Sedimentary Research, 49(3).

Hanson, S., Nicholls, R., Ranger, N., Hallegatte, S., Corfee-Morlot, J., Herweijer, C., \& Chateau, J. (2011). A global ranking of port cities with high exposure to climate extremes. Climatic change, 104(1), 89-111. 
Harley, G. L., Grissino-Mayer, H. D., \& Horn, S. P. (2011). The dendrochronology of Pinus elliottii in the lower Florida Keys: chronology development and climate response. Tree-Ring Research, 67(1), 39-50

Harley, G. L., Grissino-Mayer, H. D., Franklin, J. A., Anderson, C., \& Köse, N. (2012). Cambial activity of Pinus elliottii var. densa reveals influence of seasonal insolation on growth dynamics in the Florida Keys. Trees, 26(5), 1449-1459.

Harris, D. L. (1963). Characteristics of the hurricane storm surge. Department of Commerce, Weather Bureau.

Helsen, M. M. (2006). On the interpretation of stable isotopes in Antarctic precipitation. Unpublished doctoral dissertation). Utrecht University, The Netherlands.

Henson, B. (2015, September 7). Remembering the Labor Day Hurricane of 1935 in the Florida Keys Retrieved from https://www.wunderground.com.

Herbert, P. J., \& Frank, N. L. (1974). Atlantic hurricane season of 1973. Monthly Weather Review, 102, 280-289.

Hetzinger, S., Pfeiffer, M., Dullo, W. C., Keenlyside, N., Latif, M., \& Zinke, J. (2008). Caribbean coral tracks Atlantic Multidecadal Oscillation and past hurricane activity. Geology, 36(1), $11-14$.

Hippensteel, S. P. (2010). Paleotempestology and the pursuit of the perfect paleostorm proxy. GSA Today, 20(4), 52-53.

Hoefs, J., (1997). Stable isotope geochemistry (Vol. 201). Berlin: Springer.

Hoffmeister, J. E., \& Multer, H. G. (1968). Geology and origin of the Florida Keys. Geological Society of America Bulletin, 79(11), 1487-1502.

Holland, G. J. (1993). Tropical cyclone motion. Global Guide to Tropical Cyclone Forecasting, 31.

Houston, S. H., \& Powell, M. D. (2003). Surface wind fields for Florida Bay hurricanes. Journal of Coastal Research, 503-513.

Jarrell, J. D., Hebert, P. J., \& Mayfield, M. (1992). Hurricane experience levels of coastal county populations from Texas to Maine (Vol. 46). US Department of Commerce, National Oceanic and Atmospheric Administration, National Weather Service, National Hurricane Center.

Knutson, T. R., McBride, J. L., Chan, J., Emanuel, K., Holland, G., Landsea, C., Held, I., Kossin, J.P., Srivastava, A.K.\& Sugi, M. (2010). Tropical cyclones and climate change. Nature Geoscience, 3(3), 157-163.

Landsea, C. W. (2007). Counting Atlantic tropical cyclones back to 1900. Eos, 88(18), 197-202. 
Lawrence, R. J., \& Gedzelman, D. S. (1996). Low stable isotope ratios of tropical cyclone rains. Geophysical Research Letters, 23(5), 527-530.

Lawrence, J. R. (1998). Isotopic spikes from tropical cyclones in surface waters: opportunities in hydrology and paleoclimatology. Chemical Geology, 144(1), 153-160.

Lawrence, J. R., Gedzelman, S. D., Zhang, X., \& Arnold, R. (1998). Stable isotope ratios of rain and vapor in 1995 hurricanes. Journal of Geophysical Research: Atmospheres, 103(D10), 11381-11400.

Lawrence, J. R., Gedzelman, S. D., Gamache, J., \& Black, M. (2002). Stable isotope ratios: hurricane Olivia. Journal of Atmospheric Chemistry, 41(1), 67-82.

Lawrence, J. R., Gedzelman, S. D., Dexheimer, D., Cho, H. K., Carrie, G. D., Gasparini, R., ... \& Biggerstaff, M. I. (2004). Stable isotopic composition of water vapor in the tropics. Journal of Geophysical Research: Atmospheres, 109(D6).

Leavitt, S. W., \& Long, A. (1991). Seasonal stable-carbon isotope variability in tree-rings: possible paleoenvironmental signals. Chemical Geology: Isotope Geoscience section, 87(1), 59-70.

Lewis, D. B. (2009). Deciphering climate form the characterization of ring width, carbon, and oxygen isotopes in latewood tree-ring cellulose, Big Thicket National Preserve, Texas, USA (Unpublished doctoral dissertation). University of Tennessee, Knoxville.

Liu, K. B. (2007). Paleotempestology. Encyclopedia of Quaternary Science. Elsevier, Oxford, 1978-1986.

Liu, K. B., \& Fearn, M. L. (2000). Reconstruction of prehistoric landfall frequencies of catastrophic hurricanes in northwestern Florida from lake sediment records. Quaternary Research, 54(2), 238-245.

Lonfat, M., Marks Jr, F. D., \& Chen, S. S. (2004). Precipitation distribution in tropical cyclones using the Tropical Rainfall Measuring Mission (TRMM) microwave imager: A global perspective. Monthly Weather Review, 132(7), 1645-1660.

McCarroll, D., \& Loader, N. J. (2004). Stable isotopes in tree-rings. Quaternary Science Reviews, 23(7), 771-801.

Majoube, M. (1971). Oxygen-18 and deuterium fractionation between water and steam. Journal de Chimie Physique et de Physico-Chimie Biologique, 68(10), 1423.

Managave, S. R., Sheshshayee, M. S., Borgaonkar, H. P., \& Ramesh, R. (2010). Past breakmonsoon conditions detectable by high resolution intra-annual $\delta 18 \mathrm{O}$ analysis of teak rings. Geophysical Research Letters, 37(5).

Mann, M. E., \& Emanuel, K. A. (2006). Atlantic hurricane trends linked to climate change. Eos, Transactions American Geophysical Union, 87(24), 233-241. 
Mann, M. E., Woodruff, J. D., Donnelly, J. P., \& Zhang, Z. (2009). Atlantic hurricanes and climate over the past 1,500 years. Nature, 460(7257), 880-883.

Miller, D. L., Mora, C. I., Grissino-Mayer, H. D., Mock, C. J., Uhle, M. E., \& Sharp, Z. (2006). Tree-ring isotope records of tropical cyclone activity. Proceedings of the National Academy of Sciences, 103(39), 14294-14297.

Mock, C. J. (2004). Tropical cyclone reconstructions from documentary records; examples from South Carolina. Hurricanes and Typhoons: Past Present and Potential, 121-148.

Moses, C. S., Anderson, W. T., Saunders, C., \& Sklar, F. (2013). Regional climate gradients in precipitation and temperature in response to climate teleconnections in the Greater Everglades ecosystem of South Florida. Journal of paleolimnology, 49(1), 5-14.

Munksgaard, N. C., Zwart, C., Kurita, N., Bass, A., Nott, J., \& Bird, M. I. (2015). Stable isotope anatomy of tropical cyclone Ita, North-Eastern Australia, April 2014. PloS one, 10(3), e0119728.

National Academies of Sciences, Engineering, and Medicine (NASEM). (2016). Attribution of extreme weather events in the context of climate change. The National Academies Press. doi:10.17226/21852.

National Climate Data Center (NCDC). (2016). NOAA climate data inventories for Florida. National Oceanic and Atmospheric Administration Satellite and Information Service, web. http://www.csc.noaa.gov/

National Hurricane Center (NHC). (2016). Tropical cyclone climatology. National Oceanic and Atmospheric Administration, web. http://www.nhc.noaa.gov/climo/

National Weather Service (NWS). 2016 Florida Keys climatology: record temperature and precipitation tables. http://www.srh.noaa.gov/

Nelson, W. L. (2008). Assessing the tree-ring oxygen isotope hurricane proxy along the Atlantic and Gulf coastal seaboard (Unpublished doctoral dissertation). University of Tennessee, Knoxville.

Neumann, C. J. (1993). Global Overview, Chapter 1 Global Guide to Tropical Cyclone Forecasting, WMO. TC, (560).

Nicholls, R.J., P.P. Wong, V.R. Burkett, J.O. Codignotto, J.E. Hay, R.F. McLean, S. Ragoonaden and C.D. Woodroffe. (2007). Coastal systems and low-lying areas. Climate Change 2007: Impacts, Adaptation and Vulnerability. Contribution of Working Group II to the Fourth Assessment Report of the Intergovernmental Panel on Climate Change, M.L. Parry, O.F. Canziani, J.P. Palutikof, P.J. van der Linden and C.E. Hanson, Eds., Cambridge University Press,.

Nicolini, E., Jusserand, C., Blavoux, B., Coudray, J., Eberschweiler, C., Mairine, P., \& Aubouin, J. (1989). Appauvrissement en isotopes lourds des précipitations liées aux 
cyclones. Comptes rendus de l'Académie des sciences. Série 2, Mécanique, Physique, Chimie, Sciences de l'univers, Sciences de la Terre, 309(11), 1255-1260.

Nott, J., \& Hayne, M. (2001). High frequency of 'super-cyclones' along the Great Barrier Reef over the past 5,000 years. Nature, 413(6855), 508-512.

Ogurcak, D. E. (2015). The effect of disturbance and freshwater availability on Lower Florida Keys' coastal forest dynamics (Unpublished doctoral dissertation). Florida International University, Miami, Florida.

O'Leary, M. H. (1988). Carbon isotopes in photosynthesis: fractionation techniques may reveal new aspects of carbon dynamics in plants. Bioscience, 38(5), 328-336.

Pearman, G. I., Francey, R. J., \& Fraser, P. J. B. (1976). Climatic implications of stable carbon isotopes in tree-rings. Nature, 260(5554), 771-773.

Peel, M. C., Finlayson, B. L., \& McMahon, T. A. (2007). Updated world map of the Köppen-Geiger climate classification. Hydrology and earth system sciences discussions, 4(2), 439-473.

Price, R. M., Swart, P. K., \& Willoughby, H. E. (2008). Seasonal and spatial variation in the stable isotopic composition $\left(\delta^{18} \mathrm{O}\right.$ and $\left.\delta \mathrm{D}\right)$ of precipitation in south Florida. Journal of Hydrology, 358(3), 193-205.

Querejeta, J. I., Estrada-Medina, H., Allen, M. F., \& Jiménez-Osornio, J. J. (2007). Water source partitioning among trees growing on shallow karst soils in a seasonally dry tropical climate. Oecologia, 152(1), 26-36.

Rappaport, E. N., Fuchs, M., \& Lorenston, M. (1999). The threat to life in inland areas of the United States from Atlantic tropical cyclones. In Preprints, 23d Conf. on Hurricanes and Tropical Meteorology, Dallas, TX, Amer. Meteor. Soc (pp. 811-814).

Roden, J. S., Lin, G., \& Ehleringer, J. R. (2000). A mechanistic model for interpretation of hydrogen and oxygen isotope ratios in tree-ring cellulose. Geochimica et Cosmochimica Acta, 64(1), 21-35.

Ross, M. S., O'Brien, J. J., \& Flynn, L. J. (1992). Ecological site classification of Florida Keys terrestrial habitats. Biotropica, 488-502.

Ross, M. S., O'Brien, J. J., \& da Silveira Lobo Sternberg, L. (1994). Sea-Level Rise and the Reduction in Pine Forests in the Florida Keys. Ecological Applications, 4(1), 144-156.

Ross, M. S., O'Brien, J. J., Ford, R. G., Zhang, K., \& Morkill, A. (2009). Disturbance and the rising tide: the challenge of biodiversity management on low-island ecosystems. Frontiers in Ecology and the Environment, 7(9), 471-478.

Rowlett, R. (2004). How many? A dictionary of units of measurements. https://www.unc.edu/ rowlett/units/index.html. 
Rozanski, K., Araguás-Araguás, L., \& Gonfiantini, R. (1993). Isotopic patterns in modern global precipitation. Climate change in continental isotopic records, 1-36.

Sah, J. P., Ross, M. S., Snyder, J. R., \& Ogurcak, D. E. (2010). Tree mortality following prescribed fire and a storm surge event in slash pine (Pinus elliottii var. densa) forests in the Florida Keys, USA. International Journal of Forestry Research, 2010.

Santer, B. D., Wigley, T. M. L., Gleckler, P. J., Bonfils, C., Wehner, M. F., AchutaRao, K., ... \& Gillett, N. (2006). Forced and unforced ocean temperature changes in Atlantic and Pacific tropical cyclogenesis regions. Proceedings of the National Academy of Sciences, 103(38), 13905-13910.

Saurer, M., Aellen, K. A. S. R., \& Siegwolf, R. (1997). Correlating $\delta 13 \mathrm{C}$ and $\delta 18 \mathrm{O}$ in cellulose of trees. Plant, Cell \& Environment, 20(12), 1543-1550.

Schott, T., Landsea, C., Hafele, G., Lorens, J., Taylor, A., Thurm, H., ... \& Zaleski, W. (2012). The Saffir-Simpson hurricane wind scale. National Weather Services, National Hurricane Centre, National Oceanic and Atmospheric Administration (NOAA) factsheet. URL: http://www.nhc.noaa.gov/pdf/sshws.pdf.

Schweingruber, F. H. (1988). Tree-rings. Springer Science \& Business Media.

Smith, A. B., \& Katz, R. W. (2013). US billion-dollar weather and climate disasters: data sources, trends, accuracy and biases. Natural hazards, 67(2), 387-410.

Sternberg, L S.D. L., Mulkey, S. S., \& Wright, S. J. (1989). Oxygen isotope ratio stratification in a tropical moist forest. Oecologia, 81(1), 51-56.

Stott, P. A., Christidis, N., Otto, F. E., Sun, Y., Vanderlinden, J. P., van Oldenborgh, G. J., ... \& Zwiers, F. W. (2016). Attribution of extreme weather and climate-related events. Wiley Interdisciplinary Reviews: Climate Change, 7(1), 23-41.

Tang, K., \& Feng, X. (2001). The effect of soil hydrology on the oxygen and hydrogen isotopic compositions of plants' source water. Earth and Planetary Science Letters, 185(3), 355367.

The Canberra Times (1948, September 23). Storm damage at U.S. naval base in Florida. The Canberra Times. Retrieved from http://trove.nla.gov.au/.

The Key West Citizen (1948, October 6). Key West damage slight. The Key West Citizen. Retrieved from http://ufdc.ufl.edu/.

Tokay, A., Wolff, D. B., Wolff, K. R., \& Bashor, P. (2003). Rain gauge and disdrometer measurements during the Keys Area Microphysics Project (KAMP). Journal of Atmospheric and Oceanic Technology, 20(11), 1460-1477.

Tomlinson, P. B., \& Craighead, F. C. (1972). Growth-ring studies on the native trees of sub-tropical Florida. Ghouse, A, K, M, Yunus, $M$ ed(s). Research trends in plant anatomy. Reprint, 4894, 39-51. 
Trenberth, K. E., Fasullo, J. T., \& Shepherd, T. G. (2015). Attribution of climate extreme events. Nature Climate Change.

Sandrik, A., \& Landsea, C. (2003). Chronological listing of tropical cyclones affecting north Florida and coastal Georgia, 1565-1899. US Department of Commerce, National Oceanic and Atmospheric Administration, National Weather Service, Southern Region, Scientific Services Division.

Schaller, N., Kay, A. L., Lamb, R., Massey, N. R., Van Oldenborgh, G. J., Otto, F. E., ... \& Bowery, A. (2016). Human influence on climate in the 2014 southern England winter floods and their impacts. Nature Climate Change.

Sea Systems Corporation. (1998). South Florida high water marks - post Georges. United States Army Corps of Engineers, Jacksonville District, Survey Number 98-282, 141 pp.

United States Fish and Wildlife Service (USFWS). (1999). South Florida Multi-Species Recovery Plan: Pine Rocklands. United States Fish and Wildlife Service, Atlanta.

Urey, H. C. (1947). The thermodynamic properties of isotopic substances. Journal of the Chemical Society (Resumed), 562-581.

Vacher, H. L., Wightman, M. J., \& Stewat M. T. (1992). Hydrology of meteoric diagenesis: effect of Pleistocene stratigraphy on freshwater lenses of Big Pine Key, Florida. In Quaternary coasts of the United States: marine and lacustrine systems v 48. (pp. 213-219). Society of Economic Paleontologists and Mineralogists Special Publications.

Van Rees, K. C. J., \& Comerford, N. B. (1986). Vertical root distribution and strontium uptake of a slash pine stand on a Florida spodosol. Soil Science Society of America Journal, 50(4), 1042-1046.

Vecchi, G. A., \& Knutson, T. R. (2008). On Estimates of Historical North Atlantic Tropical Cyclone Activity*. Journal of Climate, 21(14), 3580-3600.

Wang, P., \& Horwitz, M. H. (2007). Erosional and depositional characteristics of regional overwash deposits caused by multiple hurricanes. Sedimentology, 54(3), 545-564.

Wightman, M. J. (1990). Geophysical analysis and Dupuit-Ghyben-Herzberg modeling of freshwater lenses on Big Pine Key, Florida (Unpublished Master of Science thesis). University of South Florida, Tampa, Florida.

Worbes, M. (2002). One hundred years of tree-ring research in the tropics-a brief history and an outlook to future challenges. Dendrochronologia, 20(1), 217-231. 


\subsection{Figures}

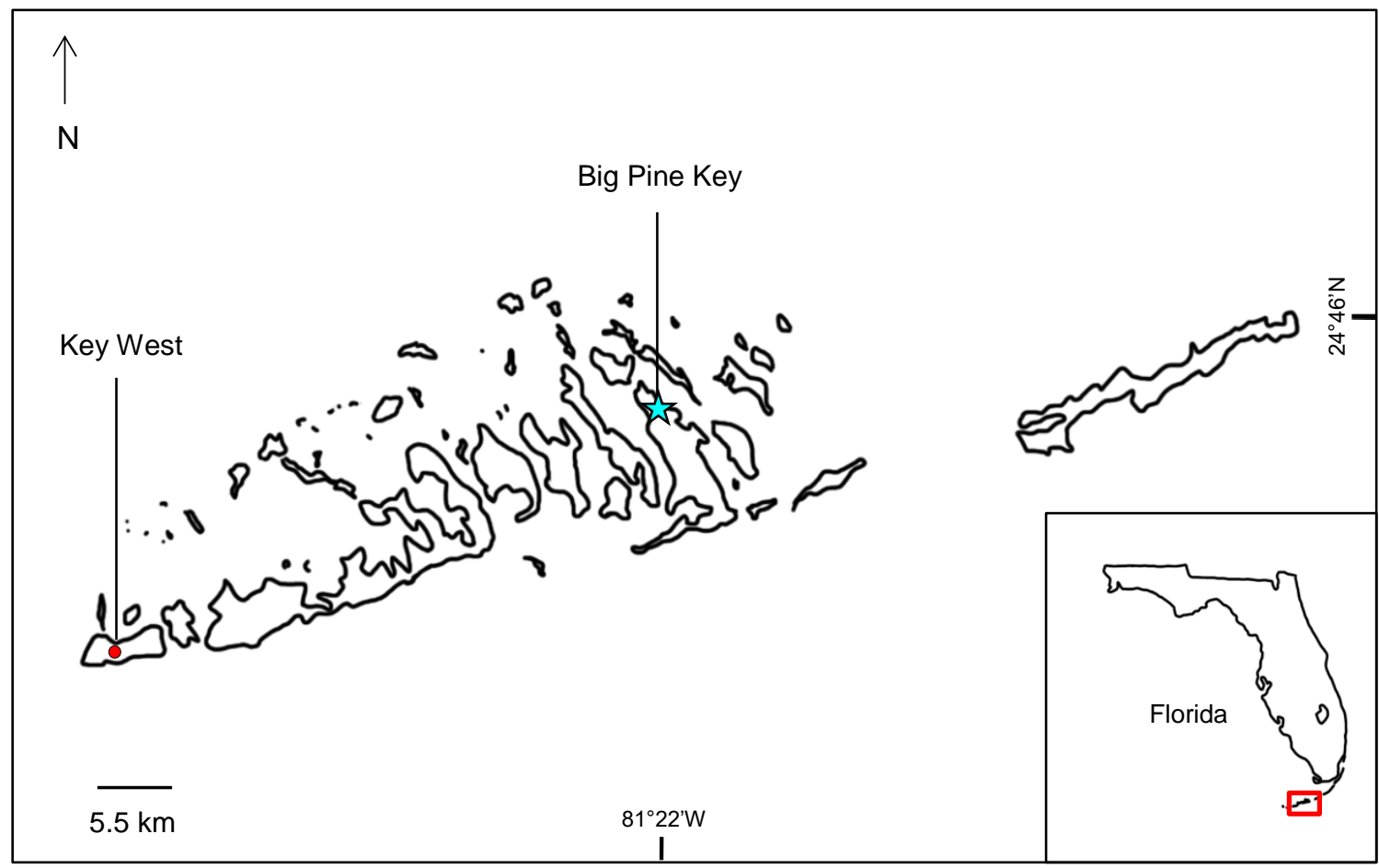

Figure 4.1 Map of the Lower Florida Keys showing the sampling site on Big Pine Key (blue star) and the location of the nearest, historically continuous climate station, Key West (red circle). The red box in the inset shows the area of the Florida Keys referenced. 

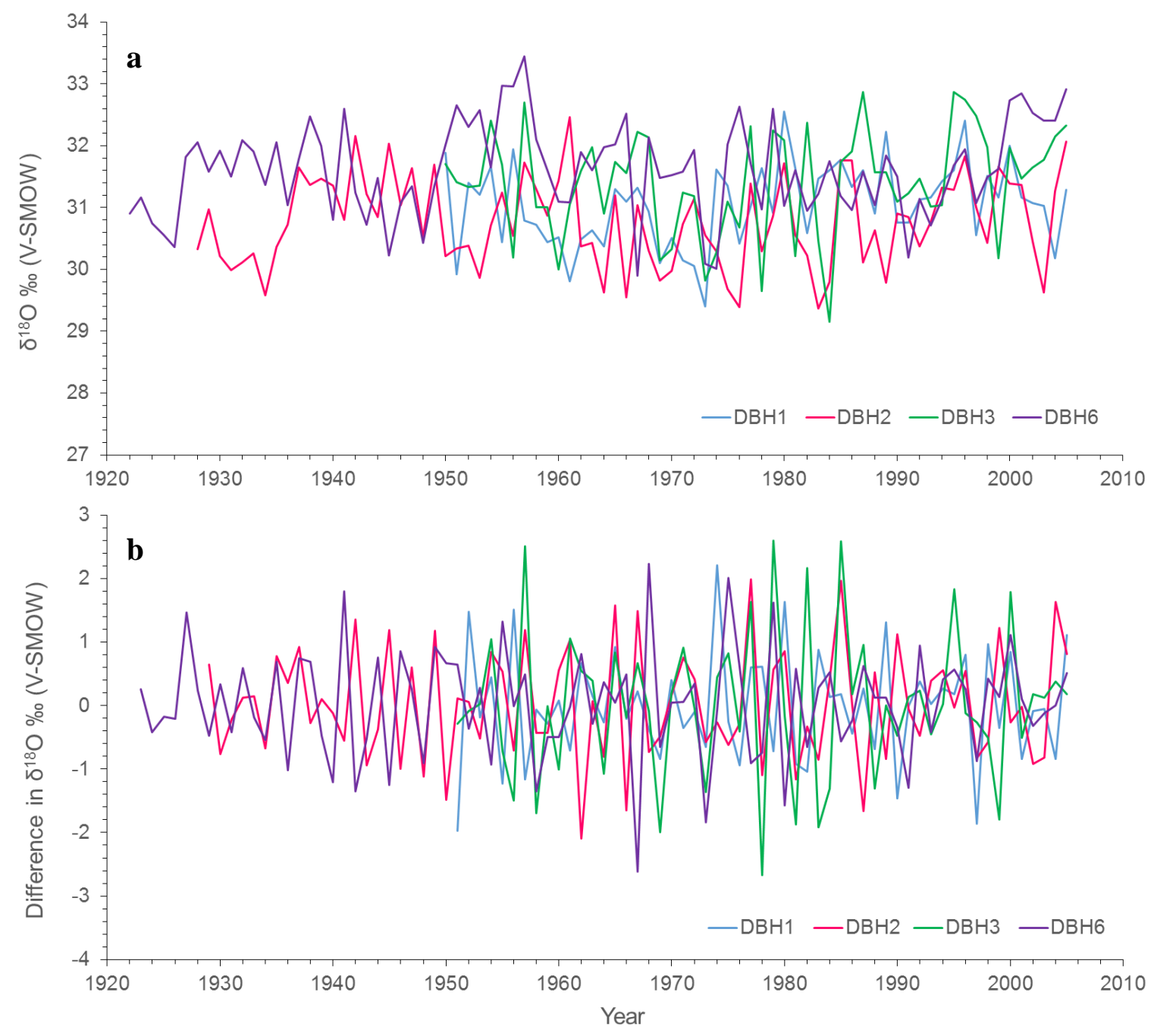

Figure 4.2 Oxygen isotope values for the four P. elliottii var. densa trees. a) Latewood $\delta^{18} \mathrm{O}$ measurements for individual trees (\%o V-SMOW). Trees DBH1 and DBH3 span the period 19502005, while the time series for DBH2 and DBH6 extend to 1928 and 1922, respectively. b) The first-order difference values for each tree in per mil $\left(\delta^{18} \mathrm{Ot}_{2}-\delta^{18} \mathrm{Ot}_{1}\right)$. There are variations in the amplitudes of the annual values among individuals; however, the trees follow similar trends during several periods throughout the time series. 


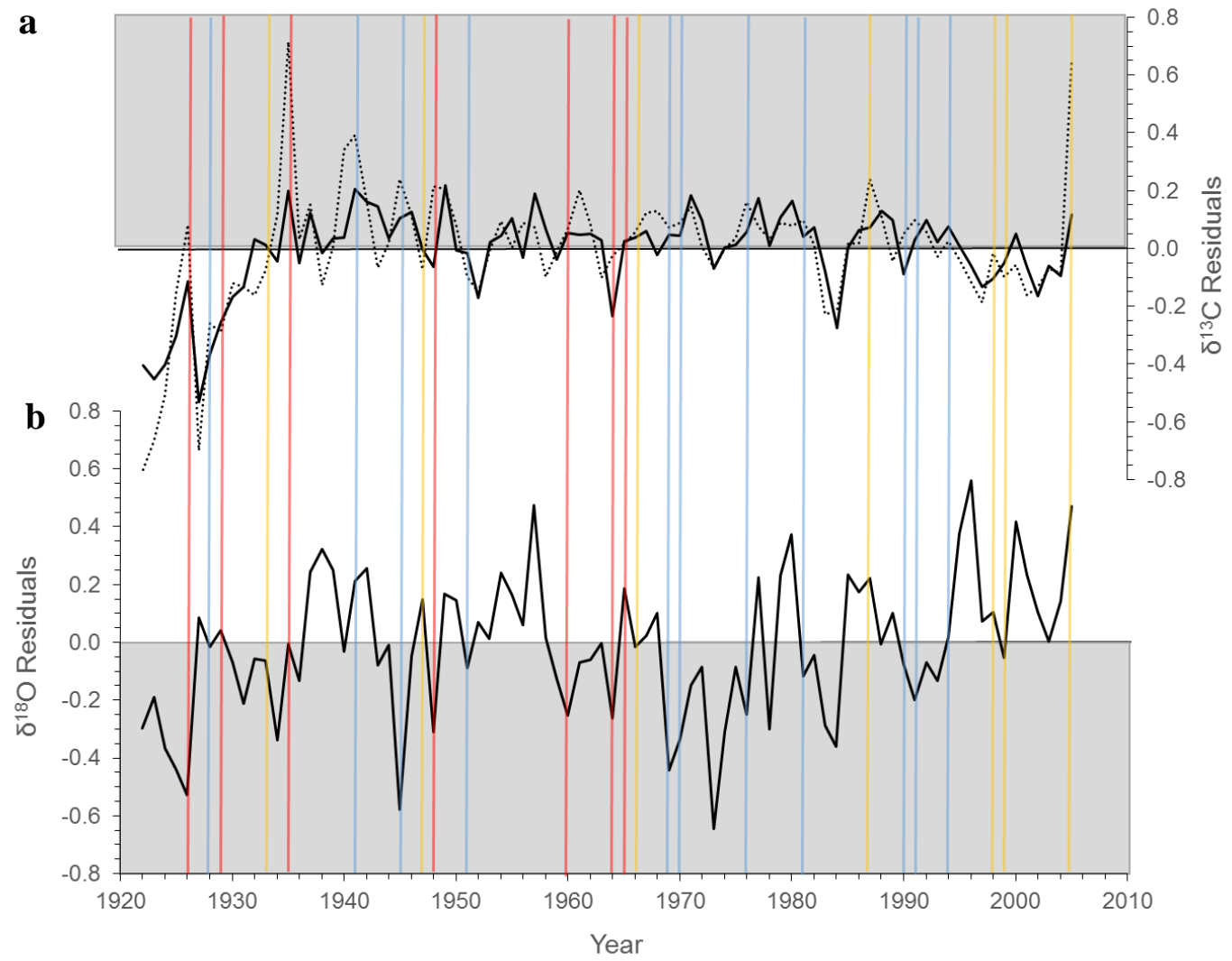

Figure 4.3 Combined average carbon and oxygen residuals for the four P. elliottii var. densa trees from Big Pine Key over the period 1922 - 2005. a) Carbon isotope residuals for the latewood (solid black line) and the one season offset earlywood (dashed line) samples. The gray shaded area includes all residuals greater than zero; indicating enriched $\delta^{13} \mathrm{C}$ values and possible sustained periods of environmental stress. b) Oxygen isotope residual values for the latewood tree-rings. All residual values less than zero are included in the gray shaded box. Previous studies have defined the threshold for anomalously depleted oxygen residual values as $\geq-0.5$; however, that value may be too stringent for the Big Pine Key data. The solid vertical lines highlight all tropical cyclone events within $100 \mathrm{~km}$ of Big Pine Key occurring between the years 1922-2005 (See table 4.3). Blue lines are tropical depressions and tropical storms, orange lines are minor hurricanes (categories 1 and 2) and red lines are major hurricanes (categories $3-5$ ). In years with multiple tropical cyclone events, the color representing the strongest storm is used. 


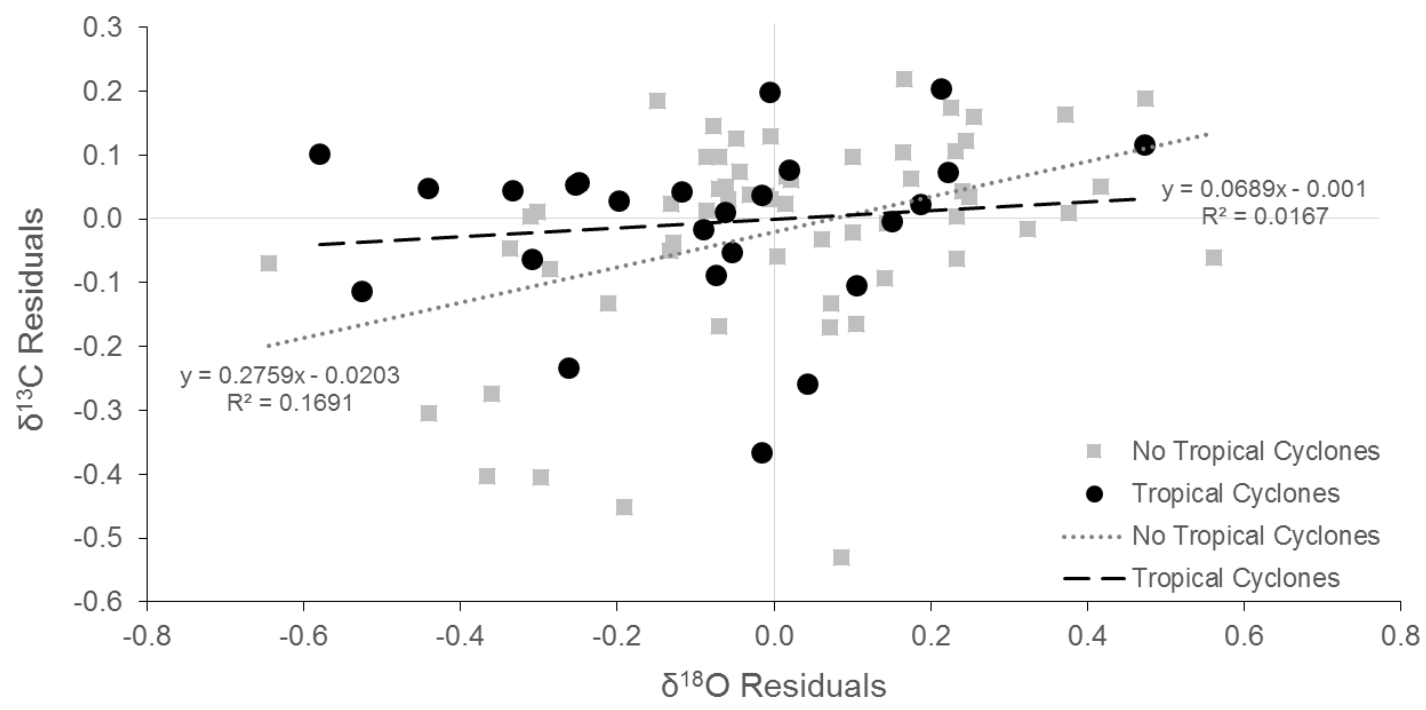

Figure 4.4 Plot showing the relationship between corresponding latewood carbon and oxygen isotope residuals for the years 1922-2005. The gray boxes represent years when there were no reported tropical cyclone activity within a $250 \mathrm{~km}$ radius of Big Pine Key, while the black circles indicate years with tropical cyclone activity. The data do not follow the predicted relationship of enriched carbon isotope residuals corresponding to depleted oxygen isotope residuals during tropical cyclone years. There is little difference in the relationship between the carbon and oxygen isotopes during tropical cyclone versus non-tropical cyclone seasons. 

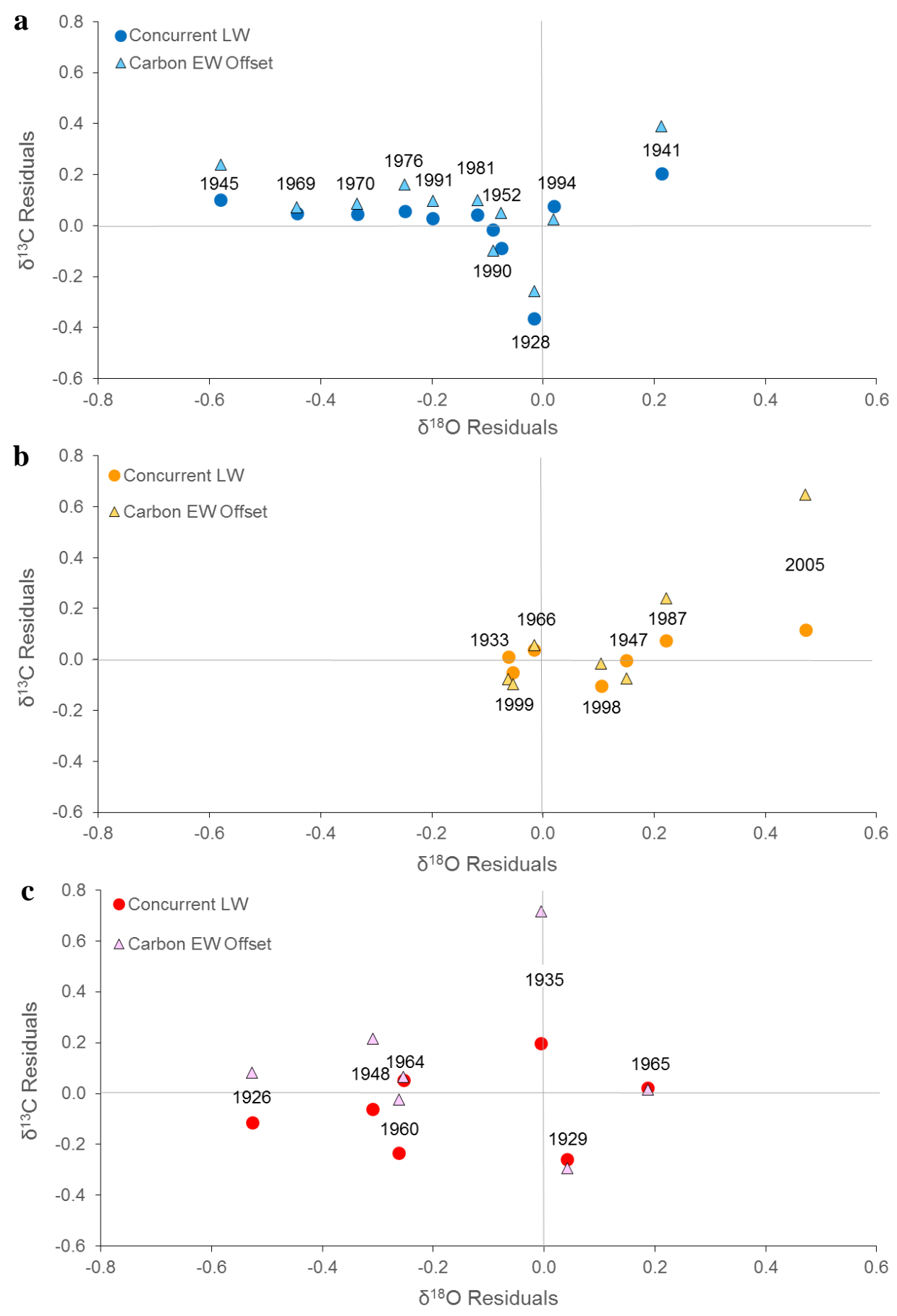

Figure 4.5 Carbon and oxygen isotope residuals by tropical cyclone type for the years 1922-2005. In all graphs, the circles represent the concurrent latewood (LW) residuals for both carbon isotopes and oxygen isotopes and the triangles show a one season offset where the current latewood oxygen isotope residual is plotted with carbon isotope residual for the next earlywood (EW) season. The hurricane seasons are labeled by year and, when possible, the label is placed between the two data points for each year. a) Tropical storms and tropical depressions. b) Minor hurricanes (categories 1-2). c) Major hurricanes (categories 3-5). See text for discussion. 

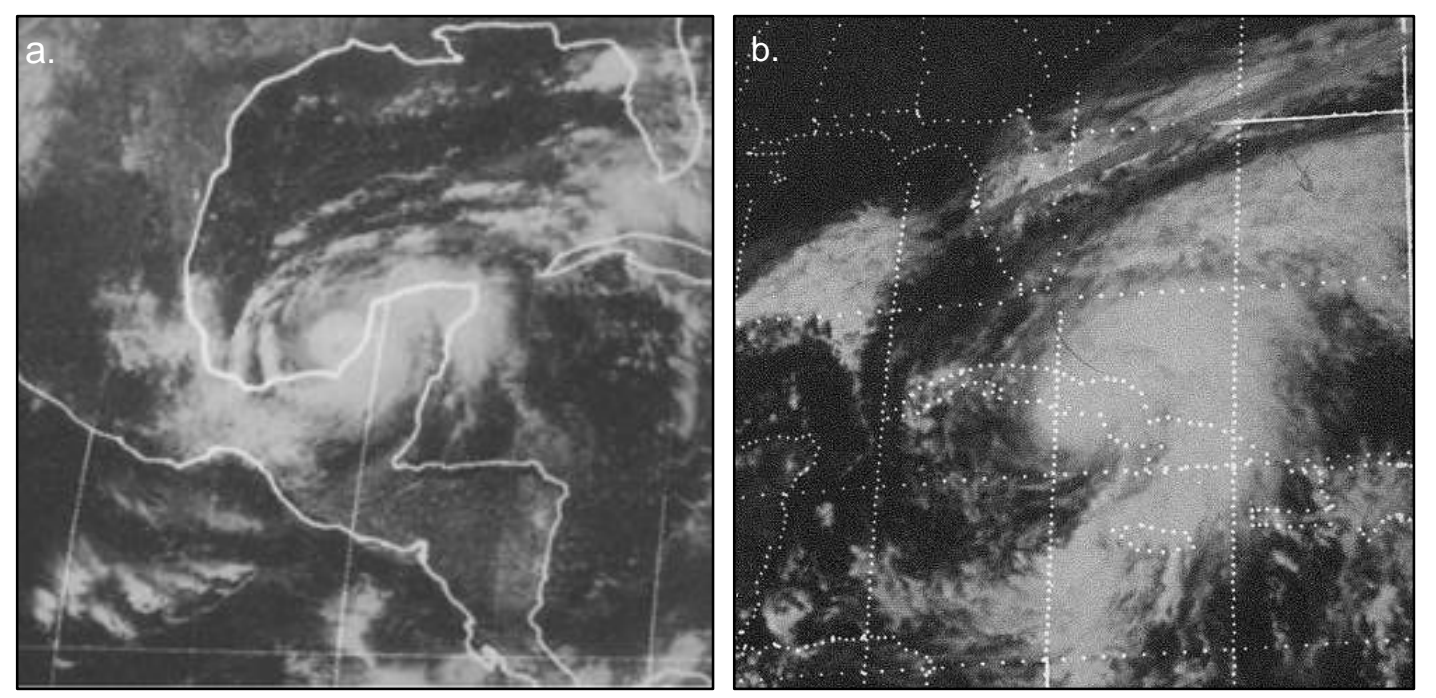

Figure 4.6 Satellite images of two tropical cyclones from the 1973 hurricane season. a) Hurricane Brenda which formed near the Yucatan Peninsula in late August, arced westward and made landfall in the Yucatan. The rain bands are shown extending across the southern Gulf of Mexico to the Florida Keys. b) Tropical Storm Gilda formed in the Caribbean Sea and crossed central Cuba as it moved out into the Atlantic Ocean. The two storms could have contributed to the precipitation recorded by the Key West weather station and to the most depleted $\delta^{18} \mathrm{O}$ residual value in the treering chronology. Image source: The National Hurricane Center Archive http://www.nhc.noaa.gov/archive. 
4.9 Tables

Table 4.1 Saffir-Simpson Hurricane Intensity Scale

\begin{tabular}{|c|c|c|c|c|}
\hline \multirow[t]{2}{*}{ Category } & \multicolumn{2}{|c|}{$\begin{array}{c}\text { Maximum Sustained Wind } \\
\text { Speed }\end{array}$} & \multirow{2}{*}{$\begin{array}{c}\text { Minimum Surface } \\
\text { Pressure } \\
\mathrm{mb}\end{array}$} & \multirow{2}{*}{$\begin{array}{c}\text { Storm Surge } \\
m^{\star}\end{array}$} \\
\hline & $\mathrm{km} / \mathrm{h}$ & kts & & \\
\hline 1 & $119-153$ & $64-82$ & $>980$ & $1.0-1.7$ \\
\hline 2 & $154-177$ & $83-95$ & $979-965$ & $1.8-2.6$ \\
\hline 3 & $178-208$ & $96-112$ & $964-945$ & $2.7-3.8$ \\
\hline 4 & $209-251$ & $113-136$ & $944-920$ & $3.9-5.6$ \\
\hline 5 & $>252$ & $>137$ & $<920$ & $>5.7$ \\
\hline
\end{tabular}

Table 4.1 Saffir-Simpson Hurricane Intensity Scale. Classification of hurricane intensity by wind speed. *Actual storm surge inundation depends heavily on coastal morphology, the speed at which the hurricane is moving, and the angle of the wind direction relative to the coast. Table is modified from Rowlett (2004) and Schott et al. (2012). 





Table 4.3 Tropical Cyclone Activity for 1922-2005 within a $100 \mathrm{~km}$ Radius of Big Pine Key

\begin{tabular}{cccccc}
\hline Date & Tropical Cyclone & $\begin{array}{c}\text { Closest } \\
\text { Approach }\end{array}$ & $\begin{array}{c}\text { Category at } \\
\text { Passage }\end{array}$ & $\begin{array}{c}\text { Key West } \\
\text { Precipitation } \\
(\mathrm{cm})\end{array}$ & $\begin{array}{c}\text { Wind Speed } \\
(\mathrm{kts})\end{array}$ \\
\hline \hline 1926 & Unnamed & Oct 21 & H3/H4 & - & 110 \\
1928 & Unnamed & Aug 13 & TS & - & 60 \\
1929 & Unnamed & Sep 28 & H2/H3 & - & $95-100$ \\
1933 & Unnamed & Oct 5 & H2 & $34.39^{\star}$ & 95 \\
1935 & Labor Day Hurricane & Sep 3 & H5 & - & 160 \\
1941 & Unnamed & Oct 17 & TD & - & 25 \\
1945 & Unnamed & Sep 4 & TS & $9.19^{\star}$ & 35 \\
1947 & Unnamed & Oct 12 & H1 & - & 80 \\
1948 & Unnamed & Sep 21 & H3 & $11.50^{\star}$ & 105 \\
& Unnamed & Oct 5 & H2/H3 & $11.45^{\star}$ & $90-105$ \\
1952 & Unnamed & Feb 3 & TS & 5.33 & 35 \\
1960 & Donna & Sep 10 & H4 & 5.08 & $115-120$ \\
& Florence & Sep 23 & TD & 4.06 & 25 \\
1964 & Isbell & Oct 14 & H3 & 3.55 & 110 \\
1965 & Betsy & Sep 8 & H3 & $9.91^{*}$ & 110 \\
1966 & Inez & Oct 5 & H1 & 2.54 & 75 \\
1969 & Jenny & Oct 21 & TD/TS & 0.23 & $30-40$ \\
1970 & Felice & Sep 13 & TD & 0 & 30 \\
& Greta & Sep 27 & TD/TS & 2.26 & $30-45$ \\
1976 & Dottie & Aug 19 & TD/TS & 6.35 & $30-35$ \\
1981 & Dennis & Aug 16 & TS & 11.83 & 30 \\
1987 & Floyd & Oct 12 & H1 & 12.06 & 65 \\
1990 & Marco & Oct 10 & TS & 9.42 & $35-40$ \\
1991 & Fabian & Oct 16 & TS & 5.48 & 40 \\
1994 & Gordon & Nov 15 & TS & 2.39 & 45 \\
1998 & Georges & Sep 25 & H2 & $21.28^{\star}$ & 90 \\
1999 & Irene & Oct 15 & H1 & $21.82^{*}$ & 65 \\
2005 & Katrina & Aug 26 & H1 & $24.54^{*}$ & $65-75$ \\
& Rita & Sep 20 & H1/H2 & 9.47 & $70-95$ \\
\hline
\end{tabular}

Table 4.3 Tropical Cyclone Activity for 1922-2005 within a 100km Radius of Big Pine Key. Bold font indicates that the eye of the hurricane passed within $25 \mathrm{~km}$ of Big Pine Key. * Record precipitation for that date, as of May 2016. - Instrumental data unavailable. Data from The National Hurricane Center (http://www.nhc.noaa.gov) and National Climate Data Center website (http://www.csc.noaa.gov/). 
Table 4.4 Paired T-Test Comparison of Individual Trees

\begin{tabular}{cccccc}
\hline Trees & Mean & $\begin{array}{c}\text { Standard } \\
\text { Error }\end{array}$ & T-value & P-value & $\begin{array}{c}\text { Number of } \\
\text { Observations }\end{array}$ \\
\hline \hline DBH1-DBH2 & 0.01 & 0.90 & -0.26 & 0.80 & 55 \\
DBH1-DBH3 & 0.00 & 1.04 & -0.11 & 0.91 & 55 \\
DBH1-DBH6 & 0.00 & 0.88 & -0.16 & 0.87 & 55 \\
DBH2-DBH3 & 0.02 & 1.06 & 0.14 & 0.89 & 55 \\
DBH2-DBH6 & 0.02 & 0.88 & 0.07 & 0.94 & 77 \\
DBH3-DBH6 & 0.01 & 1.05 & -0.03 & 0.98 & 55 \\
\hline
\end{tabular}

Table 4.4 Paired T-Test Comparison of Individual Trees. Table contains data for all combinations of individual P. elliottii var. densa trees. All trees were compared over the years 1950-2005 with the exception of DBH2-DBH6, in which a longer time series, 1928-2005, was used. No combination of two trees was found to be statistically different from each other. 


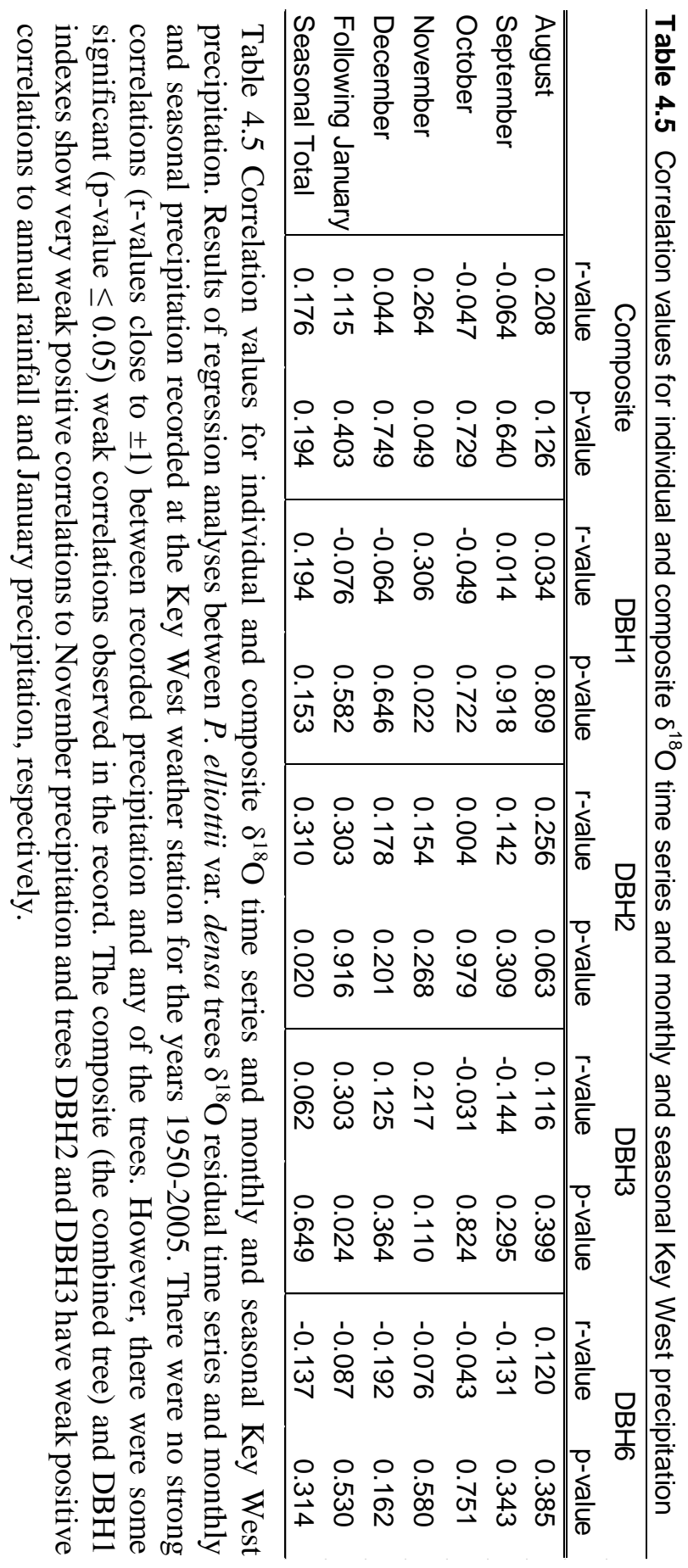




\begin{tabular}{|c|c|c|c|c|c|}
\hline \multirow{2}{*}{ Year } & \multicolumn{5}{|c|}{ Tree } \\
\hline & DBH1 & DBH2 & DBH3 & DBH6 & Composite \\
\hline 1926 & & & & $\bar{x}$ & $\bar{x}$ \\
\hline 1928 & & & & & \\
\hline 1929 & & & & & \\
\hline 1933 & & $x$ & & & $x$ \\
\hline 1935 & & $x$ & & & \\
\hline 1941 & & & & & \\
\hline 1945 & & & & $x$ & $x$ \\
\hline 1947 & & & & & \\
\hline 1948 & & & & $x$ & $x$ \\
\hline 1952 & $x$ & $x$ & & & $x$ \\
\hline 1960 & $x$ & & $x$ & $x$ & $x$ \\
\hline 1964 & $x$ & $x$ & $x$ & & $x$ \\
\hline 1965 & & & & & \\
\hline 1966 & & $x$ & & & \\
\hline 1969 & $x$ & & $x$ & & $x$ \\
\hline 1970 & $x$ & & $x$ & & $x$ \\
\hline 1976 & $x$ & $x$ & & & $x$ \\
\hline 1981 & & & $x$ & & $x$ \\
\hline 1987 & & $x$ & & & \\
\hline 1990 & & & & & $x$ \\
\hline 1991 & & & & $x$ & $x$ \\
\hline 1994 & & & $x$ & & \\
\hline 1998 & & $x$ & & & \\
\hline 1999 & & & $x$ & & $x$ \\
\hline 2005 & & & & & \\
\hline
\end{tabular}

Table 4.6 Tropical cyclones recorded in the $\delta^{18} \mathrm{O}$ residual values. An " $\mathrm{X}$ " denotes that time series recorded an oxygen isotope residual value $<-0.01$ during years with reported tropical cyclone activity. The blue boxes indicate tropical cyclones with at least $5.0 \mathrm{~cm}$ of associated precipitation recorded at the Key West weather station. 
Table 4.7 Anomalies in the Oxygen Residual Record

\begin{tabular}{cc|cc}
\hline \multicolumn{2}{|c|}{ False Negatives } & \multicolumn{2}{c|}{ False Positives } \\
Year & $\begin{array}{c}\delta^{-18} \text { O Residual } \\
\text { Value }\end{array}$ & Year & $\begin{array}{c}\delta^{18} \text { O Residual } \\
\text { Value }\end{array}$ \\
\hline \hline 1929 & 0.041 & 1923 & -0.190 \\
1941 & 0.213 & 1924 & -0.356 \\
1947 & 0.150 & 1931 & -0.210 \\
1965 & 0.186 & 1934 & -0.337 \\
1987 & 0.221 & 1936 & -0.132 \\
1998 & 0.104 & 1959 & -0.127 \\
2005 & 0.472 & 1971 & -0.149 \\
& & 1973 & -0.644 \\
& & 1978 & -0.301 \\
& & 1983 & -0.286 \\
& & 1984 & -0.359 \\
\hline
\end{tabular}

Table 4.7 Anomalies in the Oxygen Residual Record. List of years with false negatives and false positives in the $\delta^{18} \mathrm{O}$ residuals in the combined tree time series. False negatives are years with reported tropical cyclones occurring within $100 \mathrm{~km}$ of Big Pine Key but the storms are not recorded in the $\delta^{18} \mathrm{O}$ residual values (residual values > zero). False positives in the oxygen residual record are indicated by residual values less than -0.1 in years without tropical cyclone activity. 


\section{CHAPTER 5: SUMMARY AND CONCLUSIONS}

Trees are repositories of subannual information concerning their physiologic responses to changes in its environment. Collectively, tree-ring studies have produced paleoclimate reconstructions spanning centuries, yet the vast majority of studies are concentrated in the temperate latitudes of the northern hemisphere. There is a dearth of dendrochronology archives for the tropical region. The recent interest in high-resolution climate forecast modelling for the coastal regions that are highly susceptible to climate change has enhanced the need for reliable tropical paleoclimate archives.

Dendrochronology studies are limited in the subtropics because precipitation-driven seasonality can lead to the production of complex physical ring structures that are challenging to interpret and to crossdate among trees. The slash pine, Pinus elliottii Engelm. var. densa, of the pine rocklands in the Lower Florida Keys produces visually distinct rings; however, the frequent appearance of intra-annual density fluctuations, IADFs, complicates their dendrochronological interpretation. Previous studies using ring width measurements for P. elliottii var. densa in the Lower Keys have not been able to establish correlations with the major climate drivers controlling South Florida precipitation, the El Niño-Southern Oscillation (ENSO) and the Atlantic Multidecadal Oscillation (AMO). This study utilized the carbon $\left(\delta^{13} \mathrm{C}\right)$ and oxygen $\left(\delta^{18} \mathrm{O}\right)$ isotope records in the tree-ring cellulose of four $P$. elliottii var. densa trees to overcome the limitations of the physical ring structures and to extract information about the chemical responses of trees to tropical cyclone activity and climate trends and patterns.

The carbon isotope record in both the earlywood (lighter, thin-walled cells growing in the spring and early summer) and the latewood (darker, thick-walled cells produced in the late-summer and fall) was used to build a chronology. Traditional dendrochronology studies crossdate the patterns 
in tree-ring width measurements among trees to build a chronology; however, the uneven growth of $P$. elliottii var. densa tree-rings around the circumference of the tree and the inconsistencies in ring boundary definition caused by the IADFs makes crossdating difficult. The patterns in the $\delta^{13} \mathrm{C}$ values among the rings were used identify the IAFDs and to crossdate the four trees to construct a dateable chronology in the same way ring width patterns are used in traditional dendrochronology studies. The IADFs often had $\delta^{13} \mathrm{C}$ values very close to the adjacent ring, whereas, true annual rings had distinctly different signatures. The carbon isotope record is an indicator of the overall condition of the tree during the time in which it was growing. A tree that is water-stressed during drought conditions will assimilate more ${ }^{13} \mathrm{C}$ that season, which can be identified as a relative enrichment in the $\delta^{13} \mathrm{C}$ value. There were six periods of extreme enrichment in the combined chronology (19222005) that corresponded to the timing of the passage of major hurricanes near Big Pine Key. The isotopic analysis of the tree-rings can be used as an alternative to the traditional method of measuring ring widths along multiple radii and can provide additional information about climate and disturbance events that cannot be inferred from ring width alone.

It has been well-established that the AMO and ENSO have influences over the timing of South Florida precipitation; however, the previous dendrochronology studies have been unable to find correlations between patterns in ring width and the climate drivers. The carbon isotope records of the individual trees were compared to several large-scale climate oscillations and localized precipitation measurements on a subannual level. A four-year dendrochronology study showed that the P. elliottii var. densa in the lower Florida Keys have an immediate and opportunistic response to precipitation. The $\delta^{13} \mathrm{C}$ values of the earlywood were inversely correlated to April rainfall and the $\delta^{13} \mathrm{C}$ values of the latewood are directly correlated with November precipitation. The same counter-intuitive relationship was shown as a relative enrichment of latewood $\delta^{13} \mathrm{C}$ values during El Niño winters when there is an increase in rainfall. The additional precipitation may encourage 
tree growth, but subsequent dry periods may slow growth and cause the tree to employ waterconservation strategies. There is a distinct relationship between ENSO and the carbon isotope record; however, the prevailing phase of the AMO temporally controls whether the correlation is positive or negative. El Niño winters occurring during the cool phase of the AMO leads to more enriched $\delta^{13} \mathrm{C}$ values in latewood cellulose. The complexity in the relationship between tree growth and the major drivers of South Florida climate may have prevented previous studies from finding correlations between tree growth and ENSO. In addition, the location of the tree along the proposed hydrologic transect had a secondary effect on the growth of the tree. The tree located on the distal (coastal) edge of the hydrologic gradient was consistently more stressed $\left(\delta^{13} \mathrm{C}\right.$ values were overall more enriched) when compared to the other three trees.

The oxygen and carbon isotopes in the latewood and the carbon isotopes in the earlywood of the following season were compared to tropical cyclone activity occurring within 100km around Big Pine Key. Tropical storms and depressions appeared as anomalously depleted values in the $\delta^{18} \mathrm{O}$ residual record, reflecting large amounts of tropical rain, but there was no effect in the $\delta^{13} \mathrm{C}$ values of either the earlywood or latewood rings. The effects of hurricanes varied by storm. The minor hurricanes (categories 1-2) left little impact in the $\delta^{18} \mathrm{O}$ record; however, the earlywood season following the passage of Hurricane Wilma is highly enrichened, reflecting the lasting results of the storm surge. Many of the major hurricanes (category 3-5), especially the storms passing within $25 \mathrm{~km}$ of the sampling site, were preserved as depletions in the latewood $\delta^{18} \mathrm{O}$ records and enrichments in the $\delta^{13} \mathrm{C}$ value of the subsequent season. The damage to the slash pine caused by sustained high winds during a hurricane can persist well into the next season and could explain the enriched earlywood $\delta^{13} \mathrm{C}$ values. The carbon isotope value of the 1936 earlywood is the most enriched value in the entire $\delta^{13} \mathrm{C}$ chronology and it may be attributed to the high winds accompanying the category 5 Labor Day Hurricane of 1935 as it passed to the north of the island. 
The $\delta^{18} \mathrm{O}$ records of the cellulose may also capture the signature of depleted rains in the rain bands from hurricanes off the eastern coast of Mexico and in the Caribbean.

At the landscape level, all four trees showed responses to changes in localized hydrology relating to the phases of ENSO and, indirectly, to the phases of the AMO. The trees concurrently documented the isotopically depleted rainfall from tropical cyclone sources and site-wide disturbance events, such as the storm surge from Hurricane Wilma. On an individual level, the trees had differing responses in their carbon records to the passage of the hurricanes. For example, one tree may have been more susceptible to wind damage, resulting in the most enriched $\delta^{13} \mathrm{C}$ values in the time series. Also, the tree on the distal edge of the hydrologic transect had stronger responses to incoming precipitation, yet had the fewest occurrences of IADFs. Tree growth is primarily influenced by the major climate drivers and the control they exert over the timing of the precipitation; however, growth is ultimately controlled by the microenvironment and hydrological conditions surrounding the individual trees. 


\section{APPENDICES}

\section{APPENDIX 1}

Tree-ring sample processing and cellulose extraction method

The tree-ring samples were separated into individual earlywood and latewood components under $15 \mathrm{x}$ magnifications using a size 11 blade $\mathrm{X}$-Acto knife. Individual samples were ground to a fibrous powder using a stainless steel vial and ball set in a Spex 8000M Mixer/Mill. The period of time necessary to powder the wood varied for each individual sample; the heartwood samples were consistently denser and, consequently, required at least double the time in the Mixer/Mill than their less-dense sapwood counterparts. On average, the $P$. elliottii var. densa samples spent 25-30 minutes in the ball mill. The powdered samples underwent a chemical extraction process to isolate the $\alpha$-cellulose component of the wood using a method modified for processing the samples in test tubes after Green (1963). The extraction process removes the mobile resin component and other constituents that can jeopardize the integrity of the climate signal of the isotope analysis by introducing unnecessary noise among samples (Cullen and Grierson 2006, and Loader et al. 2007).

Depending on the amount of available sample, $30-80 \mathrm{mg}$ was placed in fritted test tubes and seated in groups of 30 into Teflon holders. The test tube holders were submersed into $1 \mathrm{~L}$ beakers filled with $600 \mathrm{ml}$ of each solution, covered with a Teflon watch glass, and left in a fume hood or a heated water bath for the duration of each step in the extraction process. The samples were sonicated in the beakers for 5 minutes each time the solution was changed. Additionally, the samples were rinsed in $600 \mathrm{ml}$ of deionized water and sonicated between each of the five stages of the extraction process. The rinsing procedure was repeated 3 times, except after the two beaching steps, when the rinse was repeated until the $\mathrm{pH}$ of the post-sonicated beaker water was equal to the

$\mathrm{pH}$ of the original deionized water. The extraction process takes seven days with an additional 1-2 days for sample desiccation in a $55-60^{\circ} \mathrm{C}$ oven. 
For the first 48 hours of the extraction process, the samples soaked in $600 \mathrm{ml}$ of a 2:1 chloroform/methanol mixture. The solution was replaced and sonicated for 3-4 times during this 48 hour period. The samples were rinsed three times in deionized water following the procedure described above. The samples were then soaked in $600 \mathrm{ml}$ of $100 \%$ ethanol for a 24 -hour period and rinsed in preparation of the bleaching steps. During the first bleaching, the samples soaked in a solution of $3 \mathrm{~g}$ of $\mathrm{NaClO}_{2}$ dissolved in $600 \mathrm{ml}$ of deionized water and $0.9 \mathrm{ml}$ of glacial acetic acid for 48 hours in a covered $70^{\circ} \mathrm{C}$ water bath. The solution was changed and sonicated 5-6 times; this step was extended with an additional bleaching for 12 hours if the samples did not appear white at the end of the 48-hour period. The samples were rinsed in deionized water until the $\mathrm{pH}$ of the postsonicated beaker water was neutralized. For the second bleaching step, the samples were submersed in a solution of $24 \mathrm{~g}$ of $\mathrm{NaOH}$ dissolved in $600 \mathrm{ml}$ of deionized water for 24 hours in a closed $70^{\circ} \mathrm{C}$ water bath. Finally, the samples were rinsed in deionized water until neutralized and left to soak in deionized water for 24 hours in the fume hood. Finally, the test tubes were drained and the samples were rinsed into wide-mouth $16 \mathrm{ml}$ glass vials using a squeeze wash bottle of deionized water. The samples were dried in a $55-60^{\circ} \mathrm{C}$ oven for $24-48$ hours and a small stainless steel spatula was used to scrape the dried sample from the bottom of the vials before isotope analysis.

\section{References}

Cullen, L. E., \& Grierson, P. F. (2006). Is cellulose extraction necessary for developing stable carbon and oxygen isotopes chronologies from Callitris glaucophylla? Palaeogeography, Palaeoclimatology, Palaeoecology, 236(3), 206-216.

Green, J. W. (1963). (3) Wood Cellulose. In Methods in carbohydrate chemistry, vol. 3: cellulose (pp. 9-20). Academic Press.

Loader, N. J., McCarroll, D., Gagen, M. H., Robertson, I., \& Jalkanen, R. (2007). Extracting climatic information from stable isotopes in tree-rings. Stable isotopes as indicators of ecological change. Terrestrial Ecology Series/Ed. Dawson, T. \& Siegwolf, R. 


\section{APPENDIX 2}

Appendix 2 Sample name, corresponding growth year, ring width, $\delta^{13} \mathrm{C}$ V-PDB, $\delta^{13} \mathrm{C}$ V-PDB corrected to changing historical atmospheric carbon, $\delta^{18} \mathrm{O} \mathrm{V}-\mathrm{SMOW}$ and the error $(1$ sigma \pm ) for $\delta^{18} \mathrm{O}$ for all samples analyzed in the dissertation research. Sample names are presented in the following format: Tree - Ring Number, Ring Type (D - dark or latewood; L - light or earlywood).

\begin{tabular}{|c|c|c|c|c|c|c|}
\hline Sample & Year & Width (mm) & $\delta^{13} \mathrm{C}(\%)$ & $\delta^{13} \mathrm{C}_{\text {corr }}(\% \circ)$ & $\delta^{18} \circ(\%)$ & $\delta^{18}$ O Error (\%) \\
\hline $1-1 D$ & & 0.28 & -26.43 & & & \\
\hline $1-1 L$ & 2006.0 & 0.85 & -26.38 & -24.62 & & \\
\hline $1-2 D$ & 2005.5 & 0.76 & -26.55 & -24.82 & 31.28 & 0.06 \\
\hline $1-2 L$ & 2005.0 & 0.83 & -26.17 & -24.44 & & \\
\hline $1-3 D$ & 2004.5 & 1.20 & -26.18 & -24.48 & 30.18 & 0.59 \\
\hline $1-3 L$ & 2004.0 & 0.44 & -25.85 & -24.15 & & \\
\hline $1-4 D$ & 2003.5 & 0.21 & -26.02 & -24.35 & 31.02 & 0.43 \\
\hline $1-4 \mathrm{~L}$ & 2003.0 & 0.49 & -26.16 & -24.49 & & \\
\hline $1-5 D$ & 2002.5 & 0.33 & -26.35 & -24.70 & 31.08 & 0.50 \\
\hline $1-5 \mathrm{~L}$ & 2002.0 & 0.33 & -26.38 & -24.73 & & \\
\hline $1-6 D$ & 2001.5 & 0.35 & -26.16 & -24.54 & 31.17 & 0.24 \\
\hline $1-6 \mathrm{~L}$ & 2001.0 & 0.60 & -26.02 & -24.40 & & \\
\hline $1-7 D$ & 2000.5 & 1.19 & -25.65 & -24.06 & 32.00 & 0.66 \\
\hline $1-7 \mathrm{~L}$ & 2000.0 & 0.32 & -26.05 & -24.46 & & \\
\hline $1-8 \mathrm{D}$ & 1999.5 & 1.18 & -26.14 & -24.58 & 31.16 & 0.20 \\
\hline $1-8 \mathrm{~L}$ & 1999.0 & 0.50 & -25.90 & -24.34 & & \\
\hline $1-9 D$ & 1998.5 & 0.22 & -25.97 & -24.44 & 31.52 & 0.27 \\
\hline $1-9 \mathrm{~L}$ & 1998.0 & 0.27 & -26.07 & -24.54 & & \\
\hline $1-10 D$ & 1997.5 & 1.20 & -26.18 & -24.67 & 30.55 & 0.32 \\
\hline $1-10 \mathrm{~L}$ & 1997.0 & 0.59 & -25.95 & -24.44 & & \\
\hline 1-11D & & 0.38 & -26.10 & & & \\
\hline 1-11L & & 0.38 & -26.20 & & & \\
\hline $1-12 D$ & & 0.26 & -26.20 & & & \\
\hline $1-12 \mathrm{~L}$ & & 0.46 & -26.17 & & & \\
\hline $1-13 D$ & 1996.5 & 0.43 & -26.16 & -24.68 & 32.41 & 0.28 \\
\hline $1-13 L$ & 1996.0 & 0.49 & -25.59 & -24.11 & & \\
\hline $1-14 D$ & 1995.5 & 0.40 & -25.86 & -24.41 & 31.61 & 0.18 \\
\hline $1-14 L$ & 1995.0 & 0.69 & -25.90 & -24.45 & & \\
\hline $1-15 D$ & & 0.46 & -25.78 & & & \\
\hline $1-15 \mathrm{~L}$ & & 0.59 & -25.67 & & & \\
\hline $1-16 D$ & & 0.89 & -25.54 & & & \\
\hline $1-16 L$ & & 0.60 & -25.50 & & & \\
\hline 1-17D & 1994.5 & 0.26 & -25.39 & -23.97 & 31.43 & 0.09 \\
\hline $1-17 L$ & 1994.0 & 0.79 & -25.12 & -23.70 & & \\
\hline $1-18 D$ & 1993.5 & 0.29 & -25.16 & -23.77 & 31.16 & 0.26 \\
\hline $1-18 \mathrm{~L}$ & 1993.0 & 0.36 & -24.93 & -23.54 & & \\
\hline $1-19 D$ & 1992.5 & 0.17 & -25.11 & -23.74 & 31.13 & 0.13 \\
\hline $1-19 \mathrm{~L}$ & 1992.0 & 0.61 & -24.75 & -23.38 & & \\
\hline $1-20 D$ & & 0.51 & -24.89 & & & \\
\hline
\end{tabular}


APPENDIX 2 continued

\begin{tabular}{|c|c|c|c|c|c|c|}
\hline Sample & Year & Width (mm) & $\delta^{13} \mathrm{C}(\%)$ & $\delta^{13} \mathrm{C}_{\text {corr }}(\%$ or) & $\delta^{18} \mathrm{O}(\%)$ & $\delta^{18}$ O Error (\%) \\
\hline $1-20 \mathrm{~L}$ & & 0.84 & -24.84 & & & \\
\hline $1-21 D$ & 1991.5 & 0.28 & -24.94 & -23.60 & 30.75 & 0.01 \\
\hline $1-21 \mathrm{~L}$ & 1991.0 & 0.98 & -24.80 & -23.46 & & \\
\hline $1-22 D$ & 1990.5 & 0.56 & -25.17 & -23.86 & 30.76 & 0.06 \\
\hline $1-22 L$ & 1990.0 & 0.50 & -25.03 & -23.72 & & \\
\hline $1-23 D$ & 1989.5 & 0.37 & -24.79 & -23.51 & 32.22 & 0.04 \\
\hline $1-23 L$ & & 0.42 & -24.76 & & & \\
\hline $1-24 D$ & & 0.37 & -24.82 & & & \\
\hline $1-24 L$ & 1989.0 & 0.52 & -24.95 & -23.67 & & \\
\hline $1-25 D$ & 1988.5 & 0.51 & -24.84 & -23.59 & 30.91 & 0.39 \\
\hline $1-25 \mathrm{~L}$ & 1988.0 & 0.77 & -24.79 & -23.54 & & \\
\hline $1-26 D$ & 1987.5 & 0.39 & -24.72 & -23.50 & 31.60 & 0.13 \\
\hline $1-26 \mathrm{~L}$ & 1987.0 & 0.27 & -24.77 & -23.55 & & \\
\hline $1-27 D$ & 1986.5 & 0.35 & -24.65 & -23.45 & 31.33 & 0.19 \\
\hline $1-27 L$ & 1986.0 & 0.49 & -24.69 & -23.49 & & \\
\hline $1-28 D$ & 1985.5 & 0.11 & -24.83 & -23.66 & 31.78 & 0.54 \\
\hline $1-28 \mathrm{~L}$ & 1985.0 & 0.50 & -25.15 & -23.98 & & \\
\hline $1-29 D$ & 1984.5 & 0.14 & -25.54 & -24.42 & 31.60 & 0.40 \\
\hline $1-29 L$ & & 0.36 & -25.59 & & & \\
\hline $1-30 D$ & & 0.33 & -25.46 & & & \\
\hline $1-30 \mathrm{~L}$ & 1984.0 & 0.35 & -25.42 & -24.30 & & \\
\hline $1-31 D$ & 1983.5 & 0.56 & -25.27 & -24.16 & 31.47 & 0.39 \\
\hline $1-31 L$ & 1983.0 & 0.67 & -25.37 & -24.26 & & \\
\hline $1-32 D$ & 1982.5 & 0.61 & -25.32 & -24.24 & 30.59 & 0.07 \\
\hline $1-32 L$ & 1982.0 & 0.59 & -25.00 & -23.92 & & \\
\hline $1-33 D$ & 1981.5 & 0.35 & -24.96 & -23.90 & 31.63 & 0.60 \\
\hline $1-33 L$ & 1981.0 & 0.65 & -25.04 & -23.98 & & \\
\hline $1-34 D$ & 1980.5 & 0.39 & -25.04 & -24.01 & 32.55 & 0.21 \\
\hline $1-34 \mathrm{~L}$ & & 0.57 & -25.02 & & & \\
\hline $1-35 D$ & & 1.57 & -25.30 & & & \\
\hline $1-35 \mathrm{~L}$ & & 0.75 & -25.25 & & & \\
\hline $1-36 D$ & & 0.69 & -25.33 & & & \\
\hline $1-36 \mathrm{~L}$ & & 0.78 & -25.26 & & & \\
\hline $1-37 D$ & & 0.56 & -24.93 & & & \\
\hline $1-37 \mathrm{~L}$ & 1980.0 & 0.56 & -25.02 & -23.99 & & \\
\hline $1-38 D$ & 1979.5 & 0.34 & -25.16 & -24.16 & 30.92 & 0.11 \\
\hline $1-38 \mathrm{~L}$ & 1979.0 & 0.32 & -25.19 & -24.19 & & \\
\hline $1-39 D$ & & 0.12 & -24.99 & & 31.76 & 0.02 \\
\hline $1-39 L$ & & 0.52 & -24.98 & & & \\
\hline $1-40 D$ & 1978.5 & 0.41 & -25.32 & -24.19 & 31.63 & 0.17 \\
\hline $1-40 \mathrm{~L}$ & 1978.0 & 0.41 & -25.06 & -24.38 & & \\
\hline 1-41D & 1977.5 & 1.24 & -25.16 & -24.12 & 31.02 & 0.41 \\
\hline $1-41 \mathrm{~L}$ & 1977.0 & 0.67 & -25.16 & -24.24 & & \\
\hline $1-42 D$ & 1976.5 & 0.54 & -25.11 & -24.24 & 30.42 & 0.67 \\
\hline
\end{tabular}


APPENDIX 2 continued

\begin{tabular}{|c|c|c|c|c|c|c|}
\hline Sample & Year & Width $(\mathrm{mm})$ & $\delta^{13} \mathrm{C}(\%)$ & $\delta^{13} \mathrm{C}_{\text {corr }}(\%)$ & $\delta^{18} \mathrm{O}(\%)$ & $\delta^{18}$ O Error (\%) \\
\hline $1-42 L$ & 1976.0 & 0.50 & -24.84 & -24.22 & & \\
\hline $1-43 D$ & 1975.5 & 0.46 & -24.91 & -23.95 & 31.35 & 0.07 \\
\hline $1-43 L$ & 1975.0 & 0.21 & -24.71 & -24.05 & & \\
\hline $1-44 D$ & 1974.5 & 0.43 & -24.70 & -23.85 & 31.61 & 0.20 \\
\hline $1-44 \mathrm{~L}$ & 1974.0 & 0.69 & -24.81 & -23.87 & & \\
\hline $1-45 D$ & 1973.5 & 0.66 & -25.12 & -23.98 & 29.40 & 0.13 \\
\hline $1-45 \mathrm{~L}$ & 1973.0 & 0.44 & -25.17 & -24.32 & & \\
\hline $1-46 D$ & 1972.5 & 1.11 & -24.59 & -24.37 & 30.05 & 0.07 \\
\hline $1-46 \mathrm{~L}$ & 1972.0 & 0.44 & -24.66 & -23.82 & & \\
\hline $1-47 D$ & 1971.5 & 0.46 & -25.03 & -23.89 & 30.15 & 0.25 \\
\hline $1-47 L$ & 1971.0 & 0.28 & -25.00 & -24.28 & & \\
\hline $1-48 D$ & 1970.5 & 0.42 & -24.89 & -24.25 & 30.50 & 0.10 \\
\hline $1-48 \mathrm{~L}$ & 1970.0 & 0.42 & -25.04 & -24.17 & & \\
\hline $1-49 D$ & 1969.5 & 0.69 & -24.51 & -23.82 & 30.10 & 0.25 \\
\hline $1-49 \mathrm{~L}$ & 1969.0 & 0.61 & -24.25 & -23.56 & & \\
\hline $1-50 D$ & & 0.33 & -24.80 & & & \\
\hline $1-50 \mathrm{~L}$ & & 0.40 & -24.85 & & & \\
\hline $1-51 D$ & 1968.5 & 0.37 & -24.83 & -24.17 & 30.94 & 0.10 \\
\hline $1-51 \mathrm{~L}$ & 1968.0 & 0.39 & -24.59 & -23.93 & & \\
\hline $1-52 D$ & & 0.57 & -24.92 & & & \\
\hline $1-52 \mathrm{~L}$ & & 0.69 & -24.89 & & & \\
\hline $1-53 D$ & 1967.5 & 0.80 & -24.64 & -24.01 & 31.32 & 0.14 \\
\hline $1-53 L$ & 1967.0 & 1.06 & -24.78 & -24.15 & & \\
\hline 1-54D & 1966.5 & 1.15 & -24.59 & -23.98 & 31.09 & 0.14 \\
\hline $1-54 \mathrm{~L}$ & 1966.0 & 0.73 & -24.67 & -24.06 & & \\
\hline $1-55 D$ & & 0.56 & -24.54 & & & \\
\hline $1-55 \mathrm{~L}$ & & 0.27 & -24.54 & & & \\
\hline $1-56 D$ & 1965.5 & 0.60 & -24.52 & -23.94 & 31.30 & 0.13 \\
\hline $1-56 \mathrm{~L}$ & 1965.0 & 0.58 & -24.42 & -23.84 & & \\
\hline $1-57 D$ & 1964.5 & 1.38 & -24.98 & -24.43 & 30.37 & 0.08 \\
\hline $1-57 \mathrm{~L}$ & 1964.0 & 0.85 & -24.63 & -24.08 & & \\
\hline $1-58 D$ & 1963.5 & 1.20 & -24.51 & -23.99 & 30.63 & 0.08 \\
\hline $1-58 \mathrm{~L}$ & 1963.0 & 0.24 & -24.31 & -23.79 & & \\
\hline $1-59 D$ & 1962.5 & 0.64 & -24.29 & -23.79 & 30.48 & 0.20 \\
\hline $1-59 \mathrm{~L}$ & 1962.0 & 0.17 & -24.43 & -23.93 & & \\
\hline $1-60 D$ & 1961.5 & 0.83 & -24.39 & -23.89 & 29.81 & 0.01 \\
\hline $1-60 \mathrm{~L}$ & 1961.0 & 0.17 & -24.82 & -24.32 & & \\
\hline $1-61 D$ & 1960.5 & 1.30 & -24.62 & -24.12 & 30.52 & 0.10 \\
\hline $1-61 \mathrm{~L}$ & 1960.0 & 1.34 & -24.68 & -24.18 & & \\
\hline $1-62 D$ & 1959.5 & 1.21 & -24.79 & -24.30 & 30.44 & 0.10 \\
\hline $1-62 \mathrm{~L}$ & 1959.0 & 0.22 & -24.74 & -24.25 & & \\
\hline $1-63 D$ & 1958.5 & 0.86 & -24.21 & -23.72 & 30.73 & 0.10 \\
\hline $1-63 \mathrm{~L}$ & 1958.0 & 1.15 & -24.43 & -23.94 & & \\
\hline $1-64 D$ & 1957.5 & 1.46 & -24.25 & -23.77 & 30.79 & 0.06 \\
\hline
\end{tabular}


APPENDIX 2 continued

\begin{tabular}{|c|c|c|c|c|c|c|}
\hline Sample & Year & Width $(\mathrm{mm})$ & $\delta^{13} \mathrm{C}(\%)$ & $\delta^{13} \mathrm{C}_{\text {corr }}(\%$ o) & $\delta^{18} \circ(\%)$ & $\delta^{18} \circ$ Error $(\%)$ \\
\hline $1-64 \mathrm{~L}$ & 1957.0 & 0.93 & -24.27 & -23.79 & & \\
\hline $1-65 D$ & 1956.5 & 0.92 & -24.38 & -23.90 & 31.95 & 0.26 \\
\hline $1-65 \mathrm{~L}$ & 1956.0 & 0.73 & -23.94 & -23.46 & & \\
\hline $1-66 D$ & 1955.5 & 2.66 & -24.36 & -23.89 & 30.44 & 0.17 \\
\hline $1-66 \mathrm{~L}$ & 1955.0 & 1.29 & -24.31 & -23.84 & & \\
\hline $1-67 D$ & 1954.5 & 1.11 & -24.29 & -23.82 & 31.66 & 0.06 \\
\hline $1-67 L$ & 1954.0 & 0.26 & -24.41 & -23.94 & & \\
\hline $1-68 D$ & 1953.5 & 1.35 & -24.07 & -23.61 & 31.21 & 0.03 \\
\hline $1-68 \mathrm{~L}$ & 1953.0 & 0.82 & -24.40 & -23.94 & & \\
\hline $1-69 D$ & 1952.5 & 0.18 & -25.19 & -24.73 & 31.40 & 0.09 \\
\hline $1-69 \mathrm{~L}$ & 1952.0 & 0.19 & -24.81 & -24.35 & & \\
\hline $1-70 D$ & 1951.5 & 0.76 & -24.83 & -24.37 & 29.92 & 0.05 \\
\hline $1-70 \mathrm{~L}$ & 1951.0 & 0.52 & -24.31 & -23.85 & & \\
\hline 1-71D & & 0.89 & -24.52 & & & \\
\hline $1-71 \mathrm{~L}$ & & 0.73 & -24.59 & & & \\
\hline $1-72 D$ & 1950.5 & 0.52 & -24.45 & -24.00 & 31.89 & 0.00 \\
\hline $1-72 \mathrm{~L}$ & 1950.0 & 1.36 & -24.12 & -23.67 & & \\
\hline 1-73D & 1949.5 & 1.86 & -24.63 & -24.18 & & \\
\hline 1-73L & 1949.0 & 0.30 & -24.13 & -23.68 & & \\
\hline $1-74 D$ & 1948.5 & 0.75 & -24.53 & -24.09 & & \\
\hline $1-74 \mathrm{~L}$ & 1948.0 & 0.67 & -24.51 & -24.07 & & \\
\hline $1-75 D$ & 1947.5 & 1.26 & -24.92 & -24.48 & & \\
\hline $1-75 \mathrm{~L}$ & 1947.0 & 1.01 & -24.92 & -24.48 & & \\
\hline $1-76 D$ & 1946.5 & 1.75 & -24.93 & -24.50 & & \\
\hline $1-76 \mathrm{~L}$ & 1946.0 & 1.62 & -24.69 & -24.26 & & \\
\hline $1-77 D$ & 1945.5 & 1.79 & -25.03 & -24.60 & & \\
\hline $1-77 \mathrm{~L}$ & 1945.0 & 0.18 & -25.23 & -24.80 & & \\
\hline $1-78 D$ & 1944.5 & 1.04 & -25.23 & -24.81 & & \\
\hline $1-78 \mathrm{~L}$ & 1944.0 & 0.28 & -25.46 & -25.04 & & \\
\hline $1-79 D$ & 1943.5 & 2.33 & -25.78 & -25.36 & & \\
\hline $1-79 \mathrm{~L}$ & 1943.0 & 0.40 & -25.92 & -25.50 & & \\
\hline $1-80 D$ & 1942.5 & 0.34 & -25.87 & -25.45 & & \\
\hline $1-80 \mathrm{~L}$ & 1942.0 & 0.24 & -26.09 & -25.67 & & \\
\hline $1-81 D$ & 1941.5 & 0.33 & -25.90 & -25.49 & & \\
\hline $1-81 \mathrm{~L}$ & 1941.0 & 1.47 & -25.47 & -25.06 & & \\
\hline $1-82 D$ & 1940.5 & 0.93 & -25.82 & -25.41 & & \\
\hline $1-82 \mathrm{~L}$ & 1940.0 & 0.38 & -25.92 & -25.51 & & \\
\hline $1-83 D$ & 1939.5 & 0.35 & -25.60 & -25.20 & & \\
\hline $1-83 \mathrm{~L}$ & 1939.0 & 0.89 & -25.49 & -25.09 & & \\
\hline $1-84 D$ & 1938.5 & 0.14 & -25.69 & -25.29 & & \\
\hline 1-84L & 1938.0 & 0.95 & -24.63 & -24.23 & & \\
\hline $1-85 D$ & 1937.5 & 0.24 & -25.63 & -25.24 & & \\
\hline $1-85 \mathrm{~L}$ & 1937.0 & 1.47 & -25.34 & -24.95 & & \\
\hline Missing Ring & 1936.5 & & & & & \\
\hline
\end{tabular}


APPENDIX 2 continued

\begin{tabular}{|c|c|c|c|c|c|c|}
\hline Sample & Year & Width $(\mathrm{mm})$ & $\delta^{13} \mathrm{C}$ (\%) & $\delta^{13} C_{\text {corr }}(\%$ o & $\delta^{18} O(\%)$ & $\delta^{18}$ O Error (\%) \\
\hline Missing Ring & 1936.0 & & & & & \\
\hline $1-86 D$ & 1935.5 & 0.97 & -25.09 & -24.71 & & \\
\hline $1-86 \mathrm{~L}$ & 1935.0 & 0.60 & -25.39 & -25.01 & & \\
\hline $1-87 D$ & 1934.5 & 0.37 & -25.34 & -24.96 & & \\
\hline 1-87L & 1934.0 & 0.76 & -25.17 & -24.79 & & \\
\hline $1-88 D$ & 1933.5 & 0.27 & -25.73 & -25.35 & & \\
\hline $1-88 \mathrm{~L}$ & 1933.0 & 1.60 & -25.10 & -24.72 & & \\
\hline $1-89 D$ & 1932.5 & 0.44 & -25.67 & -25.30 & & \\
\hline $1-89 \mathrm{~L}$ & 1932.0 & 0.81 & -24.88 & -24.51 & & \\
\hline $1-90 D$ & 1931.5 & 1.00 & -24.79 & -24.42 & & \\
\hline $1-90 \mathrm{~L}$ & 1931.0 & 1.38 & -25.46 & -25.09 & & \\
\hline $1-91 D$ & 1930.5 & 0.76 & -25.28 & -24.92 & & \\
\hline 1-91L & 1930.0 & 2.22 & -25.74 & -25.38 & & \\
\hline $1-92 D$ & 1929.5 & 0.64 & -25.52 & -25.16 & & \\
\hline $1-92 \mathrm{~L}$ & 1929.0 & 3.15 & -25.96 & -25.60 & & \\
\hline $1-93 D$ & 1928.5 & 0.62 & -25.98 & -25.63 & & \\
\hline $1-93 L$ & 1928.0 & 5.07 & -26.01 & -25.66 & & \\
\hline $2-1 D$ & & & -26.01 & & & \\
\hline $2-1 \mathrm{~L}$ & 2006.0 & 0.27 & -25.33 & -23.57 & & \\
\hline $2-2 D$ & 2005.5 & 0.08 & -23.70 & -22.03 & 32.07 & 0.28 \\
\hline $2-2 L$ & 2005.0 & 0.19 & -23.83 & -24.01 & & \\
\hline $2-3 D$ & & 0.15 & -25.20 & & & \\
\hline $2-3 L$ & & 0.30 & -26.28 & & & \\
\hline $2-4 D$ & 2004.5 & 0.12 & -26.16 & -24.46 & 31.26 & 0.31 \\
\hline $2-4 L$ & 2004.0 & 0.28 & -26.12 & -24.42 & & \\
\hline $2-5 D$ & 2003.5 & 0.24 & -26.23 & -24.56 & 29.63 & 1.68 \\
\hline $2-5 \mathrm{~L}$ & 2003.0 & 0.47 & -26.31 & -24.64 & & \\
\hline $2-6 D$ & 2002.5 & 0.19 & -26.38 & -24.73 & 30.45 & 0.26 \\
\hline $2-6 \mathrm{~L}$ & 2002.0 & 0.28 & -26.21 & -24.56 & & \\
\hline 2-7D & 2001.5 & 0.05 & -26.24 & -24.62 & 31.37 & 0.00 \\
\hline 2-7L & 2001.0 & 0.24 & -26.12 & -24.52 & & \\
\hline $2-8$ & & 0.22 & -26.15 & & & \\
\hline $2-9$ & & 0.33 & -26.15 & & & \\
\hline $2-10 D$ & & 0.10 & -25.71 & & & \\
\hline $2-10 \mathrm{~L}$ & & 0.25 & -25.67 & & & \\
\hline $2-11 D$ & 2000.5 & 0.07 & -25.56 & -23.97 & 31.39 & 0.14 \\
\hline $2-11 \mathrm{~L}$ & 2000.0 & 0.56 & -25.47 & -23.88 & & \\
\hline $2-12 D$ & 1999.5 & 0.20 & -25.51 & -23.95 & 31.66 & 0.05 \\
\hline $2-12 L$ & 1999.0 & 0.62 & -25.44 & -23.88 & & \\
\hline $2-13 D$ & 1998.5 & 1.29 & -25.98 & -24.45 & 30.43 & 0.25 \\
\hline $2-13 L$ & 1998.0 & 0.39 & -25.90 & -24.37 & & \\
\hline $2-14 D$ & 1997.5 & 0.76 & -26.20 & -24.69 & 31.00 & 0.35 \\
\hline $2-14 \mathrm{~L}$ & 1997.0 & 0.65 & -25.96 & -24.45 & & \\
\hline $2-15 D$ & 1996.5 & 0.31 & -25.65 & -24.17 & 31.83 & 0.10 \\
\hline
\end{tabular}


APPENDIX 2 continued

\begin{tabular}{|c|c|c|c|c|c|c|}
\hline Sample & Year & Width $(\mathrm{mm})$ & $\delta^{13} \mathrm{C}(\%)$ & $\delta^{13} C_{\text {corr }}(\%)$ & $\delta^{18} \bigcirc(\%)$ & $\delta^{18}$ O Error (\%) \\
\hline $2-15 \mathrm{~L}$ & 1996.0 & 0.36 & -25.63 & -24.15 & & \\
\hline $2-16 D$ & 1995.5 & 0.88 & -25.97 & -24.52 & 31.29 & 0.48 \\
\hline $2-16 \mathrm{~L}$ & 1995.0 & 0.56 & -24.96 & -23.51 & & \\
\hline $2-17 D$ & 1994.5 & 0.28 & -25.41 & -23.99 & 31.32 & 0.03 \\
\hline $2-17 \mathrm{~L}$ & 1994.0 & 0.81 & -25.57 & -24.15 & & \\
\hline $2-18 D$ & 1993.5 & 0.66 & -25.65 & -24.26 & 30.77 & 0.00 \\
\hline $2-18 \mathrm{~L}$ & 1993.0 & 0.92 & -25.63 & -24.24 & & \\
\hline $2-19 D$ & 1992.5 & 0.62 & -24.94 & -23.57 & 30.38 & 0.00 \\
\hline $2-19 L$ & 1992.0 & 0.54 & -24.83 & -23.46 & & \\
\hline $2-20 D$ & 1991.5 & 0.29 & -25.01 & -23.67 & 30.85 & 0.14 \\
\hline $2-20 \mathrm{~L}$ & 1991.0 & 0.73 & -24.95 & -23.61 & & \\
\hline $2-21 D$ & 1990.5 & 0.31 & -25.43 & -24.12 & 30.90 & 0.22 \\
\hline $2-21 \mathrm{~L}$ & 1990.0 & 0.29 & -25.10 & -23.79 & & \\
\hline $2-22 D$ & 1989.5 & 0.98 & -25.35 & -24.07 & 29.79 & 0.14 \\
\hline $2-22 \mathrm{~L}$ & 1989.0 & 0.71 & -24.75 & -23.47 & & \\
\hline $2-23 D$ & 1988.5 & 1.03 & -25.19 & -23.94 & 30.63 & 0.12 \\
\hline $2-23 L$ & & 1.10 & -25.33 & & & \\
\hline $2-24 D$ & & 1.59 & -25.06 & & & \\
\hline $2-24 \mathrm{~L}$ & 1988.0 & 0.69 & -24.59 & -23.34 & & \\
\hline $2-25 D$ & 1987.5 & 0.31 & -25.23 & -24.01 & 30.11 & 0.19 \\
\hline $2-25 \mathrm{~L}$ & 1987.0 & 0.54 & -24.86 & -23.64 & & \\
\hline $2-26 D$ & 1986.5 & 0.09 & -25.03 & -23.83 & 31.77 & 0.06 \\
\hline $2-26 \mathrm{~L}$ & 1986.0 & 0.23 & -24.88 & -23.68 & & \\
\hline $2-27 D$ & 1985.5 & 0.09 & -24.85 & -23.68 & 31.76 & 0.00 \\
\hline $2-27 L$ & & 0.28 & -25.13 & & & \\
\hline $2-28 D$ & & 0.09 & -25.43 & & & \\
\hline $2-28 \mathrm{~L}$ & & 0.34 & -25.32 & & & \\
\hline $2-29 D$ & & 0.10 & -24.98 & & & \\
\hline $2-29 \mathrm{~L}$ & & 0.31 & -24.91 & & & \\
\hline $2-30 D$ & & 0.15 & -25.58 & & & \\
\hline $2-30 \mathrm{~L}$ & 1985.0 & 0.29 & -25.96 & -24.79 & & \\
\hline $2-31 D$ & 1984.5 & 0.32 & -25.95 & -24.81 & 29.80 & 0.42 \\
\hline $2-31 L$ & 1984.0 & 0.62 & -25.59 & -24.45 & & \\
\hline $2-32 D$ & 1983.5 & 0.63 & -25.66 & -24.55 & 29.37 & 0.39 \\
\hline $2-32 \mathrm{~L}$ & 1983.0 & 0.32 & -25.33 & -24.22 & & \\
\hline $2-33 D$ & 1982.5 & 0.45 & -24.90 & -23.82 & 30.23 & 0.52 \\
\hline $2-33 L$ & 1982.0 & 0.49 & -24.61 & -23.53 & & \\
\hline $2-34 D$ & 1981.5 & 1.55 & -25.08 & -24.02 & 30.56 & 0.13 \\
\hline $2-34 \mathrm{~L}$ & 1981.0 & 0.46 & -24.55 & -23.49 & & \\
\hline $2-35 D$ & 1980.5 & 0.32 & -24.31 & -23.28 & 31.72 & 0.04 \\
\hline $2-35 \mathrm{~L}$ & 1980.0 & 0.31 & -24.70 & -23.67 & & \\
\hline $2-36 D$ & 1979.5 & 0.19 & -24.72 & -23.72 & 30.86 & 0.28 \\
\hline $2-36 \mathrm{~L}$ & 1979.0 & 0.49 & -24.82 & -23.82 & & \\
\hline $2-37 D$ & & 0.25 & -24.83 & & & \\
\hline
\end{tabular}


APPENDIX 2 continued

\begin{tabular}{|c|c|c|c|c|c|c|}
\hline Sample & Year & Width (mm) & $\delta^{13} \mathrm{C}(\%)$ & $\delta^{13} C_{\text {corr }}(\%$ o & $\delta^{18} O(\%)$ & $\delta^{18}$ O Error (\%) \\
\hline $2-37 L$ & & 0.39 & -25.06 & & & \\
\hline $2-38 D$ & 1978.5 & 0.19 & -24.74 & -23.80 & 30.29 & 0.01 \\
\hline $2-38 \mathrm{~L}$ & 1978.0 & 0.63 & -24.52 & -23.58 & & \\
\hline $2-39 D$ & 1977.5 & 0.45 & -24.42 & -23.50 & 31.39 & 0.14 \\
\hline $2-39 \mathrm{~L}$ & 1977.0 & 1.25 & -24.23 & -23.31 & & \\
\hline $2-40 D$ & 1976.5 & 2.03 & -25.33 & -24.44 & 29.39 & 0.10 \\
\hline $2-40 \mathrm{~L}$ & 1976.0 & 1.81 & -24.50 & -23.61 & & \\
\hline $2-41 D$ & 1975.5 & 1.72 & -24.97 & -24.11 & 29.68 & 0.09 \\
\hline $2-41 \mathrm{~L}$ & 1975.0 & 0.78 & -24.45 & -23.59 & & \\
\hline $2-42 D$ & 1974.5 & 1.07 & -24.89 & -24.06 & 30.30 & 0.23 \\
\hline $2-42 \mathrm{~L}$ & 1974.0 & 0.69 & -24.98 & -24.15 & & \\
\hline $2-43 D$ & 1973.5 & 0.23 & -24.99 & -24.19 & 30.56 & 0.03 \\
\hline $2-43 \mathrm{~L}$ & 1973.0 & 0.33 & -24.62 & -23.82 & & \\
\hline $2-44 D$ & 1972.5 & 0.28 & -24.25 & -23.48 & 31.14 & 0.32 \\
\hline $2-44 \mathrm{~L}$ & 1972.0 & 0.62 & -23.92 & -23.15 & & \\
\hline $2-45 D$ & 1971.5 & 0.33 & -24.47 & -23.72 & 30.73 & 0.12 \\
\hline $2-45 \mathrm{~L}$ & 1971.0 & 0.58 & -24.03 & -23.28 & & \\
\hline $2-46 D$ & 1970.5 & 0.62 & -24.50 & -23.78 & 29.98 & 0.14 \\
\hline $2-46 \mathrm{~L}$ & 1970.0 & 0.60 & -24.32 & -23.60 & & \\
\hline $2-47 D$ & 1969.5 & 0.26 & -24.54 & -23.85 & 29.82 & 0.18 \\
\hline $2-47 L$ & & 0.16 & -24.39 & & & \\
\hline $2-48 D$ & & 0.23 & -24.35 & & & \\
\hline $2-48 \mathrm{~L}$ & 1969.0 & 0.56 & -24.05 & -23.36 & & \\
\hline $2-49 D$ & 1968.5 & 0.27 & -24.57 & -23.91 & 30.30 & 0.11 \\
\hline $2-49 \mathrm{~L}$ & 1968.0 & 0.54 & -23.68 & -23.02 & & \\
\hline $2-50 D$ & 1967.5 & 0.40 & -24.11 & -23.48 & 31.04 & 0.07 \\
\hline $2-50 \mathrm{~L}$ & 1967.0 & 0.89 & -23.99 & -23.36 & & \\
\hline $2-51 D$ & 1966.5 & 0.59 & -24.26 & -23.65 & 29.55 & 0.05 \\
\hline $2-51 \mathrm{~L}$ & 1966.0 & 0.27 & -24.11 & -23.50 & & \\
\hline $2-52 D$ & 1965.5 & 0.94 & -24.28 & -23.70 & 31.19 & 0.05 \\
\hline $2-52 L$ & 1965.0 & 0.88 & -24.28 & -23.70 & & \\
\hline $2-53 D$ & 1964.5 & 0.53 & -25.22 & -24.67 & 29.62 & 0.37 \\
\hline $2-53 \mathrm{~L}$ & 1964.0 & 0.95 & -24.36 & -23.81 & & \\
\hline $2-54 D$ & 1963.5 & 0.53 & -24.42 & -23.90 & 30.43 & 0.20 \\
\hline $2-54 \mathrm{~L}$ & 1963.0 & 0.62 & -24.10 & -23.58 & & \\
\hline $2-55 D$ & 1962.5 & 0.49 & -24.16 & -23.66 & 30.37 & 0.04 \\
\hline $2-55 \mathrm{~L}$ & 1962.0 & 0.25 & -23.61 & -23.11 & & \\
\hline $2-56 D$ & 1961.5 & 0.61 & -24.14 & -23.64 & 32.46 & 0.12 \\
\hline $2-56 \mathrm{~L}$ & & 0.55 & -24.20 & & & \\
\hline $2-57 D$ & & 0.33 & -24.55 & & & \\
\hline $2-57 \mathrm{~L}$ & 1961.0 & 0.77 & -23.47 & -22.97 & & \\
\hline $2-58 \mathrm{D}$ & 1960.5 & 0.95 & -23.98 & -23.48 & 31.43 & 0.03 \\
\hline $2-58 \mathrm{~L}$ & 1960.0 & 0.68 & -24.06 & -23.56 & & \\
\hline $2-59 D$ & 1959.5 & 0.66 & -24.64 & -24.15 & 30.87 & 0.10 \\
\hline
\end{tabular}


APPENDIX 2 continued

\begin{tabular}{|c|c|c|c|c|c|c|}
\hline Sample & Year & Width $(\mathrm{mm})$ & $\delta^{13} \mathrm{C}(\%)$ & $\delta^{13} C_{\text {corr }}(\%)$ & $\delta^{18} \circ(\%)$ & $\delta^{18}$ O Error (\%) \\
\hline $2-59 \mathrm{~L}$ & 1959.0 & 0.79 & -24.53 & -24.04 & & \\
\hline $2-60 D$ & & 0.35 & -24.74 & & & \\
\hline $2-60 \mathrm{~L}$ & & 0.62 & -24.40 & & & \\
\hline $2-61 D$ & 1958.5 & 0.45 & -24.20 & -23.71 & 31.30 & 0.41 \\
\hline $2-61 \mathrm{~L}$ & 1958.0 & 0.53 & -23.89 & -23.40 & & \\
\hline $2-62 D$ & 1957.5 & 0.35 & -24.40 & -23.92 & 31.72 & 0.15 \\
\hline $2-62 L$ & 1957.0 & 0.47 & -24.28 & -23.80 & & \\
\hline $2-63 D$ & 1956.5 & 0.47 & -24.94 & -24.46 & 30.54 & 0.08 \\
\hline $2-63 L$ & 1956.0 & 0.57 & -24.92 & -24.44 & & \\
\hline $2-64 D$ & 1955.5 & 0.52 & -24.24 & -23.77 & 31.25 & 0.04 \\
\hline $2-64 L$ & 1955.0 & 0.53 & -23.81 & -23.34 & & \\
\hline $2-65 D$ & 1954.5 & 0.54 & -24.33 & -23.86 & 30.71 & 0.00 \\
\hline $2-65 \mathrm{~L}$ & 1954.0 & 0.26 & -24.38 & -23.91 & & \\
\hline $2-66 \mathrm{D}$ & 1953.5 & 0.87 & -24.79 & -24.33 & 29.87 & 0.05 \\
\hline $2-66 \mathrm{~L}$ & & 0.50 & -24.18 & & & \\
\hline $2-67 D$ & & 1.73 & -24.21 & & & \\
\hline $2-67 L$ & 1953.0 & 0.80 & -25.05 & -24.59 & & \\
\hline $2-68 D$ & 1952.5 & 0.86 & -24.62 & -24.16 & 30.39 & 0.12 \\
\hline $2-68 \mathrm{~L}$ & 1952.0 & 0.43 & -24.77 & -24.31 & & \\
\hline $2-69 D$ & 1951.5 & 1.16 & -24.57 & -24.11 & 30.33 & 0.04 \\
\hline $2-69 \mathrm{~L}$ & 1951.0 & 0.50 & -24.19 & -23.73 & & \\
\hline $2-70 D$ & 1950.5 & 0.78 & -24.59 & -24.14 & 30.22 & 0.24 \\
\hline $2-70 \mathrm{~L}$ & 1950.0 & 0.55 & -23.21 & -22.76 & & \\
\hline $2-71 D$ & 1949.5 & 0.77 & -23.90 & -23.45 & 31.70 & 0.07 \\
\hline $2-71 \mathrm{~L}$ & 1949.0 & 0.36 & -23.41 & -22.96 & & \\
\hline $2-72 D$ & 1948.5 & 1.65 & -24.52 & -24.08 & 30.52 & 0.25 \\
\hline $2-72 \mathrm{~L}$ & 1948.0 & 1.13 & -24.28 & -23.84 & & \\
\hline $2-73 D$ & 1947.5 & 1.31 & -24.51 & -24.07 & 31.64 & 0.13 \\
\hline $2-73 \mathrm{~L}$ & 1947.0 & 0.97 & -24.30 & -23.86 & & \\
\hline $2-74 D$ & 1946.5 & 1.46 & -24.22 & -23.79 & 31.03 & 0.13 \\
\hline $2-74 \mathrm{~L}$ & 1946.0 & 1.36 & -23.74 & -23.31 & & \\
\hline $2-75 D$ & 1945.5 & 1.08 & -24.42 & -23.99 & 32.04 & 0.10 \\
\hline $2-75 \mathrm{~L}$ & 1945.0 & 0.75 & -24.44 & -24.01 & & \\
\hline $2-76 D$ & 1944.5 & 0.99 & -24.92 & -24.50 & 30.85 & 0.19 \\
\hline $2-76 \mathrm{~L}$ & 1944.0 & 0.94 & -24.20 & -23.78 & & \\
\hline $2-77 D$ & 1943.5 & 1.12 & -24.89 & -24.47 & 31.22 & 0.15 \\
\hline $2-77 \mathrm{~L}$ & 1943.0 & 0.78 & -24.33 & -23.91 & & \\
\hline $2-78 D$ & 1942.5 & 1.33 & -24.63 & -24.21 & 32.16 & 0.24 \\
\hline $2-78 \mathrm{~L}$ & 1942.0 & 1.49 & -23.66 & -23.24 & & \\
\hline $2-79 D$ & & 1.79 & -24.42 & & & \\
\hline $2-79 \mathrm{~L}$ & & 2.17 & -24.69 & & & \\
\hline $2-80 D$ & & 1.43 & -24.81 & & & \\
\hline $2-80 \mathrm{~L}$ & & 1.06 & -24.34 & & & \\
\hline $2-81 D$ & 1941.5 & 0.64 & -25.10 & -24.69 & 30.81 & 0.08 \\
\hline
\end{tabular}


APPENDIX 2 continued

\begin{tabular}{|c|c|c|c|c|c|c|}
\hline Sample & Year & Width $(\mathrm{mm})$ & $\delta^{13} \mathrm{C}(\%)$ & $\delta^{13} C_{\text {corr }}(\%)$ & $\delta^{18} \circ(\%)$ & $\delta^{18}$ O Error (\%) \\
\hline $2-81 \mathrm{~L}$ & 1941.0 & 1.41 & -24.21 & -23.80 & & \\
\hline $2-82 D$ & 1940.5 & 1.34 & -24.97 & -24.56 & 31.36 & 0.06 \\
\hline $2-82 \mathrm{~L}$ & 1940.0 & 1.60 & -25.01 & -24.60 & & \\
\hline $2-83 D$ & 1939.5 & 1.12 & -25.24 & -24.84 & 31.47 & 0.00 \\
\hline $2-83 \mathrm{~L}$ & 1939.0 & 1.14 & -25.50 & -25.10 & & \\
\hline $2-84 D$ & 1938.5 & 0.69 & -25.62 & -25.22 & 31.37 & 0.05 \\
\hline $2-84 \mathrm{~L}$ & & 2.45 & -24.85 & & & \\
\hline $2-85 D$ & & 1.85 & -24.87 & & & \\
\hline $2-85 \mathrm{~L}$ & 1938.0 & 0.21 & -24.89 & -24.49 & & \\
\hline $2-86 D$ & 1937.5 & 0.62 & -25.12 & -24.73 & 31.65 & 0.06 \\
\hline $2-86 \mathrm{~L}$ & 1937.0 & 0.60 & -25.33 & -24.94 & & \\
\hline 2-87D & 1936.5 & 0.39 & -25.76 & -25.37 & 30.72 & 0.07 \\
\hline $2-87 L$ & & 0.80 & -25.85 & & & \\
\hline 2-88D & & 0.26 & -25.39 & & & \\
\hline $2-88 \mathrm{~L}$ & 1936.0 & 1.00 & -22.63 & -22.24 & & \\
\hline $2-89 D$ & 1935.5 & 1.14 & -24.67 & -24.29 & 30.37 & 0.08 \\
\hline $2-89 \mathrm{~L}$ & 1935.0 & 0.91 & -24.73 & -24.35 & & \\
\hline $2-90 D$ & 1934.5 & 0.76 & -25.76 & -25.38 & 29.58 & 0.00 \\
\hline $2-90 \mathrm{~L}$ & 1934.0 & 0.77 & -25.51 & -25.13 & & \\
\hline $2-91 D$ & 1933.5 & 1.11 & -25.74 & -25.36 & 30.26 & 0.05 \\
\hline $2-91 \mathrm{~L}$ & 1933.0 & 2.09 & -25.42 & -25.04 & & \\
\hline $2-92 D$ & 1932.5 & 0.33 & -25.53 & -25.16 & 30.12 & 0.15 \\
\hline $2-92 \mathrm{~L}$ & 1932.0 & 0.93 & -25.60 & -25.23 & & \\
\hline $2-93 D$ & 1931.5 & 0.45 & -25.81 & -25.44 & 29.99 & 0.65 \\
\hline $2-93 \mathrm{~L}$ & 1931.0 & 1.95 & -25.53 & -25.16 & & \\
\hline $2-94 D$ & 1930.5 & 0.30 & -25.84 & -25.48 & 30.21 & 0.75 \\
\hline $2-94 \mathrm{~L}$ & 1930.0 & 2.28 & -25.45 & -25.09 & & \\
\hline $2-95 D$ & 1929.5 & 0.14 & -25.52 & -25.16 & 30.97 & 0.45 \\
\hline $2-95 \mathrm{~L}$ & 1929.0 & 2.20 & -25.51 & -25.15 & & \\
\hline $2-96 D$ & 1928.5 & 0.13 & -26.52 & -26.17 & 30.33 & 0.21 \\
\hline $2-96 \mathrm{~L}$ & 1928.0 & 2.60 & -26.31 & -25.96 & & \\
\hline 3-1D & & 0.24 & -26.24 & & & \\
\hline $3-1 \mathrm{~L}$ & 2006.0 & 0.31 & -26.01 & -24.25 & & \\
\hline $3-2 D$ & 2005.5 & 0.11 & -25.63 & -23.90 & 32.33 & 0.05 \\
\hline $3-2 \mathrm{~L}$ & 2005.0 & 0.34 & -25.76 & -24.03 & & \\
\hline $3-3 D$ & 2004.5 & 0.11 & -26.13 & -24.43 & 32.15 & 0.17 \\
\hline 3-3L & 2004.0 & 0.18 & -25.95 & -24.25 & & \\
\hline $3-4 D$ & 2003.5 & 0.08 & -25.89 & -24.22 & 31.77 & 0.19 \\
\hline $3-4 \mathrm{~L}$ & 2003.0 & 0.17 & -26.00 & -24.33 & & \\
\hline $3-5 D$ & 2002.5 & 0.09 & -26.15 & -24.50 & 31.65 & 0.00 \\
\hline $3-5 \mathrm{~L}$ & & 0.12 & -25.92 & & & \\
\hline $3-6 D$ & & 0.04 & -25.85 & & & \\
\hline $3-6 \mathrm{~L}$ & 2002.0 & 0.08 & -25.71 & -24.06 & & \\
\hline 3-7D & 2001.5 & 0.11 & -25.34 & -23.72 & 31.46 & 0.08 \\
\hline
\end{tabular}


APPENDIX 2 continued

\begin{tabular}{|c|c|c|c|c|c|c|}
\hline Sample & Year & Width $(\mathrm{mm})$ & $\delta^{13} \mathrm{C}(\%)$ & $\delta^{13} C_{\text {corr }}(\%)$ & $\delta^{18} \mathrm{O}(\%)$ & $\delta^{18}$ O Error (\%) \\
\hline 3-7L & 2001.0 & 0.14 & -25.34 & -23.72 & & \\
\hline $3-8 D$ & 2000.5 & 0.11 & -25.42 & -23.83 & 31.97 & 0.28 \\
\hline $3-8 \mathrm{~L}$ & 2000.0 & 0.33 & -25.70 & -24.11 & & \\
\hline $3-9 D$ & 1999.5 & 0.11 & -25.30 & -23.74 & 30.18 & 0.22 \\
\hline $3-9 L$ & 1999.0 & 0.42 & -25.10 & -23.54 & & \\
\hline $3-10 D$ & 1998.5 & 0.10 & -25.49 & -23.96 & 31.98 & 0.11 \\
\hline $3-10 \mathrm{~L}$ & 1998.0 & 0.31 & -25.58 & -24.05 & & \\
\hline $3-11 D$ & 1997.5 & 0.11 & -25.45 & -23.94 & 32.49 & 0.12 \\
\hline $3-11 \mathrm{~L}$ & 1997.0 & 0.33 & -25.58 & -24.07 & & \\
\hline $3-12 D$ & 1996.5 & 0.08 & -25.69 & -24.21 & 32.75 & 0.11 \\
\hline $3-12 L$ & 1996.0 & 0.26 & -25.44 & -23.96 & & \\
\hline $3-13 D$ & 1995.5 & 0.09 & -25.05 & -23.60 & 32.87 & 0.04 \\
\hline 3-13L & 1995.0 & 0.37 & -25.09 & -23.64 & & \\
\hline $3-14 D$ & 1994.5 & 0.28 & -24.85 & -23.43 & 31.03 & 0.08 \\
\hline $3-14 L$ & 1994.0 & 0.61 & -25.21 & -23.79 & & \\
\hline $3-15 D$ & 1993.5 & 0.34 & -25.40 & -24.01 & 31.01 & 0.34 \\
\hline $3-15 L$ & 1993.0 & 0.27 & -25.16 & -23.77 & & \\
\hline $3-16 D$ & 1992.5 & 0.11 & -25.35 & -23.98 & 31.46 & 0.42 \\
\hline $3-16 \mathrm{~L}$ & 1992.0 & 0.34 & -25.42 & -24.05 & & \\
\hline $3-17 D$ & 1991.5 & 0.22 & -25.50 & -24.16 & 31.23 & 0.18 \\
\hline $3-17 L$ & 1991.0 & 0.30 & -25.26 & -23.92 & & \\
\hline $3-18 D$ & 1990.5 & 0.15 & -25.49 & -24.18 & 31.10 & 0.16 \\
\hline $3-18 \mathrm{~L}$ & 1990.0 & 0.43 & -25.30 & -23.99 & & \\
\hline $3-19 D$ & 1989.5 & 0.11 & -25.03 & -23.75 & 31.57 & 0.07 \\
\hline $3-19 \mathrm{~L}$ & 1989.0 & 0.25 & -24.71 & -23.43 & & \\
\hline $3-20 D$ & 1988.5 & 0.13 & -24.99 & -23.74 & 31.57 & 0.16 \\
\hline $3-20 \mathrm{~L}$ & 1988.0 & 0.40 & -24.67 & -23.42 & & \\
\hline $3-21 D$ & 1987.5 & 0.08 & -24.84 & -23.62 & 32.87 & 0.12 \\
\hline $3-21 \mathrm{~L}$ & 1987.0 & 0.13 & -25.22 & -24.00 & & \\
\hline $3-22 D$ & & 0.06 & -24.82 & & & \\
\hline $3-22 \mathrm{~L}$ & & 0.11 & -24.92 & & & \\
\hline $2-23 D$ & & 0.06 & -25.03 & & & \\
\hline $3-23 L$ & & 0.22 & -24.99 & & & \\
\hline $3-24 D$ & 1986.5 & 0.07 & -25.20 & -24.00 & 31.91 & 0.10 \\
\hline $3-24 \mathrm{~L}$ & 1986.0 & 0.12 & -25.12 & -23.92 & & \\
\hline $3-25 D$ & 1985.5 & 0.08 & -25.38 & -24.21 & 31.74 & 0.11 \\
\hline $3-25 \mathrm{~L}$ & 1985.0 & 0.32 & -25.48 & -24.31 & & \\
\hline $3-26 D$ & 1984.5 & 0.12 & -25.71 & -24.57 & 29.15 & 0.11 \\
\hline $3-26 \mathrm{~L}$ & 1984.0 & 0.59 & -25.38 & -24.24 & & \\
\hline $3-27 D$ & 1983.5 & 0.09 & -25.53 & -24.42 & 30.46 & 0.14 \\
\hline $3-27 L$ & 1983.0 & 0.17 & -24.89 & -23.78 & & \\
\hline $3-28 D$ & 1982.5 & 0.04 & -24.41 & -23.33 & 32.38 & 0.05 \\
\hline $3-28 \mathrm{~L}$ & 1982.0 & 0.10 & -24.57 & -23.49 & & \\
\hline $3-29 D$ & 1981.5 & 0.09 & -24.86 & -23.80 & 30.21 & 0.12 \\
\hline
\end{tabular}


APPENDIX 2 continued

\begin{tabular}{|c|c|c|c|c|c|c|}
\hline Sample & Year & Width $(\mathrm{mm})$ & $\delta^{13} \mathrm{C}(\%)$ & $\delta^{13} \mathrm{C}_{\text {corr }}(\%)$ & $\delta^{18} \mathrm{O}(\%)$ & $\delta^{18}$ O Error (\%) \\
\hline $3-29 \mathrm{~L}$ & 1981.0 & 0.21 & -25.00 & -23.94 & & \\
\hline $3-30 D$ & 1980.5 & 0.17 & -24.55 & -23.52 & 32.09 & 0.21 \\
\hline $3-30 \mathrm{~L}$ & & 0.29 & -24.45 & & & \\
\hline 3-31D & & 0.04 & -24.73 & & & \\
\hline 3-31L & & 0.09 & -24.81 & & & \\
\hline $3-32 D$ & & 0.06 & -24.65 & & & \\
\hline 3-32L & 1980.0 & 0.18 & -24.65 & -23.62 & & \\
\hline $3-33 D$ & 1979.5 & 0.04 & -24.69 & -23.69 & 32.25 & 0.37 \\
\hline 3-33L & 1979.0 & 0.10 & -24.73 & -23.73 & & \\
\hline $3-34 D$ & & 0.06 & -24.84 & & & \\
\hline $3-34 L$ & & 0.23 & -24.84 & & & \\
\hline $3-35 D$ & 1978.5 & 0.48 & -25.05 & -24.11 & 29.65 & 0.06 \\
\hline $3-35 L$ & 1978.0 & 0.44 & -24.38 & -23.44 & & \\
\hline $3-36 D$ & 1977.5 & 0.10 & -24.35 & -23.43 & 32.32 & 0.08 \\
\hline 3-36L & 1977.0 & 0.37 & -24.25 & -23.33 & & \\
\hline $3-37 D$ & 1976.5 & 0.30 & -24.55 & -23.66 & 30.68 & 0.14 \\
\hline 3-37L & 1976.0 & 0.37 & -24.81 & -23.92 & & \\
\hline $3-38 D$ & 1975.5 & 0.09 & -24.92 & -24.06 & 31.09 & 0.03 \\
\hline 3-38L & 1975.0 & 0.29 & -24.63 & -23.77 & & \\
\hline $3-39 D$ & & 0.10 & -24.71 & & & \\
\hline $3-39 L$ & & 0.17 & -24.59 & & & \\
\hline $3-40 D$ & & 0.24 & -24.52 & & & \\
\hline $3-40 \mathrm{~L}$ & & 0.47 & -24.35 & & & \\
\hline $3-41 D$ & 1974.5 & 0.46 & -24.63 & -23.80 & 30.27 & 0.12 \\
\hline $3-41 \mathrm{~L}$ & 1974.0 & 0.34 & -24.74 & -23.91 & & \\
\hline $3-42 D$ & 1973.5 & 0.32 & -25.00 & -24.20 & 29.82 & 0.09 \\
\hline $3-42 \mathrm{~L}$ & 1973.0 & 0.34 & -24.64 & -23.84 & & \\
\hline $3-43 D$ & 1972.5 & 0.13 & -24.74 & -23.97 & 31.19 & 0.06 \\
\hline $3-43 \mathrm{~L}$ & 1972.0 & 0.27 & -24.43 & -23.66 & & \\
\hline $3-44 D$ & 1971.5 & 0.08 & -24.78 & -24.03 & 31.25 & 0.18 \\
\hline $3-44 \mathrm{~L}$ & 1971.0 & 0.37 & -24.86 & -24.11 & & \\
\hline $3-45 D$ & & 0.32 & -24.73 & & & \\
\hline $3-45 \mathrm{~L}$ & & 0.28 & -24.79 & & & \\
\hline $3-46 D$ & 1970.5 & 0.47 & -24.84 & -24.12 & 30.33 & 0.12 \\
\hline $3-46 \mathrm{~L}$ & 1970.0 & 0.39 & -24.66 & -23.94 & & \\
\hline $3-47 D$ & 1969.5 & 0.29 & -24.86 & -24.17 & 30.14 & 0.24 \\
\hline $3-47 \mathrm{~L}$ & & 0.47 & -24.53 & & & \\
\hline $3-48 D$ & & 0.10 & -24.83 & & & \\
\hline $3-48 \mathrm{~L}$ & & 0.25 & -24.95 & & & \\
\hline $3-49 D$ & & 0.23 & -24.70 & & & \\
\hline $3-49 \mathrm{~L}$ & 1969.0 & 0.35 & -24.51 & -23.82 & & \\
\hline $3-50 D$ & 1968.5 & 0.28 & -25.07 & -24.41 & 32.13 & 0.02 \\
\hline $3-50 \mathrm{~L}$ & 1968.0 & 0.42 & -24.67 & -24.01 & & \\
\hline 3-51D & 1967.5 & 0.10 & -24.28 & -23.65 & 32.23 & 0.04 \\
\hline
\end{tabular}


APPENDIX 2 continued

\begin{tabular}{|c|c|c|c|c|c|c|}
\hline Sample & Year & Width $(\mathrm{mm})$ & $\delta^{13} \mathrm{C}(\%)$ & $\delta^{13} C_{\text {corr }}(\%)$ & $\delta^{18} O(\%)$ & $\delta^{18}$ O Error (\%) \\
\hline 3-51L & 1967.0 & 0.30 & -24.22 & -23.59 & & \\
\hline $3-52 D$ & 1966.5 & 0.24 & -24.48 & -23.87 & 31.56 & 0.10 \\
\hline $3-52 L$ & 1966.0 & 0.50 & -24.92 & -24.31 & & \\
\hline $3-53 D$ & 1965.5 & 0.28 & -24.80 & -24.22 & 31.74 & 0.05 \\
\hline 3-53L & 1965.0 & 0.46 & -25.27 & -24.69 & & \\
\hline $3-54 D$ & 1964.5 & 0.20 & -25.43 & -24.88 & 30.90 & 0.01 \\
\hline 3-54L & 1964.0 & 0.46 & -25.21 & -24.66 & & \\
\hline 3-55D & 1963.5 & 0.16 & -24.64 & -24.12 & 31.98 & 0.05 \\
\hline $3-55 \mathrm{~L}$ & 1963.0 & 0.59 & -24.51 & -23.99 & & \\
\hline $3-56 D$ & 1962.5 & 0.15 & -24.79 & -24.29 & 31.59 & 0.05 \\
\hline $3-56 \mathrm{~L}$ & & 0.39 & -24.80 & & & \\
\hline $3-57 D$ & & 0.30 & -24.90 & & & \\
\hline 3-57L & & 0.28 & -24.89 & & & \\
\hline $3-58 D$ & & 0.10 & -24.53 & & & \\
\hline $3-58 \mathrm{~L}$ & 1962.0 & 0.51 & -24.09 & -23.59 & & \\
\hline $3-59 D$ & 1961.5 & 0.16 & -24.45 & -23.95 & 31.04 & 0.11 \\
\hline $3-59 \mathrm{~L}$ & 1961.0 & 0.43 & -24.36 & -23.86 & & \\
\hline $3-60 D$ & 1960.5 & 0.43 & -24.64 & -24.14 & 29.99 & 0.13 \\
\hline $3-60 \mathrm{~L}$ & 1960.0 & 0.47 & -24.67 & -24.17 & & \\
\hline $3-61 D$ & 1959.5 & 0.47 & -24.91 & -24.42 & 31.00 & 0.04 \\
\hline $3-61 \mathrm{~L}$ & 1959.0 & 0.59 & -25.15 & -24.66 & & \\
\hline $3-62 D$ & & 0.11 & -25.19 & & & \\
\hline $3-62 \mathrm{~L}$ & & 0.25 & -25.11 & & & \\
\hline $3-63 D$ & & 0.35 & -24.93 & & & \\
\hline $3-63 L$ & & 0.29 & -24.86 & & & \\
\hline $3-64 D$ & 1958.5 & 0.30 & -24.94 & -24.45 & 31.01 & 0.02 \\
\hline $3-64 L$ & 1958.0 & 0.16 & -24.64 & -24.15 & & \\
\hline $3-65 D$ & 1957.5 & 0.10 & -24.26 & -23.78 & 32.70 & 0.02 \\
\hline $3-65 \mathrm{~L}$ & 1957.0 & 0.24 & -24.40 & -23.92 & & \\
\hline $3-66 D$ & 1956.5 & 0.52 & -25.14 & -24.66 & 30.20 & 0.01 \\
\hline $3-66 \mathrm{~L}$ & 1956.0 & 0.72 & -24.69 & -24.21 & & \\
\hline $3-67 D$ & 1955.5 & 0.53 & -24.75 & -24.28 & 31.69 & 0.09 \\
\hline $3-67 \mathrm{~L}$ & 1955.0 & 0.12 & -24.61 & -24.14 & & \\
\hline $3-68 D$ & 1954.5 & 0.38 & -24.59 & -24.12 & 32.40 & 0.21 \\
\hline $3-68 \mathrm{~L}$ & 1954.0 & 0.47 & -24.28 & -23.81 & & \\
\hline $3-69 D$ & 1953.5 & 0.46 & -24.78 & -24.32 & 31.36 & 0.08 \\
\hline $3-69 \mathrm{~L}$ & 1953.0 & 0.20 & -25.05 & -24.59 & & \\
\hline $3-70 D$ & 1952.5 & 0.32 & -25.28 & -24.82 & 31.33 & 0.12 \\
\hline $3-70 \mathrm{~L}$ & & 0.13 & -25.05 & & & \\
\hline 3-71D & & 0.35 & -25.33 & & & \\
\hline $3-71 \mathrm{~L}$ & 1952.0 & 0.10 & -24.71 & -24.25 & & \\
\hline $3-72 D$ & 1951.5 & 0.36 & -24.29 & -23.83 & 31.42 & 0.04 \\
\hline $3-72 \mathrm{~L}$ & 1951.0 & 0.66 & -24.24 & -23.78 & & \\
\hline $3-73 D$ & 1950.5 & 0.36 & -24.62 & -24.17 & 31.71 & 0.08 \\
\hline
\end{tabular}


APPENDIX 2 continued

\begin{tabular}{|c|c|c|c|c|c|c|}
\hline Sample & Year & Width $(\mathrm{mm})$ & $\delta^{13} \mathrm{C}(\%)$ & $\delta^{13} C_{\text {corr }}(\%)$ & $\delta^{18} O(\%)$ & $\delta^{18}$ O Error (\%) \\
\hline 3-73L & 1950.0 & 0.60 & -24.14 & -23.69 & & \\
\hline $3-74 D$ & 1949.5 & 0.65 & -24.37 & -23.92 & & \\
\hline $3-74 \mathrm{~L}$ & 1949.0 & 0.19 & -24.12 & -23.67 & & \\
\hline $3-75 D$ & & 0.65 & -24.32 & & & \\
\hline $3-75 \mathrm{~L}$ & & 0.46 & -24.32 & & & \\
\hline $3-76 D$ & 1948.5 & 0.70 & -24.87 & -24.43 & & \\
\hline $3-76 \mathrm{~L}$ & 1948.0 & 1.25 & -25.07 & -24.63 & & \\
\hline $3-77 D$ & 1947.5 & 0.51 & -25.35 & -24.91 & & \\
\hline 3-77L & 1947.0 & 0.48 & -25.04 & -24.60 & & \\
\hline $3-78 D$ & 1946.5 & 0.10 & -24.91 & -24.48 & & \\
\hline $3-78 \mathrm{~L}$ & 1946.0 & 0.10 & -25.07 & -24.64 & & \\
\hline $3-79 D$ & 1945.5 & 0.12 & -25.16 & -24.73 & & \\
\hline $3-79 \mathrm{~L}$ & 1945.0 & 0.20 & -25.41 & -24.98 & & \\
\hline $3-80 D$ & 1944.5 & 0.10 & -25.21 & -24.79 & & \\
\hline $3-80 \mathrm{~L}$ & 1944.0 & 0.11 & -24.59 & -24.17 & & \\
\hline $3-81 D$ & 1943.5 & 0.54 & -25.15 & -24.73 & & \\
\hline $3-81 \mathrm{~L}$ & 1943.0 & 0.22 & -25.10 & -24.68 & & \\
\hline $3-82 D$ & 1942.5 & 0.21 & -25.41 & -24.99 & & \\
\hline $3-82 L$ & 1942.0 & 0.38 & -25.42 & -25.00 & & \\
\hline $3-83 D$ & 1941.5 & 1.29 & -25.13 & -24.72 & & \\
\hline $3-83 L$ & 1941.0 & 1.12 & -25.06 & -24.65 & & \\
\hline $3-84 D$ & 1940.5 & 1.32 & -24.41 & -24.00 & & \\
\hline $3-84 L$ & 1940.0 & 0.88 & -25.00 & -24.59 & & \\
\hline $3-85 D$ & 1939.5 & 1.00 & -25.27 & -24.87 & & \\
\hline $3-85 \mathrm{~L}$ & 1939.0 & 0.41 & -25.67 & -25.27 & & \\
\hline $3-86 D$ & 1938.5 & 0.26 & -26.21 & -25.81 & & \\
\hline $3-86 \mathrm{~L}$ & 1938.0 & 0.16 & -25.81 & -25.41 & & \\
\hline $3-87 D$ & 1937.5 & 0.73 & -24.58 & -24.19 & & \\
\hline 3-87L & 1937.0 & 1.43 & -24.76 & -24.37 & & \\
\hline $3-88 D$ & 1936.5 & 1.07 & -25.33 & -24.94 & & \\
\hline $3-88 \mathrm{~L}$ & 1936.0 & 1.28 & -24.45 & -24.06 & & \\
\hline $3-89 D$ & 1935.5 & 1.36 & -24.74 & -24.36 & & \\
\hline $3-89 \mathrm{~L}$ & 1935.0 & 1.25 & -24.85 & -24.47 & & \\
\hline $3-90 D$ & 1934.5 & 0.71 & -24.59 & -24.21 & & \\
\hline $3-90 \mathrm{~L}$ & 1934.0 & 0.50 & -24.95 & -24.57 & & \\
\hline $3-91 D$ & 1933.5 & 0.79 & -24.66 & -24.28 & & \\
\hline $3-91 \mathrm{~L}$ & 1933.0 & 0.93 & -24.86 & -24.48 & & \\
\hline $3-92 D$ & 1932.5 & 0.68 & -25.41 & -25.04 & & \\
\hline $3-92 \mathrm{~L}$ & 1932.0 & 0.24 & -25.12 & -24.75 & & \\
\hline $3-93 D$ & 1931.5 & 0.45 & -25.10 & -24.73 & & \\
\hline 3-93L & 1931.0 & 1.86 & -25.28 & -24.91 & & \\
\hline $3-94 D$ & 1930.5 & 1.30 & -25.00 & -24.64 & & \\
\hline $3-94 \mathrm{~L}$ & 1930.0 & 1.60 & -24.94 & -24.58 & & \\
\hline $3-95 D$ & 1929.5 & 0.63 & -25.34 & -24.98 & & \\
\hline
\end{tabular}


APPENDIX 2 continued

\begin{tabular}{|c|c|c|c|c|c|c|}
\hline Sample & Year & Width $(\mathrm{mm})$ & $\delta^{13} \mathrm{C}$ (\%) & $\delta^{13} \mathrm{C}_{\text {corr }}(\%)$ & $\delta^{18} \circ(\%)$ & $\delta^{18}$ O Error (\%) \\
\hline $3-95 \mathrm{~L}$ & 1929.0 & 2.37 & -25.24 & -24.88 & & \\
\hline $3-96 D$ & 1928.5 & 0.59 & -25.55 & -25.20 & & \\
\hline $3-96 \mathrm{~L}$ & 1928.0 & 0.74 & -25.58 & -25.23 & & \\
\hline $3-97 D$ & 1927.5 & 1.74 & -25.08 & -24.73 & & \\
\hline 3-97L & 1927.0 & 1.85 & -25.24 & -24.89 & & \\
\hline $3-98 D$ & 1926.5 & 0.43 & -25.72 & -25.38 & & \\
\hline $3-98 \mathrm{~L}$ & 1926.0 & 3.88 & -25.52 & -25.18 & & \\
\hline $3-99 D$ & 1925.5 & 0.40 & -25.90 & -25.56 & & \\
\hline $3-99 L$ & 1925.0 & 3.54 & -25.93 & -25.59 & & \\
\hline $6-1 D$ & 2005.5 & 0.05 & -25.24 & -23.51 & 32.92 & 0.16 \\
\hline $6-1 \mathrm{~L}$ & 2005.0 & 0.16 & -24.94 & -23.21 & & \\
\hline $6-2 D$ & 2004.5 & 0.08 & -24.60 & -22.90 & 32.41 & 0.03 \\
\hline $6-2 \mathrm{~L}$ & 2004.0 & 0.34 & -24.43 & -22.73 & & \\
\hline $6-3 D$ & 2003.5 & 0.07 & -24.48 & -22.81 & 32.40 & 0.01 \\
\hline $6-3 L$ & 2003.0 & 0.24 & -24.34 & -22.67 & & \\
\hline $6-4 D$ & 2002.5 & 0.08 & -24.66 & -23.01 & 32.53 & 0.08 \\
\hline $6-4 \mathrm{~L}$ & 2002.0 & 0.18 & -24.71 & -23.06 & & \\
\hline $6-5 D$ & & 0.04 & -24.74 & & 32.66 & 0.05 \\
\hline $6-5 \mathrm{~L}$ & & 0.13 & -24.71 & & & \\
\hline $6-6 D$ & 2001.5 & 0.07 & -24.70 & -23.08 & 32.84 & 0.07 \\
\hline $6-6 \mathrm{~L}$ & 2001.0 & 0.10 & -24.42 & -22.80 & & \\
\hline $6-7 D$ & 2000.5 & 0.10 & -24.63 & -23.04 & 32.74 & 0.08 \\
\hline $6-7 \mathrm{~L}$ & 2000.0 & 0.36 & -24.94 & -23.35 & & \\
\hline $6-8 D$ & 1999.5 & 0.25 & -25.15 & -23.59 & 31.62 & 0.33 \\
\hline $6-8 \mathrm{~L}$ & 1999.0 & 0.45 & -24.85 & -23.29 & & \\
\hline $6-9 D$ & 1998.5 & 0.15 & -25.05 & -23.52 & 31.49 & 0.23 \\
\hline $6-9 \mathrm{~L}$ & 1998.0 & 0.55 & -25.20 & -23.67 & & \\
\hline $6-10 D$ & 1997.5 & 0.20 & -24.85 & -23.34 & 31.07 & 0.09 \\
\hline $6-10 \mathrm{~L}$ & 1997.0 & 0.45 & -24.55 & -23.04 & & \\
\hline $6-11 D$ & 1996.5 & 0.31 & -24.36 & -22.88 & 31.95 & 0.12 \\
\hline $6-11 \mathrm{~L}$ & 1996.0 & 0.50 & -24.51 & -23.03 & & \\
\hline $6-12 D$ & 1995.5 & 1.17 & -24.20 & -22.75 & 31.69 & 0.40 \\
\hline $6-12 \mathrm{~L}$ & 1995.0 & 0.34 & -24.51 & -23.06 & & \\
\hline $6-13 D$ & 1994.5 & 0.33 & -24.66 & -23.24 & 31.12 & 0.32 \\
\hline 6-13L & 1994.0 & 0.54 & -24.94 & -23.52 & & \\
\hline $6-14 D$ & 1993.5 & 0.82 & -24.51 & -23.12 & 30.71 & 0.32 \\
\hline $6-14 \mathrm{~L}$ & 1993.0 & 0.26 & -24.22 & -22.83 & & \\
\hline $6-15 D$ & 1992.5 & 0.39 & -24.50 & -23.14 & 31.14 & 0.10 \\
\hline $6-15 \mathrm{~L}$ & & 0.50 & -24.53 & & & \\
\hline $6-16 D$ & & 0.43 & -24.46 & -23.10 & 31.57 & 0.11 \\
\hline $6-16 L$ & 1992.0 & 0.35 & -24.48 & & & \\
\hline $6-17 D$ & 1991.5 & 0.99 & -25.01 & -23.67 & 30.20 & 0.21 \\
\hline $6-17 \mathrm{~L}$ & 1991.0 & 0.51 & -24.78 & -23.44 & & \\
\hline $6-18 D$ & 1990.5 & 0.41 & -25.36 & -24.05 & 31.50 & 0.28 \\
\hline
\end{tabular}


APPENDIX 2 continued

\begin{tabular}{|c|c|c|c|c|c|c|}
\hline Sample & Year & Width $(\mathrm{mm})$ & $\delta^{13} \mathrm{C}(\%)$ & $\delta^{13} C_{\text {corr }}(\%)$ & $\delta^{18} O(\%)$ & $\delta^{18}$ O Error (\%) \\
\hline $6-18 \mathrm{~L}$ & 1990.0 & 0.56 & -25.11 & -23.80 & & \\
\hline $6-19 D$ & 1989.5 & 0.42 & -24.39 & -23.11 & 31.84 & 0.18 \\
\hline $6-19 L$ & 1989.0 & 0.81 & -24.61 & -23.33 & & \\
\hline $6-20 D$ & 1987.5 & 0.33 & -24.75 & -23.53 & 31.58 & 0.32 \\
\hline $6-20 \mathrm{~L}$ & 1987.0 & 0.46 & -24.76 & -23.54 & & \\
\hline $6-21 D$ & 1986.5 & 0.26 & -24.68 & -23.48 & 30.96 & 0.12 \\
\hline $6-21 \mathrm{~L}$ & 1986.0 & 0.84 & -24.86 & -23.66 & & \\
\hline $6-22 D$ & 1985.5 & 0.26 & -24.96 & -23.79 & 31.19 & 0.64 \\
\hline $6-22 L$ & 1985.0 & 0.51 & -25.02 & -23.85 & & \\
\hline $6-23 D$ & 1984.5 & 0.08 & -25.33 & -24.19 & 31.75 & 0.54 \\
\hline $6-23 L$ & 1984.0 & 0.44 & -25.19 & -24.05 & & \\
\hline $6-24 D$ & 1983.5 & 0.34 & -24.10 & -22.99 & 31.22 & 0.09 \\
\hline $6-24 L$ & 1983.0 & 0.57 & -23.63 & -22.52 & & \\
\hline $6-25 D$ & 1982.5 & 0.42 & -24.36 & -23.28 & 30.95 & 0.06 \\
\hline $6-25 \mathrm{~L}$ & 1982.0 & 0.62 & -24.11 & -23.03 & & \\
\hline $6-26 D$ & 1981.5 & 0.10 & -24.29 & -23.23 & 31.61 & 0.22 \\
\hline $6-26 \mathrm{~L}$ & 1981.0 & 0.38 & -23.82 & -22.76 & & \\
\hline $6-27 D$ & 1980.5 & 0.12 & -24.02 & -22.99 & 31.03 & 0.24 \\
\hline 6-27L & 1980.0 & 0.45 & -23.84 & -22.81 & & \\
\hline $6-28 D$ & 1979.5 & 0.11 & -23.78 & -22.78 & 32.60 & 0.67 \\
\hline $6-28 \mathrm{~L}$ & 1979.0 & 0.36 & -23.87 & -22.87 & & \\
\hline $6-29 D$ & & 0.16 & -23.89 & & 32.14 & 0.14 \\
\hline $6-29 \mathrm{~L}$ & & 0.48 & -23.67 & & & \\
\hline $6-30 D$ & 1978.5 & 0.33 & -24.10 & -23.16 & 30.98 & 0.28 \\
\hline $6-30 \mathrm{~L}$ & 1978.0 & 0.52 & -23.72 & -22.78 & & \\
\hline $6-31 D$ & 1977.5 & 0.08 & -23.58 & -22.66 & 31.72 & 0.23 \\
\hline 6-31L & 1977.0 & 0.18 & -23.45 & -22.53 & & \\
\hline $6-32 D$ & 1976.5 & 0.10 & -23.37 & -22.48 & 32.63 & 0.66 \\
\hline $6-32 \mathrm{~L}$ & 1976.0 & 0.43 & -23.71 & -22.82 & & \\
\hline $6-33 D$ & 1975.5 & 0.22 & -23.98 & -23.12 & 32.03 & 0.43 \\
\hline 6-33L & 1975.0 & 0.55 & -24.34 & -23.48 & & \\
\hline $6-34 D$ & 1974.5 & 0.15 & -24.46 & -23.63 & 30.02 & 0.01 \\
\hline $6-34 \mathrm{~L}$ & 1974.0 & 0.63 & -24.42 & -23.59 & & \\
\hline $6-35 D$ & 1973.5 & 0.20 & -24.47 & -23.67 & 30.09 & 0.24 \\
\hline $6-35 \mathrm{~L}$ & 1973.0 & 0.42 & -23.64 & -22.84 & & \\
\hline $6-36 D$ & 1972.5 & 0.26 & -23.39 & -22.62 & 31.93 & 0.31 \\
\hline 6-36L & & 0.76 & -23.44 & & & \\
\hline 6-37D & & 0.33 & -24.09 & & 30.30 & 0.01 \\
\hline 6-37L & 1972.0 & 0.42 & -23.69 & -22.92 & & \\
\hline $6-38 D$ & 1971.5 & 1.23 & -22.71 & -21.96 & 31.59 & 0.34 \\
\hline 6-38L & 1971.0 & 0.32 & -23.16 & -22.41 & & \\
\hline $6-39 D$ & 1970.5 & 0.39 & -23.50 & -22.78 & 31.53 & 0.05 \\
\hline $6-39 \mathrm{~L}$ & 1970.0 & 0.94 & -23.22 & -22.50 & & \\
\hline $6-40 D$ & 1969.5 & 0.17 & -23.75 & -23.06 & 31.48 & 0.15 \\
\hline
\end{tabular}


APPENDIX 2 continued

\begin{tabular}{|c|c|c|c|c|c|c|}
\hline Sample & Year & Width $(\mathrm{mm})$ & $\delta^{13} \mathrm{C}$ (\%d) & $\delta^{13} \mathrm{C}_{\text {corr }}(\%$ ) & $\delta^{18} \circ(\%)$ & $\delta^{18} \mathrm{O}$ Error $(\%)$ \\
\hline $6-40 \mathrm{~L}$ & 1969.0 & 0.53 & -23.62 & -22.93 & & \\
\hline $6-41 D$ & 1968.5 & 0.16 & -23.80 & -23.09 & 32.14 & 0.11 \\
\hline 6-41L & & 0.48 & -23.76 & & & \\
\hline $6-42 D$ & & 0.29 & -23.70 & & 32.44 & 0.67 \\
\hline $6-42 \mathrm{~L}$ & 1968.0 & 0.60 & -23.44 & -22.78 & & \\
\hline $6-43 D$ & 1967.5 & 0.71 & -24.27 & -23.64 & 29.90 & 0.04 \\
\hline 6-43L & 1967.0 & 0.27 & -23.89 & -23.26 & & \\
\hline $6-44 D$ & 1966.5 & 0.24 & -24.12 & -23.51 & 32.52 & 0.32 \\
\hline 6-44L & 1966.0 & 0.10 & -23.48 & -22.87 & & \\
\hline $6-45 D$ & 1965.5 & 0.20 & -23.86 & -23.28 & 32.02 & 0.19 \\
\hline $6-45 \mathrm{~L}$ & 1965.0 & 0.44 & -23.45 & -22.90 & & \\
\hline $6-46 D$ & & 0.12 & -23.47 & & 32.93 & 0.57 \\
\hline $6-46 \mathrm{~L}$ & & 0.41 & -23.51 & & & \\
\hline $6-47 D$ & 1964.5 & 0.19 & -24.18 & -23.63 & 31.98 & 0.14 \\
\hline 6-47L & 1964.0 & 0.34 & -23.86 & -23.31 & & \\
\hline $6-48 \mathrm{D}$ & 1963.5 & 0.28 & -23.60 & -23.08 & 31.61 & 0.04 \\
\hline $6-48 \mathrm{~L}$ & 1963.0 & 0.46 & -23.30 & -22.78 & & \\
\hline $6-49 D$ & 1962.5 & 0.31 & -23.64 & -23.14 & 31.89 & 0.26 \\
\hline $6-49 \mathrm{~L}$ & 1962.0 & 0.23 & -22.87 & -22.37 & & \\
\hline $6-50 D$ & 1961.5 & 0.10 & -23.94 & -23.44 & 31.08 & 0.11 \\
\hline $6-50 \mathrm{~L}$ & 1961.0 & 0.57 & -23.63 & -23.13 & & \\
\hline 6-51D & 1960.5 & 0.42 & -23.61 & -23.11 & 31.10 & 0.02 \\
\hline $6-51 \mathrm{~L}$ & 1960.0 & 0.32 & -23.58 & -23.08 & & \\
\hline $6-52 D$ & 1959.5 & 0.16 & -23.35 & -22.86 & 31.60 & 0.14 \\
\hline $6-52 \mathrm{~L}$ & 1959.0 & 0.23 & -23.34 & -22.85 & & \\
\hline $6-53 D$ & 1958.5 & 0.10 & -23.35 & -22.86 & 32.10 & 0.01 \\
\hline $6-53 L$ & 1958.0 & 0.41 & -23.22 & -22.73 & & \\
\hline $6-54 D$ & 1957.5 & 0.19 & -22.57 & -22.09 & 33.45 & 0.03 \\
\hline 6-54L & 1957.0 & 0.55 & -23.03 & -22.55 & & \\
\hline $6-55 D$ & 1956.5 & 0.10 & -23.14 & -22.66 & 32.96 & 0.03 \\
\hline $6-55 \mathrm{~L}$ & 1956.0 & 0.43 & -23.25 & -22.77 & & \\
\hline $6-56 \mathrm{D}$ & 1955.5 & 0.11 & -22.91 & -22.44 & 32.97 & 0.14 \\
\hline 6-56 L & 1955.0 & 0.28 & -23.15 & -22.68 & & \\
\hline $6-57 D$ & 1954.5 & 0.25 & -23.63 & -23.16 & 31.65 & 0.06 \\
\hline 6-57L & 1954.0 & 0.62 & -23.73 & -23.26 & & \\
\hline $6-58 \mathrm{D}$ & 1953.5 & 0.50 & -23.34 & -22.88 & 32.57 & 0.06 \\
\hline $6-58 \mathrm{~L}$ & 1953.0 & 0.73 & -23.65 & -23.19 & & \\
\hline $6-59 D$ & 1952.5 & 0.33 & -23.75 & -23.29 & 32.30 & 0.11 \\
\hline $6-59 \mathrm{~L}$ & 1952.0 & 0.81 & -23.35 & -22.89 & & \\
\hline $6-60 D$ & 1951.5 & 0.39 & -23.68 & -23.22 & 32.66 & 0.13 \\
\hline $6-60 \mathrm{~L}$ & 1951.0 & 0.62 & -23.25 & -22.79 & & \\
\hline 6-61D & 1950.5 & 0.40 & -23.57 & -23.12 & 32.02 & 0.04 \\
\hline 6-61L & 1950.0 & 0.72 & -23.30 & -22.85 & & \\
\hline $6-62 D$ & 1949.5 & 0.83 & -23.68 & -23.23 & 31.35 & 0.12 \\
\hline
\end{tabular}


APPENDIX 2 continued

\begin{tabular}{|c|c|c|c|c|c|c|}
\hline Sample & Year & Width $(\mathrm{mm})$ & $\delta^{13} \mathrm{C}(\%)$ & $\delta^{13} \mathrm{C}_{\text {corr }}(\%)$ & $\delta^{18} \mathrm{O}(\%)$ & $\delta^{18} \mathrm{O}$ Error $(\%)$ \\
\hline $6-62 L$ & 1949.0 & 0.15 & -23.68 & -23.23 & & \\
\hline 6-63D & 1948.5 & 0.55 & -24.38 & -23.94 & 30.43 & 0.17 \\
\hline 6-63L & 1948.0 & 0.79 & -24.14 & -23.70 & & \\
\hline $6-64 D$ & 1947.5 & 1.07 & -24.11 & -23.67 & 31.34 & 0.13 \\
\hline 6-64L & 1947.0 & 0.34 & -23.25 & -22.81 & & \\
\hline $6-65 D$ & 1946.5 & 0.49 & -23.76 & -23.33 & 31.08 & 0.20 \\
\hline $6-65 \mathrm{~L}$ & 1946.0 & 0.39 & -23.19 & -22.76 & & \\
\hline $6-66 \mathrm{D}$ & 1945.5 & 0.63 & -23.67 & -23.24 & 30.23 & 0.10 \\
\hline 6-66L & 1945.0 & 0.28 & -23.53 & -23.10 & & \\
\hline 6-67D & 1944.5 & 0.60 & -23.47 & -23.05 & 31.48 & 0.01 \\
\hline 6-67L & 1944.0 & 0.42 & -24.15 & -23.73 & & \\
\hline $6-68 D$ & 1943.5 & 0.94 & -22.98 & -22.56 & 30.73 & 0.23 \\
\hline $6-68 \mathrm{~L}$ & 1943.0 & 0.37 & -22.95 & -22.53 & & \\
\hline $6-69 D$ & 1942.5 & 0.28 & -23.16 & -22.74 & 31.24 & 0.02 \\
\hline $6-69 L$ & 1942.0 & 0.40 & -22.55 & -22.13 & & \\
\hline 6-70D & 1941.5 & 0.39 & -22.47 & -22.06 & 32.60 & 0.03 \\
\hline $6-70 \mathrm{~L}$ & 1941.0 & 0.48 & -22.21 & -21.80 & & \\
\hline 6-71D & 1940.5 & 0.63 & -23.39 & -22.98 & 30.80 & 0.19 \\
\hline $6-71 \mathrm{~L}$ & 1940.0 & 0.69 & -22.97 & -22.56 & & \\
\hline $6-72 D$ & 1939.5 & 0.26 & -23.12 & -22.72 & 32.00 & 0.04 \\
\hline $6-72 \mathrm{~L}$ & 1939.0 & 0.20 & -23.09 & -22.69 & & \\
\hline $6-73 D$ & 1938.5 & 0.31 & -22.98 & -22.58 & 32.48 & 0.08 \\
\hline 6-73L & 1938.0 & 0.62 & -22.40 & -22.00 & & \\
\hline $6-74 D$ & 1937.5 & 0.34 & -22.79 & -22.40 & 31.78 & 0.21 \\
\hline 6-74L & 1937.0 & 0.50 & -22.50 & -22.11 & & \\
\hline $6-75 D$ & 1936.5 & 0.68 & -22.98 & -22.59 & 31.04 & 0.16 \\
\hline $6-75 \mathrm{~L}$ & 1936.0 & 0.34 & -22.01 & -21.62 & & \\
\hline $6-76 D$ & 1935.5 & 0.31 & -22.86 & -22.48 & 32.06 & 0.08 \\
\hline $6-76 \mathrm{~L}$ & 1935.0 & 0.23 & -22.68 & -22.30 & & \\
\hline 6-77D & 1934.5 & 0.30 & -22.94 & -22.56 & 31.37 & 0.17 \\
\hline $6-77 \mathrm{~L}$ & 1934.0 & 0.16 & -22.81 & -22.43 & & \\
\hline $6-78 D$ & 1933.5 & 0.71 & -22.68 & -22.30 & 31.91 & 0.24 \\
\hline $6-78 \mathrm{~L}$ & & 0.90 & -23.27 & & & \\
\hline $6-79 D$ & & 0.75 & -23.11 & -22.91 & 31.66 & 0.11 \\
\hline $6-79 \mathrm{~L}$ & 1933.0 & 0.72 & -23.31 & & & \\
\hline $6-80 D$ & 1932.5 & 0.67 & -22.78 & -22.41 & 32.09 & 0.37 \\
\hline $6-80 \mathrm{~L}$ & 1932.0 & 0.57 & -22.95 & -22.58 & & \\
\hline 6-81D & 1931.5 & 0.59 & -23.29 & -22.92 & 31.50 & 0.22 \\
\hline $6-81 \mathrm{~L}$ & 1931.0 & 1.50 & -22.96 & -22.59 & & \\
\hline $6-82 D$ & 1930.5 & 1.35 & -23.40 & -23.04 & 31.92 & 0.27 \\
\hline $6-82 L$ & 1930.0 & 1.53 & -23.83 & -23.47 & & \\
\hline 6-83D & 1929.5 & 1.48 & -24.16 & -23.80 & 31.58 & 0.25 \\
\hline 6-83L & 1929.0 & 1.01 & -23.61 & -23.25 & & \\
\hline $6-84 D$ & 1928.5 & 1.98 & -23.65 & -23.30 & 32.05 & 0.06 \\
\hline
\end{tabular}


APPENDIX 2 continued

\begin{tabular}{ccccccc}
\hline Sample & Year & Width $(\mathbf{m m})$ & $\delta^{13} \mathbf{C}(\%)$ & $\delta^{13} \mathbf{C}_{\text {corr }}(\%)$ & $\delta^{18} \mathbf{O}(\%)$ & $\delta^{18} \mathbf{O}$ Error (\%o) \\
\hline 6-84L & 1928.0 & 0.30 & -24.85 & -24.50 & & \\
6-85D & 1927.5 & 0.25 & -24.79 & -24.44 & 31.82 & 0.10 \\
6-85L & 1927.0 & 0.82 & -23.06 & -22.71 & & \\
6-86D & 1926.5 & 0.61 & -23.78 & -23.44 & 30.36 & 0.20 \\
6-86L & 1926.0 & 0.93 & -23.61 & -23.27 & & \\
6-87D & 1925.5 & 0.55 & -24.24 & -23.90 & 30.56 & 0.40 \\
6-87L & 1925.0 & 1.54 & -24.43 & -24.09 & & \\
6-88D & 1924.5 & 0.94 & -24.48 & -24.14 & 30.74 & 0.06 \\
6-88L & 1924.0 & 1.76 & -24.79 & -24.45 & & \\
6-89D & 1923.5 & 0.40 & -24.58 & -24.25 & 31.16 & 0.19 \\
6-89L & 1923.0 & 1.47 & -25.02 & -24.69 & & \\
6-90D & 1922.5 & 0.49 & -24.47 & -24.14 & 30.90 & 0.17 \\
6-90L & 1922.0 & 1.54 & -24.92 & -24.59 & &
\end{tabular}




\section{APPENDIX 3}

Appendix 3: First and second global Empirical Orthogonal Function graphs for data used in Chapter 3. The data is for the period 1950-2005 and it has been divided into earlywood (EW) and latewood (LW) components, representing climate from May - October and November - following April, respectively. DBH1, DBH2, DBH3 RW, and DBH6 are the $\delta^{13} \mathrm{C}$ values for each of the four $P$. elliottii var. densa trees. DBH1 RW, DBH2 RW, DBH3 RW, and DBH6 RW are the ring width measurements for each individual tree. $\mathrm{KW}$ is the precipitation data for the Key West weather station. ENSO and AMO are the El Niño - Southern Oscillation and the Atlantic Multidecadal Oscillation. DUST is the African aerosol dust record for Barbados. ACE is the Accumulated Cyclone Energy for the Atlantic Basin.
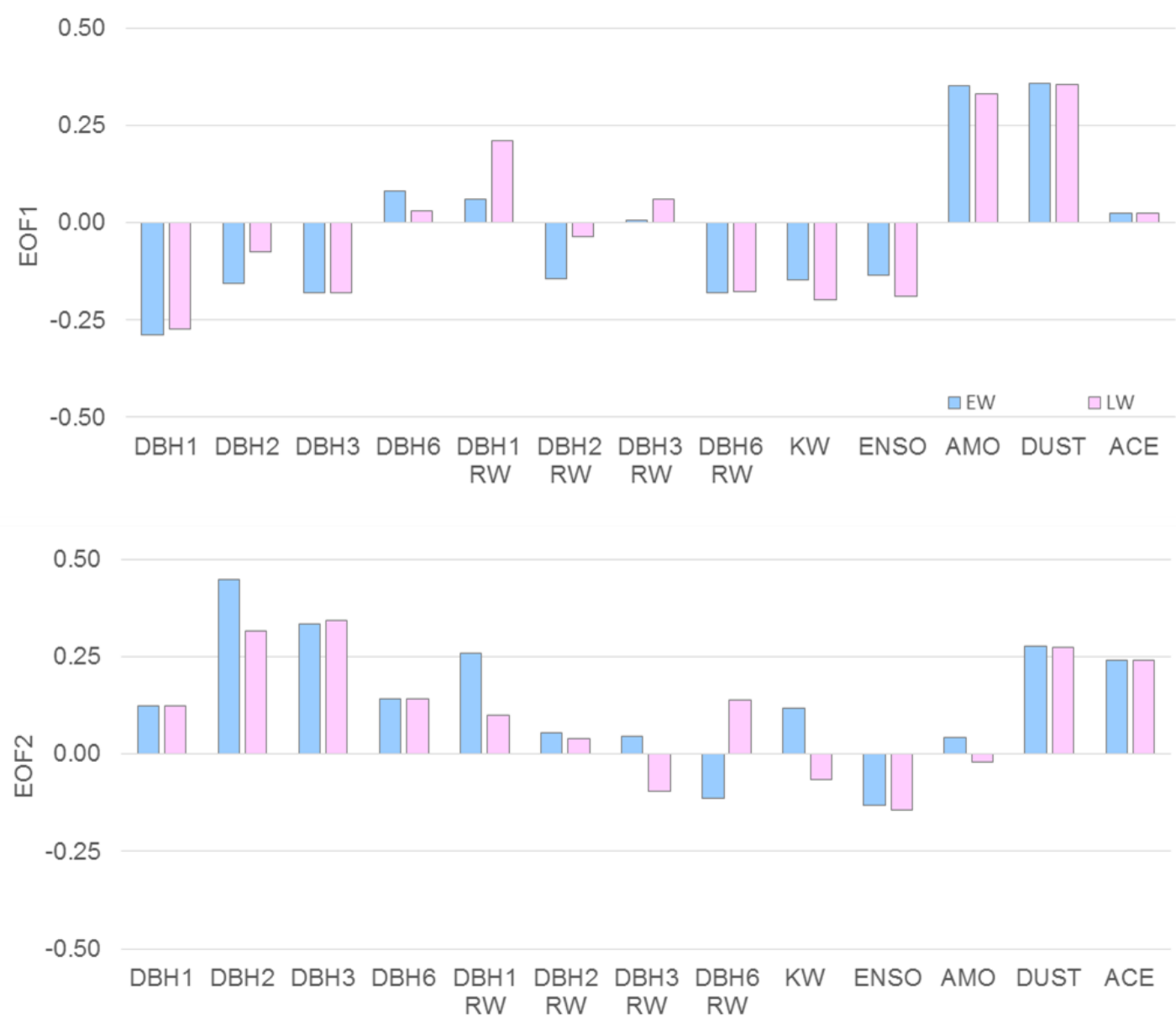


\section{CARRIE E. REBENACK}

Born, Rootstown, Ohio

2007

B.S., Geosciences

Florida International University

Miami, Florida

$2010-2016$

Doctoral Candidate

Teaching Assistant

Research Assistant

Florida International University

Miami, Florida

February, 2013

Best Ph.D. Geosciences Poster

FIU Earth and Environment Graduate Research Symposium

Miami, Florida

March 2013

Best Student Poster

FCE LTER All Scientists Meeting

Miami, Florida

February, 2014

Best Ph.D. Geosciences Poster

FIU Earth and Environment Graduate Research Symposium

Miami, Florida

2015-2016

Earth and Environmental Science Tutor

Student Athlete Academic Center

Florida International University

\section{PRESENTATIONS}

Rebenack, C. E., Anderson, W. T., Cherubini, P., (March, 2012) Using the Carbon Isotope Record of Slash Pine (Pinus elliottii) Tree-rings to Identify Seasonality and Disturbance Events in Big Pine Key, Florida. Florida Coastal Everglades Long Term Ecological Research 2012 All Scientists Meeting, Miami, Florida.

Rebenack, C. E., Anderson, W. T., Cherubini, P., (April, 2012) Seasonality and Disturbance Events in the Carbon Isotope Record of Slash Pine (Pinus elliottii) Tree-rings from Big Pine Key, Florida: Preliminary Results. FIU Earth and Environment Graduate Research Symposium, Miami Florida.

Rebenack, C. E., (June, 2012) Seasonality and Disturbance Events in the Carbon Isotope Record of Slash Pine (Pinus elliottii) Tree-Rings from Big Pine Key, Florida. $9^{\text {th }}$ INTECOL International Wetlands Conference, Orlando, Florida. Invited Oral Presentation. 
Rebenack, C. E., Cherubini, P., Anderson, W. T., (September, 2012) Disturbance Events in the Carbon Isotope Record of Slash Pine (Pinus elliottii) Tree-rings from the Florida Keys. 2012 Long Term Ecological Research Network All Scientists Meeting, Estes Park, Colorado.

Rebenack, C. E., Cherubini, P., Anderson, W. T., (December, 2012) Disturbance Events in the Carbon Isotope Record of Slash Pine (Pinus elliottii) Tree-rings from Big Pine Key, Florida. American Geophysical Union 2012 Fall Meeting, San Francisco, California. Abstract PP33A-2105

Rebenack, C. E., (September, 2012) Stable Isotopes in Chronologies with a Focus on Tree-rings in Paleoclimate Reconstruction. 2012 Long Term Ecological Research Network All Scientists Meeting, Estes Park, Colorado. Invited Oral Presentation.

Rebenack, C. E., (November, 2012) Using Carbon Isotopes in Pinus elliottii Tree-rings to Infer Past Disturbance Events in Big Pine Key, Florida. FIU Earth Science Seminar, Miami, Florida. Oral Presentation.

Rebenack, C. E., Anderson, W. T., Cherubini, P., (February, 2013) Climate Relationships in Pinus elliottii Tree-Rings from Big Pine Key, Florida. FIU Earth and Environment Graduate Research Symposium, Miami Florida.

Rebenack, C. E., Anderson, W. T., Cherubini, P., (March, 2013) Using the Carbon Isotope Record of Slash Pine (Pinus elliottii) Tree-rings to Identify Seasonality and Disturbance Events in Big Pine Key, Florida. Florida Coastal Everglades Long Term Ecological Research 2013 All Scientists Meeting, Miami, Florida.

Rebenack, C. E., Willoughby, H., Anderson, W. T., Cherubini, P., (December, 2013) Carbon Isotopes in Pinus elliottii from Big Pine Key, Florida: Indicators of Seasonal Precipitation, ENSO and Disturbance Events. American Geophysical Union 2012 Fall Meeting, San Francisco, California. Abstract PP31B-1863.

Rebenack, C. E., (February, 2015) Stable isotopes in tree-rings: what they can tell us about past climate and disturbance events. FIU Department of Earth and Environment 2015 Graduate Research Symposium, Miami, Florida. Oral Presentation. 